KONGL. SVENSKA VETENSKAPS-AKADEMIENS HANDLINGAR Bandet 1\%. N:o 3.

QQL

458,2

H9N48

1880

ENT

$\mathrm{OM}$

\title{
SVERIGES HYDRACHNIDER
}

$\mathrm{AF}$

C. J. NEUMA N.

MED 14 TAFLOR.

TILL KONGL. VETENSKAPS-AKADEMIEN INLEMNAD DEN 4 JUNI 1879.

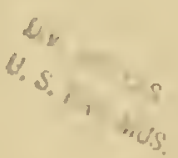




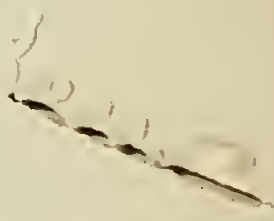

1. 


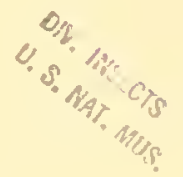

0.11

\title{
SVERIGES HYDRACHNIDER
}

AF

\author{
C. J. NEUMA N. \\ $\therefore$
}

MEN 14 TAFLOR.

TILI, KONGL. VEIESAKAPS-AKATEMIEX IXLEMAAD DEA 4 JXI $187+$

STOCKHOLM, 1880.

KONGL. BOKTRYCKRRIET.

P. A. KORStht d sonkh. 
$\mathrm{D}$ jug nu gar at offentliggöra resultaten at de iakttagelscr, jag under flere âr gjort rörance śveriges Hydrachnider, är det mig en kär pligt att till Kongl. TetenskapsAkademien i frimsta mmuet hembära min djupa tacksanbet, enär jag endast genom de understöd, jag al' Jensamma upprepade gainger erhallit, hlifvit satt i tillfalle att ntsträcka mina undersökningar öfver en sâ stor del af Sverige, sonn skett. Äfren far jag tacksamt erkämna den stora fürbindelse, hrari jag still till Herr Professor V. luLcJEBong, som först riktade min uppmärksumbet pát Hydrachniderna och atskilligá gảnger sündt mig dylika fran skilua trakter af Sverige och Norwe, sant till ITerr Professor T. Thurert oh Herr Apotekaren li. K.JerRmas, lıvilken sistnämnde ofta varit nin följeslagare pa excursioner i Testergötland och meddelat mig âtskilliga intressanta arter fràn namnde provins. De utlindske naturforskare, som haft godheten sända mig Hydrachnider, äro Professoren och Ceheimeradet H. Lebent och Professoren F. A. Foner i Morges, till hvilka jag stil i stor tacksamhetssknld för de Hydrachnider frin Genèversjön, de under senare aren skickat mig.

Taflorna till detta arbete äro under noggrann ledning af mig ritade och kolorerade

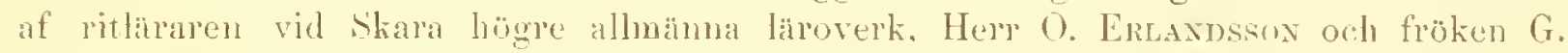
Konthoff. Ursprungligen var det min afsigt att till alla arterna bifoga figurer, men då detta stötte pa nảstan nöfvervinneliga svâligheter eller àtminstone för en längre tid sknlle hindrat arbetets länge nog fördröjda ntgifvande, nödgades jạ inskränka figurernas antal till en eller annan tyly för hrarje sägte. Beklagas maste att pí tafloma figurerna ej kmmat framställas i systematisk ordning, slägte efter slägte, cnär kostnadema cla skulle blifvit allt för stora, iffensom att icke alla till samma art hörande teckningar sammanstälts, om hvilket lörhallande jag först fatt kännedom, da det var för sent att ändra detsanma. Ien under Herr IV. Schlacnters ledning verkstilda lithographieringen förtienar i ofrigt allt erkinmande.

\section{Litteratur-offversigt.}

De Zoologer, som lemuat mer eller mindre vigtiga bidrag till Hydrachnidernas kimmedom älo, sa vidt jay har mig bekant, följande:

Steplax buankart ${ }^{1}$ ) har aflildat en llyclrachnid med dess äge, füstade pa grenar af Ceratopliyllum.

1) Schon-burg der Rupsen etc. Imsterlam lbse. 
J. L. Friscir ${ }^{1}$ ) är den förste, som beskrifvit nàgon Hydrachnid. Hans "Araneus aquaticus, ruber parvus", alserer Mëlder varil Hydrachna (Hydryphantes C. L. Kinch), despiciens Ml̈LL.

Johannes Svammelidam ${ }^{2}$ ) beskief först de pa Vepu sittande mäggenn, men kände för öfrigt hvarken deras vidare ntveckling eller sjelfva Hydrachnidernat.

LiNNÉ ${ }^{3}$ ) har lemuat följande beskrifning par en i vattnet lefvande Acartu, hvilken, ehuru nigra bestämningar tala häremot, af C. L. Kocm m. H. ansetts vara Eylais extendenes Latr.: "Acarus aquaticus lnber, abdomine deplesso, tomentoso, postice obtuso. Globum siepe trahens post se. (Jva rubra in Nepis ponens." Bestänningen ntomentosus" kan ej tillkomma nagon künd Hydrachnid, hvarföle äfven MÜLLek ansel, att LrNóé sammanblandat sin A. rqueticus med Trombidium holosericenm (LrN.). Hrad Linné menar med glohns är afven svart att inse, da Hydrachniderna ej, sason vissa landtspindlar, föra sina äger med sig.

August dон. Roesel, von Rosenmof ${ }^{4}$ ) var dell förste, sorn fullständigare beskref dessa djurs utveckling och, fastäu knapphändigt, redogjorde för deras nutrition och copulation. Han förde dem till spindlapue, enär han sett dem spinna tridar. If hans arter ar den ena: "Dic Kleine rothe Wasserspinne nit Zierathen", fig. XXIV, troligen en ung Hydrachue geoyraphica MëLLER, den andra: "Die schöne hochrothe Wissermilben, fig. XXV, Limnochares holusericens C. L. Kúnch.

Jur. Henne. Sulzer ${ }^{5}$ ) har beskrifvit en Hydrachnid, som Müllek anser vara den-

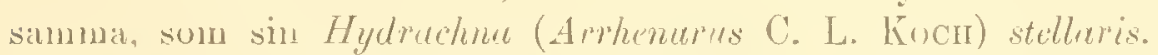

Martin Froben Ledenaülder ${ }^{6}$ ) har beskrifvit och afloildat tvả arter.

Étexne Lours Geofroy ${ }^{7}$ ) oinnäinner tvà arter, af hvilka den ena skulle valla densanma sorn dell LINNÉ beskrifvit, den andra: nAcarus aquaticus niger, abdominis medio lateribusque flavis", antagligen är en Atat- eller $N_{\text {esceartart. }}$

F. von Paula Schlink ${ }^{\circ}$ ) beskref och uftuldade tra arter, bada tillhörande slägtet. Arrenurus. Den ena: "Acarus corpore postice attenuato, elongaton, hvilken han upper Vala nstor solı ett vallmofrö, smutsgrıön med den grenomskinliga förlangningen ljusare, hardskulig", är utan tvifvel synonyun ned Arrhenurus qlobator (MëLL.); och den andra: "Acarus grlobosus cormens pedibus posteris natatoriisn, nofvan med tre mörka fläckarn,

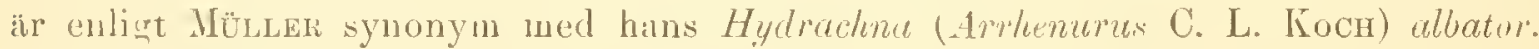

CarL IE GEer ${ }^{9}$ ) har i sjunde delen af sitt stora veh berömda verk afhandlat Qualstren eller Acari.

Efter deras vistelseort indelar han dem i sju fanniljer, af hvilka den första lefver bland lifsmedel, den andra pa memiskor och fyrfotade djur, den tredje pa fäglar, den fjerde pa insekter, den fente pa träd och växter, aen sjette ströfvar omkring ntan att

1) Beschetibung vou allerley Iusceten in Teutsch Land. Achter Theil, p. 5, t. 3, tigg. 1, 2. Berlin 1730.

2) Biblia Naturit sive Historia Insectorum, Tom. 1, p. 230, tab. 11, fig. $1 \mathrm{~g}$ och fig. 5 . Leydit 1737

3) Fauna suecied, p. 348, Stockholnie 1746. Systema Natulie. Ed. decima, p. 617. Holmin 1758.

4) Inseeten Belnstigungen. Dritter Theil, 1. 149-157, tals. 24. Nürnberg 1755 .

5) Kennzeichen der Insecten, t. 22, tig. 147. Kürich 1761.

6) Miroscopische Genüths- und Augen-Ergötzung, p. 164. Nürnberg 1761 .

7) Histoire abroge des Iusectes aux environs de Paris. Tom. 2, p. 625. Paris I76:

४) Beytratge zul Naturgeschiehtc. Augsburg 1776.

9) Memoiles pour servil a l'Histoirt des Insectes. Tom. VII. Stockholm I77E 
fästa sig pat nagot säskildt föremal och den sjunde lefver i rattnet. Till doma sist-

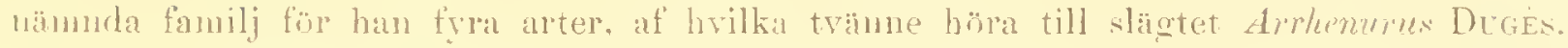
len ena af dessin: learus aquaticus caudatus, subrotundus, finsens, pufo-maculatus, abdonine "audato evlindrico, al synongm med den at C. L. Kocm beskrifina dromemes "endutus, och den andra: "Acapus aquaticus maculatus. fuscus, macula rubra, corpore

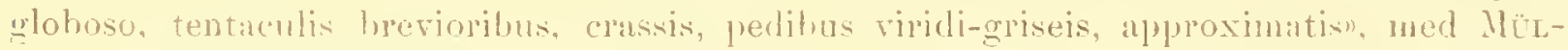

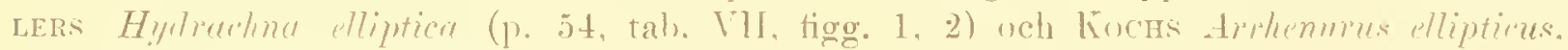
hvilken är honan till den förra.

Af de öfriga arterna är den ena: "Acarus aquaticus globosus, rubro-fisens, corpore glohoso, tentaculis brevionibus, perlibus pubris aproximatisn, tydligen syonym ned

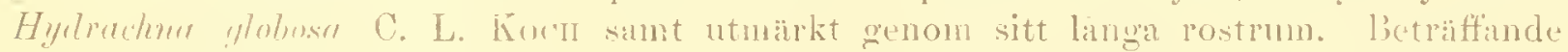
den andra: "dapus aquaticns mbers, coppore subgloboso, tentaculis longis, pedibus

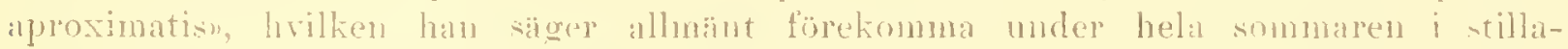
statende vatten och hlifvil ungefär sa stor son en lins, cinoberriod ned svarta flückar a ryggen, är det svart att afgöra, huruvida den är en Eylaix eller en Hydruchua. Att döna efter den följande beskrifningen pa kropuen: nedtryckt wh framtill nagot afomalnande, vure man benagen att hänfüra den till det föra slägtet, men ale följande bestämningarue: sista benparet med langa simborst, rostrum litet men tydligt, strida alldeles habenot. Kuch anser den stronym med sin Hydrachna. Snarare a den,

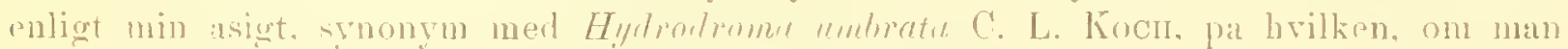
undantager de svarta täckarme, beskrifningen bäst pasiar in.

T) Grer kriticerar RoEsel, som räknar Hydrachniderna till spindlarne "nayant ni corcelet, ni tèatles, ni filieres an derpiere, ni yeux semblables il cenx des Araignces et les pattes arant lend attache immediatement au ventre."

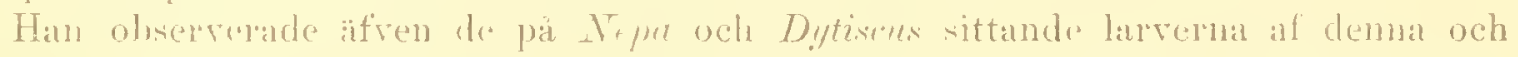
föregatude art, hrilka hau dock, i likhet med de fürut nännde fürfattarne, alısag̈ för ägre, af moderdjuret, fästade pa insekten och tillräxande, i det de fran densamma suga näringsaft ("suc: nourriciérn). Angaende mongrnes unetanorfoser nämmer han endast, att alla nuga Acari liafra 3 par ben och att det fjerde först efter skedt hudombrte firamkommer.

Den ofvan omnämnda insugningefömuagan hos aggen kan dock l)e Geer cij anıat

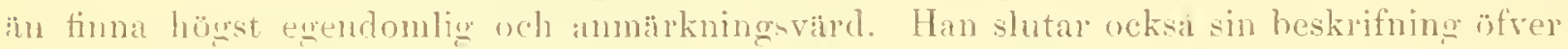
den 3:dje arten med füljande ord: nHa vi vid detta tillfalle beundra de olika oels "mnvexlande medel, naturens upphofsman gifvit djuren och sürskildt insektoun till deras fortplantning och bevarande; ty det äp högst eget att se agge tillvixa och draga näringrssaft $1 u^{2}$ kroppen pa ett ammat lefvande djum."

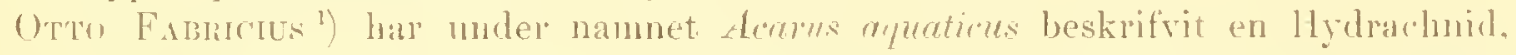
livars vigtigaste kalakterer ino: Corpus semiorbiculare antice partun angustatum, supra depressun 4 lincis punctorum inpressormm, medis antice concorrentilus. Frons

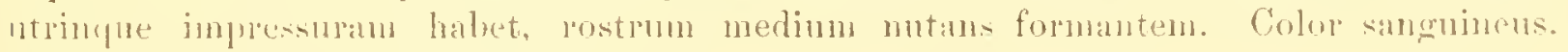
Tomontal ram in compore pedihusque.

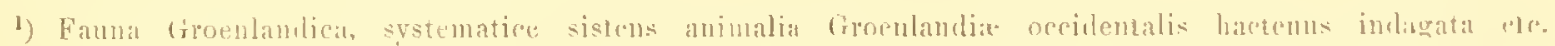
Hatula et Ioipsia 17:0 
Otto Frievirich Müller är den fürste, som mera specielt sysselsatt sig med Hydrachniderna. Redan ar 1769 kande han omkring 40 arter ${ }^{1}$ ) och i sitt 1781 utgifnal verk ${ }^{2}$ ) har han beskrifvit $49^{3}$ ). Detta arbete, son på sin tid obestridligen var utmärkt. äger ännu sitt stora värde och de af MÜLLER lemnade artbeskrifningarne äro i allmänhet rätt goda. Dock har afven detta, såsom hvarje annat arbete, sina fel, till stor del beroende pả de ofullkomliga hjelpmedel, som dả fumnos för studiet af sá smá djur. Atskilliga oriktiga uppgifter förekonma derfüre betriffande ledernas antal hos palperua sant formen på dem och benen. Figurerna till arbetet äro till en del unindre goda och färgteckningen stundom mindre naturtrogen. MüLLıß definierar Hydrachniderna pa följande sätt: Capite thorace abdomineque unitis; pedes octo; palpi duo. articulati; oculi duo, quattuor, sex. Han hänför alla artema till ett enda slägte, Hydrachna, men indelar, detta efter ögonens antal i tre underafdelningar. Till den sista af dessa räknar han blott H. umbruta (Hydrodroma umbrata C. L. Koch), hvilken dock lika litet sorn nagon annan känd Hydrachnid har sex ögon. I den andra upptager han blott fyra arter, hvilka tillhöra slägtet Limmesia C. L. Koch (calcarea, fuscata, undulate och murulata), med nteslutande af arterna geoymulica och impresse samt cruenta (Hydryphantes cruentus C. L. KoCH), hvilka han pästår ega blott tva ögon. H. cxtendens (Eylais entendens Latr.) beskrifver han riktigt äga fyra ögon, men für den ändock till första afdelningen. Uppger vidare, att Hydrachniderna hafra spinnorganer, sant bekrätar RoEsELs uppgift, att de lefval anfusorier, hrarjemte han äfven sett dem angripa Monomus sant laver af Tipula. En verklig copulation hos dem betviflar han derenot. Hos hanen af de arter, som tillhöra slïgtet Arrhenurus Dugès, utgöras enligt hans asigt generationsorganerna af de bihang, som sitta ytterst i kroppens smalare del. Hydrachniderna lägga röda sferiska ägg, som inom en manad antaga en månlik folm sant hlifva blekare. Ungarne hafva sex ben, äro försedda med sugsnabel samt ombyta hud några gånger, innan de blifva fullkomligt utbildade. Af Möllers 49 arter tillhöra 4 slägtet Atax Fabr., 3 Nescea C. T. Koch, 3 Marica Kónch. 19 Amhenurus Dugès, 1 dractides Koch, 2 Acerus Kocn, 1 Mideu Bruz., 4 Limnesia Koch, 3 Diplodontus Duges, 2 Hydrachna (Mürd.), Kocri, 2 Hydryphantes Koch, 1 Hydrodrom Koch och 1 Eylais LATr. De tre âterstảende arternas plats inom slägtena har jag ej med säkerhet kunnat bestämma (H. lunipes MëLL. = Nesan pulchra Kocn?

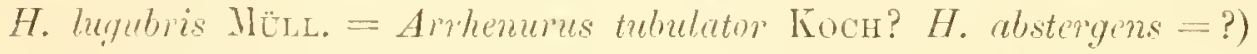

Chistop. GotTliei Bunz är den förste, som beskrifvit någon parasitiskt lefvande fullbildad Hydrachnid, Acams ypsitophorus ${ }^{4}$ ), hvilken han funnit på Mytilus cygnceus. Hans beskrifning pâ denna parasit är ungefürligen följande: Kroppen mörkbrun med ell gul Y-fornig figm a ryggen, ögonen tvả; benen med talrika simborst; sista benparet liugst.

1) Sie pag. II i hans här nedan onnimda verk.

2) Hydrachn", quas in aquis Dania palustribus detexit, descripsit, pingi ct tabulis itneis XI incidi mmavit O. F. MëLler. Lipsiae 1781.

3) Alla dessa arter med undantag af H. abstergens äro doek omuända och i korthet karakteriserade i hans arbete: Zoologife Danica Prodromus. Havnice $17 \% 6$.

*) Ohserratio I Christophi, Gottlieb Bonz. Nova acta ply̧sico-medica Acad. Caes. Leop. Caroline. Sat. rur. cont. Ephemerides etc. VIl, p. 52. Norimberg 1783. 
Joh. Christoffeli Fabriclus hal" i sitt föruämsta verk öfver insekterma ${ }^{\text {) }}$ fülenat de af honom kända 33 auterna, hvilka alla för Ml̈LLEr varit bekanta, med slägtet. Trombidium; men i ett senare arbete ${ }^{2}$ ) för han dem till det nyal slïgtet Atax, som af honom blifvit. uppstäldt med bibehillande af samma arter och samma ordning, som i det förra.

JEXs RATHKE ${ }^{3}$ ) har mnder nannet Trombidium notatum beskrifvit en Hydrachuil. som antagligen är symonym med Atax ypsilophorus (Bonz) Clapıréde.

Pinres André Latmentus ${ }^{4}$ ) indelade Hydrachnidema i trenne slagten: Limnorhare. Hydruclué och Eyluis. som han pả följande sätt karakteriserat:

Limnochare: Bonehe infërieure. Iandibnles nulles. Antennules courbées, articulées, terminees en pointe. Livre inferieure obtuse, de deux pieccs eonniventes. Pittes cilites, propres pour uager.

Caractircs Habituels: Corps ovale, mou, deprime, sans distiuction dinneaux, ronge. Deux renx. Pattes assez courtes.

Hydrachné: Intemules arquees, articulies, d'abord eylindriques, coniques ensuite, et termineses par un ongle et un pouce mobile. Ber avance, conique, consistant cu deux soies longues, recues dans une levre inférieure. Pattes ciliees, propres pour nager.

C. H. Corps glubulenx, sans distinction d'auneaux, rouge foncé; peau assez ferme. Denx ì quatre yeux.

Eyluis: Mandibules plates, munies d'un ongle à la pointe, recues dans une livre inferrienre. Anterinules en còne alongé, articnlées, arquées, pointues. Pattes propres pour nager.

C. H. Corps presque globuleux, d'une peau assez ferme, sans distinction dianneanx. Deux à quatre yenx. Conlem brunc on panachee.

Jon. Friedrich Hermann kriticerar i sitt apbete ${ }^{5}$ ) Mülluer, beträffinde först sjelfva namnet Hydrathme, hvilket enligt hans åsigt bör skrifras Hydrarmchna, enär

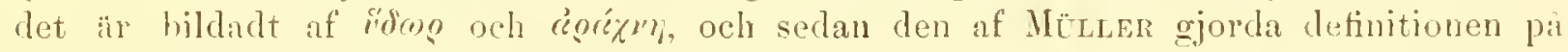
familjen. Den fullkomliga sammansmälningen af hufvud, thorax och abdomen, ïgonens antal, benens vilfüstning och palpernas form synas honom ej tillrackligt begränsa densamma. Sjelf lemmas han emellertid en lika litet tillfredsstallande detinition: nDeux palpes, bec et deux lames en forme de gaine très entièes, deux, quatre ou six yeux, pieds natatoires. (1)Ucks klandrar honom för denna beskrifning på mundelane).

Vidare redogür han für byggnaden af inundelasne hos $H$. geographica, hvars rostrum han anscr vara en sugsnabel, betickt af tvanne lineära, kortare skifvor, sour ligga nära intill hvajandra och ïro med sugsnabeln så fast förenade, att de blott med största svârighet kumna skiljas fran demsanma. Äfven omnämner han de tränne klorna pa yttre ändan af sista tarsalleden, hvilka han säger sig lufva funnit hos alla af lionon observerade arter, oaktadt han upptager itminstone tvinne, tillhörande slägtet Limnesin Koch. Hermaxx beskrifver afven iggen af Eyheis extendens, hvilka han fumnit khmpvis afsatta på sidorna af det kïrl, hvari djuret fölvarats. Af de - -4 arter, han ubserverat och, i likhet med MüLleı, fürt till ett enda slïgte, Hydrechno. iro 5 nya, nimligen:

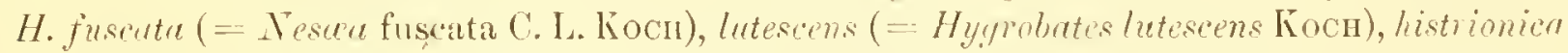

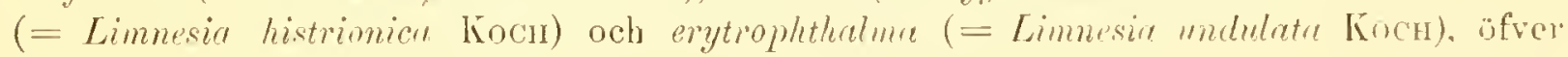

\footnotetext{
1) Entomologia Systcmatica. Tom. H, p. 399. Hafnia 17:3:.

?) Systema intliatorum. Brunsviga 1805.

3) Skrivter af Naturbist. selsk. b. 1, h. 1, p. 175, tafl. 10. 17!17.

4) Précis des Caractores genèriques des lnsectes, p. 1\&1. Paris 1796.

5) Mémoire Aptèrologique. strasshurg 1804.
} 
hrilka han lemuar mer eller mindre utförliga beskifningar. Figurelna till arbetet iro j alluänhet temligen groda.

Daldebart de Ferussac ${ }^{1}$ ) har beskrifvit 2:ne arter Hydrachnider. Hydrachna testudo och $/$. lutescens. Den fürra är troligen synonym med Midea orbiculatu Bruz., den senare en valietet af Hyqrobutes lutescens (Hern.) Kocri.

Gottrimed Rernh. Treviranus ${ }^{2}$ ) har nitgot sysselsatt sig med Hydrachnidemas anatomi, men de resultat, till hvilka han kommit, aro, isynnerhet med afseende pa respirationsorganerna, föga lyckliga oul bafva derföre af senare anatomer, sâsom DtJARDIx och SiEbold, blifvit förklarade mer eller mindre oriktiga. Treviraxus observerade trachéstanmarne, hvilka lan pastod ntunynna i en springa bakon andra henparet samt genast förgrena sig. Angànde mundelarne kommer han ej till något bestäindt lesultat, men anser troligt, att de bilda en sugsuabel. Det ljusa bandet â r’ygen af tlere Hydrachnider ansig han vara tarmkanalen, det mörka à önse sidor derom fettkroppar. Äfven fäster han uppmärksanheten pả höfternas form och fördelning sant benens och palpermas bygonad, hvarjente han slutligen bestrider RoEsELs "ppgift att Hydrachnidema spinna tradar. Da dylika trảdar hvarken af honom eller andra observerats, antager han sisom säkert, att de ej varit annat in conferver, som stundom paiträffis ä dessa djur.

Cant Pfenfer ${ }^{3}$ ) har beskrifvit en parasitisk Hydrachna, Limnochares Anodonte',

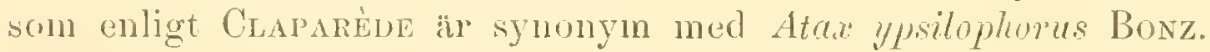

Jeax Victor Aunours har i flere smäre afhandlingar ${ }^{4}$ ) under namnet Arlysia uppsaillt ett nytt slägte, innefattande de pả Tepu och Dytiscus förekommande larverna af Hydrachnider. Detta slägte upptog äfven LATRELLE, som till en särskild afdeluing (Hecapola) och familj (Nicrophtiva) förde de sexfotade Acarillarverna.

Carl Ernst von baer ${ }^{5}$ ) observerade en på de vanligal flodmusslorna lefvande alt, soul han benämnde Hydrachna concharum, efter all sannolikhet densamma, som Boxz beskrifvit under namnet Acarus ypsilophorus. Han visade äfven $\mathrm{i}$ en mindre uppsats ${ }^{6}$ ) att det var larver och ej igg af Hydrachuider, som voro fistade pa Nipa veh Dytiscus. De af honom iakttagna larverna tillhörde troligtvis Hydrachna geographica MüLI.

CH. DE TInés, som àr 1830 undersökt Hydrachnid-faunan kring Laon, bar i bref till Auboun ${ }^{7}$ ) beskrifvit tvenne nya arter, Hydrachna chrysis och runica, den föra (= Eylais enligt Dugés) troligen hörande till slïgtet Hydrachna eller Hydrodroma Koch, den senare sammolikt en Nesce lioncr. I följd af de ofullstindiga beskifningarne, hrari

$\left.{ }^{3}\right)$ Deseription de deux nouvelles especes d'Hydrachnes in Annales du museum d'hist. nat. 1806, 13. 216. pl. 12, figg. 2 a, b, e och 3 a, b, e.

2) Termischte Sehriften anatomischen und physiologischen lubalts. Erster Band, p. 41 . Göttingen 1816

3) Naturgeschichte deutschcr l,and- und Süsswasser Mollusken. Abth. 2, p. 27-28, Taf. 1. Meimar 1825.

4) Tote sur une nonvelle espece d'Açlıysie. Annales des sciences Nat. Tom. 1T, p. 497. 1824. Sur nu noureal geme d'Arachnide trachéenne, Achlysia Dytisci. Bull. Sciences Soc. P’hilom. p. 12-14, 1827. Memoire de la Societe d'histoirc nat. de Paris, 'lonne 1, p. 98, t. 5, fig. 8.

5) Teiträge zur henntniss der niederen Thiere. Nova Aeta Mead. Nat. Cur. Tol. XIII, p. 590, p XX゙IX. 1827.

6) Isis $1832, \mathrm{p} .783$.

7) Annales des Sciences Nat. Tom. 27. 1832. 
nästan blutt kroppsform och färgteckning ommänmus, ä detta dock omöjligt att med säliuhct afgöra. Bland öfriga i demna trakt anträflade arter nämnas füljande: $H$. extendens, H. undulatr. II. abstergens, H. histrionica, H. elliptice och $H$. lontescens.

Carl Will. Habs upptager i sitt af ('. L. Koch fortsatta arbete öfrer Arachni-

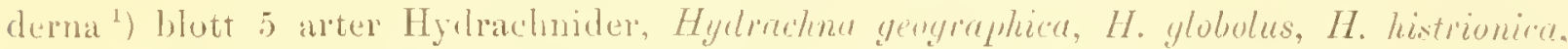

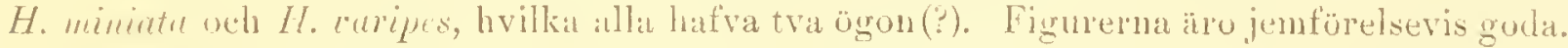

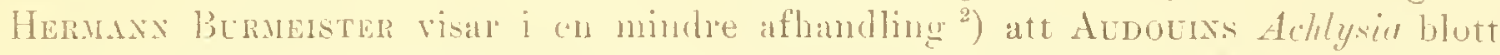
äl en ntrecklingsform af Ilyedrhme. Ehuru hans anigter i betydlig man äro oriktigal, skola vi doek nagot närmare redogärat für dem. - Dal han närmare modersökte de a Sepe sittande päronformiga blasorna, fann han dem äga ett dubbelt hölje, nätmligen ett yttre. fastale och ogenomskinlight, samt ett inre, fint oeh genomskinligt. Det förral var i den smalare ändan hakformigt tillbakabüjgt och härigenom füstadt vid insekten, det senare afsmalnade likaledes $\mathrm{i}$ ena ändan och dess spets inträngele till en del $\mathrm{i}$ det Jttre hüljets. Bada höljena onslüto en tjock, lö̈latigr viitskil, hvarigenom b. kom till den asigten, att blasin var ett ägen, som af Hyduachnan blifvit füstalt ba insekten. Att ägrgets fïstande vid denne skulle utgöral ett nödvändigt vilkor för dess vidare ntveekling, kunde han ej antagal, da insekter med dylikit ägr högrt sällan paträftades. sjelf hade han blott observerat trenne. Efter nagon tids förlope kunde han i densa äg urskilja larverna, som hade en tjoek, rundad kropl' och sex uutvecklide ben. De förblefro temligen linge inom ägget och syntes hemta friskt vatten och föda genom en öppuing å höljet, nära äggets fästpunkt. Cienown denna öppning ntsträteker, sidsom han antager, larven sin sugsuabel för att insuga insektens lifssafter. Nagot senalre framkom fjerde benpalet, som först efter skedt hudombyte erhöll sin behüriga form weh storlek. Den art, hvilkens ntreckling han följt, benänmes Hydrackna amcinta weh utmärker sig genom en omvändt äggrund, nagot langsträtekt kroplsoform, skall-

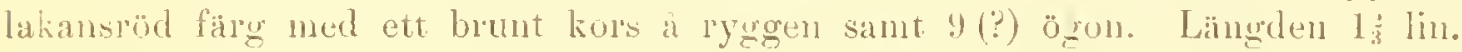

Axtone Degés har i trenne afhandlingar i Annales des Sciences för ar $183 t$ lemnat utförligare beskrifningar öfver Hydrachniderna äh nagon före homom och sailskildt betriffinde deras metamorphoser framlagt resultatet af nuychet nougramal och intressantit iakttagelser. I dun förstal af dessat afhandlingar ${ }^{3}$ ) lemnar han en öfrersigt af Arachnidernas indelning enligt följande tableatu:

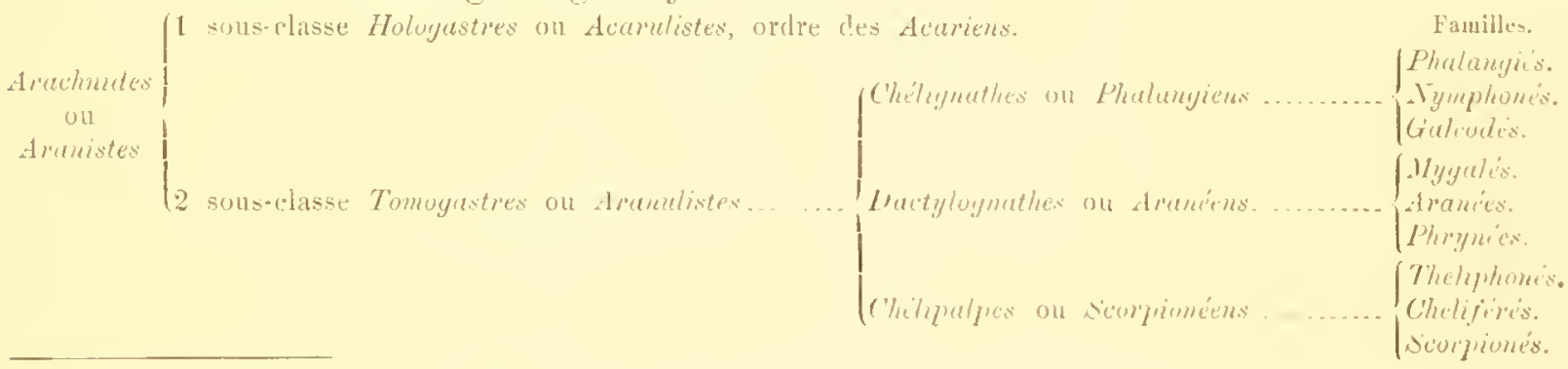

1) Die Arachniden, getreu nach der Xatur abgebilde und besthriben von Dr. C. II. Hanx. 13. I, IL. Nüruber'g $15: 31-4$.

2) Teber die Gattung Achlysia Aud. Isis 1834, p. 138. Tai. 1, liggr. 1-6.

3) Recherches sur lordre des Acariens en general et la fauille des l'rombidics en particulier. Plemier Memoile. Tome I. p. 5.

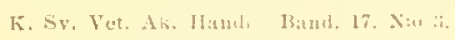


Acari indelas vidare efter palpernas olika form i fóljande 7 fumiljer:

Palpes ravisseurs (ceux qui, rentles par leur milien, ont l'avant-dernier article d'un ou

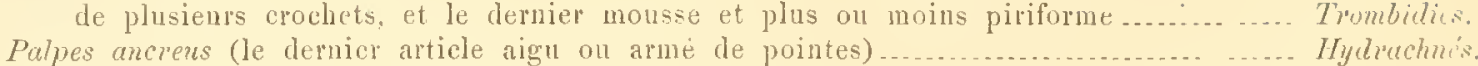

Palpes ritiformes (pen sensiblement renfles, obtus au bout. sans grifie alu penultieme

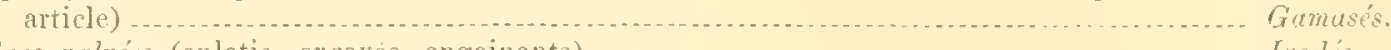

Acariens Palpes valvéts (aplatis, excaves, engainants)

Palpes alhérens (sourles à la lève par la majeure partie de leur longeur et toujours peu

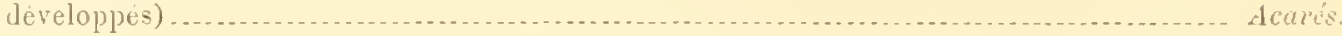

Palpes antenniformes (filiformes aussi, unais à articles trés-raries dnus leur longeur, dailleurs generalement dirariques, redressés ou rejetés en arriere) ............................... Bilellés.

Pulpes fusiformes (rentles, obtus an bout, sans griffe au penultième article)............... (Iribatés.

Den andra familjen, Hylraclunes, innefattar 6 slägten: Atax, Diplodontus, Arrhenurus, Eyluis, Limuchares och Mydrachnu. af hrilka det andra och tredje äro nya. Dessa slägten äro grundarle i synnerhet pä palpernas och mandiblernas olika form, nen äfven på den olikil bildningen af rostrum, epimerer orh generintionsfält. Ogonens antal och benens form synes författaren mindre luafva tagit i betraktande, dai han t. ex. kumnat hanföra Limnesia Kocir till slägtet Atax. Mindre riktigt har DrGis npptagit Limnochures bland Hydrachniderua, enär den bör föras till en särskild familj, hvilket ocksi Koch gjort.

I den andra afhandlingen ${ }^{1}$ ) der han nteshtande sysselsätter sig merl Hydrachniderna, lemnar l)iciss först en kort karakteristik öfver familjen, som oufsedt palpernas redan omnämnda form, utmärker sig genon sina med sinborst försedda ben, hrilkas sista led i yttersta ändan har tvenue krökta klor. Att loöfternas fördelning i fyra grupper alltid skulle rara ntmärkande för Hrdrachniderna, är ett påstiende, som. enligt senatre gjorela observationer, är oriktigt, men som dock träffade in på ris af Dugiss iakttagna arterna. För hans bestämningar af de forut omnämuda slägtena skola vi un lemna en utförligare redogörelse.

1. Atar Fabr. Palpi longi, articulus quartus longior, quintus unguiformis; Iandibulre ungruinulate; rostrum breve, corpus inflatum; oculi distantes; coxa posterior latissima; vulve labia utrimque tribus stemmatibus ornata. Larre hexaporlic, aquatica, adulto dissimiles.

Sisom ţ̣per för detta slïgte namner han Irychachna (Limnesin Kocir), histrionice HekM. och 11. (Hygrobates Ko(n), lutescens IIERu. samt H. runica DE THÉrs, hvilken, son vi redan uänmt, saunolikt hör till det af Koc'H bildade slägtet Nesica. Eit slägte, som omfattade arter af en sidan olikhet, knnde ej länge bestå utan att blifva deladt i Here. Kocn gjorde detta och bildade deraf s]ïgtena Atax (sensu strictiore), Nesce, Piona, Hygrobates, Hydrochorentes och Limnesia.

2. Diplodontus Duges. Palpi breviusculi, articulus quartus longior cum quinto extenso forpicem fingens; Mandibula chelatre (bidentes), rostrum breve; corpus depressun; oculi distantes; vulva labia globuligera. Larve hexapodie, terlestres, adulto dissimiles.

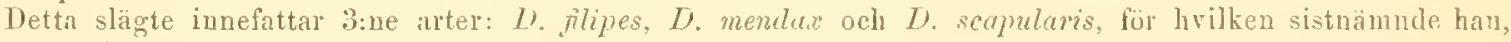
isynnerhet angående ntvecklingen, noga redogöl.

3. Arrhenurus, Dugiss. Palpi breves, clavati, articulus quartus longior et crassior, quintus falcatus; mandibulix unguiculate, rostrum breve; corpus loricatum, in mare caudatum; oculi distantes; coxie latissima: vulva labia plana. Larvie?

Till detta slägte böra de tolf första arterna af dem, hvilka Mưı,er beskrifrit. Duges har af dessa blott funnit 2, nämligen A. cusprilator och A. ulbator, samt en ny ari, som han benämuer A. virilis. Om dessas utreckling har han sig intet bekant.

4. Eylais LATr. Palpi longiusculi. articulns quartus longior, quintus obtusus, tumidulus, spinosus; Mandibulic unguiculate; rostrum brevissimum, ore rotundo; corpus depressum; Oculi proximi; coxr angustate, (jnarta a tertia distans; Larve hexapodre, aquaticie, adnlio dissimiles.

Dugies upptager häl blott en art, E. extenlens, föl hvars utveckling älvensom mundelar han noga redogör. Hans observationer i afseende på dessa senare synas dock, enligt nyare iakttagelser, cj vara fullt riktiga.

5. Hydrachna MüıLer. Palpi longiusculi, articulus tertius longior, quartus et quintus sinul chelnformes; Mandibule ensiformes; rostum longum, vix minus ac palpi; corpus rotundatum; Oculi distantes; Vulva scuto operta. Larva aquatice, parasite, adulto dissimiles (Achlysiu Audoct. ${ }^{2}$ ).

Såson hithörande nämner Ducies 2:ne arter, H. geographica och II. globosa. Den senares utvecklingr

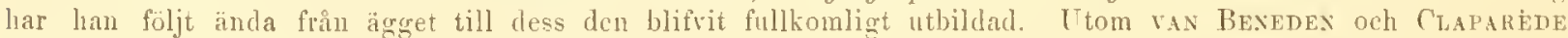
har ingen sầ noggrant som Degìs sysselsatt sig med studiet af Hydrachuidernas utvecking.

p. 144

1) Remarques sur la famille des llydrachnes. Denxieme mémoile sur lordre des Acariens. Tome 1.

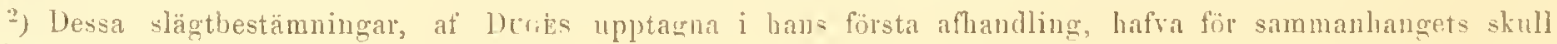
hitr fitt sin plats. 
Jag har här kanske räl utförligt redogjont fö Dugés afhandlingar; men da han

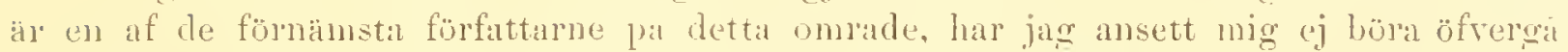
till nitgon annan, imnan jag meddelat atminstone det räsendtligaste af hans asigter.

Daxd weh WheLper hafra kort efter lecies $j$ en mindre afhandling ') beskrifvit 2:ne parasitiska arter fran trakten af New-Haven i Tord-America, der de skola alluant fürekomma à Anodonta- och Alasmidonta-arter. De benàmma dem Hydrachna formosa oclı H. pyriformis. simnt lemna öfver don rätt noggramma beskrifungar. Till slägtet Hydrudina i inskränktale nening (d. v. s. sasom det af l) eries och C. L. liocn definieras) kuma de dock pi urrund af flere räsendtliga olikheter ej föras. Snarare böra le, savidt de ej skola bilda ett nytt slägte, hvautill fimnas flere skäl, sätas nära den

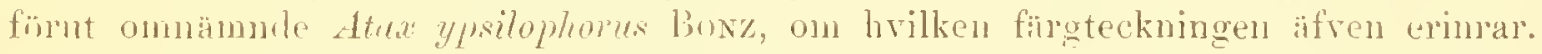

R. A. P'nulpr ${ }^{2}$ ) har lennat beskrifning öfver en i hatsviken vid Neapel anträffarl art, den enda $\mathrm{i}$ salt vatten förekommande, för hvilken han bildat ett nytt

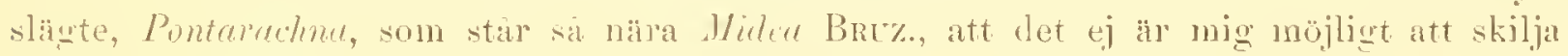
dessa bada slägten.

Hatdenax, som i liklet med de treme föregaende författarne egnat sign at studiet af Hydrachiderna i Nordamerika, har specirlt afhandlat de paraitiska formerna, för hvilka han npostälde ett nytt slägte, Cnionicoln. onfuttande flere arter ${ }^{3}$ ). Dessutom har han beskrifvit 4 arter $\left.{ }^{4}\right)$, men heskriningarne pá den ano ganska ofullständiga.

Cam, Lunwig liocn har fört kämnedomen on Hydrachidema ett betydligt steg framat, företridesvis betriffande slägt-indelningen. Hen on hans atgörande härntimman utan trifvel lïnder honom till stor förtjenst, är hans behandling af' anterna langt ifran att göra detsamma, och i stallet att häl spara den noggrame retenskilpsummen, kämnel man sig henägen att tro, det hans hufvudsyfte hlott varit att fà gifra sa manga nya namm som mojligt. KocH har namligen nästan uteslutande hemtat sina artkarakterer frun furgteckningen, och has harigenom lyckats exhlua et utomordentligt stort antal nya "arter". Da man emellertid kämnes att dessil djur hade after alder och lokal ganska myeket fürändras, sà kan med säkerhet antagas, att en stor del af de Kochska arterna ej äro annat än varieteter. I sitt arlete ofver Tysklands Crustaccer, Myriapoder och Arachnider ${ }^{\circ}$ ) beskifves Kocu de särskilda artema utan nagon ordninğ, inen $\mathrm{i}$ ett senare verk ${ }^{6}$ ) meduelar han en systematisk öfrersigt öfver faniljer, slägtun och arter. Han indelar här Hydrachniderna (die Wassermilben) i 2:ne familjer, Hyyrobatides (Fussmilben) och Mydrachnides (Neihermilluen), af hvilka den förra innefattar arter med 2; den schare med 4 ögon. Fär slägtbestimningarne, af brilka jag kommer att till stor del bequgna mign i detta arbete, anser jag öfrerflüdigt att här p. 181 .

1) Un two Anericali species of the grenus flydrachna. Sillim. Amer. joumal 1836 vol. 30), p. 354.

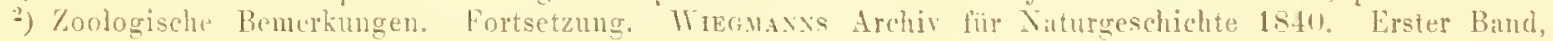

$\left.{ }^{3}\right)$ On some Ameriean species of Hỵdrachicle. Zool. Contrib. 1s42. Detta arbete har for mig cj rarit tillgängligt.

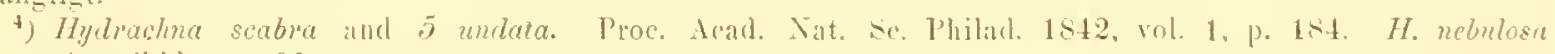
and coecinea ibid. 3. 196.

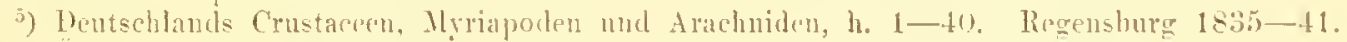

${ }^{6}$ ) Lbersicht des Arachnidensystems ro: ('. 1. Koct, h. B. Nirnberg 181?. 
närmare redogöra, och vill endast anmärka, att de künnctecken, fioch homtat fran den regelbundna fördehningen af ryggens "stigmatan och som han ansett sa vigtiog, ej synts mig värda att lïgra sa stor vigt vid. DUGis nämuer intet om dem och BrTzELIUS, som kunske näst homom grmuligast observerat Hydrachniderna, har ej heller fästat nägon uppmärksanhet vid desamma. Hvad mị betraffar, tillstar jag, att det.

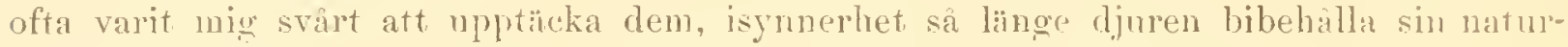
liga färo. Hafra de nagon tid fölvarats i sprit och färgorna försvmnnit, sa framträda de nammde nstignatan tydligare, ehmor joke ens da hos alla arter.

Bland mindre fel, till hvilka kuch gjort sig skyldig, vilja vi nainna placerandet uf slärtet Diplndontus. Dugès i den första familjen, oaktadt den enligt. Dugés har fyra ögon, sant hans mindre riktiga beskrifning pâ epimerernas fördeluing los slägtena Hydrachma och Eylais. Han säger nämligen, att de tveme fritmre paren $\ddot{a}$ hvarje sicla ej genom nagot märkbart mellanrmm äro skilda fran de tyenne bakre, oaktadt detta mellanmm, isymnerhet hos Eylnis, ̈̈r ganska tydligt. Kincin upptager 15 slagten ned tillsammans 182 arter, hvaraf 10 slagten med 145 arter höra till den första och 5 slïgten med 37 arter till den andra faniljen. Antaga vi, att omkring 50 af dessil arter förut rarit kända, hal Kocn saledes upptäckt och beskrifvit omkring 130 nya. funna inom en jemförelsevis föga ntsträckt areal, da de med fâ undantạ äro frân dammar och grafvar i trakten af Regensbur $\underline{\underline{c}}$.

FÉlix Dumandx har i sin afhandling öfver Acari ${ }^{1}$ ) meddelat atskilliga obserrationer üfver Hydrachnidernas anatomi, hvilka dock till en del aro oriktiga. Han anser dem sakna sürskild matstume, mage och tamkanal samt antager, att de organiska sufter, hvaraf dessa djur lefva, äro inrymda i lakuner, som sakna egna räggar, i midten af en brumktig parenchynatös massa, motsvarande lefvern. Den ljusare $Y$-formiga figuren i ryægen af manga Hydrichnider, anser han vara bildad af et.t mder huden liggande fettlager. Hvad respirationen vidkommer, är han af des asigten, att inandningen sker genom de à huden befintliga stomata, som äun analoga med räxternas. Under dessa befinner sig en rund ihalighet, begränsad af ett vackert nüt med runda lika stora maskor och genomskinliç substans. Vid sidan af hrarje stoma ür ett hả., som synes sta $i$ samband med den beskrifna ihaligheten. Utandningen iter sker genom de trenne stora trachestammarne, som mynna med en aflang och af 2 :ne flikar tillshiten öppning vid insidan af mandiblemas bas. Dessa stanmar dela sig på något afstånd frân mynningen $;$ en tofs af tubulösa tracheer, som ntan nagon förgrening fördela sig öfver hela kroppen.

Huppolyte Lucas ${ }^{2}$ ) har beskrifvit och afbildat 4 Hydrachnider fran Algier: Hydrachno erythina, H. rostrata, H. cyanipes och H.tomentosa. Den första af dessa, hvilken mest liknar Eylais extend'ns Latr., men i flera afseenden skiljer sig fron demna, synes büra füras till ett nytt släg̣te. H. rostrata äl tydligen en Diplodontus Dugès, liksom H. manipes en Anurania Non. o. H. tomentosa anser jag sti Hydrodroma C. L. Kínch

1) Premier Mémoire lur les Aeariens et en particulier sur l'appareil respiratiore et sur les organes de la manducation chez plusieurs le ces animax. Am. des Sciences Vat. Tome IIl, p. 5. Taris 1845.

2) Eploration scientifique de l'Algérie, prenclant les annes 1840-42. Tom. 1, 2. Araehnides. p. 31:; Tryekt 18.19. 
sa näla, att det ej är skäl föra den till nagot nytt slägte. Sirräl beskrifningen som isymerhet figmerma aro goda.

P. J. var Bexenex har i en vidlyftigare afhandling ${ }^{1}$ ) beskrifrit utrecklingen af

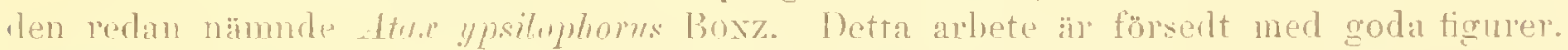

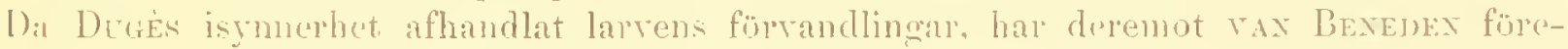
tradesvis fästat sig vid sjelfina ägets sucessival ntreckling, hrapemot han förofallep mindre tydlig $\mathrm{i}$ afseende pa larstadiet. I följul häraf komplettera dessa bada arbeten hvaraudra.

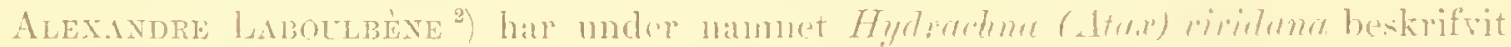

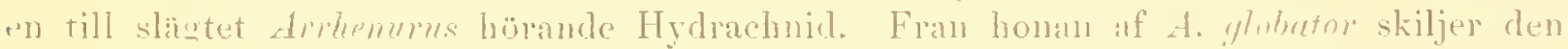
sig blott derigemon att kroplen ar betrolligt smalare $i$ främe andan och att den $i$

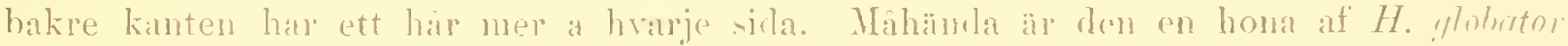
i 2:rra larvstadiet.

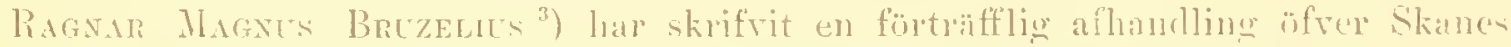

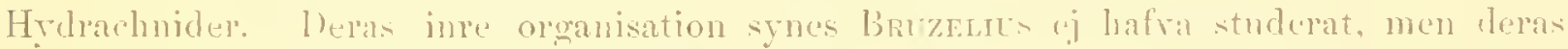
yttre organer ha han pa det noggramnaste beskrifrit och hiröfer meddelat roda och fortydligande figurar. I motsats till Koch har han i de flesta fall albildat dessi

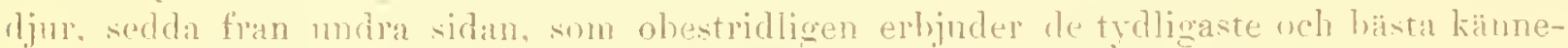

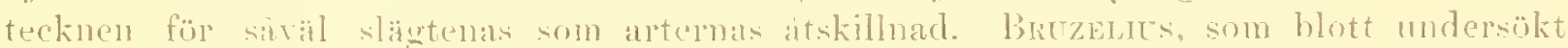
an och andla mindro rattensamlingar i Skane, har ej antriffat nagon förut okïnd alt.

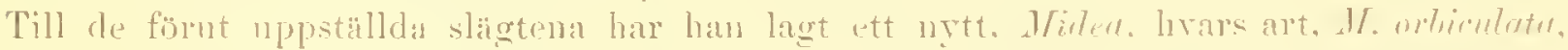

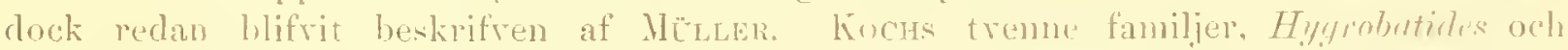
Hydrormiles. har han sammanfört till en enda, hrilken erhallit den senare benäm-

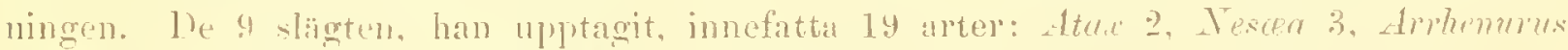

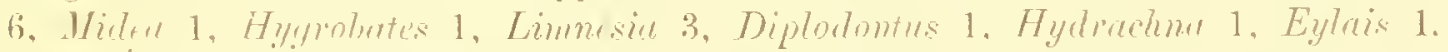

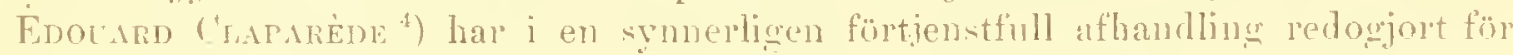

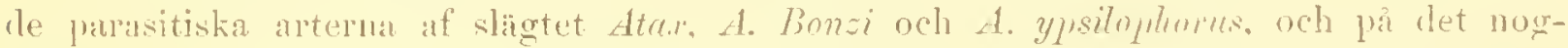

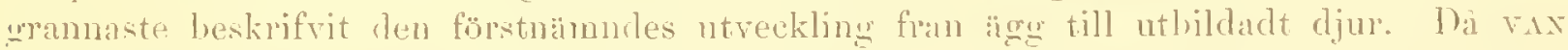

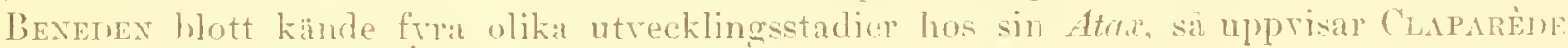
j, tillïgande ret $\therefore$. k. n)entovmmn-stadiet. Han skildran: 1:o) ntrecklingen i ägget och bildandet af "Dentovum", 2:0) ntvecklingun inom detta, 3:0) förstal larvformen, 4:0) ätergangen till ett igglikt (pupp) stadinm och den andra larvformen, och .i:n) det ntbildade djuret.

Vidare lemnall han redogorelse för artens anatomie och de kïnnctecken, genom

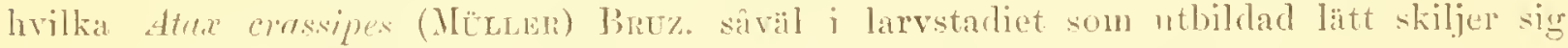
fran de parasitiska arterna. 1)a hrar och en, som önskar noggrannare studera Hydrach-

1) Recherches sur l'histoire naturetle et to developpenent de litax rpsiloplonus, vivant en parasite sur les Anodontrs. Vémoires de l'Acalemie rovale des scicnces, des lettres et des beanx-arts de Belgique. Tome XXIT. Bruxelles 1850.

2) Hoscription de quolpues acariens et d'un Hydrachne i Inmales de la societe entomolorique de lirance. ser. ?. Tome neuviome, p. $80: 3$, pl. 9, higg. 5-9. Paris 1851 .

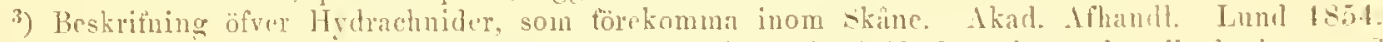

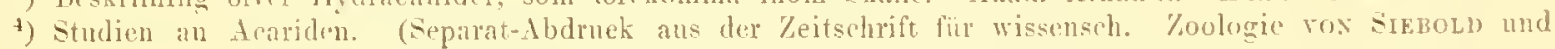
Kördaker. TYHI Band. 1 Heft. p, Hi). Leipzig 186s. 
niderna, onndgängligen maste förskalfi sig detta arbete, tomde det vara öfrerflüdigt att Lä̆ närmare redogöra för detsamma.

Cari, Neumax ${ }^{1}$ ). Hvad mina egna tidigare uppsatser öfver Hydrachnider heträffar, anser ją ofrerflödigt att för dem lemna någon särskild redogörelse, enär det raisendtligaste $\mathrm{i}$ desamma finnes liả anyo intaget.

ThNerLan Thoreli ${ }^{2}$ ) har under namnet Mygrobutes Fubricii beskrifvit en Hydrachnid frân Gröland, hvilken han anser mölligen vara Fabricii Acarus aquaticus (ad partem). Hans beskrifuing är ganska fulistindig och tydlig. Att den beskrifua arten, oaktadt nhera afvikelser, bör föras till slägtet Hygrobates C. L. Kincri, anser äfven jag. livaremot jag bestamdt àr öfvertygar om, att den ej kan vara synonym med Fabricii art.

HeRMAN LEBERT ${ }^{3}$ ) har beskrifvit ett nytt sligte, som lian gifvit mammet CampoImutha. Detta ir emellertid enligt min asigt ej beriattigadt, endr det inmefattar furmer som höra till slägtena Hygrobutes uch Limnesia C. L. Kun. Den af honom anförda arten C. Foreti, âr ritt cgendomlig. Ocksa är den antraffacl pa ett djup af 300 meter. I ett senare arbete ${ }^{4}$ ) som är under ntoifvande och hvilkut han haft godheten sända mig till genomseunde, npptager Laber'l 19 arter, af hvilka de Hesta äro nya, fördelade pa 10 slägten. LnuERt skildring af Hydrachnidernas förekomst pa olika djup är rät intressant och hams beskrifingar, isymuerhet af Cumpognatha Foreli. ganska noggranna och omstiundligat.

P. KRaner har i tvänne afhandlingar ${ }^{5}$ ) lemnat rätt vigtiga bidrag till kämedomen om Hy̛lrachniderna. I förra hälften af den första redogör han för deras anatomie och isymerhet för benänningen af deras munclelar; deras ntveckling leremot har han cj iaktagit. I den senare, den systematiska, delen upptager han 7 slägten, som han anträffat nära Sehlensingen, numligen: Arrkennms, Aturne, Axonu, Eylais, Limmesa, Atax och ITesea, af hvilka Aturus och Axoma aro nya. Till det sistnämmda raknas en art $A$. viridis, hvilken ä synonym med Kocis och BruzeLil Arrhenu'us versicolor, men mycket afviker fran öfrige Amhenmms-arter. Da han under slägtet Amhenums upptagit 2:ne aster, A. limeatus och A. reticulatus med mjuk hud, synes detta rara mindre riktiot, orh anser jug dessa båda bör:a föras till det af mig upjeställda slägtet Anurania. För de sîskilda arterna lemnas goda och onstandliga beskrifningar, hvarjente de lifogade fignrema iro rät förtydligande. 27 arter äro beskrifne, af hrilka nära hïlften eller 12 tillhöra slägtet Nesce. Kramer har emellertid siväl af detta slägte som af Jimmesia beskrifvit larverna i andra stadjet som skilda arter; dessa larrformer uppgi till fem. Di han vidare $\mathrm{j}$ bihanget till afhandlingen klandrar Kocn för

1) Vestergotlands 11ydrachnider. Öfversigt af Kongl. Vet. Acad:s Förhandl. 1870. N:0 2, p. 105.

Om nya arter och slägten Hydrachnider. Föredrag vid Skandinaviska Naturforskare-mötet $\mathrm{i}$ Köpenhamm $187:$ S. Se Hötets Förhandingar, p. 108.

Gottlands och Ölands spindlar och vattenqualstel. Översigt af Kongl. let. Akad:s Fönhandl. 1875. Ni: 2, p. 91.

2) Oun nïgra Arachnider frón Grönland i övers, af Kongl. Tet. Akid:s Förhandl. 1872. N:0 2, p. 163.

3) Matcriaux pour servir a l'etude le la faune profonde du late Leman par le doctem F. A. Foren.. Hydrachnides. Wxtrait du Bulletin de la Societé. Vaud. des Sciences Natnrelles. Toun. NIII. N:o 72. Lansanue 1874.

4) Les llydrachnides du lav Lẻnun.

¡) Beitrige zur Naturgesehichte der Hydrachniden. Nrehiv für Naturgesehichte XXXXl Jahrgang, 1 B. p. 20:3, 1875 och Grundzüge zur Systematik der Milben, i samma Mrehiv XXXXIII Jahrgang, 1 13., p. 236. 187. 
hans defintion pa slightena Iygrobates (star Hydrochoreutes), Marim och Mydrodroma, och påstar, att man virl dem ej kan füsta nagot afseende, sả har han blott till en del rätt. Marica synes mig rara tydligt nog defineralt och äfen de üfriga slägtena har jag i dema afhandling bihehallit, ued tillägg af nagra af Kocm ej ommämnda karakterer. Att Atax blott gnenom närvaron af de linga rörliga taggame pa fürsta benparet skulle skilja sig fran Lespe, oel att derföre A. Bunzi slinlle benännas logun Bonzi, kan jag oj heller gilla. Bemparens längdförhallande och renerationsfältens bildning skilja tillräcklingt dessia bada slägten.

I den senare afhandlingen indelar han Hydrachnjderna i 4 underfaniljer: Hydrach-

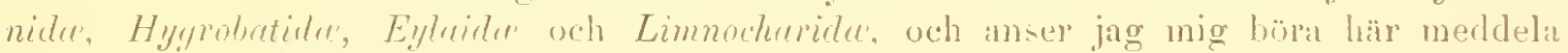
hurn dessil karakteriseras:

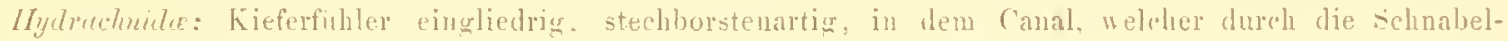
artig verlängerte Tuterlippe gebildet wird. laufend. Kiefertaster tiinlegliedlig. Irie Angen beiderseits am

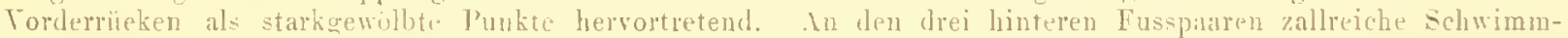

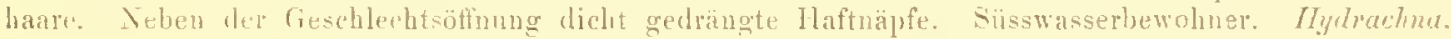

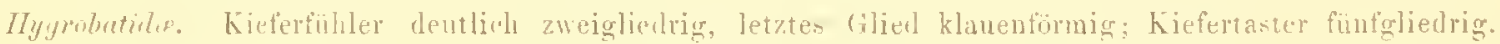
Angen ohne lesondere Hombant, neben der Cieschlechtsöftumg IJaftnäjfe. Siis-wasserbewohner.

I) till denna familj hörande slägtena äro ordnade och bestäma pí sätt följande tabell visar:

1) Las fünfte Kiefertasterglied ist gagen einen spitzeren oder stumpferen Fortsatz des vierten Gliedes beweu-

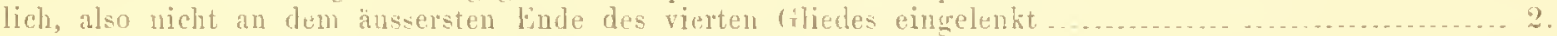

Dis fiinfte Kiefertasterglied ist am vorderen Find des vierten Gliedes eingelenkt .........................

3) Die (ilicher der Kiefertaster sehr schlink. Miplodontus.

Dir cilieder der Kiefertitster sehr gedrunken, dick. droltum

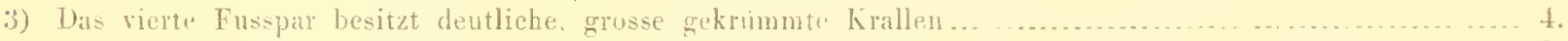

Das vicrte Fusplu besitzt keine krallen .... ...... .

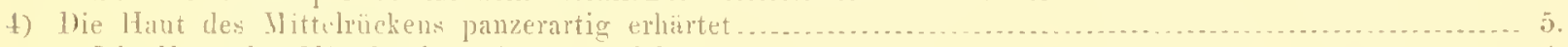

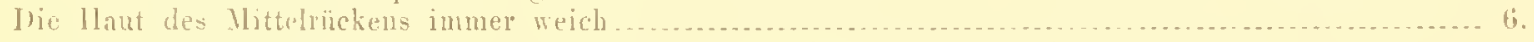

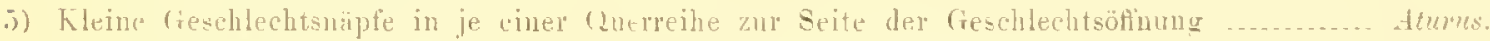

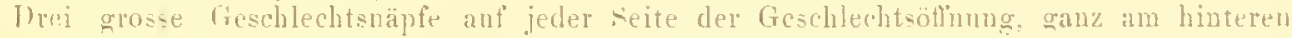

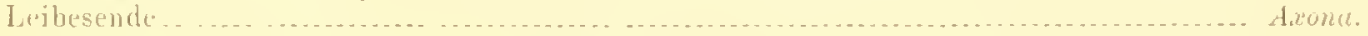

(i) Las zweite (ilied an den Füssen des rsten l'ares mit grossen Höckern, in welche ein

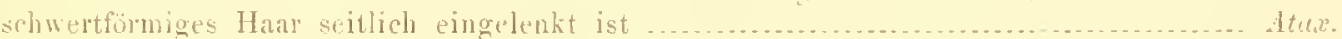

Las zweite Cilied an den Fïssen des ersten Paares ubme Höcker, alle Haarporen ringwallartig $u 1 n$ rand let . . . . . . .

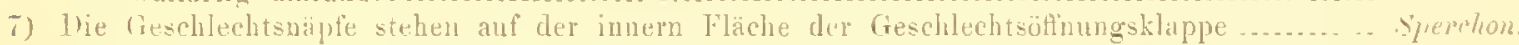

Die Creschlechtsuäpfe stehen auf einer schmalen Leiste rings un die lieschlechtsöhung ... Muleu.

Die Geschlechtsuäpf. stehen neben der Gexchlechtsöfunng in der Leibeshaut ..............

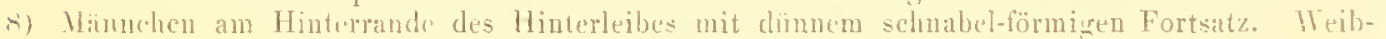
shen an vierten Tasterglied mit vielen llaaren anssu den drex Horkerborsten............... Mrydrochorentes.

Ilänuchen mit abgerundetem Hintreleib; Meibrhen am vierten lastergliede nur mit den drei Höckerborsten .................................... ... ........... Vesciu.

9) Das letzte Fussglied des vicrtcu Fusses trigt an der spitzc eiue sehr lange und starke sehwimnborste, danelon noch wine kurze setiederte. Jeibesform lang oval ................. Omus.

Das letzte Fussglied des vierten Fusses einfich zugespitzt oder mit sipuren von kirallen in Form kleiner spitzen. Leibesform kuenelförmig

Limnesia.

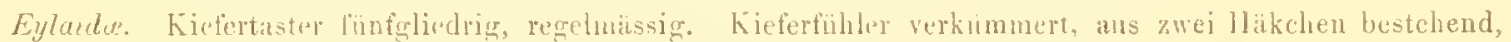
welche durch eine winzige (Jeftiung del l'nterseite der Lippenplatte treten. Feschlechtsuäpfe fehlen. Das vierte Fnssparir ohne Ridwinmborsten. Eylars.

Limoclumile. Kielerfihler und Luterlippe zu einem festen Koptsibek verwachsen, welches vorn cine kreislornige Geflnung besitzt. Kiefertaster lïnlgliedrig. regelmässig. Die Augen auf tiner mittleren llauter-

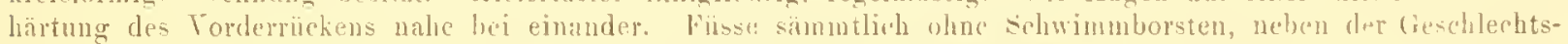
öfinung keine Greselılechtsuitjte.

Pewolner des süssen Wassers. Jimnoclumes. 
A. Cronebriag ${ }^{1}$ ) lan meddelat atskilliga intressanta upplysuingar angaende digentions- och generationsorganerna hos slägtena Eylais, Hydrachna och. Nesara.

Att, sasom Kramer gjort, indela Hydrachniderma i flera faniljer hat af mangat skäl synts nig afverflöligt. I likhet med Bruzeruss har jag deremot simmlnantört de af C. L. KoCH uppstälda faniljema Hygrobutides (Flussmilbens) och Hydrardmides (weihermilben) till en enda, för hvilken det sista namnet bibehallits.

\section{Familia HYDRACHNIDES (Koch) IsRuzelus.}

Animalia aquatilia. Corpus integrum, capite, thorace abdomineque sine discrimine unitis, plerunque ovatum. Peales adnltorum octo, ex internodiis sex compasiti, matatoris pilis nubilibus plermmque instructi, internodio ultino pedum parium primitertii unguibus semper terminato. Epimera parinm duorum prinorum posterioribus minora. Palpi quinque-articulati, articulo tertio ant quarto longissimo, quinto acuto, apice sepe inciso, cum yuarto interdum forpicem formanti. Rostrum, qumm adest. conicum. Oculi quatuor, dno ntriusque lateris sapissime concreti.

Hithörande djur lefva uteshutande i rattuet oeh blott larverua af Eylaix LATr. (och af Diplodontus sectpuluris enligt Duges) göra härifran undantag, enär de äfren springa onkroing pa vattenytan. Kroppen, som ej företer nagon skilnad mellan hnfvnd, thorax och abdomen, är vanligen iggormig eller rmudad oeh oftast temligen höghväilfil. Dess betackning är antiıgen mjuk och slät eller hàd och dả vanligen granulerad. Epimereruls 2 früme par äro mindre än de 2 bakre; ranligen bilda de 4 grupper stundom 3 och nera sâllan en enda grupp, dà de hos nâgra slägten äfven sammanväxa ned hvarandra.

Benen, som hos de fullt ntbildade äro 8 , bestai af 6 internodier och äro vanligen försedda med rörliga simhảr (undantag härifrản göra dock slägtena Bradybates NEuMax sant Aturus och Sperchon líname); deras sista intelnodie har 2 kräkta klor, som antingen äro dubbla ellel mera sällan enkla; det främsta parets äro nindre och rakare än de băda följande parens. Dessa klor knnna fallas in i en sned urholkning af internodien. Hos slägtena Limnesia C. L. Koch, Larica C. L. Kuch och Pseudomarica Neunax ar 4:de parets sista internodie spetsig och silknar klor. benen tilltagal vanligren i länuch frin fürsta till fjerde palet. Hos slägtet Atex (Dugès) Bruzelrus är rlock andra paret längre än tredje och hos Megapus Neuman ar första paret längre in andia och tredje. Hos hammine af slägtet Nescer C. L. Koch sant vissa arter af

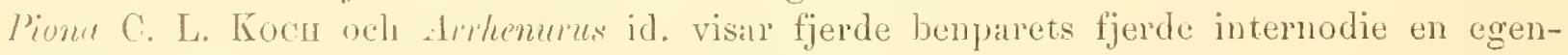
domlig form. Hos Vesen ä den nämligen ì undre sidan djupt concaverad och försedd ned talrika korta och styfva har sant i yttre andan nued langa simbar. Hos

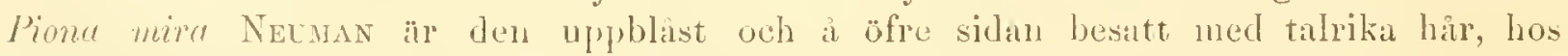
Pionn abnormis Neuman hästan trianguläl med tätt sittande har a öfra sidan. Hus

J) Über deu Bau der Hydrachniden, i Zoologischer Anzeiger, herausgegeben ron J. T. CAks p. 316. Leipzig 1878. Detta är dock ctt utdrag ur haus störe arbete: Über den Bau von Eylais extendens ncbst Bemerkungen über rerwande Formen in den Nachrichten der Gesellschaft der Fremde der Naturkmude in Moskau R. XXIX. Lief. 2, mit $B$ 'T'ufeln. Detta arbete är författudt på ryska spráket. 
Amhenmes utsünder den vanligen en lang process, som j spetsen ar försedd med ett knjpe S-formigt böjda har. I'dpermu äro femledide; första leden liten (nmdantag:

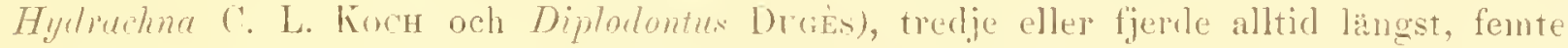
obetyllig. spetsig och krïkt, j spetsen ofta nästan onürkligt inskuren, med fierde leden stumdom billande ett slags tang. Rostrum. som tydligt blott fürekommer hos nagrat slägten, är koniskt och jünunt atsmaluande. Labinem, hrilken hos olika slägten vexlar till

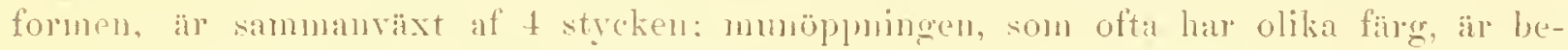
lägen $i$ dess främro del. Mandiblerna besta af tvenne delar. nämligen en stüre, baktill vanligen bredare wch snedt tillspetsad. wrpus, wch den $\mathrm{i}$ främre ändau af denua füstade klon, som till formen betydligt varierar hos skilda slägten och arter. V’jul basen af dema klo fimnes ofta eft himartadt bihang, som stundom nar nästan upp

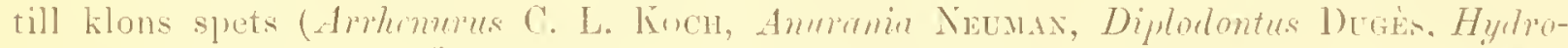
droma ('. L. Kóner). Ügonen. som hos larverna alltid äro fyra, synas i följy af san-

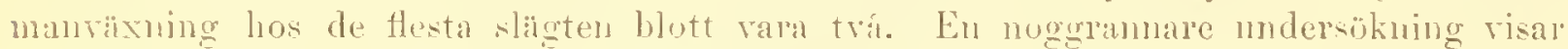
emellertid. att livart och cett af dessa harda oggon har treme comeor och salunda ej kan ansế, sâsoun ett enda.

Digestionsoryanema ${ }^{1}$ ). Fran munöplningen gar en tämligen lang matstrupe till magen, som blott ï en utridgning at densamma. Enligt Kraver visar mageu stundom Here olika afrlelningar. Fran densamma leder en kort tarm till analöppungen. Ofran magen ligarer den ovanligt stora lefvern, som framtill ar treflikig, baktill oftust rundad sannt ofran demna det Y-fomign exeretionsorganet, som äfren nymar ut i amus.

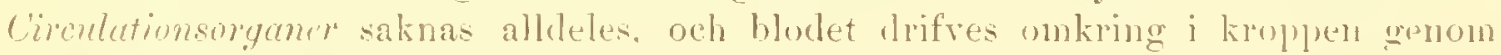
de olikit muskeluörelserna hos de olika orgunerna.

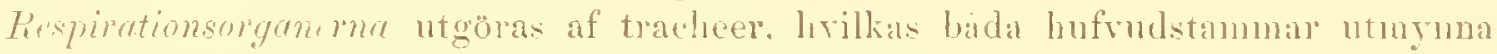
a kroplens öfre sida megër midt öfer mü̈ppungen.

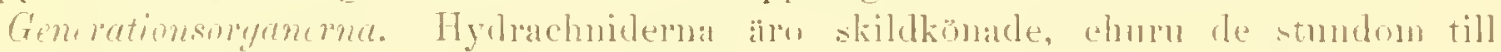
sin gestalt äro sa lika, att det är omöjligt att efter deras utseconde skilja könen.

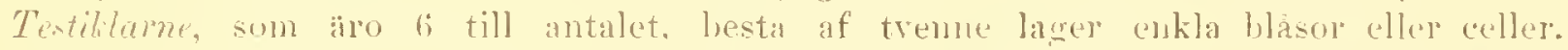
Det yttre lagrets äro spheriska och fyllas till största delen af en rmnelad cellkärna. Det inse lagrets äro betydliert mindre, ned en liten stafformig kärua. Ifessa celler äro antagligen zoospermer. Huruvida någon särskild sïdesledane finnes. är änun valfgiordt. Lqustorkarne, som liyga under lefrem nara kroppskanten, äro drufklastormiga och synas ofta sakna äggledale. loj äggen mogna, lossma de och komma antingen in i kroppsaviteten (Eyluis) eller crenom en serskild oriduct till generationsïplungen.

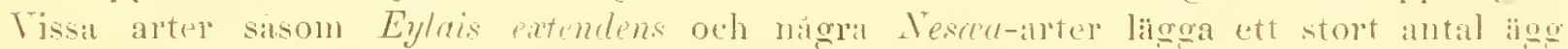

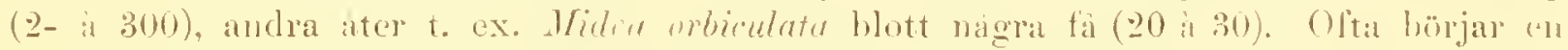

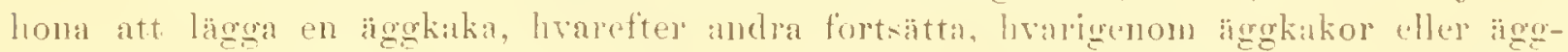

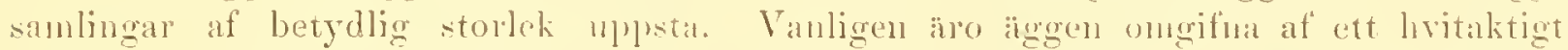
geleartadt imne, som i beröring med rattuet stelnar och ofta hlir sa luardt, att man

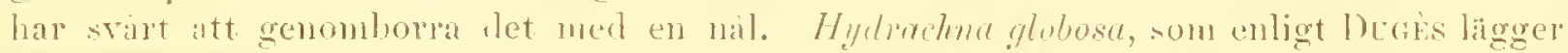

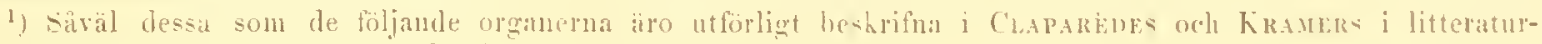
öfversigten omnända arbeten, till hrilka jag fir himrisa. 
sina ägg i stjülkarne af vattenvaxter, omgifver dem ej med detta skyddande ämne. Oftast füstas de vid vattenväxter, stenar eller andra föremål, men stumdom läg@as de pa lösa bottnen t. ex. Hygrobates (= Campognatha) Foreli LeBert. Efter 2 till 6 veckors tid utkläckas de (jfr Eylais) och de med blott sex ben (hvart och ett med 5 internodier) och et.t làngt rostrum försedda larvema frankomma. Det af Ciaparède hos de primasitiska Alax-arterna observerade s. k. Deutoum-strudiet har jag ej iakttagit. Ett egendomligt undantag frin alla andra Hydrachnider, hvilkas utveckling man observerat, gör Limnesia pardina Neums, som alldeles öfrerhoppar första larv- och puppstadiet. Den nyss utkläckte larven i första stadiet fäster sig med sin sugsnabel rid i eller pa vattnet lefvinde insekter såsoun Dytiscus, Depa, Hydrometra etc., förpuppas ofulständigt, hralefter den i alhuänhet fritt lefvande larven af andra stadiet framkomner. Denne har 8 ben med samma antal internodier, som det fullbildade djuret, från hvilket den inest skiljer sig genom sitt ontvecklarle generationsfailt. Han füster sign efter wảgon tid vid vattenväxter eller väggarue $i$ kärlet, hvari han förvaras och genomgir ytterligare ett puppstadium, hrarefter det fullbildade djuret framkommer ${ }^{1}$ ). Hurnvida detta sedan byter om hud, kan jag ej afgöra.

Hydrachnider förekomma i Sverige fràn Skane till Lappland (Quickjock, Karesuando) i de Hesta vattensamlingar. Endast i killor med mycket kallt, klart vatten och i sjöa näla snögränsen har jag ej antrüffat nuğa. Vissa arter tillhöra nteslutande sjöar med djupt. klart vatteri t. ex. Hyyobates (Campognatha) linpoli LeberT, som i Generersjün antraffnts pi 300 meters djup, Limmesia pardina och L. marmata Neuman sant flere Nesen-alter. Andra àter förekomma nteslutande eller nästau ute-

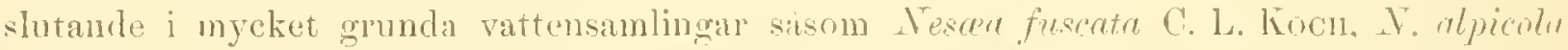

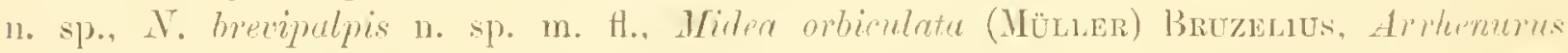

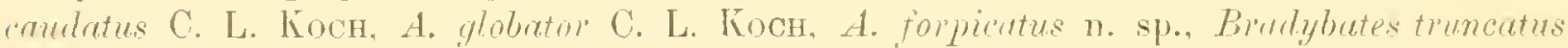
Neumax. De Hesta uppträda dock pa rätt skilda lokiler. Tissa arter visa sig nycket tidigt om varen t. ex. Hydrodromu genast efter islossnimgen. I Mlạ månal är denna talrikast, livarcfter den frampa sommaren blir mer och mer sällsynt. Andra åter forekomma lika tahikt under sommaren och hösten t. ex. Limmesin purlinu, hrilken af mig anträffats allmän i slutet af oktober manad.

Hydrachniderna synas mot vintern krypa ned i mossan och gytjun, der de ligga i dvala, till dess de af virsolens vämande strilar väckas till nytt lif.

1) Dugès och Clapakíne hafra i sina i litteraturöfrersigten nämda arbeten utförligt redogjort för Hỵdrachnidernas utveckling. 
KONGL SY. VET. AKADEMEXY HANDLINGAR. BAND. 17. N:0 3.

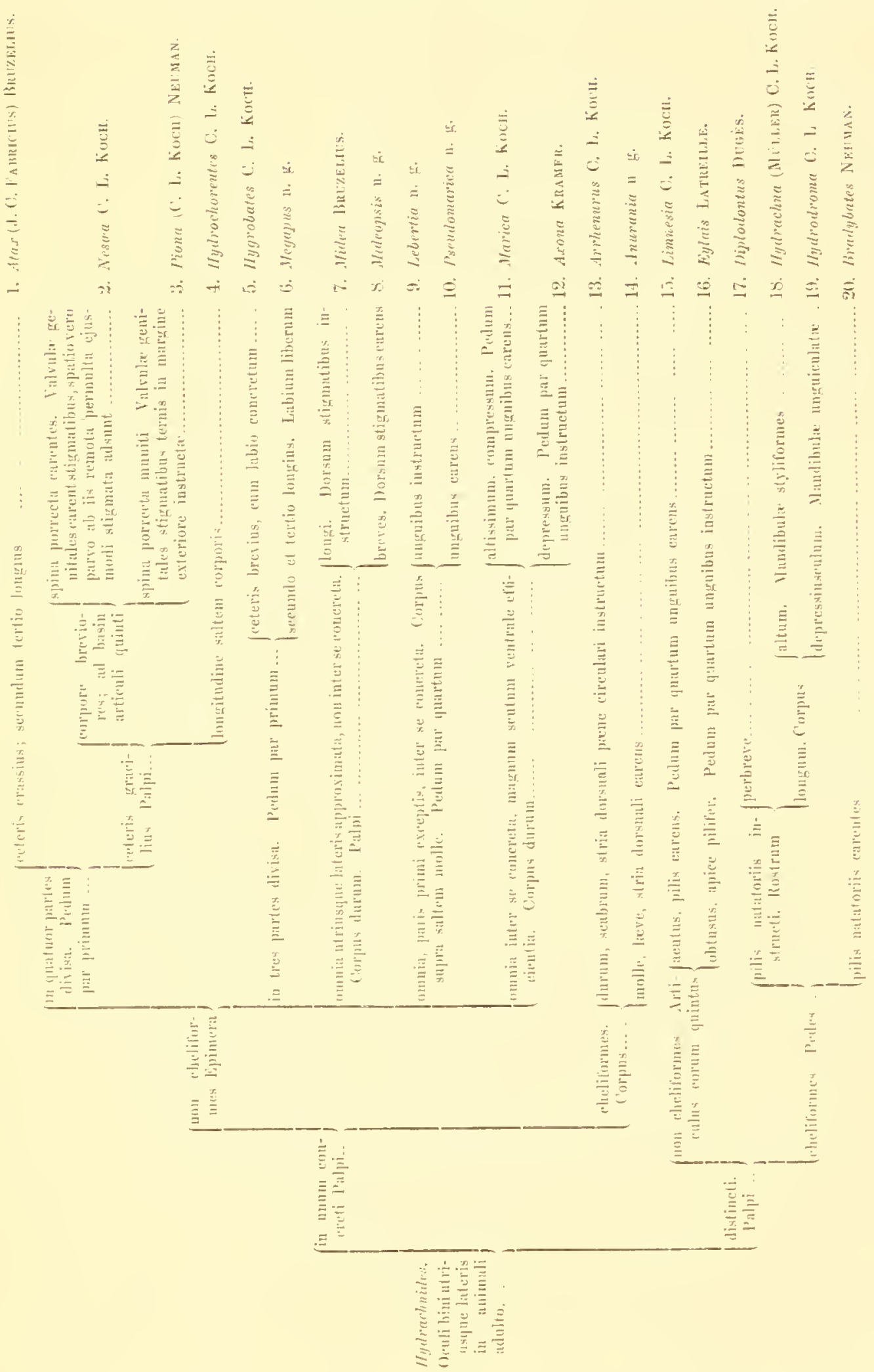




\section{Genus I. ATAX (.J. C. Fabricius) Bruzelues}

Syn. 1781 Hydrachna Muller, Hydrachnae etc, p. 41 (ad partem).

1793 Trombilizm f. C. Fablicius, Entom. syst. II, p. 400 (ad partem).

1805 Atux id. Syst. Antliatorum p. 364.

1834 " Dugés, Anu. A. Sc. nat. t. 1, p. 5 (ad parten).

1811 "C. L. Koch, Uebersicht des Arachn.-Eystems,-h. 3, p. \&.

1854 " Brczelús Beskr. ö. Hydrachn., som förek. i Skåne, p. 8.

1868 "Claparéde, Studien an Acariden, p. 446.

$1855 "$ Kramer, Beitr. zur Naturgesch. der Hydrachnideu, p. 292.

Corpus lieve, molle, obovatum, aut oratum, antice rotublatmm, postice trumcatum aut rotumdatums. Pedum par prinum ceteris crassius et apud species libere in aqua viventes spinis plerumque pilos longos et mobiles gerentibus instructun. Pur secundum tertio longints. Palpi longi (in A. vernali tantum breviores), articulo quarto longissimo, attenuato, in latere interiore dentibus cluobus, in exteriore nno dente majore armato, quinto simplici, acuto, apice dentato. Area genitulis in extrema corporis posterioris parte collocata (excepto A. vernali). Oculi bini utriusque lateris aleo approximati, ut singuli videantm:

DUGés, som först uppstallde detta slägte sisom skildt frin Diplodontus, Arrhenume, Eylris och Hydrachna, gaf det en sa omfattande begräisning, att han dit fönde de af Koch uppstälda siagtena Nesca, Piona, Hyyrobates och Limnesir. Den här angifna sliigtkarakteren ä uppstäld efter Bruzenıs, med tillbörligt afseende füstadı rid de parasitiska arterua, bvilka hvarken af honom eller Koch observerats.

Kroppen är omvändt äggrund eller oval, glatt, framtill rundad, baktill tvär eller rundad. Benens längd varierar mycket. Hos de parasitiskt lefvande arterna A. Bonzi Claparede, och A.ypsilophorus (Bonz.) Claparène, äro de nämligen tämligen korta, och let fjerde paret är hos honurna föga längre än kloppen; hos haname dock längre. Hos de $\mathrm{i}$ vattnet fritt lefvande är deremot nände benpas (utom hos A. vernulis) hos honorna $1 \frac{1}{2}$ a 2 ganger, hos lianarne $2^{1 / 2}$ à 3 ganger langre an kroppen. Epinererna aro fördelade i 4 skildal grupper; fjerde paret nästan fyrkantiga och utom hos $A$. érwalis dubbelt större än det tredje. Labium är fri, bakat nästan halfcirkelformigt afrumdad och utsändande treme utskott, som med sina ntat riktade spetsar nästan berör"a fürsta epimerparet; främre kantell visar ytterst ä hvarje sida en kort spets, derimuanför en urbugtning och a midten tvenne korta, trubbiga flikar, atskilda af en fin springa, som nästan sträicker sig till munöppningen. Palperna äro langa (utom hos A. vernalis) och i förhallande till första benparet ganska smala; de parasitiska anternas ano dock tjockare. Fjerde leden ä lingst, pî inre sidan försedd med tvâ taggar, pâ den yttre med en; hos de parasitiska arterna samt A. remalis itro dessa taggar obetrdliga: femte leden ä kort och betydligt afsmahande mot spetsen, der han aj tydligt tandad.

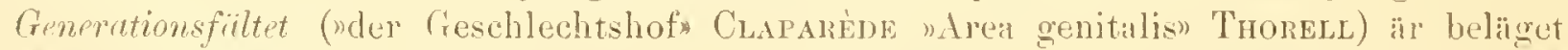
si langt bakat (utom hos A. vemalis), att det saillan kan fullständigt urskiljas, da djuret betraktas fran mole sidan. Det delas $\mathrm{i}$ midten af en längsgaende springa, omgifven af tvenne skifvor, förserda med stigmer (Stigmata BruzkLus, Näpfe, Sangnäpfe, Geschlechtsnäpfe Krnask och CLaparède) som till antalet variera hos de olika arterna. Dessa skifvor aro genom en chitinlist ofta delade $\mathrm{i}$ trenute, sâ att stigmena komma att intaga fyra fült. 
Hithörande arter lefia sasom fullt utbildade dels fritt i klart, stillastatende eller sakta rinmande vatten, der de äro ganskil alluänna, dels parasitiskt par L'niu- och Anndonta-arter. De fürra ïro i sina rörelser tämligen raska och fürete i siattet att simma en egenhet, som genast skiljer dem fran ofriga Hydrachuider. De ila nämligen hastigt framat och mppat samt sjunka derefter, hallande bencu alldeles orörliga, nedat, hvarefter samma rörelse mprepas. De aro föga rof giriga.

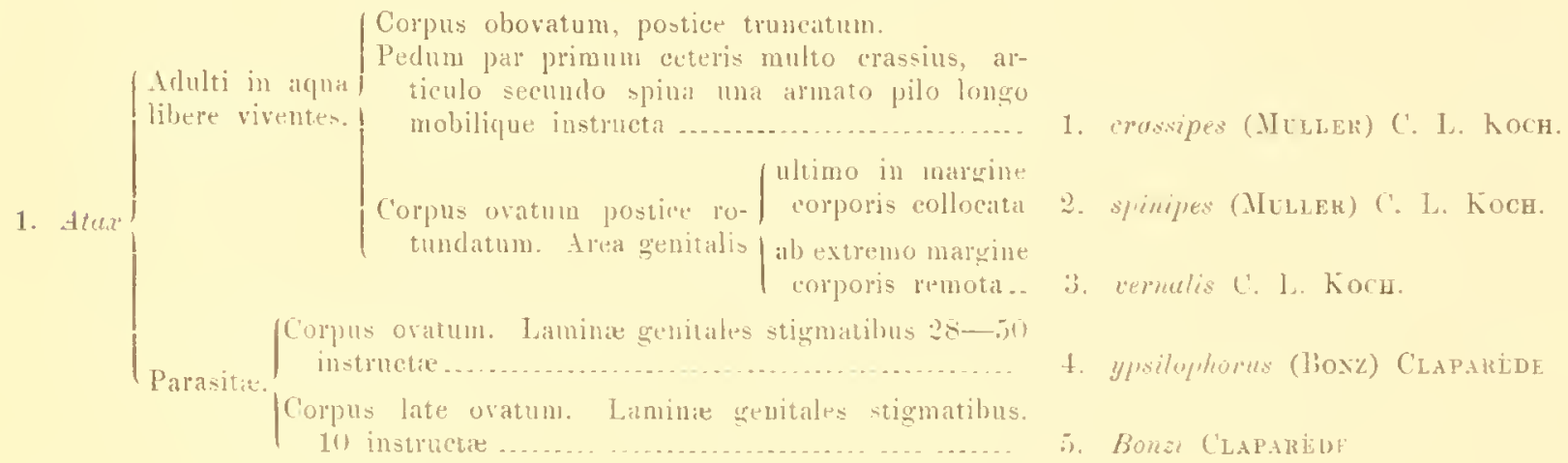

\section{Atax crassipes (MürLek) Brizzlulus.}

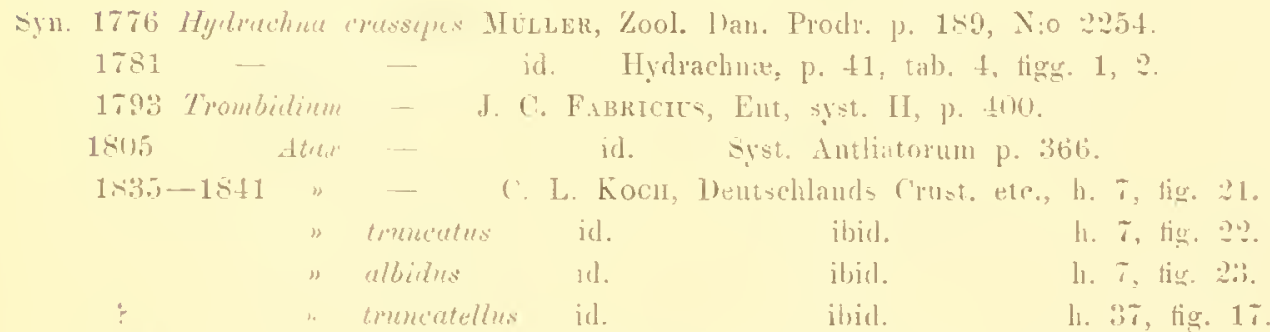

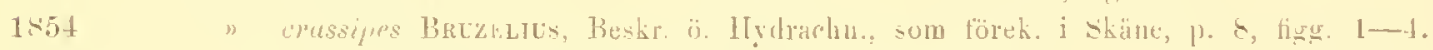

1Sie " " Claptedene, studien an Acariden, p. 471.

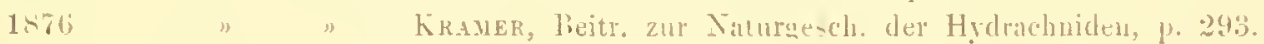

Conpus obovatum, antice rotundatum, postice truceatum, tuberculis prominentibus, satis altum, albo-flaven scens, maculis fuscentibus plerumgue distinctis, linea dorsuali') lutra. Perles et palpe longissini, abbi, pedun par primum ceteris multo rrassius, articulo secundo una armato spian, pilo longo moloilique instructa. Laminu genitales in binas diviste stigmatibus ternis instructas. Lomgitudo rinciter 1, $;-1,4$ millim. (Tab. t, fig. 1).

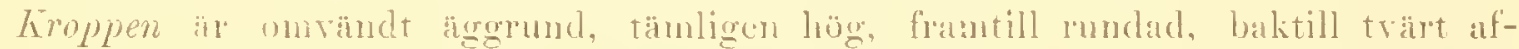
huggen, rned hörnen bildade al tra bakat riktade knölar (analkörtar, "Steiszdiünen", Clapsiène). Desaa äro hon haname ganska starkt ntrocklade, men hos homorna. inynnerhet da dessa äro fyllda af ägre ofta obetydliga, sil att dre stmmlom blott vid starkare förstoring kunm skënjas. bakkanten synes derfüre hos dylika honor nästan fullkomligt rundad. Dessa kürthr aro bildade af stora spoltormiga, kinnförande celler, mellan

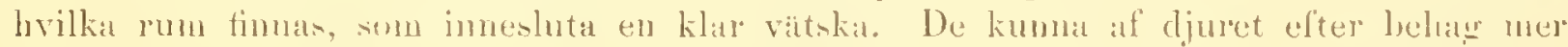
eller mindre indragas. Benen äro mycket langar; förstal paret kortast oeh uästan dubbelt tjockare an de efriga; le trenne ytterste intermodierna aro dock myeket smala.

I) Organum excretionis, plerunique I forme. 
Egentliga simhar (knippris sittande) siknas helt och lallet pá detta par, son deremot ntmälkes af sina a undre eller böjsidan (ndie beugeseiten, Chaparéde) i treme rader" sittande glesa, linga och styfva has.

Dessa har sitta pa större och nindre kuölar, som flan andra internodien ${ }^{1}$ ), der knölen uppenar till tredjedelen af harets längd eller till 0,1 millim., not yttre internodjerna allt mer aftaga i storlek; den sista saknar dem alldeles. I) äro ej fästade i spetsen af knölen utan a sidan af densanma i en ränna, upptagunde ungefär en tredjedel af knölens längd, äro ganslia rörliga och synas vid stark förstoring försertda med trenue rader af smala, nästan vinkelrät mot hvarandra stälda asar. Ofre eller stracksidan (odie Strecksciten, ClapArÈde) af detta henpar är blott fürsedt med korta, glesa hâr, son ej äro fästade pa magra knölar. Fürsta internodien är mycket kurt, nästan rundad. De öfriga benparen, af hvilka tredje âl smalast, sakna alldeles dessa gröfre har. Fjerde paret har simhar i glesa knippen vid spetsen af fjerde och femte internodierna. Dess första internodie ar bredt kolffornig.

Första paret eprimerer i franre andam breda, langstrackta, bakat trubbigt afsmalnande och bär stötande till andla paret, som äro nągot kortare och frản föregaende lap till störpe delen skilda genom ett nästan ovalt ellel elliptiskt mellamrum. Tredje paret mycket sma, bredt viggformiga, slutande sig näla intill fjerde paret, som äro mycket stora, dubbelt störe än tredje och till formen nästan rlmonboidiska. Alla aro glattr.

Labium är fri och firan undre sidan sedd plattad, framtill bredare och försedd ned trenne bugter, utat begrïnsade af spetsiga hörn, i milten synes en utskjutande trubbig knöl (ett slags rudimentät rostrum), delad af en fin springa, som nästan nar till munöppningen; bakat är labiun afruidad, med utskjutande langa och divergerande processer. Frin sidan sedd ä den ganska tjuck. Palperna, som aro hälften smalare an första benparet, na naggot offer midten af samma pars tredje internodic. Första lerlen :il helt liten utiu har, andra betydligt tjockure med fyra korta, grofva har a öfe sidan, tredje kortale, men obetydligt smalare, med tva linga, suala laar, fjerde längst, jämnsmal, a undre sidan naggot concav med en lang, smal, ntat och framat riktad knöl a yttre sidan, i hrals spets ett litet nedat löjolt, fint bar sitter; nastan midt emot demar men nagot längre ned, fimes a in se sidan en betydligt kortare och smalare knöl, äfren med ett har i spetsen, och is samma sicla, not ledens spets, en tjocksue, trubbigare, nästan roitt utat riktad ntan har. Sista leden, kolt och spetsig, shutar med cu rid stark förstoring synlig tretandad spets.

Mandibleme corpus är kort och bakat föga bredare, nästan tvär, saknande den utdragna spets, som times hos Nescra; framtill al den afven trärt afhnggen och försedd med en stor, wot och krök klo.

Grnerationsfaltet, som ä beläget ytterst i lakre kroppskinten delas af en mycket lange springa, ongifven af täta, fina ocl korta bar, som blott synas vid stank förstoring:- A ounce sidor um dema springas bakre del ligga trenme nagot upphöja fahlt, det framre störe, niastan rhomboidiskt, det bakre mer triangulät ned rundade hörn.

\footnotetext{
1) Fingelus, som rahnat epimererna till benen, benamer derfore namde internodie tredje leden.
} 
Hvalt och ett af dessa fült ä försedt med tronne stigmer, mellan livilka kolta horst sta. I midten af dessa stigmer synes en ring, fran hvilken radierande, talrika streck nteit. Ctclissekerade, haf a aumde fät mycken likhet med en fiarils fyrat utskgna vingar: riu

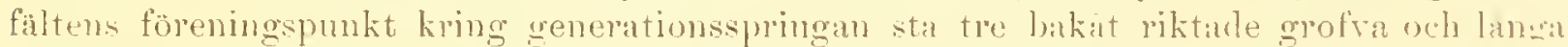

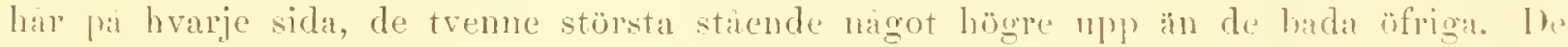
barla bakre fülten kunna blott otydligt skönjas, da ljuret betraktas fran undre sidan. Gigomen aro stora och rödbruna; hvart weh cit hestar tyolligen af tremne sammanvixua ogon, enäl det har trenite corneor, en riktad flanat och en at sidan. I frimpe kanten mellan ägonen sta tveme hap pei hvarje sida. af hrilka det undpe à dubbelt störo än let öfe. Imus är liten, belägen i själfra bakkanten af klopjen och rrolig blott

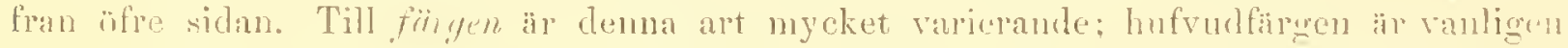
livit med en anstrrkning af gult elle blatt; Hackarne, som oftast äm distinkta, ino brunaktiga, stundom nästan svarta, och rariera betrdligt till storlek och lorm. liygstrecket (excretionsorganet) klart gult. Palper och ben samt undue sidan hvitgula; i lakkinten, mot generationsfältet symas tva störe bruna fläckar. Humm skiljas fran lonorna genom sin ringare storlek och sina i förhallando till kroppen lingre ben, ridare derigenom, att fjerle paret epinerer a kpoppens midt endast skiljas at gonom "u

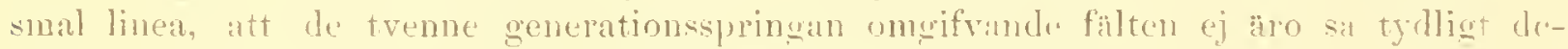
lade, samt att de trenne hatren virl dess sidor ano hetydlint smalare.

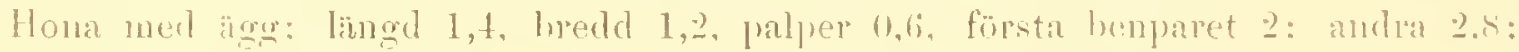
tredje 2,2 ; fjerde 2,8 willim.

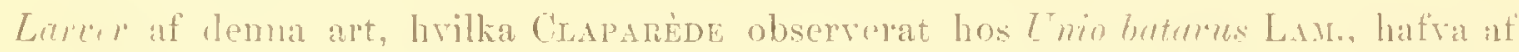

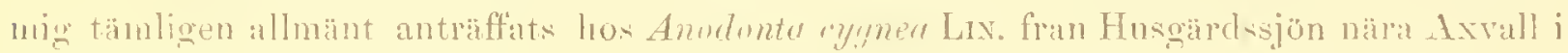
Vestreötland. Treme former har jag olserverat, af hvilka den ena, det pupplika larr-

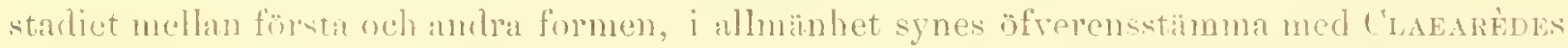

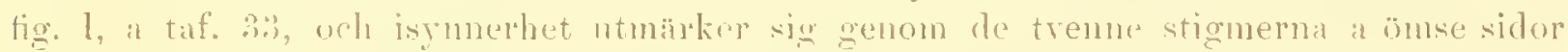

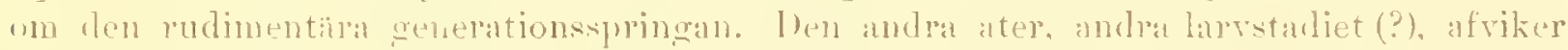
i flera afreenden hetylligt saval fran förecande stadie som fran det utbildade djuret. koppens bakkant visar, ofranifran sedd, i midten en djup halfeirkelformig inskïniug. och a ömse sidor on denna syma trenne stigmer; dr bada köptlame aro ril ntrecklade och ofran dem stir ett lange styft hay sinnt nagot dorofran ett dylikt; straxt öfrer stionelna ett hal. Betraktas djupet frin nudre sidall, visa sig häl" trenne stigmer, genon eft smalt mellanmm skilda fran de öfiga tre, nästan sisom hos A. Pmzi

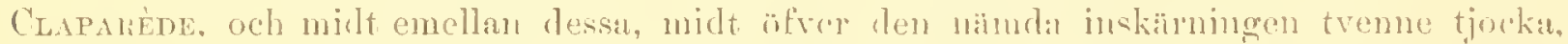
rät utit riktade taggar. Palperna äro mycket tjocka, tjockare än fönsta henparet, hrars

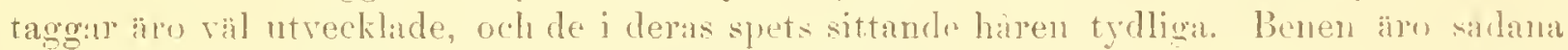
som hos det ntbidade djuret. De balla ögonen a ömse sidor ej sammanvixna. Längr 0,8 , breald 0,6 , julpor 0,4, första henparef 1,4, fjerde 1, n millim.

En amman larvform togs $\mathrm{i}$ början af juni $1876 \mathrm{i}$ Asunten och $1869 \mathrm{i}$ Statken $\mathrm{i}$ Testerö̈tand. Den tillhör dock knappast demua art. Kroppen är nämligen $i$ bakkanten rundad, och benen aro nyeket smala. Första parests andma internodie silinar tage. B]ott treme stigmer finmas a hvarje sicla on gunerationsejpringan. 
Ärgen, som jag uttagit ur honorna, ảro föga ovala, nïstan klotrunda, britgula, omkring (1,17 milln. j diancter. Märkvärdig är honornas obenägenhet att under fangenskapen liagra ägg. Ofta har jag haft honol alldeles fulla dermed, sil att kroppsöbljet varit nära att brista, men andock hafra de aldrig lact nagra. Mahända lägga de sina ägg i musslor, der larverna ofta anträftas. Dylika honor kunna muder hela sommaren erhillas. De synas lefva al infusorier, ty jag has aldrig sett den angripa nagot med blotta zagat symbart djur i det käl, der de fürvarats. Arten förekomuer tanligen allüin i klart ratten i lappland rid Qvickjock. Upland, (̈)stergötland och Vestergötland, Dalsland, Blekinge, Skâne; mera sällsynt pit Gotland och Öland.

Itt BRUzeleus ansett C. L. KoCHs A. truncatus och A. albidus sasom varieteter af A. crasivipes, synes mig alldeles riktigt, enär jag ofta anträffat de af honom nämda ofveroungsormerna. Afren A. truncatellus torde blott vara en dylik form, ehuru taggama à främre benparet, att döma efter figuren, synas vara tämligen obetydliga.

\section{Atax spinipes (MÜller) Bruzeluts ${ }^{1}$ ).}

Syn. 1776 IIydrucher spinipes Mulden, Kool. Dan. Prodr. p. 189, X:o 2257.

$17 \Sigma 1$ - - id. Hydrachne, p. 14 , tab. 4 , figg. 5 et 6.

17:33 T'rombritium - J. C. FABriciles, Eut. syst. II, p. 404.

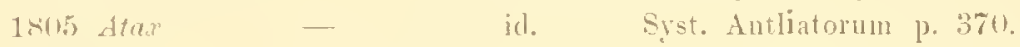

1854 - - Brtzeluus, Beski. o. Hyrlraclin.. som förek. i Skåne, p. 13.

('uplus ovale, antice et postice rotumlatum, flavo-rirescens, maculis nigricantilus, linea dorsuali lutea, Perles et pulyi longi, pedum par primum ceteris multo ${ }^{2}$ ) crassius, articulo secundo duabus armato spinis 10 agnis, pilos apjee serratos gerentibus. In margine corporis octo puncta nigra reqvalibus intervallis disposita. Lamine yeritules fere triangulax, crebris stignatibus ornite. Longitudo 1 millim.

Kroppen oval, i bida andarne afrundad. Benen proportionsvis kortare an hos föregaconde art, och första paret annu tjockare. Letta pars andra led är försedd med trenne stora knölar. besatta med linga mot spetsen sigtandade hár. Palperna äro kortare. Generationsfältet delas af en fin springa. begräusad af trenne nigot upphöjda smala lister. Pa sidorna om dessa och nâgot bakít ligga tvenne mörkare, nästan triangulära fält, tätt belagda ned sma stigmer. Kring kropjokanten sitta földelade pả lika mellanrum 8 smá svarta, mphöjda punkter, tva i bakre kanten, hvardera bärande ett fint harr, tra pa hvardera sidan och tvi i främre kanten. Palper, mandibler och labium som hos föregiende art. Till fïrpen är den gulgrön med gnlt ryggsstreck och svartaktiga Hickar. Ben och palper än geulaktiga, liksom kroppen nágot genomskinliga. (̈̈gomen sula, svarta (MÜLALR).

Dema art îr vida sällsyntare i Skane an föregaende och enclast nagra gânger i juni och juli antraffad pa summa ställen som lenua.

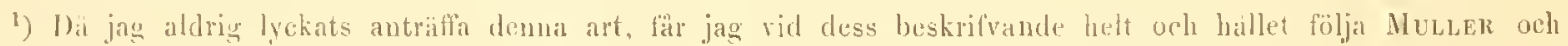
BRL\%LLITS.

2) "pauto" MULLer. 


\section{:. Atax vernalis (MüLter?) C. L. Korm.}

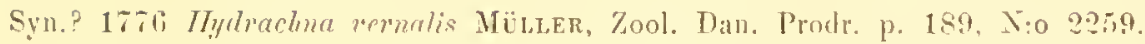

1781 - - id. Hydrachna, p. 48, tab. 5, fig. 1

1793 Trombilium remale J. C. Falsicius, Ent. syst. II, p. 404.

1805 Atua vemalis id. Syst. Antliatorum p. 370.

$1835-41-$ C. L. Kock, Deutschlauds Crust. ptc., h. 7 , fig. 11.

Corpus late ovatum, autice ct postice rotundatum. fornicatum, flavo-vircscens, maculis nigris confluentibus; linea dorsualis miniacen. Pedes et falpi breviusculi, pedum par primum ceteris paulo crassins, articulo secundo spinis duabus parvis, pilis breviusculis, apice non serratis, instructo. Lamina genifales semilunata, latissimar, stigmatibus vicenis instructie. Longitudo fere 1 millim. (Tab. III, fig. 4).

Di Kocn anser denna art samolikt identisk med A. spinipes MëLuer, oaktalt han ej knnnat upptäeka de för densamma karakteristiska 8 srarta punkterna i kroppskanten, sil ij detta uppenbarligt ett stort misstag. Den skiljes nämligen lütt sàväl frân denna som frim offriga arter genom sina korta och spensliga palper, hvilkas fjerde led ar försedd med sma tänder, sisom hos de parasitiska arterna; tredje leden har it öfre sidan tvenue lânga hatr och den andra trenne korta. Labrum bakat nagot ntdragen med otydliga processer a midten, främre kanten med trubliga sidohörn. De fyra epimurgruprena blott skilda genom smala mellanrum; fürsta paret mycket langa, nästan jämubredil, andra paret minst, tredje paret ovanligt stora och init föga af-malnande, fjerde paret nastan rektangulära, knappt en half gang bredare än tredje. Bakom den tvà stigmer a hvarje sida. Fjerde benparet füreter äfen en fran de öfriga arterna afvikande form, derigenom att dess tre fürsta internodier äro mycket tjocka, isynnerhet den tredje, hvilken i tjocklek öfrertuffar de cröfsta internodierna af första paret. Dema internodies böjsida är liksom de twa füljandes fürsedd med korta, fjäderlika har. Strucksidan deremot är som ranligt fürsedd med korta, spetsiga, samt rid andarue af fjerde och femte internodierna ned langru simhår. Hơn â de öfriga henparen äro mycket glesare. Första paret har at tredje, fjerde och femte interuodiernas böjsida likaledes fjälerlika harr, hvilka ifven enstaka anträftas vid ändan af fjerde och fente internodiema a andra orh tredje benparet. Crenerationsfialtet, som tydligt synes fran undre sidan, äl beliget nïmare fjerle epimerparet än kroplens hakre kant och visar i midten en smal, nästan oval oppluing, ongifven af trenue bredt halfmanformiga, npplüjda fält

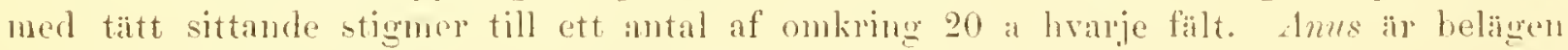
nïra lakre kroppkanten. De af MëLLen och Kocn omuanda haren i bakkanten saknas helt och hallet. Deremot symax a undre sidan mult om kpoppskanten sex stigmer. Ögonen äro mycket stora och rëdbruna. Till färgen är den gnulgrön med stora sammanhängande, svarta ryggfläckar och rörlgult ryggstreck. Ben och palper äo gulgröna; moler sidan med trenne mörkale fläkar vid qenerationsfültet.

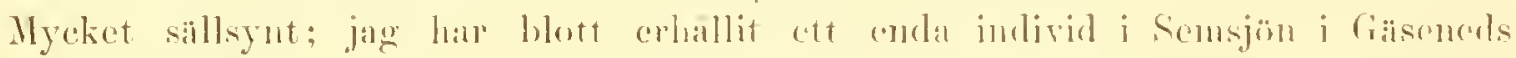
häract i Vestergötland. 


\section{Atax ypsilophorus (Bonz.) Claparède.}

Syı. 1783 Acemes ypsilophomes Bon\%, Observatio Cinkss. Gotenteb Bovz in noval acta phys. med. Acal. Cats. Leop. Casol. Nat. cul. cont. eplemerides ete. 'Tom. VIl, p. 52.

I797 Trombidiun notatum Ratnle, skrivter af Natudhisi.-selsk. Bd. 4, h. 1, p. 175 (sec. Chapanine).

1525 Limnochares anodonte Prinfrek, Naturgesch, deutscher Land- und Süsswasser-Mollusken, Abth. ?. p. 27-28, Taf. 1 (sec. Ciaparide).

1827 Mydrachna concharum r. BaER, Beju. zur Kennthiss der uiederen Thiere, in nova acta pliys. med. Acad. Ces. Leop. Carol. Nat. cur. Tom. MIIl, p. 590, pl. MXIX.

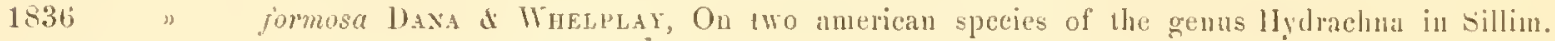
americal Journal, v. 30, p. 331.

1868 Atra ypsilophorns Cuapreve, Studicn an Acariden, p. 47.1 t. MXXII in \%eitschrift für wissenschaftl. \%oologie, Bd. XVIII.

Corpes ovatum, antice et jostice rotundatum, altum, Havo-album, maculis magnis fuscis rel nigris, sirpissime confucutibus; linea dorsualis Jutea. Pedes et palpi breves, pedum par primum latitudincu tantum corjoris iepuaus, ceteris paullo erassius, spiuas nullas gerens. Lamine genilales late, imegularcs, fore semilunatre, eohat rentes, stigmatibus $28-50$ instructic. Longitudo circiter 1,5 millim. (Tab. I, fig. :).

Kroppen äggmond, hos hanarne mycket langsträkt, hos honorna, isynnerhet aldre ouh med ägr fyllda, bredare, i bada ändame afrundad, höghvälfd. Benen korta: förstit paret lika langt som kroppens bredd sant föga tjockare än de of riga paren; a stricksidan med talrika, nagot krökta och franat riktade korta, grofva har, a böjsidan med raka, glesare och längre. Fjerde internodien är längst, fente och sjette aftagande i längd. Den sistnamde nästan cylindrisk, dit den deremot hos de öfriga patren air mer eller mindre kolfformig. 'T'redje paret är spensligast och försedt med tätare hir än de båda föregaende paren; dock sitta dessa ej knippris. Fjerde, som är obetydligt längre än kroppen, lar mycket täta dylika, lingre och kortare har, dock ej i knippen. Fürsta paret epimerer minst, nästan jamnbreda, utat dock nagot bredare, inat afrumdade; andrat paret bredare och inat ner tillspetsade. Bada paren gräisa utefter hela sin lingd intill hvarandra. Tredje paret smala, nästan jämnlreda, inat tviart afrundade, genom ett tämligen bredt mellanrum skilda fran andral paret, nen tätt slutande sig intill fjerde, som äro nästan qradratiska till formen. Alla synas vid stark förstoring fint punkterade Labium nästan som hos A. crasipes, men nagot bredare i förhallande till längden sant nerl kortare frin bakre kanten utskjutande processer och tämligen lingt rudimentät rostrum. Palperna äro korta och mycket tjocka, tjockare än fürsta bemparet; fürsta leden mycket liten, andra ganska tjock, med tvenne lar ofran at yttre sidan och utt vida längre vid gränsen till tredje leden. Denna äl afven tjock men nästan häliten koltare, fjerde nagot smalare, längst, med tre sma tänder a undre sidan, af hrilka blott de tví nedersta, stisom lios A. crassipes, ino försedda med sma har; femte myeket kort, med tva sma hitr a unde sidan, i spetsen tydligen tretandad. Mandiblerna ïro myeket smån. Corpms i fiamre ändan mera rundad äl hos A. rassipes och försedd med en liten, mycket krökt klo. Generationsfältet, som är belinget ytterst i bakre kroppskanten, delas uf en springa, som till he]a sin längd begränsas af treme breda, framom och bakon springan sammanhängande irregnhera, nästan halfmantormiga skifror med talrika (14 i 25 a hvalue skifva) stigmer, som likna dem hos A. "rassipes. Dessa skifvol" bikla nämast springan en hetydlig mphöjning, hvilkrn jag dock oj funnit likna en 
stympad kïgla, síson CLAPAlièn mpleger, utan snarare en pả ryorgkanten stäende mussla, hvars smalare inda äl riktad franat. De springan omgifvande kanterma öplna och sluta sig äfren pâ samma sätt, som en dylik mussla. Vid springans midt stí tráa par nảgot krökta, styfva hår, och nagot längre bakât ett par större sâdana. Antalet stigmer är sällan lika â de båda genterationsskifvorna. Hos äldre individ synas de vara talrikare. Amus, som tydligast synes fran öfe sidan, är stor och smalt oval. — Till färgen är denna art livitgul, med stora kastaniebrunil eller svarta, ofta med hvarandra sammanflytande ryggflickar, som mpptaga största delen af öfe kroppsilan; rygrostrecket air gult, smalt, ofta otydligt och afbrutet; palper och ben, liksom mdre sidan graigula: kring generationsfältet en större ljusgul fläck. Ögonen ej stora, rödbruna. Äggen äro grulhrita, ovala, 0,24 millim. langa, 0,17 breda.

Honans längd 1,6, bredd 1,1, palper 0,4, första benparet 1, andra 1,4, tredje 1,3, fjerde 2 millim. En aman, fylld med agg: lïngd 1,8, bredd 1,3, palper 0,4, första licnparet 1,1 ; andra 1,5 ; tredje 1,4 ; fjerde 2,1 millim.

Mycket trög i sina rörelser, kryper denna art blott helt sakta omking på bottnen af det kärl, der den fölvaras. Oroad, risar den sig fül ett ögonblick något smabhare, men aterfaller genast $\mathrm{i}$ sin foma tröghet. Haname synas likväl vara nagot litligare ïn honoma. Oaktadt dessa djur lefra parasitiskt, har jag dock förvarat dem i glas 5 à 6 veckor lefrande.

Denna art luar af mig antrifftats a Anodonta cygmea Las. frin Hornborgasjün oeh sjön vid Husgärdet nöra Axevalla i Vestergötland. Den syiles vara rätt sällsyut och antraffas knappast i en bland tjugo musslor. I yngre individ har jag aldrig funnit den.

\section{Atax Bonzi CLAPARÈn.}

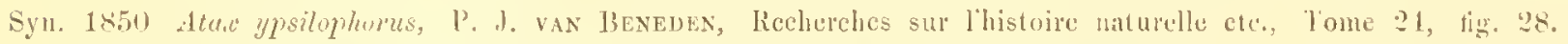

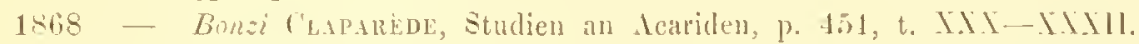

Corpus late ovatum parne rotundum, autice et postice paene truncatum, allum, maculis subfuscis minoribus sparsum; linca dorsualis latissima, alba, ramis brevibus instructa. Pedes brevissiuj; pal primum cetcris vix erassius, latitudine corporis brevius, spinis carens; par quartum longitudine eorpus adiequalls. l'ulpi longiores, eadum erassitudine ac pedun par primum. Rostrum prominens. Lamine yenitules stimmatibus quinis instructa. Longitudo $0,7-0,8$ millim.

Kroppen bredt oval, nästan rund, i främre oel bakre kanten nàgot tvär.

Benen mycket korta; 1:sta paret obetydligt tjockare än de of riga, korture än kroppens bredd, utan knölar och gröfre hår; tide paret mugefïr lika lingt sonu liroppens bredd. Alla benen besatta ned glesa hâr. Sista internodierna särdeles ogendomligat. De äro, sảsom hos A. ypsilophorks, kolfformiga, med en stor, langstrickt fördjupning

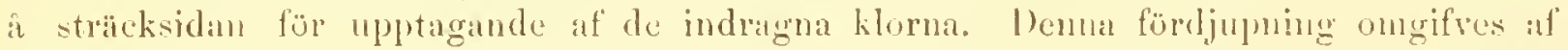
2:ue sidoutskott, som divergera a sträckidan. Pà spetsen af det flüure sitter ett här, pai det bakre trenne. Vid basen af klon och pai det främre ntskottet sitter en liten päronformig process. Klons bảda grenar aro olika storat. Första paret equmere langa, nästan jämmbreda, bilda tillsammans med andia paret, sum älo bredt vigglika, en nästan triangulär figur; tredje paret jümubreda och genom ett bredt mellamrum skildal frỉn 
andra paret; fjerde paret nüstan fyrkantiga. Alla paren ïga den för arten egendomligra facetteringen cller punkteringen. Palperna linga, nacnde till slutet af första benparets fjesde internodie, och obetydligt tjockare än minda benpar. Andra och tredje lederna merl några glesa hâr, f̈jerde med de tre knölarne ovanligt sma, femte leden som hos $A$. ypsitophorus. Generationstialtet liknar mest det hos A. crassipres, ehuru hvardera af de generationspringan omgifvande skifvorna här hafva blott fem stigmer: tvi̊ främre och tre bakre. Hos homan äro de främre stigunerna skilda från de bakre genom en egendomligt krökt, dubbel chitinlist; der dessa lister nå generationsspringan, stå i ömse sidor om demna tvenne korta och tjocka hår, af livilka det bakre ïr dubbelt så stort som det fränre. Vanligen äro kanterna af springan ("die Schanlippen» Cuapaíne) tryckta intill hvarandra, men slảs stundom tillbaka, hvarvid deras trekantiga forı franträder. De styfva hîren tjüna sảial denma som föregående art (och kanske äfven $A$. crassipes) att vid äggläggningen införa äggen i musslans gälväfnad.

Hanarne sakna (enligt CLAPAREDE) den näinda chitinösa listen; springan visar sig, di dess kanter äro skilda, framtill betydligt bredare med nistan afrundad framkant, bakìt småningon afsmalnande $i$ en spets. Den främre bredare delen omgifves af två halfmånformiga, krölita skifror, af hvilka hvar och en i öfre kanten bäl en rad porer; a bakre delen af dessa skifvor stỉ de tvâ främre stigmerna, och från undre sidan utgâ två chitinösa bildningar, som förena sig i springans midt.

Till fürgen är denna art hvit eller hvitgul ined mindre, bruna, sammanlöpande flückar; ryggstrecket nästan hvitt och vanligen myeket bredt; ben och palper genomskinliga. Alygen (1),17 millim. langa) aro ovala och ¿̊ ena sidan något plattade. Larverna äro smalt ägoformiga, i bảda ïndarne afrundade. I kroppens bakre kant stả 2 mycket långa borst; innanför dem 4 korta och utanför desamma 2 korta, tjocka taggar (bildade af de utskjutande epimererna). $\hat{\AA}$ hvarje sida stå 7 hår, och framför hvardera ögonparet trenne, af hvilka det främre är dubbelt sả kort som det bakre. Ögonen stora, rödbruna, de tvenne á hvarje sida tydligt skilda. Till färgen äro de gulaktiga ned stor brunaktig rygggfack, som i l'ramre ändan ä bredt och tvärt urringad, i bakre förserd med en oval mringning. Larven i andra stadiet skiljes fran det utbildade djuret företrädesvis genom sitt ontvecklade generationsfält, hvilket, såsom hos $A$. crassipes, består af en kort springa med två stigmer ả hvarje sida.

Förekommer i schweiz alhnän i Unio batavus LAM. Ty vïr har jag aldrig varit i tillfülle att undersöka störe former af slägtet Unio, men är öfrertygad, att A. Bonzi lika väl som A. ypsilophoms fmues hos oss. I ett af mig vid raturforskaremötet $\mathrm{i}$ Köpenhamn 1873 hållet förechrag on Hydrachnider nämde jag, att jag funnit A. Bonzi i̊ Anodonta cygnea lıN. Detta var emellertid, sisom jag sedan fumit, ett misstag, cuär den af mig antriffarle formen befumits vara den omnämde larvfornen af $A$. uassipes, hvilkun i synnerhet i afseende på gencrationsfültets bildning liknar A. Bomsi. 
Genus 2. NESTA C. L. Kuch.

Syn. 1st2 Vesce C. 1. Krocil, Vebersicht des Arachnidensystems, h. 3, p. 10.

18.54 - Brt\%elıus, Beskr. 0. Hỵtrachu., som förek. i skinu, p. 14.

1875 - Krayen, Beitr. 2ur Naturgesch. der Hydracjniden, p. $29 \%$.

Corpus laeve molle, ovatum aut obovatum, antice rotundatum, truncatum, cmarginatum; postice ntringue mpressum, interdum rotnudatum. Peles omnes cidem fure erassitudinc, a primo pari ad quartum (apul fouinam saltcm) fougritudiue grarlatim crescentes; in mare internodium quatum paris quarti eurvatum cavatumque, pilis densis instructum. Pulpi plerumgne longi, articulo quarto longissimo, dentibus ut in genere priecedenti instructo. Area gonitalis mox pone cpimera quarti pris pedum, nou in extrema colporis parte, collocata (excepta $N$. mirabili). Oculi ut in genere precedenti.

1) K Kocn och äfven Blivzenl's företrädesvis ansett slägtet Nesan skildt frân Atak genom formen pa palperna, hvilkas fjerele led hos Nesoa sknlle vara försedd med blott

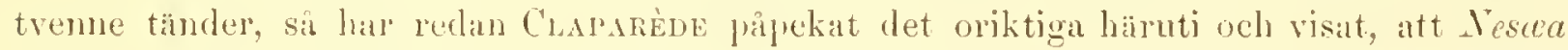
síväl som Alux a nätnde led äger treme tänder, en yttre och trâ inre, lovilka till storleken i hög grad varjera hos olika arter. Stundom äro de sá sula att de blott vid stark förstoring kunna skünjas. De trenne längsta äro försedda med har i spetsen. Men di sistrände författare anser, att Tesea bür sammanslảs med Atax, emedun inga generiska skiluater den encllan skulle finnas, sâ är jag långt ifrin att häruti gifva honom rätt. Eluru dessa bida slägten onekligen sta hvarandra myeket nara, skiljes dock Neswa litt genom trenne konstanta generiska karakterer: benons ungefir like tjocklek och sucessivt tilltagande längl, atminstone hos honorna, (hos haname af $N$. rosea och $N$. alpina îr tredje paret kortare in andra, men detta är mâhanda fallet blott i larvstadict) sumt generationsfältets plats omedelbart bakom sista epinerparet, hvarigenom det ej kommer att ligga si langt luka sut sum hos Atax. Ett nndantag härifrin gör dock N. mirabilis, hos hvilken detta fält är beläget i lukre kroppskanten.

kroppsformen äl i hög grad varierande: äggrund, oval eller omvändt äggrund, nedplattad eller höghvälfd, framkanten rundad, tvär eller intryekt, bakkanten vanligen med en intryckning a önse sidor, stundom rundad. Benen vanligen länga (undantag $N$. brexipes), af nistan lika tjocklek. De bada främre paren med mer eller mindre talrika simhar vid fjerde och femte internodierna. Klorma apo isymerhet pai framre benen stora och starka, vanligen dubbla. Egendomlig ä hos haname fjerde benparets fjerde internodie, som a sträcksidan ä föga höjd men a böjsidan är djupt concaverad, med en nedskjutande trubbig fürlangning och tät sittande har, af hvilka de a midten befintliga aro korta och tjocka, de vid andarne langa och smala. loe sistal internodierna af sista benparet äro fürsedda med tätare simhân än hos Atur. Epimererna öfverensstämma mycket med dem los Atur. Fjercle pret utmärka sig genom en it midten bakit utskjutande, lingre eller korture process, tredje och fjerde parens inre ändar ino hos honoma skilda genom ett bredt mellanrum, hos haname deremot stöta de inre kanterna nästan tillsammans. Lahium veh palper likna i det närmaste den hos Atur. Mandibleme corpus ntsinder frin sin bakre inda en lingt utskjutande spets, som in öfre sidan är concav och lemmar fiste för de nuskler, som röru corpus; klon är krökt, af olika storlek hos olika arter. Cenerationsfältet delas af en lingre eller kortare springa, som hörjar straxt bakom fjerk epinẹparet. Denma springa, son frantill är he- 


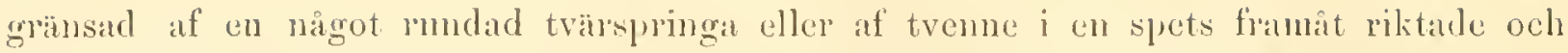
baktill af en tvär eller tvenne $i$ en dylik spets fülenade, omgifves af tvenne smala skifror, frản hvilkas bakre ändar ât sidorna ntigả tvâ fält af onvexlande form med mer eller mindre talrika stigmer.

Hithörande djur, af hvilka honorna äro măngdubbelt talrikare äfvensom betydligt större an hanarne, fürekomma silväl i sjöar och bärkal med klart vatten, som i danmar och diken, der vattnet är ganska grumligt. De äro ytterst snabba i silla rürelser och bland de rofgirigaste af alla Hydrachnider, hrarföre man vid insumling af Nesiou ej bör hafva den tillsammans med andra arter. De mânga arterna af detta slägte, som jämte Arrhenurus hos oss är tallikast leplesenteradt, kuma pâ följande sät inclelas:

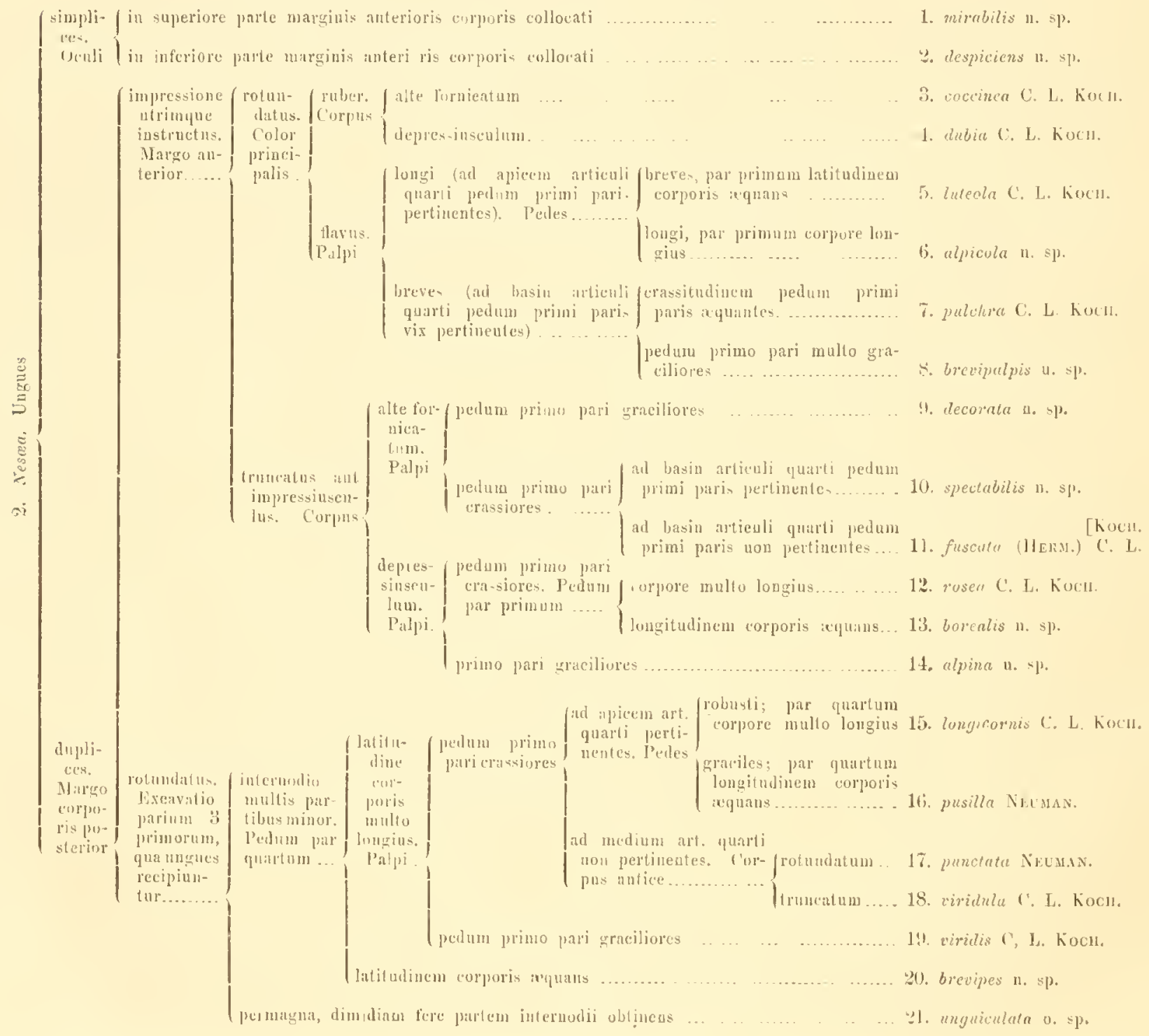




\section{Nesæa mirabilis n. sp.}

Femina: Corpus late ovatum, altum subl vix fornicatum, postice aliquanto altius, antioe rotumatum, postiec

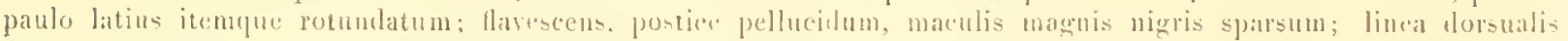
tlava, punctulis lubris immixtis. L'eles longi, duo paria atuteriora, prasertim primum, cransa robustague, inter-

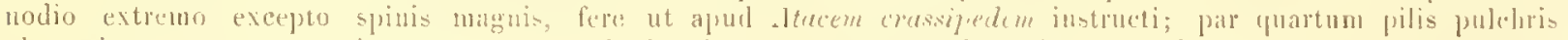

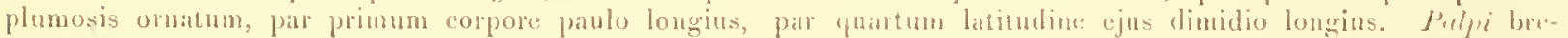

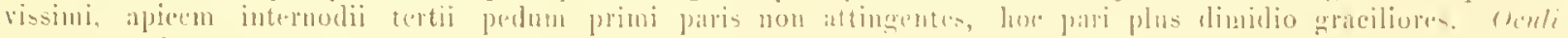
magni, balle inter se remoti, Jusci vel nigri, in magine rorporis rollocati. Longitudo 1, ? millim. (lab). Ill, tig. :i).

Hona: Kroppen är oval, baktill olectydligt vidęad, i bảda andame rundal, lög men füga hvalfd, bakre delen betydlignt bögre an fränre. lienen langa, de tva främe paren tjocka och starka med molantag af sista internodien, som ar myeket smal och nagot liökt, andra - femte intemodierna a bojpidan besatta med bingal. spiral-

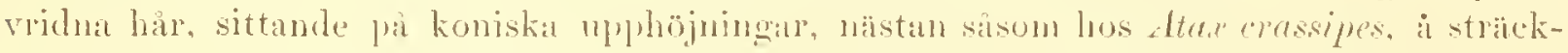
sidan sant sidorna försedde ned har af vanlig form; tredje parets internodion saknal liksom fjerde parets dessi spiralformiga har, men har talrika kortare sant langa sinhar rid basen af de tra sista internodierma: vid basen af den yttersta intemodien star ett fäblerlikt har. Fjerde benparet har at tredje - femte internodiernas boijsida fjärlerlika har, tillagande i länged fran internodicrmas bas, tredje intemodien 3 till antalet, hos de bada följande 6 eller 7 , sant linga simhar pa fjerde och fente internodierna.

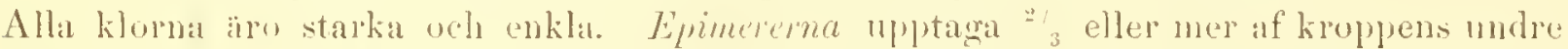
sidan; första paret äro smala, jämmbreda, not labium obetydligt concalverade, med inre

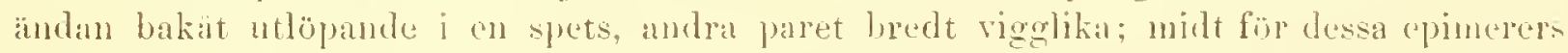
yttre anda synes $\mathrm{i}$ kroppskanten ott litet stigma med ett kort hả. Afstandet mellam labinm veh första paret epimerer obetydligt. Tredje paret nästan jümmbreda, skilda frim andra paret genom ett nïstan lika bredt mollanmm som mellan deras inre indar; fjerde paret, som knappt äro dubbelt bredare än tredje, utmärka sigg genom frinvaron

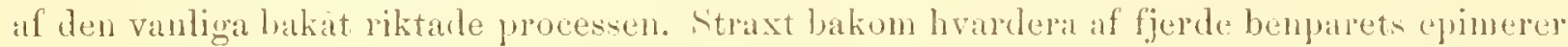
synes eft stïrre stigma samt nagot längre bakat i kroppskanten ett mindre salunt, bairande ett kort hal. Palpernu mycket korta. ej nacule till spetsen af första benpalets

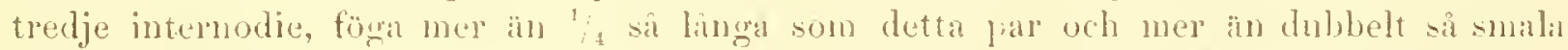
som detsamma: första leden mycket kort, med ett kort laar. andra langsträtckt, föga kulfformig, med ett kort has och tvenne längre, tredje nagot mer an hälften sa lang som

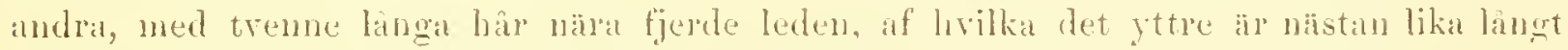
som sistnände led, hrilken är najgot längre äln andra, smal och försedd med mycket smà, knaplet syoliga tiuler; vid basen af femte leden synas tra mycket smala, men tamligen langa hàr, blott synliga vid stark förstoring, nämde lerl i spetsen rrokłnfven. Lubium liten, smalt hjürtlik, de bakit utskjutande procensernat nästan laka. Hendiblemas corpus bred och kort, kuaplt dubbelt längre äu klon, bakit nästan rätvinkligt slutande $i$ en högot obetydlig spets, klon ovanligt stor oels stark, mindre kiökt in hos de flesta arter at detta slagte.

Generationsfialtet: Springan börjar straxt bakon fjerde paret epinerer och sträckre

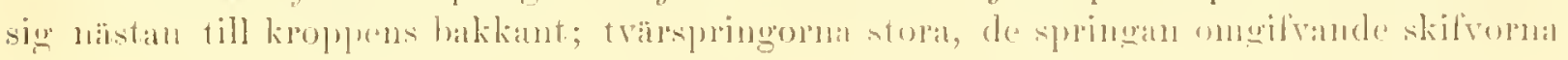


utan tydlig begränsning: fälten ned stigmema äro bredt päronformiga med den smalare ändan riktad not genitalspringans hakre tvärppinga och strïckande sig utåt och framảt till något öfver springans midt; stigmerna å hvarje fält mycket talrika (30 it 40), men sma. Straxt bakom dessa fiilt synes i yttersta kroppskanten å hvarje sida ett tämligen upphöjdt stigma och straxt bredvid detta ett hår. Alldeles i kroppens bakkant, knappt synlig frản undre sidan, ligger anus.

Till färgen är denna art ofvan gulgrả, bakảt nästan hvitgul med stora svarta, ofta sammanlöpande fläckar, ryggstrecket gult, beströdt mel mycket smį röda punkter; n1der sidan är ljusare, med höfter och ben stötande i gredelint, hvilken fürg tydligast upptrïder på de med stigmer försedda fälten. Ögonen stora, långt skilda, svartbruma, belägna i yttersta kropjeskanten.

Lïngd 1,2, bredd 1, palper 0,35, fürsta benparet 1,3, andra 1.4, tredje 1,45, fjerde $1,5.5$ millim.

Nàgra fã honexemplar af denna vackra och egcndomliga art, som i flera afseenden tenderar àt Atax och rerföre bör sta främst bland Nesoa-arterna, har jag blott fumnit i Vestergötland, nümligen i de numera nästan igenvuxna vallgrafrarne vid Axevalla hus, i sjön vid Skärfs kyrka, vid Björkelmul samt kanalen vjd Brogånden i Skara;

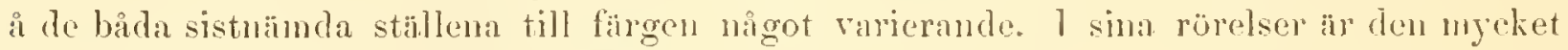
lingsam och synes vara füga rofgirig.

\section{Nesæa despiciens n. sp.}

Cormus late ovatum. fere rotundafum, parva altitudine, flavum, maculis magnis fuscis conspersum. Pedes Iongiores, par primum latitudine corporis; colcm fere modo atque in $N$. mimbili ronstructi. Pulpi brevissimi, apiren artienli tertii pedum primi paris non attingentes, hoc pari dimidio graciliores. Oculi magni, rubri distantes, in inferiore parte marginis anterioris siti. Longitudo 1,5 millim.

Kroppen är bredt ovil, nästan rund, af obetydlig höjd. Benon tämligen linga, i symerhet det fjerde paret och $i$ alluamhet af samma form och med samma harbeklädnad som hos 1 . minalitis; skilnaden i tjocklek mollan de främre och bakre paren dock (j) sà stor hos $N$. despiciens. Palperme hafva afven samma form som hos $N$. mirulilis, men ïro ämn kortare i fürhållande till de främre benen. Epimererna liksom labium belägna långt inat, smá, tillsammans mptagande nästan hälften af mudre sidan, främre parets inre indar blott genom en smal springa skilda frin hvarandra sant frin labimm, andra paret som hos $V$. miralilis, mellanrummet mellan detta samt tredje paret epimerer füga smalare än nellammumet mellan tredje och fjerde parens inre ändar samt utcit försedt med ett stigma. Fjerde paret knappt hälften bredare in tredje, utan nigon bakit utskjutande process. Generationsfältet: Springan, som büjar straxt bakom fjerde epinerparets inre spetsar, ir lâng (0,2t millim.) och försedd med breda tvîrspringor, den frimre längst, lalfminformigt rmolad och nïstan af samma längl som mellanrmmet mellan fjerde eprimerparets inre andar, den bakre nogot kortare men bredare, äfven halfminformig; de med stigner försedda fälten anordnale pá samma

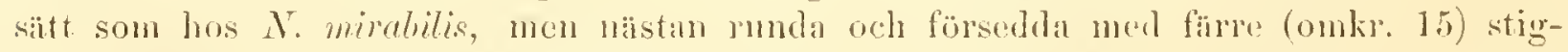

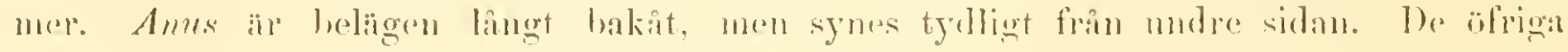




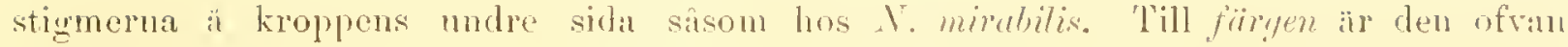
gulaktig eller gulhrum, med stora svarthruna flickar, moler ljusare med ott par brun-

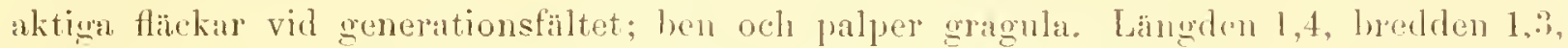
palper 0,3 ; 1 :a benparet $1,3,2:$ dra 1,4 , :3:dje 1,45, 4:de 1,8 millin.

Blott ett individ af denua art antraffiades i Maj 1856 vid björkelumbl niara Skana.

\section{Nesæa coccinea Kón.}

Syn. 1835-41 Neseru roccinea C. L. Körem, Dentsolidands Crust. etc. I. S, figg. 11 et 1:.

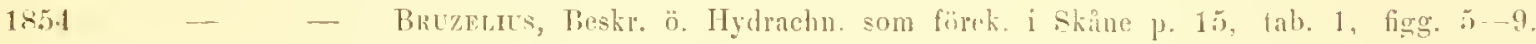

Corpus ovatum, altum, autice rotundatum, impressione postice utrimque instructum, coccincum, antice ct postice plemmque pallidius, maculis nigrieantibus. Pecles maris longiores, par quartum corpore lougius; femiuse pedes breviores, par thatum longitudine corporis. Palpi longi, pari pedum primo crassiores, Jasin interuolii quinti fere attingentes. Longitudo circiter 3 millim.

Honan har bredt ägrgrund och mycket hög kropp, wî att den für det oberiapnade ögat synes nastan klutrund. Benen iaro tamligen korta. Fösta paret olyetydligt kortare är kroppens bledd, fjerde sâ linga som kroppen; de ę fränre paren curo försedda med ganska tät sittande har, som à sträickidan äro korta, a bäjsidan langar ; de sistü̈mda sitta dock ej sisom på tredje och fjerde henparen knipvis pa internodierna, ntan parvis fördelade på dessa. Första paret epimerer linga, smala och nästan jünnbreda, andra paret kortare, viggformiga, tätt slutande sig intill füregiende par; mellanrummet mellan andra orh tredje paren af ringa hredd. Sistnanda par af ungelär samma form som första, men längre, tätt liggande intill fjerde, med hrilka de oftast mat mot kroppens midt äro ntan grans förenade. Fjeple paret nästan 3 ginger hredare ün tredje, 5-sidiga, med en bakåt utskjutande spets. Labium nästan som los Atare crassipes.

Palperna linga, nående ölver hälften af fürsta benparet, hvilket de i tjocklek öfverträffa. Fjerde leden är längst, mot bida indame obrotydligt afsmalnande och å mulpe sidan niggot concav. Straxt ofvan midten sitter it yttre sidan en större, framat och utît riktad knöl med ett hà i spetsen, och nagot längre ned å insidan en mindre dylik. Vid spetsen af leden times dessuton a ine sidan en tjockare, kortare tand eller knöl utan hår. Tid mycket stark förstoring synas afven a undre sidan of de större knölarne trenne mycket sma med ytterst fina har. Andra och tredje lederua

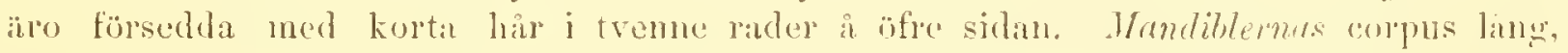
med en frin bakre ändan trublvinkligt ntskjutande ling spets, hvilken jünte "n rlel af corpus är coneaverad. Pà den senares fränre, tvärt afrundale ända sitter cu lange, füga krökt, brunğul klo.

Generationsfïltet: Springan, som börar straxt bakom fjerde epinerparet, begränals framtill af trenne tripspringor, hvilka förena sigr i en framat riktad spets, baktill af en rak och kort twirspringa. Pa hrarje sida ligger en ljusare skifva, hrilka tillsammams

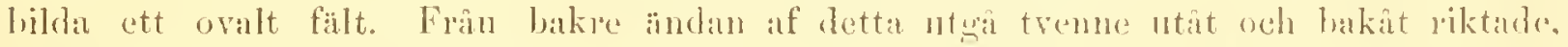

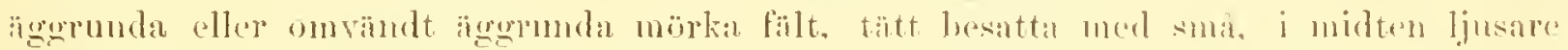


stigmer. Nigot längre bakit ligger anus sant äunu längre mot bakre kroppskanten trå sulå stigmer. Tvenne dylika finnas ïfven bakom fjerde epimerparet.

Längd 3, bredd 2,5, höjd 2, palper 1,2, första benparet 2,2, andra 2.6, tredje 2,8 , fjerde 3 millim.

Hanen har kroppen mera långsträckt och benen i fürhaillande till densanma längu'c än hos honan. De yttersta intemodierna å dessa äro kortare än de näst föregînde. Iclanrummen mellan eprimegrupperno ohetydliga; de bada sista epinerparens inre iindar stöta nästan tillsammans á kroppens midt. Tredje benparets sista internorlie nycket kort och kolfformig. Generationsfältet, son gränsur onedelbart intill inre hörnen af fjerde epimerparet, visar en särdeles kort springa, omgifven af tvenne gnlaktiga skifror. Dessa äro omgifna af ett ovalt, mörkt, slätt fält, frain hvilket àt hvardera sidan ntgår ett något bakảt riktadt fält, hvilket börjar med en sinal gren och serlan llastigt vidgar sig, men ảnyo afsmalnar mot yttersta spetsen. Dessa fült äro liksom hos honan försedda med små och mycket talrika stigmer. Midt i fültet synes ett störe stigna och vid dess främre smalare ända ett dylikt. Färgen är hos bàda künen rörl, i båda andarne oftast nâgot ljusare, med svarta ej särdeles skarpt begränsade fläckar. Labium, palper och ben äro gulpöda. De sistnämdas yttersta ledar mer stötande i rödt, högst sällan i grönt, epimerema mörka.

Honan lägger sina runda, gulgröna ågg (0,26 millim. i diameter) på vattenväixters had eller ả bottnen och sidorna af det kärl, hvari den förvaras, i stora kakor med ända till 100 ägg i hvarje. Lavernu, som efter 3 à 4 veckor utkläckas, äro smalt päronformiga med mycket nedtryckt rygg, blagröna med frümre delen af kroppen mellan ögonen äfvensom rostrum stötande i gult. Ryggen är alivgrön med en hvit I formig figur nära bakre kanten. benen hvitgula, med glesa korta hår samt ett och annat längre sådant. Första paret epimerer små, weh skilda frin andral paret genom en tydlig gräns. A hvardera står ett bakât riktadt har. Andra paret äro utìt till ungefär halfva längden genom tydlig gräns skilda fràn tredje paret, hrilka äro ntomordentliggt stora och upptaga nästan hela bakre delen af kroppens undersida. Ett litet bakåt riktadt hår fimnes äfven här ả epineremas främre ända. Mellanummet mellan deras inre spetsar å kroppens midt tämligen bredt. De treledade palperni korta och tjockin, med en stark och krökt klo i spetsen; vid basen af andra leden visade ett långt hår. Generationsfältet är mycket rudimentärt och visar blott en rund öppung, å ömse sidor on hvilken stî tvenne hìr. Bakon denna öppning synas 4 bakat riktade hâr $\mathrm{i}$ cn rad. Ytterst i bakre kanten sta tvenne koniska knölar, hvardera med ett lingt laar, och något framom dessa tvenne mindre knölar, likaledes fürsedda med hår. Trenne hår sitta dessutom å hvarje sida något längre fram. Att längre följa deras utreckling har ej lyckats mig, dỉ de ej velat füsta sig på till den insläppta vatteninsekter, utan efter någon tids förlopp dött.

Längd 0,4 millim. till basen af rostrum, (som är 0,1), bredd 0,25, första benparct 0,4. andra 0,46, tredje obetydligt lingre in andra.

Denna art är mycket snabl, $i$ sina rörelser och särdeles rofgirig. Förckommer

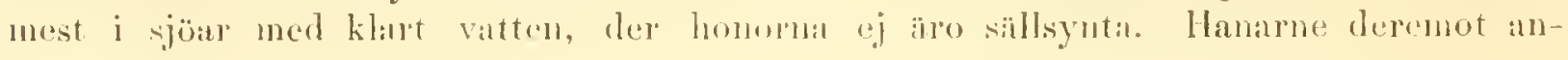




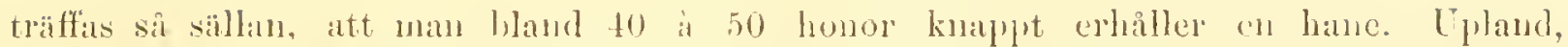
Vestergötland, Ostergötland, Dalsland, Skåne, Gothand (i Heide träisk), Öland (allmän i Borga trüiski).

\section{Nesæa dubia Kocn.}

Syn. 1835- 11 Nesede dubia ('. L. Kocn, Deutschlands Crust. ete. h. :37, fig. 12.

Femine: corpes ovatum, depressiusculum, antice rotundatum, postice ntrinque impsessum, latericium, antice lutesecus, maculis nigris; linea dorsualis losea aut lutescens. Pedes breves, par quartum solum corpore paulo longius; interodia quartun quintumque omnium parum pilis natatoris instructa. Longitudo circ. 1 millim.

Honu: Froplen är ägrund, mågot nedtryckt, främre kanten bredt afrundad, bakre fürnedd ned en stark intryekning å ümse sidor. Benen kortare än kroppens längd, utom fjercle paret, som är betydligt lïngre än denna. Alla benen nästan lika tjocka med utåt föga afsmalnande internodier. Den sista internodien föga kolfformig, med mycket snedt spetsad ända. Klorna ovanligt stora, basaldelen försedd med en himartad bred thk a böjsidan, hvilken flik når nästan till klogrenarne. Äfven de tvenne fränre benparen äro a fjerde och femte internodiema försedda med knippris sittande sinhår, som äro lika taita och långa som de tveme bakre parens. Epimererna äro

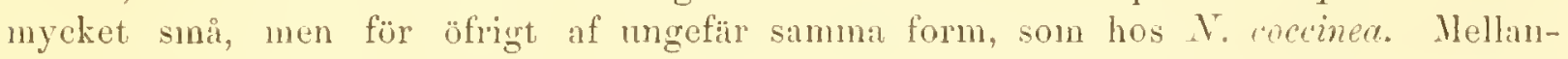
rummet mellan de tva sista epimerparens spetsal mycket bredt, hos äggfyllda honor nistan qvadratiskt. Labium lang och smal. Palperna aro mycket korta; deras längd utgör $1 / 3$ af fürsta benparet, och de ná till basen af dess fjerde internodie sumt äro smalare ïn detta par. Andra leden försedd med nảgra glesa, korta hår, tredje med ett längre hår â hvardera sidan, fjerde ned sî små tänder, att de blott vid stark förstoring skünjas. Mandiblernas corpus lânğ och smal, med den utdragnat spetsen jämförelsevis kort; klon kort och tjock sant föga krökt, pa insidan tydligt concaverad. Generutionsfiltet: Springan, som börjar midt cmellan inse hörnen af fjerde paret epinerer, begränsas framtill af en bred och djup, halferrkelformig tvärspringa och baktill af en kort och bred nästan rak dylik. Den är ganska lång, och â ömse sidor om dess midt synas tvenne små runda fördjupningar. De ongifrante skifromas conturer högst otydliga: de synas utan tydlig gräns öfvergå i kroppsbetäckningen. Något framom de båda nämda fördjupningarna stân å hvarje sida ett större stigma och franför detta tveme mycket små dylikat. Rätt utât, ett stycke från springans bakre grans, ligger a hvarje sida ett litet fült med 6 till 10 störe och nigra mycket små stigmer. Nagot bakom generationsfältet ligger amus, som är oval och tämligen stor, med ett stigma a hvarje sida. Ett dylikt tinnes äfven bakom fjerde paret epinerer.

Färgen är tegellöd, i framkanten stötande i gult, med trakten kring ögonen nästan hvit, genomskinlig; fläckarne svarta eller mörkbruna, ryggstrecket ljusrödt, stundom gulaktigt. Palper och ben gulgrâ. Ögonen stora, rödbruna. Undertill äl grrundfürgen som ofvan. Bakom generationsfültet star en stor gul fläck, omgifvinde anus, och i hvarje sida om denna en stor brunaktig fläck. Dessa båra bilda tillsammans ('n nïstan lyrfornig tigur. Ejimererna äro gulgrât. 
Mindre snabb i sina rürelser, synes den äfven vara jünförelsevis füga rofgirig. Endast honor hafvar antriffiats i Vettern vid lä̈desmnd, i Assunden vid Uhicehamu och vid 'Tholsjölıult j Undenäis fürsanling i Vestergötland.

\section{Nesæa luteola C. L. Koun.}

Syn. 1835-11. Nesca luteolu C. L. Koril, Deutschlands Crust. etc., h. 9, figg. 18 et 19.

Femina: Corpus late ovatum, parva altitudine, antice rotundatum, postice, presertim in mare, lere rotundatum, in fomiua impressione utriuque parvula instruetum, flavum, maeulis fuseis. Pedes breves, par primum eorpus latitudine, par quartum longitudine aquaus. Omnia paria pedum pilis raris instrueta, pilis natatoriis pane earentia. Palpi longi, internodium quintum pedum primi paris fere attingentes, hoe pari multo erassiores. Jongitudo 1 millim.

Hona: Kroppen bredt oval, af' ringa höjd, framkanten rundad, med en obetydlig intryckning ä ömse sidor. Benen korta; första paret af kroppens bredr, fjerde af dess längd, alla med glesa, styfva hår och saknande knippvis sittande simborst. Första paret epimerer nästan jämmbrediı, a millen af inre sidan concaverade samt nned de inre spetsarne trubbiga, andra paret nagot kortare, viggforniga, tredje paret, som genom ett obetydligt nellanrun äro skilda från andra, rektangulïra och inat snedt tillspetsade, fjerde paret dubbelt bredare in tredje och ungefür af samma form som hos $N$. coccinea. Mellanrummet mellau epimeremas inve spetsar ovanligt stort. Labium kort, lika bred som lảng och bildande en nästan liksidig sexhörning. Palperna linga, nảende till femte leden af fösta benparet samt nycket tjockare än detta benpar; andra och tredje lederna äro försedda med korta, styfva hår, som å den fürstnämda leden ïro talıikare (4 i 5); fjerde ledens tänder tïmligen stora, med tydliga hår i spetsen. Mandiblernas corpus lang, bakåt nästan rảtvinkligt slutande $\mathrm{j}$ en fölüngd, conciverad spets. Främe inndan, som är mera tvär än hos $N$. coecinea, ir försedd med en kort, myeket krökt klo af gulbrun furg; corpus deremot blakktig. Generationsfätet: Springan sisom hos föregĩende art; de båda fälten med stigrmer utit och bakat riktade, nästan pälonfolmiga uned 15 ì 20 stigmer ì hvarje fält. Till fürgen ïr den gul, i kroppskanten nagot ljusare; flückarne bruna, tydliga, ryggflickarne sällan nående till kroppens bakkant, det I-formiga excretionsorganet ljusare med korta grenar. Under gullivit ined tvenne mörkare fläckar i bakkroppen, framre delen något blaktig eller stötande $\mathbf{i}$ grått. Ben och palper grågula; ögonen brunüda.

Hanen itr betydligt mindre in homan. Kroppen mer rundad och benen något lïngre i förhallande till densamma än hos honan. Fürsta paret epimerer nästan halfcirkelformigt inåtböjda, med spetsarne nästan mötande hvilandra under labium, andra paret kortare, äfen inatböjda. Tredje paret sammanhänga utan gräins inåt med fjerde hvilka jünfürelsevis äo nyeket större än hos honan. Generutionsfältet ligger nä1'a kruplens bakre kant; de springan ongifvande skifvorna äro försedda med fürre och och otydligare stigner än hos houan. 'Lill färgen öfverensstänmer hanen med honan.

Demma art itr wanska saillsynt och har af mig blott en enda gång antriflfits i ån vid Lyrestads prestgind i Vestergütland 1869. 


\section{Nesæa alpicola 11. sp.}

Femina: Corpus late oratum antice truncato-rotundatum; postice utrimguc paululum impressum, flarum, maculis fuscis distinctis; linea dorsualis lutea. Pedes loneri, par primum corpore longius, cetera paria gradatim longitudiue erescentia, primo execpto pilis instructa natatoriis, intcrnodiis quarto el quinto affixis. Pulpi longi, ad apicem internodii quarti pedum prini paris pertinentes et hoc pari crassiores, dentibus magnis instructi. Oculi marni, rubri. Longitudo 1,3 milliu.

Hona: Kroppen bredt oval, nästan rund, ntan tydlig intryckning it bakkantens sidor; framkanten trärt afrundad. Benen linga; första paret längre än kroppen, de öfriga jümnt tilltagande i längd; första paret med lânga nen ghlesa hâr, de 3 öfriga med simhan vid fjerde och femte internodierna; sista internodien i alla paren mycket smal och kortare än näst föregáende intermodie; kloma oranligt smâ. Epimerema äro smà och upptaga ej fullt hälften af undre kroppssiclu; de tre fräunsta paren langa och smala, tredje paret tydligare skilda frin fjerde, som i inre andan äro mycket smala, knappt dubbelt bredare än tredje; utît vidgas de smảningom uch utsända bakảt en obetydlig, trubbig spets. Palpema äro mycket linga, naende anda till suretsen af första benparets fjerde internodie och äro tjockare än detta par. Fjerde ledens tänder äro ovanlight stora. Labim ner lred an langg, med tvenne storar spetsar i fränre kanten och bakkinten bredt afrumlad, ned otydliga processer. Generutionsfältet med korta och breda skifvor, hvarigenom det blir nästan rundt; stignerna mycket talrika (onkring 40), bilda en rund figur och begränsas bakât af hvar sin stora rödbruma fläck, beströdd med svarta punkter, nästan liknande stignema.

Mellan dessa Häckal ligger unus, närmare generationsspringan än bakkanten och omgifven af en ljusgul fläck. § ofre sidan ä dema art till fïmgen gnl eller gulgra ned tydliga stori bruna fläckar och ljusgnlt ryggstreck. Ögonen röda, stora, sittande nära kanten.

Laingd 1,3, bredd 1,1, palper 0,i, första benparet 1, j, andra 1,6, tredje 1, 8 , fjerde 2 millim.

Ett individ i ett kärr vid Qvickjock i Lappland.

\section{Nesæa pulchra C. l.. Kíoci. $\left.{ }^{\prime}\right)$}

Syu.: 1835-41 Nesce pulchre C. L. Koch, leutschlands Crust. ete., h. 8, figg. ") et 10.

Corpus ovatum, antice paululum rotundatum, pieue truncitum, postice utrinque impressione instructum, parva altitudine, Juteolum, maculis luseis, maximam fere partem dorsi occupantibus; linea dorsuatis parva, lutea. Pedes broviusculi, carulei; par primum latitudine corporis brevius, par quartum longiludinc corpus aquans. Pulpi breves, curulei, basin internodii quati pedum primi paris attingentes, crassitudine hujus paris. Oculi magni, mbri. Longitudo 1 uillim. (Tab. VI, fig. 4.)

Hone: Kroppen ä äggrund, af obetydlig höjd; framkanten föga rondad, nästan trär, bakkanten försedd med en intryekning å önse sidor. Benen äro korta; förstal

1) Ehuru den art, jag här beskrifvit, genour sina korta palper afviker frîn C. 1. Kocus . N. pulchra, öfrereusstämmer den likväl i så mänga al'seenden med denna, att jag ej funnit skäl att uppställa den saisom en ny art. 
paret kortare än kroppens bredd, fjerde lika lingt som kroppen. De tre främre paren aro besatta med täta, styfva, längre och kortare har, men sakna knippvis sittande sinlı̂n; de yttersta intermodierna äro kolfformiga; fjerde paret är försedt med simhår pấ fjerde och fente internodierna, äfvensom med glesa, styfva och tjocka hår å dessa internodiers sträcksida sant ned några fa langre a de öfrigas böjsida; sista internodien jümntjock med en mindre klo. Eprimererne upptaga ungefïr hältten af kroppens und»c sida; första paret epimerer äro genom ett bredt mellansmu skilda fran labium, i inre spetsen något vidgade och tvärt afhnggna; andra paret korta, bredt vigglika. Mellanrummet mellan andra och tredje paren temligen bredt. Det sistuämda paret af vanlig for'ın; fjerde af obetydlig bredd med kort, bakât utskjutande spets. Mellanrummet mellan epimeremas inre ändar stort. Labium är mycket bred, bakât rundad, med tvâ tydliga, i spetsen divergerande processer. Palpernu äro korta, blott natende till bascn if första benparets fjerde internodic. Deras andra och tredje leder äro af samma tjocklek soon detta par ocl hafva blott nàgra fá korta hår. Tänderna ả fjerde leden tydliga; fente leden mycket kort och smal, i spetsen otydligt delad. Mandiblernas corpus à lảng, bakảt slutande in en nästan rätvinkligt utdragen, lang spets; fränne ändan trubbig, med en nästan halfcirkelformigt böjd klo. Generationsfältet: Springan ä. ovanligt lång och omgifves af tvemne mycket suala rektangulära skifvor, å hvilkas midt synas tvả små runda fördjupningar. Nagot franom dessa ser man ả ömse sidor trí med livarandra förenade stigmer, och bakom dessa de vanliga grupperna af dylika, bildande en fran bakre delen af springan utgâende, utåt och framat riktad, oregelbunden stundom päronformiğ figur, med 15 à 20 stignes. Färgen ăr nörkgul med mer eller mindre oregelbundna, ofta sammanflytande, mörkbruna ryggfäckar; ryggstrecket ljusgult, ögonen röda. P̊̊ nudre sidan stöter färgen mellan epinererna i rödgult; bakre hälften är gulbrun med en stor mörklmun fläck bakon fjerde epimerparet. Dessa flickar bilda tillsammans en lyrformig figur, i hvars midt, straxt hakon generationsspringan, man ser en uästan sexkantig gul fläck, ongifvande anus. Ben, epimerer, palper och labiun bli̊. Den sistnamde ned röd munöppuing.

Läingd 1, bredd 0,82, första benparet 0,7 , fjerde 1 millim.

Hanen är mindre an honall och har i bakkanten starkale intryckningar än denna. Fïrgen ä oftast nagot ljusare. Epinererna upptaga omkring $\% / 3$ af undre kroplssidan; tredje och fjerde epimerparens inre ändar sammanvuxna. Generationsspringan kortare och de ongifvande fälten försedda med ett mindıe antal stigmer sant belägna 1üistul i kroppens bakle kant.

Mycket trög i sina rörelser. Allmän i Asmnden i Vestergötland; vid Björkelund samt nâgra andra ställen kring Skala tämligen sällsyut.

\section{Nesæa brevipalpis 11. sp}

Femine: Corpus depressiusculum, oblongo-ovatum, intice rotundatum, ante oculos impressum, postice impressione utrimque instructum, flavorufescens, maculis magnis nigris confueutibus; linea dorsualis flava, para. Pedes longiores; par primum latitudine corporis paullo longius, par quartum ejus fere longitudine. Pulpi gracillimi, ad medium internodium tertium pedum primi paris pertinentes, dentibus vix conspienis muniti. Oevli magni, rubri, distantes, prope marginem corporis callocati. Longitudo? millim. 
Hona: Kroppen i symerliet framtill nagot nedtryekt, langstrackt oval, framtill afrundad med en intryckning framfö livaje oga, laktill med en intryckning a hvarjo. sida. Benen lingą, utan nagon större skillnad i längd; andra och fjerde paren lika linga och nagot koptare än kroppen, tredje paret är föga längre äu kroppen är bred. Epimerema, som äro tydligt skilda frin deu ofriga kroppsbetickningen, mprtaga nigot mer an hälften af undre kroppssidas. De tre första paren äro ovanligt langa och smatia, i synucrlet det tredje; fjerde paret ntsïnder hakat en lang spets. Mellanmmmen mellan de särkilda grupperna hreda. Cabium stor, tydligen delad längs efter i fyra delar. Palperna ovanligt korta och smala; knappt hïlften sil tjocka som fürsta bemparet, nal de blott till midten af' detsimmmas tredje internorlie. Anrial och tredje lederna med glesa, nen tämligen lànga har: it den fjerdes undre sida synas ingia täntänder men î den inse en liten rudinentär tand. Generationsfaltet med mycket otydliga skifror; springan är kolt och fülteu med stigmerna likaledes otydliga. De äro rundade, och stigmerna af ringa antal och storlek.

Till färgm är demna art brungul med rödaktig anstrykning och mörkbruna sammanlöpande fläckar â ryogen; ryggotrecket gulaktigt. Palper, ben och lalimm rödbruna, munoploningen röd. Cndersidan ljusare, i synerhet epimererna; pat bakkroppen fimnes en mörkbrm fläck a hvardera sidan om generationsfältet oxh mellan dessa längre bakit en hritgul fläck, i hvilken anus ligger,

längd 2, bredd 1,4, palper 0,4, första henparet 1,6, andra 1,, , tredje 1,7, ljerde 1,8 millin.

Blott ett enda individ i en dam rid Qrickjock.

\section{Nesæa decorata n. sp.}

Femina: Corpus ovatum, altissimum, eadem fere altitudine ac latiudine, antice truncatum vel paululum impressum, postice utringue impressum, lufo-anantiacum, maculis nigris, parris, distinctis. Pedes breves, graviles, pallide flaveceutes, par promum latiludinem, par quartum longitudiuen corporis aquans. Palpi parvi, basin internodii quarti pedum primi paris attingentes, loc pari multo glaciliores. Oculi pari, late distantes. in margine extremo corporis collocati, rubri. Longitudo cira 1 millim. (Tah. VIII, fig. 1).

Hona: Kroppen är oval och mycket hög. nästan lika hög som bred, frankanten tvär elles till och med nagot intryckt, bakkanten med en intryckning a ömse sidor. Benen äro korta, spensligar; första parcet af kloppens bredd, fjerde af deos längal, alla med tahrika har och simhar vid de yttersta internodierna, som äro nästan jämmtjocka: dubbelklorna stora, tydliga. Ejmmereme ano ovanligt sma, liksom lalium belägna langt inat; första parets inre spetsal divererande; afstandet fran labiun ej sardeles stort. Mellanrummet mellan andra och tredje cpimerparen af tredje parets bredd. Fierde paret sma med den bakat utskjutande processen trubbig; mellanrmumet mellan de jure ändarne hredt och stort. Labium är ganska lingsträckt, med de bakit utskjutande divergerande processema myeket storil. L'alperne äro sulâ, nacnde högst obetydligt ofver basen af första benparets fijerde internodie, samt mycket smalate än namela par, och fürsedda med nâgra fa har, af lovilka de hada framat riktade it tredje internodien

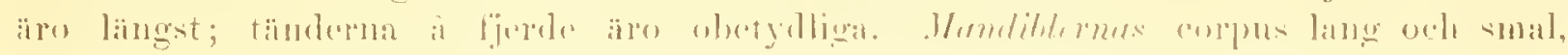


bakre ändan naistan riitvinkligt böjd och slutande med en obetydliğt fürlïngd spets; klon halfeirkelformigt böjd. Cenerationsfïltet: Springan tamligen ling, omgifven af tvenne glatta, i yttre sidan convexa, it inre concara skifor; vid springans midt synes dessa skifvor en liten rundad fördjupuing och $i$ samma linea som dessa stir lüngre utât ett stigma. Tid bakre indan af dessa skifvor sti de ranliga fiilten med mycket smi stigmer af ringa intal ( 8 i 10$)$; dessa fült äro nästan runda, rät utat riktade. Nlidt emellan bakre andan af generationsspringan och kroppskanten ligger ams, och nagot bakom denna synas de vanliga tvâ stignerna. Färgen an klart röd, eller rödgnl, i frankanten, i synnerhet kring ögonen, ljusare, nästan gulhvit; ryggflickarne äro svarta, tiamligen små, alltid tydlight begränsade, ryggstrecket nagot ljusare rödt; under sidan gulröd med höfter, palper, ben och labimu gulaktiga; kring anus en gul fläck, omgifren af tremne svartbruma flickar.

Längden 1,2, bresld 1, 1:a benparet 1, 4:de 1,5 nillim.

Blott honan af denna lilla vackra art, som till fürgteokningen närmast ofverens-

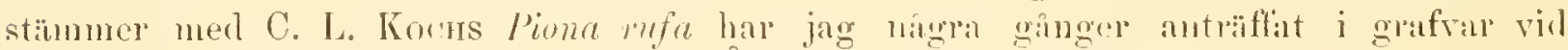

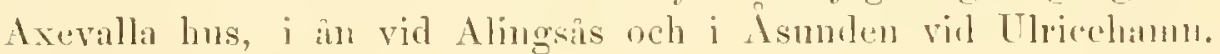

\section{Nesæa spectabilis 11. sp.}

Corpus late ovatum, altissimum, antice impressiusculum, postice ynoque parvula ntrimque impressione instructum, tlavo-virens, maeulis magnis fuscis, siepe confuentibus; liura dorsualis flava ant coccinua. Pedes longiores, pilis densis instructi, pas primum quarto pauło brevius. Pulpi longissimi, basin articuli quinti pedum primi paris attingentes et hoc pari paulo crissiores. Oeuli rubri, parvi, distantes. Longitudo $2.5-3$ milliu.

Hona: Froppen oval, mycket hög, framkanten med en intryckning mellan öguncn, bakkanten wed en mycket obetydlig dylik a ömse sidor. Benen tamligen långa; första paret obetydligt kortare in de ofrign, sista internodien ej kolfformig, kortare in rïst föreginende internodic, de tre sista benparen med talrika kortare hån och simhan; dublolklorna väl ntvecklade. Epimereme, som upptaga onking hälften af undre kroppssidan, ïro suni, till form och fördelning närnast öfverensstammande med epimererna hos $\mathrm{N}^{\top}$. rosere. Mellanrummet mellan de ine ändame dock betydligt större. Labium mycket liten, bakit rundad, med obetydlina processer. Palperna mycket linga, nânde till basen af första benparets fente internodie, obetydligt tjockale in detta benpar, andra och tredje lederna med nagrat fâ korta hirr, fjerde med mycket sma tïnder. Mandiblema som hos N. cocenere. Generationsfailtet: Springan och de omgifvande skifvorma som hos $N$. rosed; fälten merl stigmerna aro äfven rumdade, men belizgna längre bakit, stignerna a hvarje fiilt äro stora och talrika (omkring 30), grupperade omkring trente, som älo vida större in de öfrign. Färyen är gुulgrön med storat, bruna, ofta sammanflytande ryggflackar, den Y-forniga tiguren gul eller rödğul. Undersilan nảgot ljusare. Amms omgrifres af en gulhvit tlïck, och î hvarje sida om doma ser man cu större brun flïck. l'alper, labium, eprimerer och hen gonlg'röna. 
Längd 2, bredd 1,6, palpel 1, första benparet 2,4, fjorde 2, fi millim. ${ }^{2}$ )

Hanen är mindre än honan; dess kroply unel langsträckt, benen jämförelseris längre, epimererna äfrensom fälten kring generationsorganerna stöne. Färơn som hos lonlan.

Längd 1.4, bredd 1, palper 0,8, första benparet - millin., de öfriga paren obetydligt längre.

Äggen äro gulhvita och af sammu storlek som hos $\mathrm{X}$. coecinea. Lareerna lse tufl. XII, fig. 4) som efter fyra reckor ntklïckas, iro nistan flaskformiga med träl bakkant, a hvilken synas tra utskjutande knölar, hrardera med ett myeket langt hâr; i hakkanteus hörn synes ett liar wch å livardera sidan fyra samt ett vid hvardera ügat; lygegen något nedtryckt. Fïgen blaaktig. i kantena stütande i gult; a rrggen befinner sig en stor, hrun, bredt halfmanformig flikek med spetsarne riktade finarit, sant en betydligt mindre af samma füro, stötande intill den fürre, och ned spetsarne riktarle bakit. l)ene senare flick omsluter en hrit. ben och palper stötande i gult. Ögonen röda, de birla å ümse sidor alldeles intill hrarandra, tillsammans bildande en trekant. Postrum tjockt och làngt. Epimerer, renerationsfält och hâl it undre sidan som hos larven af I. eoreine

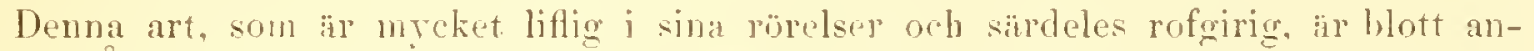
trïftad i Asmolen vid Ulrivehamn, i Borga trask pa Öland sant rid Karesnande i Tornea lappmark. (Prof. Lima.reborg.)

\section{Nesæa fuscata (Hermaxy) C. L. Kornert.}

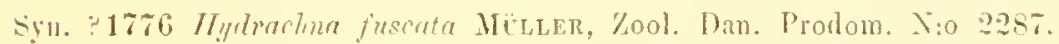

\begin{tabular}{|c|c|c|c|}
\hline $17 ミ 1$ & $"$ & , & Hydlachnet, p. 79. tab. 11, tig. 2. \\
\hline 18004 & $n$ & , & Iervasi, Mem. aptél. p. os, tab. Vi, fig. a. \\
\hline-41 & 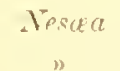 & & Dentschlands r'ust. etc. h. 9, figg. 21 o. 22. \\
\hline
\end{tabular}

Feminu: Corpus oratum. antice trutratum, postice utrimque impressione ornatum, rubro-ferrugincum, maculis nigris maguis, siepe contuentibus; liuca dorsualis plerumgue coccinca. Pedes breves, graciles. Alavoforruginei par primum latitudine corporis paulo longrus, cetera paria cadem fere longituline ac corpus. I"mlpi hrevissimi, basin internodii quarti pedum primi paris non attingentes, loc pari paulo crassiores. Oculi parri, lubri, approximati, in margine extremo corporis collocati. Iongitulo 1.5-? millim.

Honu: Kropren är ïggrund, lı̈ghrälfd, fraukanten triil, bakkanten försedd med en intryckning ì ömse sidor. lienen kortal, spensliga: första patret obetydligt längre än kroppens bredd, de tre ofriga paren, som sims encllan itro nästan lika langa. af dess

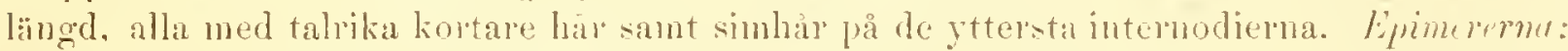

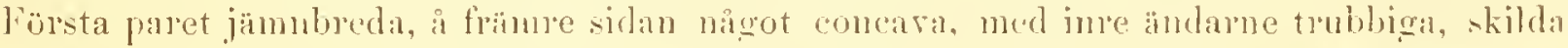

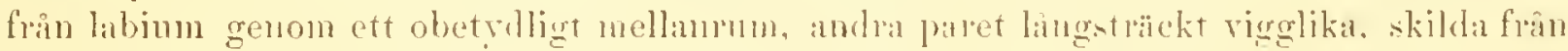

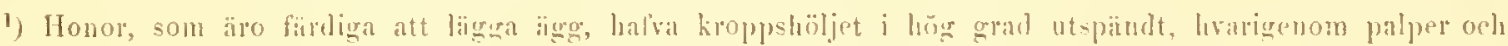

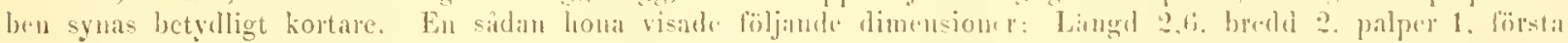
licuparet 2,4 , fjorle 2.6 millim. 
tredje genom ett smalt mellanrum, fjerde paret nyeket stora, med den bakit utskjutande processen langg och spetsig. Epimererna upptaga omking hälften af undre sidan; mellanrummet mellan de imre spetsarme obetydligt. Labium nảstan jämnbred, med de bakåt utlöpande processerna obetydliga och otydliga. Palperna äro korta, ej nående till basen af första benparets fjerde internodie, tjockare an detta benpar’; andra leden myeket tjoek, men kort, höjden större än längden, tredje tjock, föga kortare än andra, lika hög som lång, båda med kortare lrår; fjerde betydligt smalare än tredje, med obetydliga tander, femte i spetsen otydligt tredelad. Mandiblernas corpus lang oeh smal, bakre ändan trubbvinkligt böjd och slutande med en kort spets; klon stark, krökt. Generationsfältet: Springan som hos $N$. decorata, skifvorna bredare, bakåt nargot bredare och afrundade, tillsammans bildande en nästan hjärtlik figur, hvars spets är framåt riktad; de båda fälten med stigmer myeket otydliga, å skifvornas sidor bildande en figur i form af en sinal likbent triangel; dennes spets sträcker sig nagot framom skifvornas midt, dess bas obetydligt bakom deras bakre kant. Stigmerna iro till antalet $\delta$ it 10 större, mellan hvilka andra, knappt hälften så stora, synas.

Till färgen är den brumröd, med stora svarta fläekar, som ofta sammanflyta, sant rödt ryggstreek; å undre sidan är den gulbrun med en stor brunaktig fläek å ömse sidor om anus, som omgifves af en grulaktig fläek. Labium, palper, epinerer och ben gulbıuna. Hanen är betydligt mindre samt till färgen ljusare än honan. Äggen, som äro röda, läggas i kakor om 20 ì 25 stycken och utkläckas efter 3 ì 4 veckor.

Allmän i dammar och diken med mindre klart vatten. Ehuru tämligen liflig i i sina rörelser, synes den varu föga rofgirig. Lappland, Upland, Vestergötland, Skåne, Blekinge, Gotland och Öland.

\section{Nesæa rosea C. L. Kосн.}

Syu. 1835-41 Nesca rosea C. L. Kocu, Dentschlands Crust. ete. h. 10, fig. 7 (O).

Femina: Corpus obovatum, depressinseulum, antice truncatum vel paululum impressum, postice ntrimque impressione preditum, roseum, antice et postice pallidius, maculis fusco-ferugincis; linea dorsulis ignca. Pedes lougissimi, pellucide flavescentes; par primum latitudinem corporis duplicem, par quartum longitudinem simul et latitudiuem corporis equans. Palpi longissimi, medium internodium quartum pedum primi paris attingentes, hoc pari paulo crassiores. Oculi permagni, late distantes, rubri. Longitudo 1,6 millim.

Hona: Kroppen år ounvändt åggrund, något nedtryckt; framkanten tvảr, eller försedd med obetydlig intryekning; bakkanten ned en intryckning å ömse sidor, myeket tvärt afrundard. Benen äro ovanligt långa; första paret dubbelt längre än kroppens bredd, fjerde lika långt som bredden och längden tillsammantagna, alla paren försedda med talrika, mycket långa, styfva hår à böjsirlan samt bögst fa, kortare hâr å strïcksidan; tredje paret med en knippa simhâr vid slutet af femte internodien; fjerde med dylika hår på fjerde ocl femte internodierna. Epimererna upptaga nästan $2 / 3$ af undre kroppssidan; första paret åro genom ett högst obetydligt mellanrum skilda från labium, inåt afsmalnande $i$ en trubbig spets; andra paret förete den vanliga vigglika formen, hafva sanma bredd i yttre ändan som fürsta paret sant ïro nagot kortare än dessa; tredje paret linga och smala, af nästan rektangulär form, skikla fran andra parcet genom ett högst 
obetydligt mellanrum, sant genom en tydlig gräns fran fjerde, hvilka älo ovanligt stol"a, och i symuerhet utıärka sig derigenom, att det vanligen skarpa hörn, som gräısar intill generationsspringan, häl äl alldeles af 'undadt; den bakìt utskjutande spetsen äl. mycket trubbig. Mellamrummet nellan detta pars inse ändar ovanligt smalt. Labium bredt hjürtlik. Palpernce mycket lảnga, nâende till midten af första benparets fjerde. internodie; de likna till formen mycket palperna hos $N$. roccinea, men hafva tänderna pa fjerde leden betydligt mindre. Mandillemu hafira samma form som hos $\Lambda$. eocrinea. Gemerationsfältet: Springan är tämligen kort, de båda fälten med stigmer rundarle, belägna ¿ mer, omkring 20 till antalet, äro ytterst små och kumu hos det lefvande djuret blott skönjas vid starkare förstöring. Till färgen är arten rosenröd, frantill och baktill ble kare, bakom ögonen nästan hvitaktig; fläckarne tydliga. rödbruna, ryggstrecket eldröd†. Ogonen mycket stora och lingt skilda, nästan trekantiga, rödaktjug. Labium och epinterer josenröda. Bakon f̈jerde epimerparet ser man en aflảng, brun fläek à hvarje sida, omgifvande en oval hvit fläek, i hvars midt anns ligger. Ben oeh palper äro gulaktiga, genomskinliga.

Längd 1,6 ; bredd 1,2, palper 1 , första benparet 2,4, andra 2,6 , tredje 2,65 , fjerde 2,8 millim.

Tamligen sällsynt i Asunden och sjöar i Valle härad samt vid Borås.

En form af clenna art (se tafl. lII, fig. 1), som jag ej vágar anse för utbildad hane, utan för en hane $i$ andra lavetadiet, har jag några gånger träffat à samma ställen som honorna. Mindre än dessa, ofverensstämmer den till form oeh furgteckning med dem. Epimererna äro, som vanligt hos hanarue, större ä hos honan, oeh a kroppens midt äro de inre ändarne af trerlje oelı fjerde paren ảtskilda blott genom en smal springa, fjerde benparet visar den karakteriska urholkningen poi fjerde leden. Hvad som emellertid hos dema form är särdeles egendomligt ä tredje benparet, hvilket ar myeket kolt, kortare än första, med sista internodien mer un hälften kortare än näst föregående, förtjockad och nästan kolfformig, krökt och i spetsen tväit aflınggen, samt der försedd med en enkel, lång och mycket krökt klo.

Generationsfältet visar i stället för den vanliga springan en stor fördjupning, son nästan har formen af en hattsvamp, hvars fot ür bakât riktad. De nästan rundade fälten med stigmer äro belägna å ömse sidor om demn fot; stignema talrika (omkr. 20). Dả djuret simmar eller när man lägger det pá ryggen, insticker det ofta de kolfformiga spetsama af tredje benparet i generationsöppningen och haller dem fast med den nämnda klon, hvarigenom benen hallas bagformigt böjdal mot kroppen. A ryggen synas bakoun ögonen tva längsgiende gropar samt något längre bort tva par stigmer, af́ hivilka det bakre parets stả lıvarandra mycket nărnare. Mer trög i sina rörelser än honan.

Längd 1,2, bredd 1, palper 0,9, första benparet 1,8, andra 1,9, tredje 1,5, fjerde 1,9 millim. 


\section{Nesæa borealis n. sp.}

Femina: Corpus lite ovitun, parva altitudine, antice impressiusculum, postier impressionc utrinque justructum, flavo-fuseum maculis magnis fuseis plerumque confluentibus; linea dorsualis lutea. Palpi longi, mediunı a!ticuli quarti pedum primi paris attingentes et hoc pari paullo crassiores. Pecles longi, pilis densis iustructi; par primum longitudinem corporis aquans, quartum corporc multo longius. Oculi rubri, magni, distantes. Lougitudo 1,6 millim.

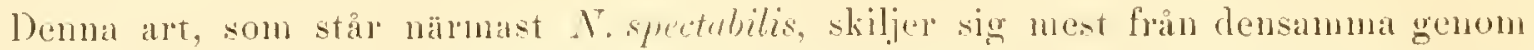
den nedplattade ryggen, de kortare palperna, sant det högst obetydliga mellamrunmet

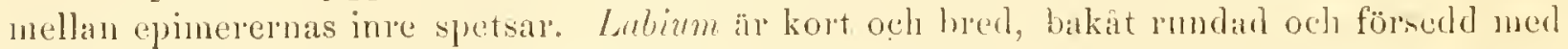

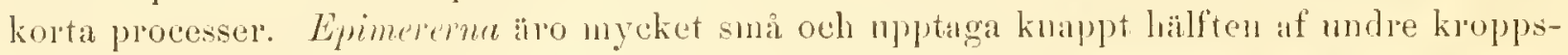

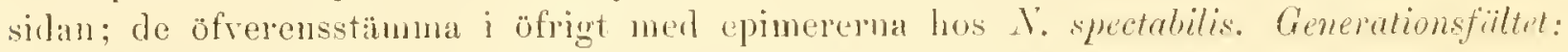
Springan är nyeket liort och belägen lingt franat; de rmuda fälten a ömse sidor om dess bakre ända äro försedda ned mycket talpika, sma och otydliga stigmer, ntan nagrat större. Till färgen är arten gulbrun med mörkare brunakfiga, mest sammanlöpande fläckar. Undersidan ir ljusine; epimerer, ben, palper vch labimm smutsgnla. Anus, som ligger närmare generationspuningan än kroppens bakkant, ä ongifven af en ljusgrul flick.

Lïngd 1,6, bredd 1,4, palper 0,8, första benparet 1,6, andra 1,7, tredje 1,8, fjerde 2 millim.

Denna art, som ej är symerligen snabb i sina rörelser, har blote anträffats vid Qviekjock i Lappland ouh är der saillsynt.

\section{Nesæa alpina 11. sp.}

Hus: Corpus late uvatum, parsa altitudine, antice impressiusculum, postiece impressione utrimgute prieditun, albo-flaveseeus, maculis magnis fuscis confluentibus; linca dorsualis plerumque obsoluta. Oculi rubri, permagni, valde inter sc remoti. Pedes longi, par primum corpore longius, sccundum longissimum. tertium brevissimum, corpore panllo longius; ommia, tertio excepto, pilis densis matatoris in iuternodiis quarto et quinto instructa. Epimera totum pente latus inferins occupantia. Palpi al apicem internodii tertii pedum primi paris pertineutes et hoe pari paulo graciliores. Longitudo 1,2 millim.

Hone: Kroppen oval, i frankauten mellan ögonen obetydligt intryckt; i bakkanten med en intryckning i önse sidor; höjden ringa. Benen äro langa och deras länglproportioner annärkningsrärda, enär andra benparet är längst, sedan fjerde, vidare första; det tredje äl kortast och risal sanma afvikande form, som är beskrifven hos . I. roseca. l)e bada fränsta paren hafva $\mathrm{i}$ yttersta andan af fjerde och fente internodierna tiita oah langa simhâr. Tredje paret är mycket gleshårigt och har blott nảgra fà dylika hår i spetsen af fente internodien; fjerde parct är försedt med talrika simhảr och ntmärker sig genom den ovanligt tjucka process, som det utsänder frin den lualfeirkelformiga, mringade fjerde internodicus ofre eller yttre sida och som är försedd med

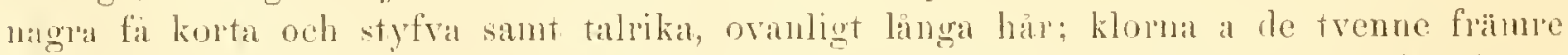

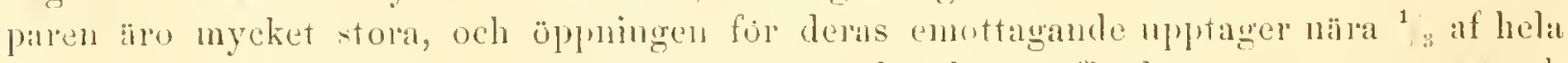
internodien; tredje parets älo starkast, men unycliet korta; lijerde parets ytter-t sma och svana. Palperna, som äro nyeket smalare än första benparet, na till slutet af detta pars tredje internodie. De salkua tydliga tänder oels visa blott ett rudiment till en sådan â inre 


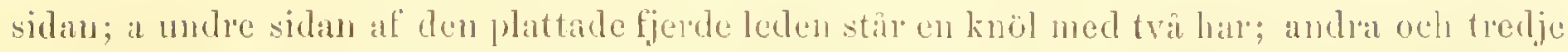

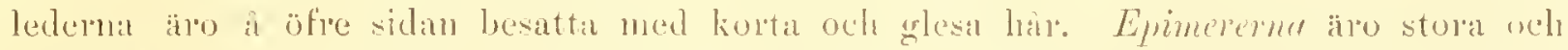

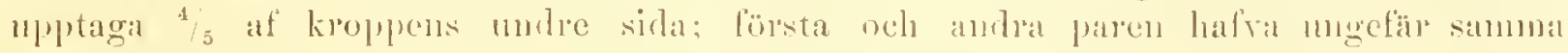
bredd; det första paret limgre och i inre andan nagut bredare ä a midten och tvärt

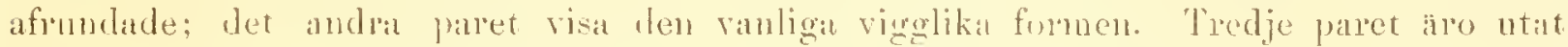
ganska breda, men afsmalna hastigt och förena sig utan tydlig grans med ljerde, som

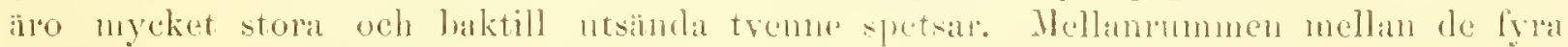

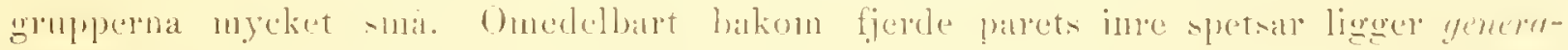

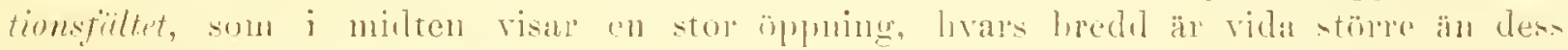

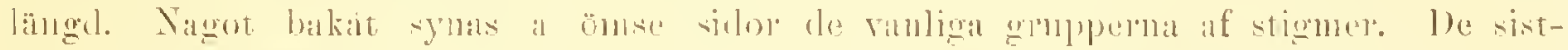

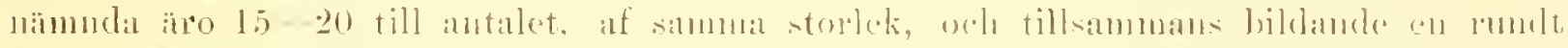

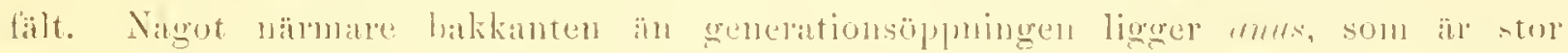

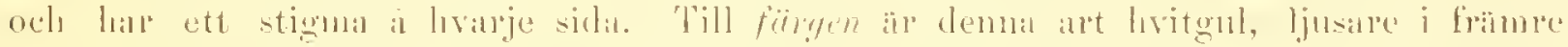
kanten, nud bruma eller starta, sammanlöpande fläclial', som upptaga nästan liela ryg-

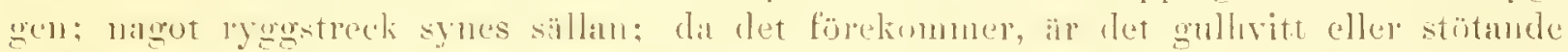

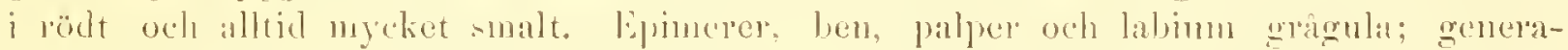

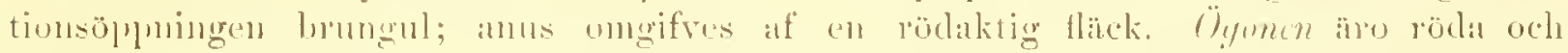

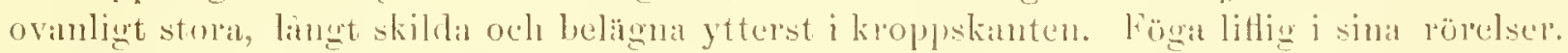
Jâhändal larv $i$ andrit stadiet.

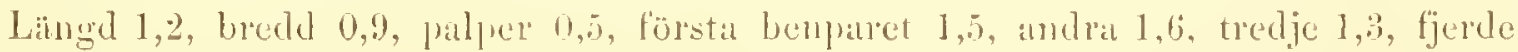
$1,+$ millim.

Täimligen allmän i kïrren vid (Qvickjock.

\section{Nesæa Iongicornis (. L. Kón.}

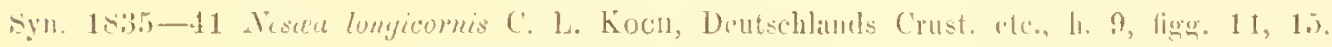

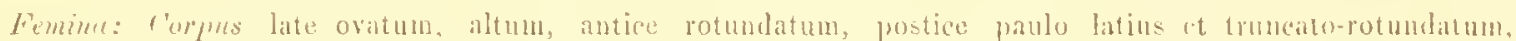

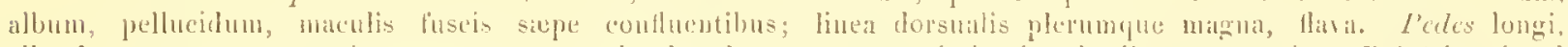

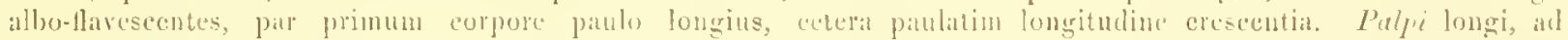
apicen internodii quatri pedum prini pris pertinentes, hoe pari erassiors. Oculi magni, rubri, distantes, a margine corporis remoti. Longitudo 1,? millim. (Tab. 11, tig. "2).

Hona: Kroppen är bredt oval, lı̈̈g, framkinten rundad, bakkanten bredare ach

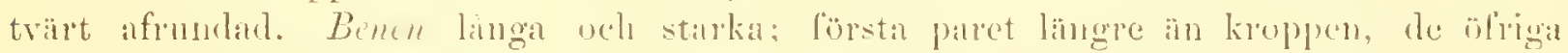

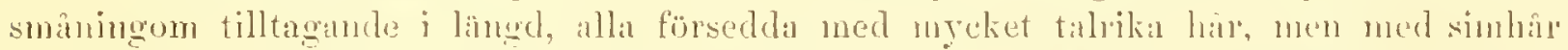

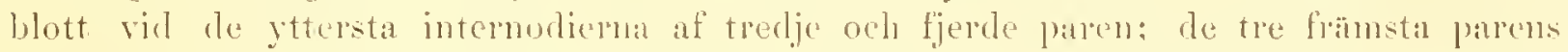

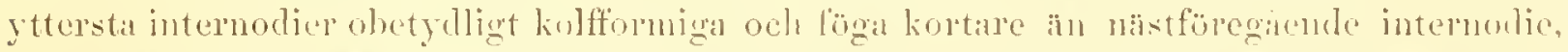

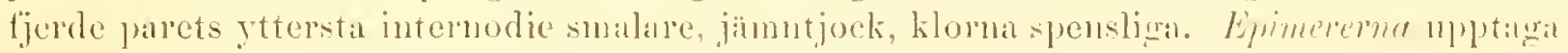

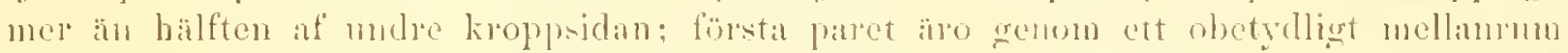

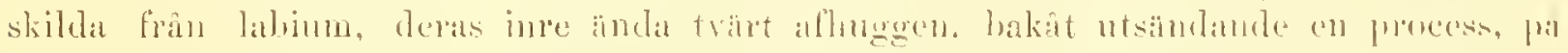

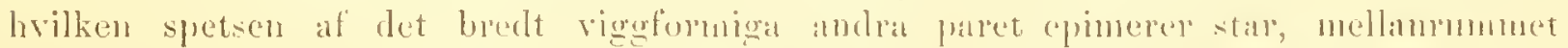

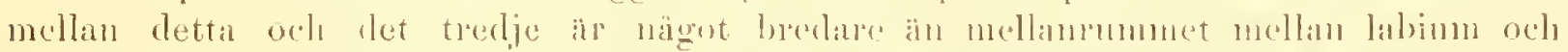
först apraret, tredje parets yttersta anda ntsinder an lang, lianat och ntat riktal, pro-

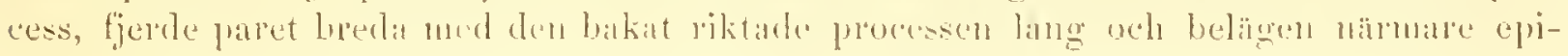


merens yttre ända. Mellanrummet mellan de inre epimerändarne tämligen stort. Labium som hos $N$. pulchra. Palperna linga, nående till spetsen af första benparets fjerde internodie och tjockare än detta par; andra leden är utä nycket fürtjockad och besatt med några få korta hår, tredje leden äl nastan fyrkantig med ett par dylika hår, fjerde nycket lângsträickt, å undre sidan tillplattad med obetydliga tänder i förhållande till palpernas storlek, femte mycket kort, i spetsen otydligt tredelad. Mandiblernu som

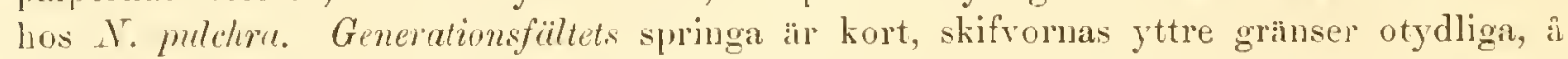
deras midt synas rid springan trà mycket små fürdjupningar; fälten med stigmerna små, bildande tillsammans en hjärtlik figur, luvars spets är framåt riktad; stigmerna myeket små och kunna i det lefvande djuret knappast skönjas, talrika (omkring 20 å hvarje fält), isynnerhet tätt gyttrade mot bakre delen af fültet. Ams rundad, belïgen närmare kroppens bakkant än bakre ändan af genitalspringan. Färgen är hos denna art hvit, med stora, bruna, oftast sammanlöpande fläckar och med ett vanligen bredt korslikt ryggstreck; undre sidan grålıvit, epimererna stötande i brunt; bakonn generationsfältet ser man två ljusbruna fläckar omslutande en gul fläck, i hvilken anus ligger; labium är gråhvit med en gulbrun fläck kring munöppningen, ben och palper hvita eller gulgrå, genomskinliga.

Längd 1,2, bredd 1, palper 0,6 , första benpar 1,3, andra 1,35, tredje 1,4, fjerde 1,5 millim.

Hanen är betydligt mindre än lonan, med bakre kanten mera tvär; han utmärker sig isynnerhet genom den egendomliga bildningen af generationsfältet: Tid inre hörnen af de med hvarandra nästan utan gräns sammanlöpande epimererna af fjerde paret ligger ett ovalt. fält, bakàt och till en del på sidorna begränsadt af en uästan qvadratisk fördjupning (jfr $N$. rosea), omgifven af trenue windre fält med färre stigmer än lıos honan; bakom dessa fält stå fyla stigmer nästan bildande en quadrat, i livars midt anus äl belägen.

Mycket liflig i sina rörelser och ganska rofgirig.

Honorna äro allmänna i Vettern vid liödesund och Hjo, i sjön vid Skärfs kyrka i Valle härad, i hvilken sjö hanen äfven anträffats, sant i Mälaren vid Kungshann.

\section{Nesæa pusilla NeumaN.}

Syn. 1875 Nescu pusilla Neumax, Gotlands och Ölands spindlar och vattenqvalster, i Öfrers. af Kongl. V'et.Akad. förh. N:0 2, p. 100.

Femina: Corpus altum, ovatum, impressionibus carens, pellucidum maculis fuscis; linea dorsualis flavescens. Peles breviores, pilis raris instucti, cerulescentes, par primum latitudinem, par quartum longitudinem corporis requans. Pulpi pari primo pedum multo crassiores, ad medium hujus paris, hoc cst paene ad apicem articuli quarti pertinentes. Oculi magni, rubri vel fusci, distantes. Longitudo 0,8 milliu. (Tab. V, fig. 5.)

Hona: Kroppen hög, oval, i bida ändarne afrundad, ryggen saknar alldeles de i rader stående stigmer, som ïro sâ karakteristiska för N. punctata, med lıvilken denna art i många afseenden har stor likhet. Benen äro korta och spensliga; första paret af kroppens bredd, fjerde af dess längd, med glesal lıirr, hvilka doek äro talrikare 
än hos följande art; simhår finmas iffven på tredje parets yttersta internodier. De tre frïmre parens yttersta internodier föga kolfformiga, nảgot kortare än nästföregảende internodie, fjerde parets yttersta internorlie inycket smal, cylindrisk. Illa benens klor äro ovanligt små. Epimerema sảsom hos följande art, mellamrummen mellam de olikal gruppernal dock större. Lubium kort och bred, bakit afrundad, med tämligen tydliga processer, framkantens hörn ej sả spetsiga och franskjutande som hos följande. Palpernc nästan dubbelt tjockare in första benparet; de sträcka sig till parets midt, nästan till spetsen af dess fjerde led och äro försedda med blott några fả hâr à andra och tredje lederna; fjerde leden har mycket små otydliga tänder, blott synliga vid starkare förstoring. Mandiblem af samma form som hos $Y^{\prime}$. decorata. Generationsfältets springa lảngsträckt, skifrorna tydliga, li̊nga, halfmånformiga, fräure tvïrspringan tämligen kort; fülten mer stigmerna (omkr. 15) obetydligt strickande sig ntait, men längre bakit. Färgen gulhvit, genomskinlig, med bruna ryggfickar, ryggstrecket mörkare gult; undersidan hvitgul ned tvả storn flackar bakom generationsfältet; ben, palper och labium bliaktiga.

Längd 0,8 , bredd 0,6, palper 0,3, första benparet 0,6, andra 0,65 , tredje 0,7 , fjerde 0,8 millim.

Hanen (se tafl. V, fig. 6), som är föga mer ̈̈u hälften sil stor som honan, har nästan rund kroppsform, och visar i öfrigt de för hanarne egendomliga karakterer, hvarigenom de skiljas frản howorna.

Blott anträffad i Rökïrr i Föra socken í (Oland, i juli 1874, men derstädes nycket allmän.

\section{Nesæa punctata Neuman.}

Syn. 1875 Neseca punctata Neumax, Gotlands oclı Olauds spindlar och vattenqralster, i Öfvers. af Kongl. Tet.Akid. Förh. N:0 2, p. 101.

Femina: Corpus altum, late ovatum, impressionibus carens, pellucidum, maculis fuscis distinctis sparsum; linea dorsualis Havescens. Dorsum punctis sive stigmatibus in quatuor series dispositis ornatum. Pedes breviores, graciles, pilis rarioribus instructi, carulescentes, par primum latitudine corporis, par guartum longitudiue cjus paulo longius. Palpi pari primo pedum crassiores, al unedium lujus paris non pertinentcs, mediun articuli quarti vix attingentes. Oculi parvi, rubri, approximati, in margine extremo corporis collocati. Longitudo 0,8 millim. (Tab. V, fig. 4.)

Honn: Kroppen hög, bredt oval, i bâda andarne afrumdad, ryggen med fyra rader särdeles tydliga, nảgot upphöjda stigmer, de mellersta raderna med sju stigmer i hvarje rad, de yttersta, befiutliga alleles i kroppskanten, med fyra. De trå stiginerna franför ögonelı, utsünda ett langt hår hvardera. Benen korta, spensliga; första paret lika långa som kroppens bredd, fjerde nảgot längre in kroppen; de tre framre paren äro försedda med mycket glesa hår, nen sakna alldeles simhår, fjerde paret har glesa dylika pâ de sista intemodierna. De tre framre parens yttersta internodier äro obetydligt kolfformiga, af samma lingd som näst föregånde internodie; fjerde parets yttersta internodie är jimnbred; dubbelklorna tydliga. Epimererna, som upptaga hälften

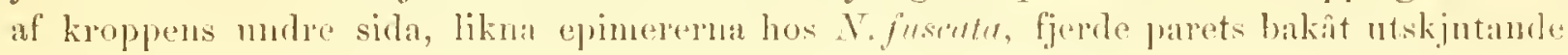


process dock obetydlig och mycket trublivinklig. Labium kort och bred, bakåt afrundad, med otydliga processer, de hâda främre hörnen ovanligt skarpa och utdragua. Palperna, som äro tjockare in första benparet, nả ej till detta pars midt och knappt till midten af dess fjerde internodie; andra och tredje lederna besatta med glesa hior. fjerde ledens tainder små, men tydliga. Mandiblema som hos $\mathbf{N}$. decorata. Grenerationsfältet: Springan tämligen langsträekt, med te omgifvande skifvornas yttre gräns otydlig: froinne tvïrspringan ovanligt stor, upptager nästan hela mellanrummet mellan fjerde epinerparets inre andar. Straxt bakom denna bürja de med stigmer fürsedda fälten, som strïcka sig utât och bakảt tills de komma i rät linea med den bakre trärspringan, bredvid hvilken en sammangyttrad mupp af 3. it 4 stiguer à hvarje sida stâr. Stigmerna äro ej talrika, omkr. 15 i hvarje fült. (Se für öfrigt figuren.) Anus, som är bredt oval och ovanligt stor, ïr belägen unidt emellan bakre trärspringan och kroppskanten och har a ämse sidor ett litet stigma, längre bakiht och wtit stirr ett större dylikt å hvarje sida. Fïrgen hvitaktig, genomskinlig, med mörkbruna, tydliga ryggflickar, rygostrecket gulaktigt. Undersidan gulbrun. Mellan epimerema och onkring generationsfältet är färgen mörkare gul. Anus omslutes af en rund eller oval hvit flack, som åter â ömse sidor omgifves af tvenne större, aflànğa, bruna tlackar. Epimerer, palper och ben blakatiga. Munöppningen brunröd Blott nâgla fa honexemplar af denna lilla särdeles rackra ant antraffades $i$ juni $1874 \mathrm{i}$ ens. k. lorya eller dam vid Grodde i Fleringe socken sant vid Petes i Hamra pa Gotland.

\section{Nesæa viridula C. I. Kori.}

Syn. 183:-41 Nescra vimidula C. T. Kocur, Deutschl. Crust. ele., h. 10, fig. 9.

Femina: Corpus altissimum, late ovatum, autice truncatum, postice rotundatum, flarovirens. maculis magnis distiuctis fuscis rel nigris. Perles breviores, par primum latitndiuen corporis acquans, quartum longitudinem ejus patlo superans. Palpi breviores, ad basin intemodii quarti pelum primi paris pertinentes et hoc pari paulo crassiores, sicut pedes albescentes. Oculi in pxtremo margine corporis collocati, magni, distantes, fusci. Longitudo 1,8 millim.

Hona: Kroppen är mycket hög, äggrmul eller nästan oval; framkanten tvär, bakkanten rundad. Benen timligen kolta; första paret af kroppens bredd, fjerde obetydliggt längre an kroppen; alla paren besatta med glesa hår, likson hos N. dreoratr. Epimererna ijon, sisom hos denna, mycket smi och belägna lingt inat; tredje paret inat utan gräns fürenade med fjerde; mellanrmmet mellan de bida sista parens inre andar mycket bredt. Palpesna in korta, nânde till basen af första benparets fjerde internodie samt högst obetydligt tjockare ïn detta par. Andra och tredje ledema försedda med glesa hiir, fjerde ledens täinder mycket smit. Labium, som genom ett tämligen bredt mellanrum är skild frim första eprincrparet, är liten, med langa, tyalliga processer. Generationsfialtel liknar mycket samma fält hos N. derorata; stigmerma bilda a ämse sidor om den linga springans bakkant tvenme lïlt: de frimme med störe glesare, de bakre med talrikare mindre stigmer; längre fran mot springans midt sti a luvije sidal trenno stïre med hvarandra fürensde stigner. Till färgen äl den glöngul, i frankanten nästan

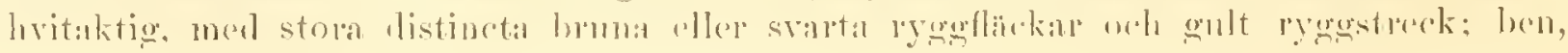


rpimerer och palpel mer stötande i gult. A mndersidan sta mot bakre kroplskanten trume hrma täkitu, omslutande en grul, i hrilken anus ligger. De langt skilda, stora, rödhruna ögonen äro belïgua alldeles i frimle kroppskanten.

liillged 1,3. breth 1, palper 0,4, första benparet 1,1 , andra 1,2 , tredje 1,3 , fjerde 1,4 millim.

Söllsynt. Blott nảgra fä homexumplar har jog antriffat $i$ graframe vid Axeralla

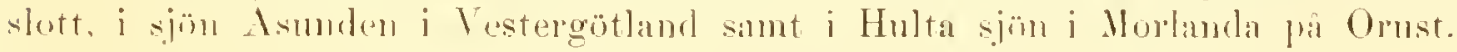

\section{Nesæa viridis C. L. KócII ${ }^{1}$ ).}

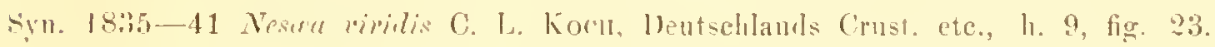

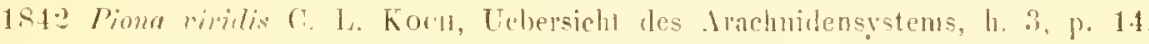

1854 " "Brtzelits, Reskr. ö. Hỵdrachn.. som förek. i. Skinm p. 19.

Corpms ovale, altum, antice ot postice rotundatum, flavoviresecus marolis nigricantibus. Pros longi,

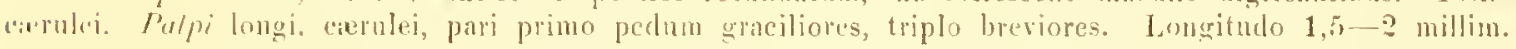

Kroplun oval, hög, i bida ändarne afrumdad. Ben och palper lang̨a, skönt mörk-

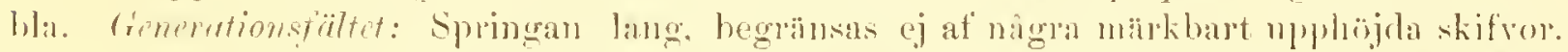
l’a livardera sirlan om lemes midt sta nagra sma upplöjda lumkter (stigmer) samt nagot

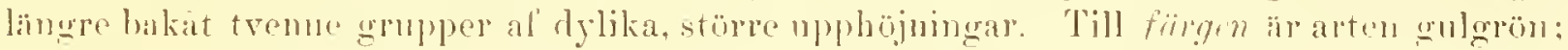

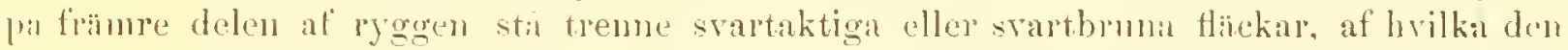

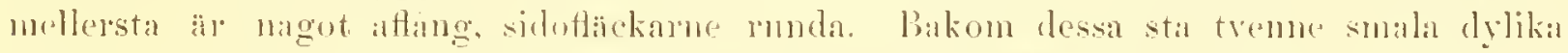

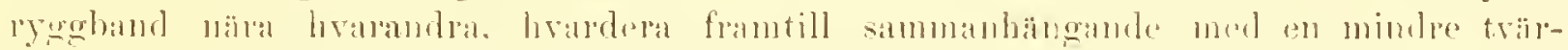

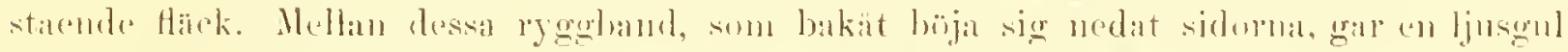
lored strinma. Endast antriffal $i$ en â vid St. liöpinge i Skane.

\section{Nesæa brevipes 11. sp.}

Fomime: Compms ovatum. altissimum, fornieatum, autice et postice rofundatum, allum, pelluricluul,

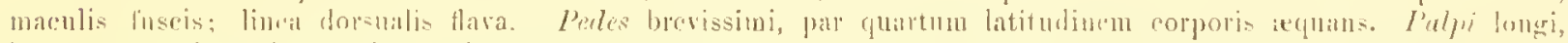
basin introudii quinti perlun pumi paris attingentes, loc pari crassiores. Oculi magni, rubri, satis approsimati, in extremo mareine corporis collocati. Longitudo 1 millim. (Tab. II. fig. :i).

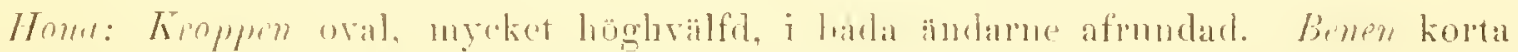
wh starka, med talrika har a internodierna; andra, tredjo och tjerde paren med länere simbar vid basen af den ytersta internodien, hrilka hal äro dubbelt sa langu som

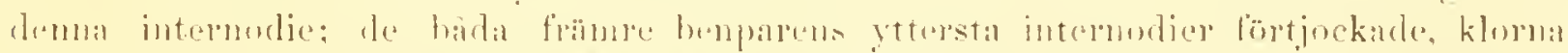

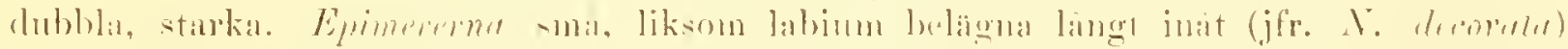

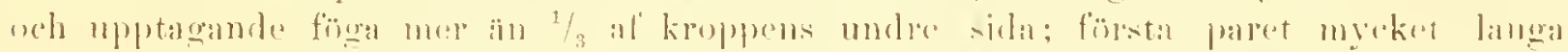

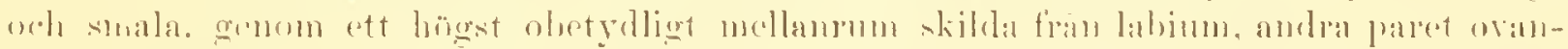

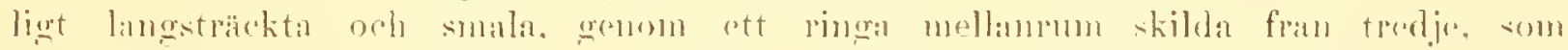

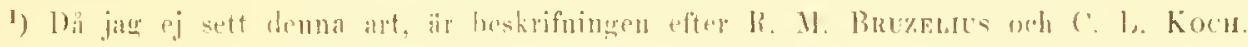

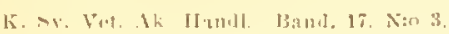


aro jümnhreda och likaledes sinala, fjerde paret nästan rhombiska, med långt bakåt ntlöpande process. Mellanrummet mellan de inre andarne mycket bredt. Labinm kort och bred, bakat twärt afrundad, med stora, föga divergerande, otydliga processer. Palperna äro långa, nånde till basen af första beuparets femte internodie, tjockare än detta par; andra leden betydligt förtjockar, med nigra korta hår å öfre sidan, tredje kortare, med några dylika hår, fjerde jämförelsevis kort, af andra ledens längd; i stället för de vanliga tänderna har denna led ett par, blott vid stark förstoring synliga, "pphöjningar med ytterst smala hår; femte leden lâng, föga kortare än fjerde, tjock och utan den vanliga tredelningen i spetsen. Generationsfätet: Springan lång, skifvorna tydligt begränsade, å midten af yttre sidan concaverade; de med stigmer försedda fälten ovala, sträckande sig frin bakre häften af genitalskifvorna utåt och bakåt; stigmerna talrika. Midt enellan bakre ïndan af genitalspringan och kroppens bakkant ligger anus. Nảgot längre bakit synes a ömse sidor derom ett mindre stigma och bakom dem ett större; de båcla bakre pii längre afstånd från hvarandra ün de fränre. Hanen obekant. Längd 1,1, bresd 0,8 , palper 0,3 , första benparet 0,5 , andra 0,6 , tredje 0,7 , fjerde $0,8 \mathrm{millim}$.

Eu amnan forı, (larv i andra stadiet?) togs på samma gång. Den skiljer sig mest genon frånvaron af generationsfälten, i hvilkas ställe blott tvenne stigner å hvarje sidar synas: benen äro längre och smalare $\mathrm{i}$ förhållande till kroppen än hos def fullt utbildarle djuret. Till färgen är den liksom honan hvit med stora svartbruna fläckar och gult ryggstreck.

Blott dessa tvemne exemplar togos i Asunden vid Ulricehamn i juni 1876.

\section{Nesæa unguiculata $n$. sp.}

Corpus oblongo-ovatum, antice ante oculos coartatum, inter oculos fere truncatum, postice latius, rotundatum, canum vel cano-flavescens, maculis oruatum rubro-fuscis, plerumyue distinctis. Linea dorsualis coccinea. Pedes breviores, pal primum corpore paulo brevius, par quartum longitudinem corporis aequans. Exervatio internodionm pedum parinm prini-terti permagna, plus tertiam ac prene dimidiam internodiorum partem occupans. Ungues permagni (quarti paris tamen parvi), duplices. Palpi brevissimi, basin internodii tertii pedum primi paris paulo superantes, gracillimi, hoc pari dimidio fere graciliores. "Opuli magui, rubri, distantes, in margine extremo corporis collocati. Longitudo 1,8 millim. (Tah. V, fig. 3.)

Kroppen är långsträckt oval, bakảt bredare, afrundad, frantill med en inknipning framför ögonen, mellan destmma tvär eller högst obetydlight convex. Benen tämligen korta; första paret ni̊got kortare än kroppen, fjerde at dennes längd, de tre första intemodicrua hesatta med några fí kortare hår, fjerde och femte deremot fürsedda med tvá rader langa hör a bojsidan, den ena raden bestaende af 6 à 7 gröfre, den andra af dubbelt si många längre och finare simhảr; a stricksidall ha dessa intemodier tya myeket kolta hår. Yttersta internodien af de tre früme paren är nästan ntan hår, nigot kolfformig, och ej kortare än nast füregiende internodie. Nest utmärkande für arten är. att den sncda fördjupningen för kloma, som hos üfriga arter och äfven los demua

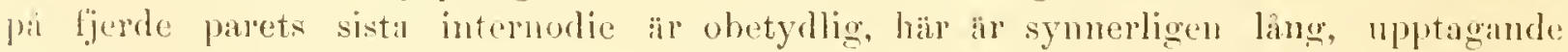

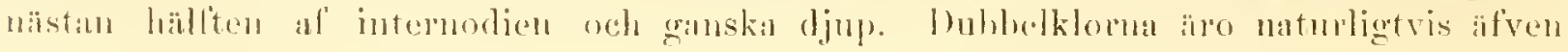


ovanligt stora, men deras grenar, som äro af samma längd som den öfriga delen, äro smala. Fjerde parets ytersta internodie jümntjock, klorna smi.

Epimerema upptaga nära $2 / 3$ af undre kroppssidan; första paret äro ovanligt långa, nästan jümnbreda, i yttre ändan frantill skarpt tillspetsade, i den inne, som strücker sign langt rerlanför labimm afrundade, afstandet frản labimm obetydligt, andra paret nästan lika lainga som första, smalt vigglika, genom ett obetydligt mellanrum skilda fiảu tredje paret, som nïstan äro lika smala, fjerde paret tre ginger bredare än tredje, med en lång, spetsig, bakît utskjutande process. Labium lang och smal. Palperna mycket korta, knappt nảende öfver basen af första benparets tredje intemodie och hälften smalare än detta par; andra leden äl kolfformig, försedd med 2 korta harr; tredje mycket kortare och smalare, med 2 hâr, fjerde linnz, lika ling som andra och tredje tillsammans, läilten smalare in tredje, pai undre sidan försedd med ytterst små, knappt synliga tänder cller knölar, men med tydliga laar, fente leden är lika lâng som tredje, smal och i spetsen tydligt treklufven. Mandiblernas corpus ling och smal, med den bakre kanten utlöpande i on kort, nästan räitvinklig spets; klon ganslia stark och mycket böjd. Generationsfältet: Springan, som börjar straxt bakom fjerde epimerparets inre lörn, är kort; skifvornas yttre konturer otydliga, deras bakre häft omgifves af' de utit och bakat riktade rundade fïlten med stigmer (omkring 20 till antalet). 'T'ill

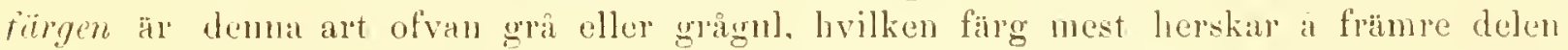
af kroppen, fläekame rödbruma, oftast tydligt skilda, rygastrecket ljusrödt; under är den främre delen grågul, den bakre grảorun, bakom generationsfältet ser man en ljusrüd fläck ongifvande anus. Palper och ben wrålnvitil, stundon stötande i blâtt. Jängl 1,8, bredd 1,3 millin,, första benparet 1,6, fjercle 1,8 millim.

Denna art anträffudes ej sällsynt $i$ en cistern vid sjette slussen á Göta kanal mellan Lyrestad och Sjötorp.

\section{Gemus 3. PIONA [C. L. Kóocn.]}

Syn. 1842 Piona C. I. Koch, Uebersielı tes Arachnidensystems, h. 3 p. 13.

Corpus laeve, molle, ovatum, altun, antice rotumbatum ant pene truncitum, postice panlo latius, utrimgue impressionc iustuctum, aut rotundatum. Pedes longioses, pari fere inter se crassitulinc, paria tria anteriorat pilis instructa raris, par quatum longis et densis, intermolis quarto at quinto allixis. L'ulpi buevioues, articule quarto longissimo et dentibus plerumque carenti, ad basin articuli quinti spina porrecta munti. Area genitules nox pone epimera pechm quarti paris collocata: Aperturi brevis, laminie mimus comspicuae. sligmatilus trinis instructic. Oculi magni, bini moiusque lateris plerumpue vix concreti.

1 min redogörelse för Gutlands och Ölands spindlar och vattemqualster ${ }^{1}$ ) yttrade jag, att jag länge tvekat upptaga de hithörande arterna under ett sibskildt slïgrte, dat

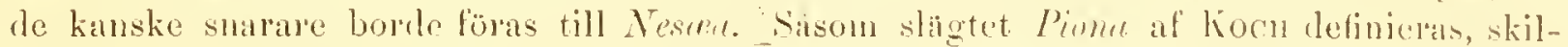
jande sig från Vesee blott genom den olika föpdelningen af de sil kallarle nliachen-

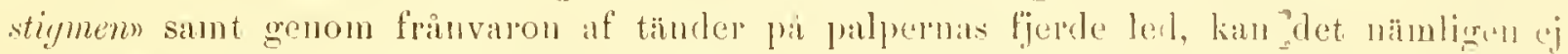

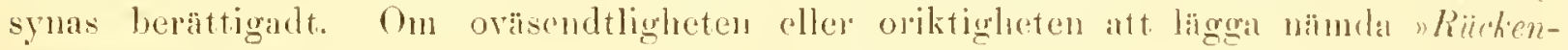

\footnotetext{
1) Ofversigt al Kongl. Vetenskapsakatemiens förlandlingar 1 है75 X:0 2, s. 111.
} 
stigmenn till grund för sägtindelningen har jag redan förnt yttrat mig. Att palporna sakna tänder, kunde synas vara ett battre skiljemärke, om ej det förhallandet inträffade, att vissa Nesca-anter ega så smá palptänder, att de blott vid mycket stark förstoringr kuma urskiljas, simnt att Piona abnormis äfven är försedl med dylika. Den vid spetsen uf fjerde leden sittande, framat riktade taggen, som stundom blì hälften sâ lång som femte leden, synes derenot vara egendomlig för detta slïgte. En amnan väsendtligare olikhet mellan Vesce oeh Piona visar sig i bildningen af deras generationsfält. Dessal hafva näınligen hos den sistnämda ungefär samma form som hos Limnexiu oclı Hygro-

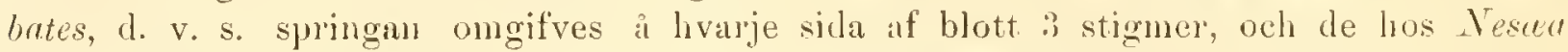
förekommande fälten med talrika mindre dylika saknas alldeles. De Nesaor man stmudom antraffar med blott två stigmes a ömse sidor om generationsspringan a a sasom jag redan nänt - larver i andra stadiet. I afseende pi vistelseort och lefuadssätt öfverensstämma arterna af slägtet Pionu med dem af slägtet Nesea, dock äro de fögra rofgiriga sunt mer tröga i sina rölelser än de sistnämda. Mellan könen synes cj Vara nảgon annan skiluad än den, att epincrerna hos hanch äro betydligt större än hos honan, oeh att de harda bakre parens ine ändar a kroppens midt nästan grainsa tillsammans. benen äro äfven i lörhâllande till kroplen letydlige längle än hos honim. Hunvida den egentomliga bihlningen af fjerde benparet hos $l$. mime $P$. almormis är ntmärkande för den utbildade hanen, eller blott för lanven i andral stadiet, kan jạn ännu ej afgöra.

De hithörande arterna kumna pá följande sätt indelas:

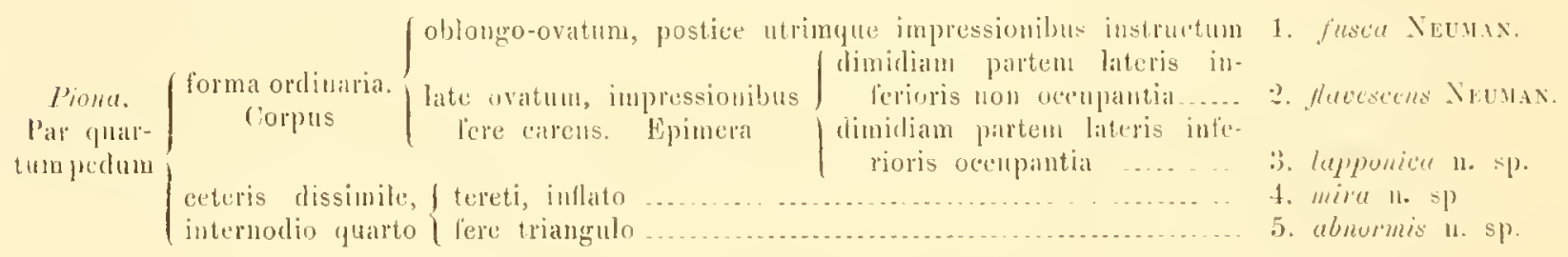

\section{Piona fusca Neuman.}

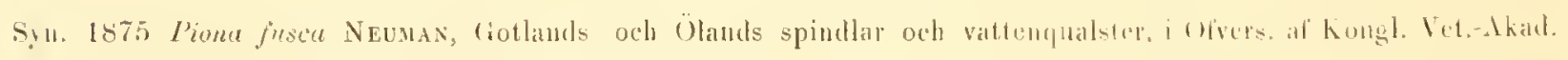
Förliandl. N:02, p. 101.

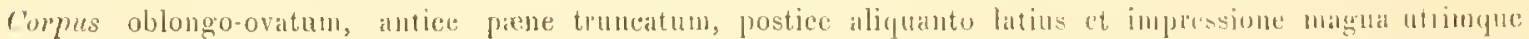
instructum, fulum, antice huteum, maenlis magnis nigro-fuscis confluentibus; limea dorsmalis plerumpur parum

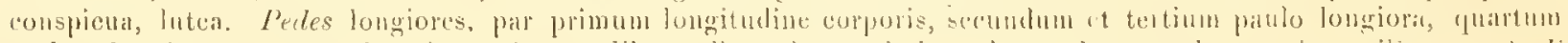
mult, longius. Palpi al apicem internolii tertii pedun primi paris pertinentes, hoe pani graciliores. Uenti magni, rubri, approximati, in malgine extremo copporis collocati. Longitudo 2 nillim. (Tal,. 111, tig. "2.)

Ilona: Kroppen ä langstrackt ägromis, i hakre kanten betydligt breclare än i frïune och törsedd med en stank intryckning ä ömse sidor; ej symerligen lı̈g. A

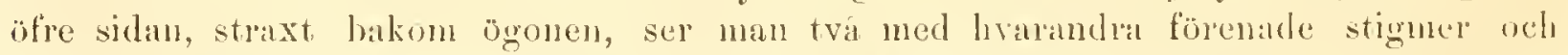
bakom ögronfläckarne stá fyra stigner, de tval frömme nämare lavarandra. Benen tänligen langa och starlia; första pantet ungefar af kroplens längl, andra och treclje föga längre, fjerde derenut betydligt lingle; sistat internodien a alla paren liop- 
tare än näst föregatende internodie; pá de tre fürsta parcu ar den obetydligt kolfformig, men visande en stor sned inskäming för de starka dubbelklorna; de bada framre paren äro besatta med glesa hår. andra paret med en knippa simhan vid yttersta internodien, tredju och fjerde paren likaledes, men dessa par lafva dessntom a fjerde och fente in-

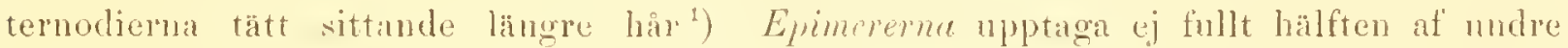
kroppssidan och ligga liksom lahinm langt ifrà yttre kloppskanten. Första paret langa och smala, nästan jämbbreda, andra paret smalt vigg̣lika, lảnga, mellanmunnet mellan detta par och tredje ej betydligt. 'Tredje paret linga, smala ocl jämubreda, fjerde $2^{1}{ }_{2}$ gang bredare än tredje, med hing, spetsig, bakat ntskjutande process. Labium in lang

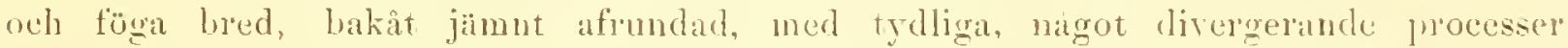
sant genom ett obetydligt mellanmon skilil fran första paret epinerer. I'alperno, som aro smalare an första benparet, na till spetsen af detta pars tredje internodie; andra leden är ling, tjock, not spetsen obetydligt kolfformig, och färsedel med nảgra fá korta och starka har. Tredjo leden mer än hälften kortare an andra af nugefür samma längd som höjd, och besatt med ett jal nagot lingere, stytia har. Fjerde leden lang och smal, af samua längd som andra och tredje tillsammans, frim midten till spetsen nagot tjockare, moler tillpattad mod en concavering, i hvillon den böjliga femte leden kan inläggas. A ledens midt, der dema börjar, sta tra mycket sma knölar, försedda med smalit, men tämligen langa lan: i ledens spets pa inpe sidan star en franatriktarl, parallelt med femte leden gaende tageg, nästan nânde till midten af nämde led; ofvan är fjerde leden fürsedn med flera, myeket kurta, smala hâr: f’ente leden, som är nästan lika lang som tredje, slutar med trenne spetsur och är försedd med nágra sura. ytterst fina har. Mumbliblernas corpus lang och smal med bakie andan trublerinklignt ntöpande i en lang, nen tänligen trublig spets; klon stark och ovanligt nycket böjd.

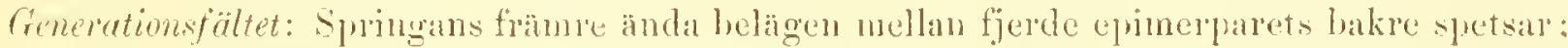
le tre stigmerna ä ömse sidor stora. Midt emellan dessa och bakkmten ligger anms och längre hakảt synes ả ömse siclor ett stignat. Till fï̈gen är den ofvan rödgul, framtill ljusgul, med stora, mülkbruna, sammanhängande flackar, upptagande stärve delen af rygen; det vanliga Y-formiga regrestrecket ä otydlignt, gult, veh of a blott antydt genom en störe triangulär fläck. Undersidan stöter i gratt, bakum epinnelel oeh senerationsfäl i brunt, med en jusqul eller gullöd tlïck, som omgifver anns.

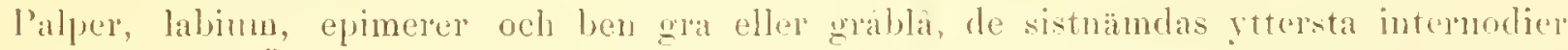

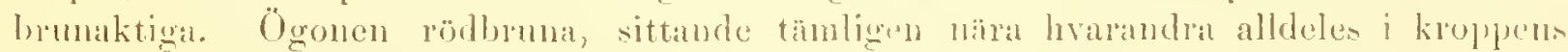
framkant. Länged 2, hredd 1,25, första lieuparet 2, ljerde 2,5 millim.

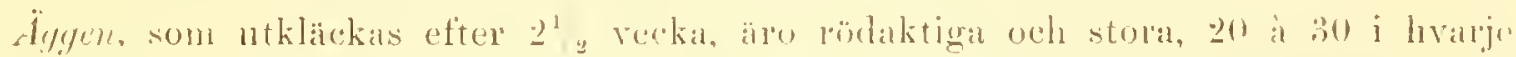

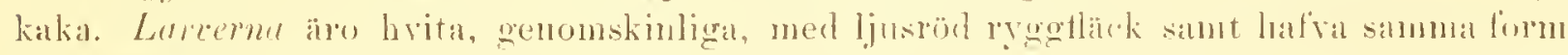
som Sesech-linverna.

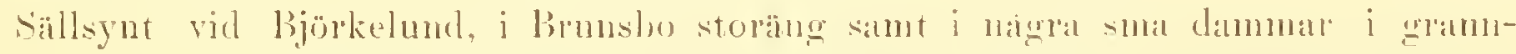
skapet af Skara. Gotland: Kinner, i ens. k, brya eller dam näria gëistgilvalegarden.

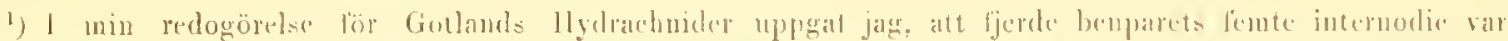

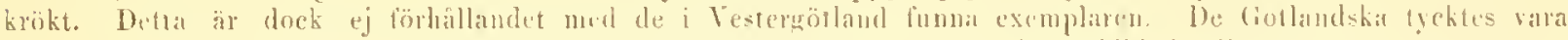
unga individ. mallanda $\mathrm{j}$ andra larlstadiet, luilhut alltid skiljer sig fran del utbildadu djuret. 


\section{Piona flavescens Neuman.}

Syn. 1875 Piona flavescens Neumas, Gotlands och Olands spindlar och vattengvalster, i Öfvers. af Kongl. Yel. Akad. Föliandl. N:o 2, ]. 10:.

Femina: Corpus ovatum, postice paulo lintiss et impressione minore puam apud speciem pracelentem utrimque instructum, fulvum, interlum fere album, maculis nigris vel luscis, plerumpue distinctis; finea dorsualis lutca. Pedes pro magnitudine corporis breviores quam itpud P. fuscam; par prinum latitudiucm corporis aequans, par quartum longitudinem ejus paulo superaus. Palpi brevores, ad basin internodii quarti pedum primi paris peltinentes, loc pari graciliores. Jongitudo 1,5-2 millim. (Tab. 11. fig. 1.)

Hone: Froppen är oval, ej synuerligen hög, framkanten tväiare afmudal in hos $l$. fused, bakkanten obetydligt bredare, ntan betydligare intryckning i sidoma. Bmen tämligen korta; första paree lika langt som kroppen ar bred, fjerde något längre än kroppen; intermodiema och hảen som hos $P$. fusca, de semare dock talrikare, isynnerbet sinharen, som här finnas pâ andra parets internodier och vid tredje och fjerde proms trenme sista. Eprmerema äro liksom labium belägna långt inăt och upptaga pá langt när ej häften af undre kroppssilan, hafva samma form som hos P. fusca, men mellanlummet mellan de olika grupperna ä störe. A mellanrummet mellan andra och trerlje paren star helt nära det förra ett tyelligt stigna. Palperna likna dem hos P. fuscu. Labium ä bredare i förhållande till längden än hos $P$. fusca, dess båda processer nästan raka. Handiblernas corpus kort och bred, bakat trubbvinkligt ntlöpande $\mathrm{i}$ en kort spets med stark concavering för musklernas füste; klon spensligare än hos P. fused, ej särdeles böjd. Cienerationsfälet liknar föregatende arts. Langt bakom detsamma ligger anus. och längre bort nära kroppens bakkint synas tvenne stigmer.

Till färgen äl den hrandgul eller gnlgra. stundom ljusare, nastan hvitaktig, i syunerhet i framkanten och ytterst a sidoma, med svarta eller bruma flickar, som oftast aro tydligt skilda, ryggstrecket ljusggult; undersidan ä gragul ned tveme mycket stora nörkbruna thackar bakom fjerde epimerparet; dussa omgifva en stor ljusgul, oval (ller korslik flack, i hvilken anus ligger. Labium, palper, epimerer och ben grả eller «råblaı.

Längd 1,5, bredd 1,1, palper 0,:, första benparet 1, 1, andra 1,4, tredje 1,5, fjerde 1, , imillim.

Mas. Corpus fere rotundatum, impressionibus postice carens; Pedes pro magnitudine corporis duplo

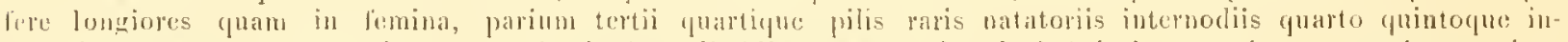
structi. Epimera multo majora yuam in lemina, dinidian partem lateris inferiuris corporis oceupantia, margines

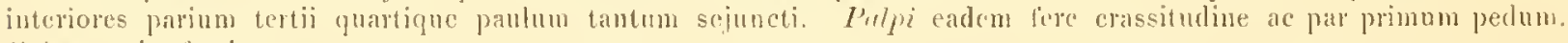
rolor ut in lemina. 1, i) millin.

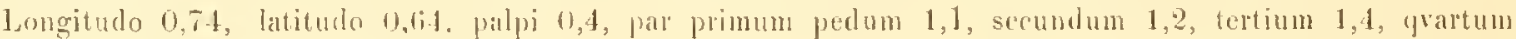

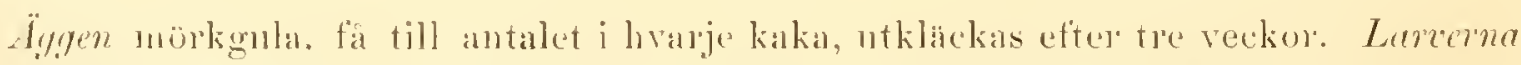

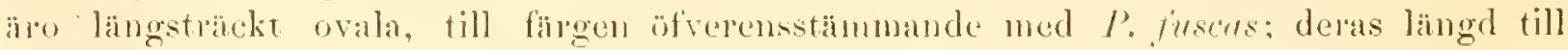
spetsen af rostrum 0,18, bredel 0,16, första benparet 0,18 , andra 0,19 , tredje 0,20 millim. l)ena art anträfas $\mathrm{i}$ dammar, hvilkas botten bestar af torfjord, och som äro väl för-

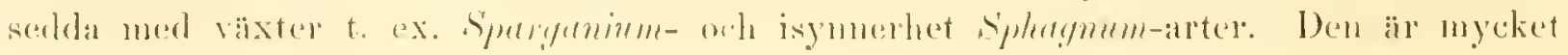


längsan i sina rörelser. Honan anträffade jag mycket allinän i en dann, vid Scunsholm i Vestergötand 1869 men följande iret var den alldeles förssmmen. Sillsynt förekommer den vil Hellstenitorp oeh Skilltorp samt i Brunsbo storäng (näral Skalra), der den beskrifne hanen äfven anträtits. l'a Gotland fanns den tämligen allnän i an danı vid kimner.

\section{Piona lapponica $11 . \mathrm{sp}$.}

Femina: Corpore coloseque P. Prefecenti simillina. Peales lougiores, par primum longitudine fere eorporis, quartum aliquanto Jongius. Fmimera majora, dinidian partem lateris infurioris corporis oepupantia. Pulpi longiores ad medium articuli fuati pedum primi paris pertinentes et hoc pari paullo crassiores. Longitudo 1,3 millim.

'Till form och fürg öfverensstämmel dema art myeket med l'. flavescens, men är dels ej obetydligt mindre, dels äfven $i$ anseende till henens, palpernas oeh epinemens längd och form ej litut afvikande. De förstnämda äro vida längle i föhallande till kroppen än hos $P$. flavescens orh afven spensligare sant fürsedda med tahikare hår. Epimererna, som stricka sig virla längre ut mot kjoppskanten, upptaga fullkomligt hält'ten af undre kroppssidan. I'ulperna äro betydlight längre och na till midten at första benparets fjerte internodie sant älo mgot tjockare cller atminstonc lika tjocka som detta par. Deu framstiende taggen vid basen af fente leden är högst obetydlig. Generationsskiferna äro korta och ganska breda; de trenne stigmerna a livaje sida mycket sma. Midt enellan dem och bakkanten ligger unus.

Liingd 1,3, bredd 1, palper 0,42, första benparet 1,2, andra 1.25, tredje 1,4, fjerde 1,8 millim.

Qvickjock allın̈n i kijren.

\section{Piona mira 11. sp.}

Corpus late ovatum, autice et postice rotumlatum, flavescens, maculis magnis nigro-fuscis conlluentibus; linea dorsualis Hava. Peles, tertio pari exeepto, longiores, internodium quartum pedum quanti paris teres, inflattum, pilis densis instructum, quintum apiee processum emittens. Pulpi breviores, ultra hasin intronodii quarti pelum primi paris pertincutes eorunque erassitudine. Omli magni, fusci. Longitudo 1,5. (Tab. Il, tig. I.)

Kroppen ä. bredt oval, frantill högst obetydligt afsmalnande, i båda ändarne jännt alrmolad. Benen utmärka sig isymerhet derigenom, att trodje paret är myeket kortale in de öfriga och af kruppons längd. Fjerde parets fjerde internodie är betyollight tjockare än de ofriga och har längs inre sidan en talrik mäugd utomordentligt sná stigmer sant ofvan dessal tiitt sittande lïngre har; $i$ dess spets synes ett gröfre hail. Fente intemodien, som är lungst, är snalast nagot äver midten sinnt slutar med en tämligen bred, nïstan trianguläl process på inre sidall. I)en är i symucrhet virl hada andarne försedd merl talloka längre hâr. S̈jette är krökt oeh har hott kortare hâr. H.

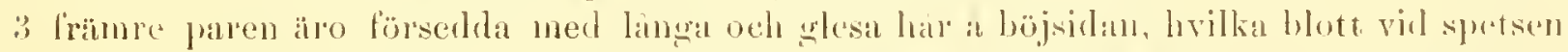

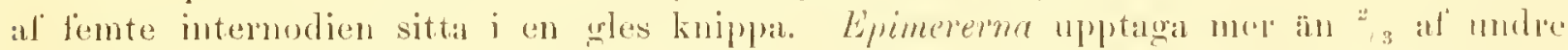

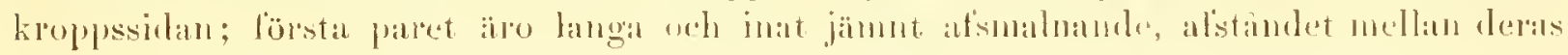


ince andar obetydligt, andra paret bredare och kortare, nastan viguformign, med en liten inbugtning at bake sidan. Afstandet mellan andra och tredje paren högst obetydligt: de sistümda äro nästan jämmbreda och betydligt större än andra. Fjerde paret nästan quadratiska, myeket stora. mer än dubbelt störe an tredje. Siviil tredje som fjerde palens inve ändar aro a kroppens midt atskilda genom ett lögst obetydligt mellanrum Labrum, som genom et obetydligt mellanrum är skild fran fömsta epinerparre är bakat jämnt afrundad, utan nagra processes. I'alperna, som äro lika tjocka som fürsta benparet na öfrer basen af dess fjerde internodie. Andra leden ir som vanligt tjockast och omkring ${ }^{1}$ g ging lingre än tredje samt försedd med ett par korta hâr. Tredje har tra korta wh ett langt har. Fjerde leden, som ar lika ling som de båda füregaende tillsammans, har blott tremne mycket fina hâ a modre sidan. Femte leden in liten och nhigot krökt; den vid basen sittande taggen al’ ledens halfva längd. Crenerationsfältrt. som ligger straxt bakom fjerde epimerparet, delas af en kort springa, som ej synes varn ongifren af särskilda skifror; i ömse sidor on densamma stå tre stürre stigmer. Mellan detta fält och kroppens bakkant sta tremne mindre stigmes, som utsända lival sitt linga har bakit; $\mathfrak{a}$ ömse sidor om dessa synes ett kortare hår och â sidan midt för groinsen mellan tredje och fjerde epimerparen ett dylikt.

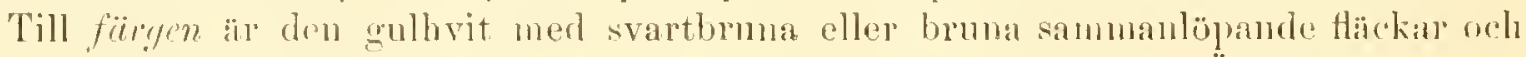

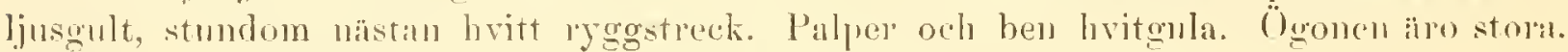
rödlıpma, de båda i livaje sida i rimga grad sammanräxta.

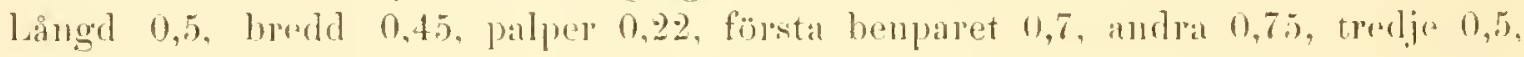
fjerde $(0,75$ millim.

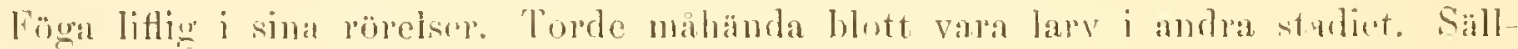

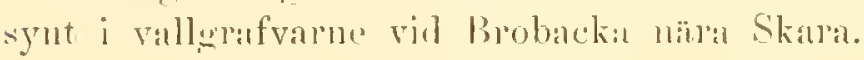

\section{Piona abnormis n. sp.}

Comms late oratum. antice et postice rotundatum, rubrum. Perles parium trium primorum forma ordinaria, pilis perraris instrueti, quarti paris forma insolitia: internodinm quartum hujus paris latissimum, lore triangulum. pilis lensissimis instruetum, fuintum longissimum, curvatum, Jatepe inderiore et apice pilis densis ornatum, sextum gracillimum, curratum, pilis parvis. Palpi broviores, al basin internodii guarti pedun primi paris pertinentes cormmque crassitudine. Oculi magni, fusci. Tong. 0.5 millim. (Tab. Vlll, fig. :3.)

Kroppen bredt oval, i bada ändarne afrundar. Benen äro sueeessivt tilltagande $\mathrm{j}$

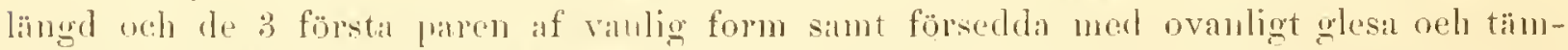
ligen korta lar, som ingenstides äro knippvis fürenade. Fjerle parets fjerde intermorlie hat en condomlig form. Den är nämligen nästan trianguläı, med triangelus trubliga spets riktal inat; liongs hela sträksidan orh vid basen af böjsidan sta talrika, myeket sma ringar eller stigner sant ytterst taita, langa och fina hâr, fente internodien in krökt inht och pa höjsidan fürserld med täta har, i spetsen sitter a strílksirlan ett tät knippe har, som är längre an sjette internodien. Denne ar utat höjl ocla har blott

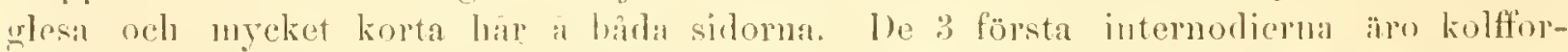

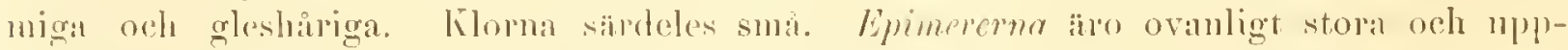

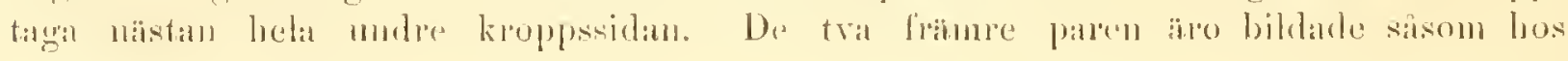


förcgíende art, tredje paret, som inat ej äro genom tydlig gräns skilda fran fjerde, visa it midten af bakre sidan en tvär inbugtning. Fjerde paret äro mycket stora och nästan rhomboidiska. Bada parens inre andar blott åtskilda genom ett mycket sunalt mellanrum. Labium är kort och lored sant utsänder bakat trenne raka, tjocka och trubbiga processer. Palperna, som ná till basen af fjerde internodien af första benpartet och äro af dess tjocklek hafvi andra leden mer än dubbelt större än tredje; à fjerde lerlens undre sida sitter en knöl, försedd med ett litet hâr sant a den öfre nảgra ytterst fina, korta hår. Generationsfültet, som ligger ytterst i kroppens bakre kant, visar en kort splinga, omgifven af trenne otydliga, rundade fält med tre stora stigmer a hrardera fältet. Bakom dessa sta trả korta hâr a ömse sidor. Till fürgen är denna art röd med palper och ben nâgot stötande i gult.

Langd 0,56 , bredd 0,48 , palper 0,30 , första bemparet 0,80 , andra 0,83 , trerlje 0,85 , fierde 1 millim.

len är liksom föregaiende art trög i sina rörelser och torde likaledes blott vara en larvform i andra stadiet.

Blott funnen några gånger $i$ en dam nảra torpet Lahall vid Skara.

\section{Genus 4. HIDROCHOREUTES C. L. Koch.}

Syn. 18.12 Hydrochoreutes C. L. Косн, Uebcrsicht des Arachnidensystcms, 1. 3, p. 16.

Corpus lave, molle, ovatum ant rotundatum (in $H$. mngulato f'ere sexaugulun!), parva altitudine. Pedes longissimi, par primum cornore plus duplo longius, cetera paria longitudine sensim crescentia, pilis raris natatoriis in internodiis $4-5$ parium $3-4$ instructa. Palyi longissimi, aut longitudinem corporis agvantes [H. ungulatus]. aut longiores, articulo secundo et tertio cadcm fere longitudine, quarto longissimo, dentibus carenti, articulis his omnibus pilis brevibus plerumque raris instructis, quinto paro, apice tridentato, pilis destituto. Area yenifulis in extremo margine corporis collocata (praterquan iu $H$. crucigero), laminæ ejus stigunatibus trinis instructe, in parte exteriore laminarum plerumque sitis. Oculi magni, distantes.

Sroppen är glatt och mjuk, oftast oval, stundom rund (hos H. mmgulatus nästan (b-sidig), af obetydlig höjd. Benen mycket linga och spensliga (hos $1 /$. ungulatus dock starkare), första paret mer än dubbelt längre än kroppen, de öfriga jämnt tilltagande i längd, de bada frïmre försedda med glesa, kortare hår, de bàda bakre med tätare dylika samt unycket glesa simhar vid fjerde och femte internodiema. Epimerema uptaga onkring $2 / 3$ eller mer af undre kroppssidan. Palpemuäro särdeles linga, åtuinstone af kroppens längd, andra och tredje leden naistan lika linga, fjerde längst, saknande tinder och taggar, rundad; alla med korta, glesa har, femte kolt och sinal, i spetsen mer eller mindre tydligt treflikig. Generationsfïltet, som är beläget länıst bort i bakre andan af kroppen (utom hos $H$. cruciger), delas af en kort springa; fälten eller skifvorna kring denna äro försedda ned 3 stigner, som vanligen ligga vid yttre kanten. Ügonen stora, ridt skilda.

Hithörande djur äro ganska sällsynta och fürekomma endast i klart ratten. I sina rörelser äro de lângsamma och lialla sig ofta med utspärrade ben liksom sväframle i vattnet, hvarefter de ìtertaga sin jämna ging utan att göra några snabbare sprang, såsom Atax crassipes. Da KoCH i sin karakteristik af detta slägte säger, att hanen i bakre ändan af kroplen eger ett rörligt bihang ("ein bewegliches Stielchenn), gäller 
detta knappast mer än för $H$. ungulatus, aiminstone har jag af $H$. jilipes anträffat forner, som antyda hanar, men som saknat detta bihang. Äfven tredje benparet har ej visat någon egendornlig bildning. Tre arter.

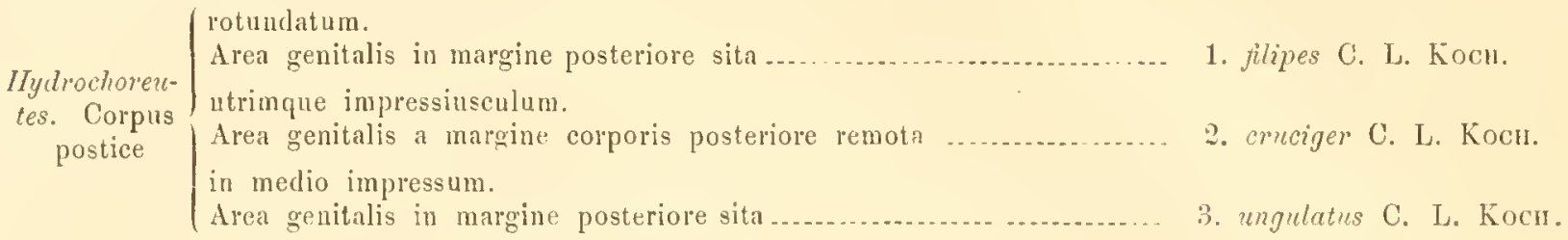

\section{Hydrochoreutes filipes C. I. KocII.}

Syn. 1835-41 Hydrochoreutes filipes C. L. Koch, Dentschlands Crust. etc., h. 11, fig. 14.

Corpus late ovatum, cano-finvescens, antice flavum maculis nigro-fuscis; linea dorsualis flava. Pedes longissimi, par primum corpore triplo cireiter longius. Palpi corpore longiores, pilis perraris instructi, ad apicem internodii quati pedum primi paris pertinentes et hoc pari paulo crassiores. Oculi magni, fusci. Longitudo 0,8 millim. (Tab. IV, fig. 3, mas.)

Hond. Kroppen är oval, i båda ïndarne jäınnt afrundad, tämligen hög. Benen inycket långa; fürsta paret omkring tre gånger längre än kroppen, särdeles smala ned sista internodien naigot kortare än de näst föregảende, ej kolfformig samt med obetydlign, sned afskärning för upptagande af de smi dubbla klorna. Epimerema upptaga oinkring $3 / 4$ af undre kroppssidan; första paret äro lânga och genom ett tämligen stort mellanum skilda från labinu; andra paret äro längre och inåt nîgot smalare, mellanrummet mellan detta par och tredje bredt, sistnämde par föga bredare ïn andra, inät trubbigt afsmalnande; fjerde paret stora, omkring tre gånger bredare än tredje med en betydlig bakåt riktad process. Labinm mer lingsträckt och med kortare, mindre divergerande processer" än hos följande. Palperna mycket hinga, lïnge än kroppen, samt abetydligt tjockare an första benparet, till hvars fente internodie de nästan nả. Andra, tredje och fjerde lederna äro försedda med glesa hår. Generationsfältet, som är beläget ytterst i bakre kanten, delas af en tämligen kort, springa, som sträcker sic bakat till kroppsanten och ar ougifven af tvenne breda, tydligt begränsade skifvor, af hvilka hvar och en vid yttre grränsen är försedd med tre stigmer, bildande en halfcirkel. Utanför dessa stå alldeles i skifvornas kant flera betydligt mindre stigmer, hvart och ett försedt med ett fint hår. Bakom det längst bakảt belägna af de större stå. fyra smả dylika med hairen bakit riktade och tydligen synliga utanfür kroppens bakkant. Hela generationsfültets bredd är störe ün dess lähgd. Färgen är hos denna art å öfre sidan gulgrả, framtill gulare med mörkbruna eller svartaktiga, oftast sammanlöpande fäckar; ryggstrecket gult; undersilan ä̉ grâgul eller grảhvit med tvả mörkbruna flïckar ả bakkroppen, hvilka omsluta en ginl. Palper och ben griognla eller gråhvita.

Längd 0,8, bredd 0,7, palper 1,1 första penparet 2,2, fjerde 2,4 millim.

Hanen, som blott en ging anträffats, skiljer sig frỉn honan, genom samma skiljemärken som hos Pionn.

Högst sällsynt i Venern, Vettern samt Hẹde träsk pẩ Gotland. 
KONGL, SV, VET. AKADEMIENS HANDLINGAP. BAND. 17. N:O 3.

\section{Hydrochoreutes cruciger C. l. Kioch.}

Syn. 1835-41 Hydrochoreutes cruciger. C. L. Kocri, Deutschlands Crust. etc., J. 11, fig. 15.

Corpus oratum, postice paulo latius, utrimque impressiusculum, altissimum, albo-flarum, maculis nigris ant tuscis, liaud magnis, conflueutibus, linea dorsuali flava. Pedes breviores quam in specie pracedenti, par primum corpore duplo longius, cetera paulation lougitudine erescentia, omuia paria pilis raris instructa Palpi longitudine corporis, graciles, ad basin iuternodii quinti pedum primi paris pertinentes et crassituline hujus paris; articulus quartus pilis densioribus instructus. Oculi magni fusci. Lougitudo 1,5 millim. (Tab. IV, fig. 2.)

Hond: Kroppen är mycket hög, isymerhet bakiat, bredt oval, framtill föga smalare, afrundad; bakkanten försedd med en obetydlig intryckning å ömse sidor. Benen i förhallande till kroplen kortare in hos föregâende art, första paret ungefär dubbelt längre, än densamma, de öfriga smâningom tilltagande i längd, försedda med korta, glesa hår å sträcksidan samt längre och tätare a böjsidan, isynnerhet a fjerde och femte internodierna; den yttersta internodien å alla benparen, som är obetydligt kortare än näst föregående internodie, är ej kolfformig utan afsmalnande utảt. Klorna äro mycket små, och fördjupningen, i hvilken de nedfüllas, nästan rundad. Epimerema, som upptaga något iner än hälften af undre kroppssidall, hafva första och andra paren ungefür saisom hos füregảende art, det sistuäuda paret visa à bakre sidan trenne starka concaveringar, fjerde paret äro deremot i förhâllande till tredje mycket smala, ej ens dubbelt bredare, med den bakât utskjutande processen trubbig och obetydlig. Labium bredt hịiptlik med divergerande processer. Mandiblemas corpus kort och bred, bakît trubbvinkligt förlängd i en kort spets, med stor, men föga djup concavering pa undre sidan för musklernas vidfästande. Palperna äro af kroppens lüngd och nå till basen af första benparets femte intcrnodie samt hafva samma tjocklek som detta par; fjerle leden ä å undre sidan försedd med talrika, tämligen långa hår samt nâgra fả kortare â öfre; andra och tredje lederna hafva blott några hortare liår å öfre sidan; femte, som har trà små fina hảr $\mathrm{i}$ spetsen, är mycket smal och krökt â midten. Generationsfältet, som hos dema art är tänligen lảngt beläget från bakre kroplskanten, delas af en ej särdeles lâng springa, omgifven af trenne tämligen breda, framtill smalare skifror med tre mycket små nästan i en rad stälda stigmer i yttre kanten; franför och mellan dessa sta trenne betydligt mindre. Hela generationsfältets längd är större än dess hredd. Vidt emellan detta fält och bakkanten ligger anus. Tiłl färgen ar arten gulluvit med de mörkbruna eller srapta fläckarme sammanlöpande: kring det gula lyggstrecket; undersidan gulbrit med tvenne mörkbruna fäckar bakom generationsfältet; anus ougifves af en gul fläck. Lahimu, palper, epimerer och ben grâgula. Ögonen stora, mörkbuma. Längd 1,4, bredd 1,1 , palper 1,3 , första benparet 2,2 , fjerde 2,4 milliw. (Full af äger.)

Hanens dimensioner: längd 0,9 , bredd 0,7 , palper 1.3, första benparet 2, 2, fjerde 2,4 millim.

Äggen ljusgula, runda, 40 a 50 i hvarje kaka, utkläckas efter 3 veckor. Larerna äro nüstan püronformiga med mycket nedtryckt rygg, liroppsbetackningen chagrinlik, färgen gulgrön med gulbruna rygeflackar, bakom hrilka en stor, nästan rund, hrit fläck stâr. Kroppskanten är rundt omkling försedd med hâr, af hvilka de bakom ögonen och i bakkanten stiende äro längst. Ögonen stora rödbruna, de båda à hvarje sida 
tydligt skilda. Längd 0,24 bredd 0,16 , tredje paret 0,20 , de båda üfriga obetydligt kortare.

Ej så sällsynt i klart vatten på ringa djup. Veneru, Vettern, ¿sunden samt i Vingsjön och bäcken vid Brobacka nära Skara.

\section{Hydrochoreutes ungulatus C. L. KocH.}

Syn. 1835-41 S'pio ungulata C. L. Kocn, Dentschlands Crust. etc., h. 5, fig. 17.

1842 Hydrochoreutes ungulatus C. L. Косн, Uebersicht des Arachnidensystems h. 3, p. 17, Tab. 11, fig. 6 .

Corpus fere sexaugulum, angulis valde obtusis, autice truncatum, in medio maroinis postici impressione permagna preditım, in qua area genitalis collocata est; flarescens maculis rubro-fuscis; linea dorsualis lutea. Pedes longiores; par primum corpore duplo et dimidio longiores, robustiores quam apud species præcedentes; par tcrtium intcrnodio quarto apice dilatato et tripartito, parte exteriore brevi, internodium quintum gerenti, parte interiore spina armata magna paulum curvata; parte superiore maxima, curvata, in apice suo interiore spina magna ad basin valde curvata, in apice exteriore spinis duabus minoribus instructa. Palpi longitudine corporis, ad apicem internodii quarti pedum primi paris pertinentes et hoc pari paulo graciliores. Oculi rubri. Longitudo 0,5 millim. (Tab. IV, fig. 1.)

Kroppen är nästan sex-sidig, med mycket trubbiga hürn, lika bred soun lảng, finukanten trär, i bakkantens midt en bred fördjupning, i hvilken generationsfältet ligger. Benen ganska langa; fürsta paret $2 \frac{1}{2}$ winger längre än kroppen, starkare än hos de baida föregiende arterna, deras yttersta internodier af sannma längd som den näst föregâende, men betydligt smalare, klorna mycket smả och den sneda afskärningen, i hvilken de indlagas, således också obetydlig, nästan rund. Särdeles egendomlig är bildningen af tredje benparets fjerde internodie. Denna är nämligen i spetsen vidgad och liksom delad i 3 arıar, af hrilka den inre och yttre äro korta och ungefür lika långa, den öfre deremot betydligt lïngre. Från spetsen af den yttre armen utgår fente internodien, från den inre en lang, styf och något böjd tagg. Den öfre armen är lika lång som själfva internodien och tjockare än femte, är i spetsen på inre sidan försedd med en stor klo eller hake, som vid basen är halfcirkelformigt böjd, men sedan rak och af samma längd som själfva armen; i spetsen pầ yttre sidan synas tvenne obetydligt krökta taggar. De tvà fräınce benparen äro försedda med korta, styfva och glesa hil", den yttersta internodien med längre, tätare samt finare dylika; tredje paret med aimmu glesare hår, i spetsen af femte internodien stâs en knippa korta simharr, ordnade i en rad, sista internodien såsom hos de föregående paren. Fjerde paret har tätare, kortare hår på böjsidan af internodierna samt vid slutet af fjerde och fente internodierna knippvis sittande längre simhair. Epimerema upptaga $\frac{2}{3}$ eller nagot mer af undre sidan, de bâda första paren äro lánga och smala, fürsta paret blott genom ett obetydligt mellanrum skilda fran labium och ned inre ändarne riktade nästan rakt bakât; mellan de yttre andarne af detta och följande par ett taumligen stort mellanrum. Tredje paret granski breda, skilda frản det andra genom ett lika bredt mellanrum som nellan fjerde parets båda inre ändar. Detta sistnämda par ej dubbelt störe än tredje, med en bakåt utskjutande, trubbig process. Palperna, som äro af kroppens längd, nå till spetsen af första benparets fjerde internodie sant äro obetydligt smalare än detta, för öfrigt 
liknande dem hos $H$. filipes. Generationffïltet, som ligger i den ofvamärnda fördjupningeu i kroppens bakkant, visar en ovanligt bred, frantill rundad springa, son nagot bakom midten afsmalnar och sedan iter ridgar sig. De omgifvande fülten, som fruntill äro betydligt afsmalnande och förenade frumför springan, aro försedda med treme i rad stiende stigmer, som bakât tilltaga i storlek. Bakom springan synes en utskjutande, kort, uppat riktad spets, som vid närmare undersükning utgüres af treme, af hvilka den mellersta är nästan jümnbred och med trubbig spets, de bada yttre med bred, nästan triangulïr bas och starkt tillspetsade. Dennit spets synes tydligt, dia man betraktar djuret frin üfre sidan. A ömse sidor om densamma synas a molre sidan 5 a 6 korta och mycket fina hảr. Fägen ïr hos demna art gulhrit ned stora röd- eller svartbruna flackar och gult ryggstreck. Ögonen röda. Undersidan har treme bruna fläckitr å bakkroppen samt en gul, omslutande generationsfültet. Palper och ben hritgula. Lüngd, bredd oeh palper 0,5 , första henparet 1,3 , andra och tredje $\mathbf{1}, 4$, fjerde 1,6 millin.

Denna egendomliga art ür af mig blott antrüfud vid Brobacka nära Skara. vid ofvergàngstälet till Stenum, der den ä mycket sällsynt.

Gems 5. HYGROBATES C. L. Kuch.

syn. 1835-41 Hygrobates C. L. Kocm, Dentschlands Crust. ete., b. 10.

1842 - id. Uebersicht des Arachniclensystems p. 14.

1851 - Bruzelưs, Beskr. ö. Hỵdrachn., som förek. i skåne p. 27.

1871 Cumpognatha Lebert, Hydrachnides, Bulletin de la Soc. vaud. des Sciences naturelles t. MIIl, $\mathrm{N}: 07:$, p. 67 (ad partem).

Corpus lave, molle, altum, subrotundum. Peles longiusculi, pilis natatoris fere carcntes. Epimera perlum primi paris cum parte posteriore labii commata. Palpi longiores, articnlo secundo apice multo latiore ibique in latere interiore deute vel spina obtusa armato, tertio panlo breviore, utroque articulo pilis brevioribus instructo, quarto longissino, dentibus carenti, quinto brevi, acuto. Area genitulis modium tenet inter cpimera pedum yquarti paris et marginem posticum corporis; lamina semilunares, stigmatibus ternis, nagnis ormatæ.

Detta slagte skiljes derigenom ]ät froin öfriga, att första paret epinerer äro med bakre delen af labium och sinsenellan sâ sammanvuxna, att ingen gräns synes. Kroppen är glitt och mjuk, myeket hög och nästan liki hred som läng. Benen tämligen langa; första paret af kroppens längl eller lüngre, alla förseclda med korta har jünte nagra furre längre, i symerlet a de bada bakre parens fjerde och fente internodier; de vanliga simharen saknas deremot; yttersta intemodien af alla paren smalare och kortare än näst föreqiende internodie; klorna dubbla, obotydliga. Epimerma, som hos detta slïgte bilda blott tre grupper, upptaga omkring hälften af undre kroppssidan. Palperna äro langa med andra leden not spetsen betydligt bredare och pai inre sidan försedd ined en tydlig tand eller trubbig tagg, som ïr rïtt utat riktad. ') 'Tredje led('n

1) Eget nog synes detta skiljemärke alldeles undgitt den skarpsynte prol. BRuzeLı uppmärksamlet, hvilket jag endast kan förklara deraf, att de exemplar, han unctersökt, ej voro fullbildade. Hos larverua i andra stadiet lörckommer nämligen lenua tagg ej. Lpimerermas sammanvïxande omnämner lan först vich artheskrifningen af $I I$. rotundatus. 
nästan lika lâng, men något smalare, fjerde lång, knappt hälften så tjock som tredje, rundar samt sakuande tänder, femte kort, i spetsen otydligt delad. Generationsfältet, som är beläget midt emellan fjerde epimerparet och kroppens bakre kant, visar en tämligren lång och bred springa, orngifven af tvenne halfmånformiga skifvor; de tre stigmesna à hvardera skifvan äro myeket stora och upptaga nästan hela skifvan. Ögonen äro stora och vidt àtskilda.

Hithörande djur simma stundom rïtt snabbt, oaktadt bristen på egentliga s. k. simhår, men krypa oftast oukring på bottnen af det kärl, hvari man förvarar dem, då de bâda sista paren släpas efter ntan att det minsta bidraga till rörelsen. ${ }^{1}$ ), De uppehålla sig mest i klart vatten. Nỉgon skilnad könen emellan har jag icke fumnit. KocH säger hanen vara mindre och hafva längre ben. Af detta slägte har jag funnit tvenne arter.

\section{Hygrobates rotundatus C. L. Kо оcH.}

Syn. 1835-41 IIygrobates rotundatus C. L. KocH, Dentschlands Crust. h. 10, figg. 15 och 16.

1854 - - Bruzelius, Beskr. ö. Hydrachn,, som fölek. i Skảne, p. 38, tals. IV, fig. 1.

Corpus subglobosuın, fusco-flavescens maculis fuscis; linea dorsualis flavescens. Pedum par primum corpore paulo longius, secundum et tertinm eo paulo longiola, quartum multo longius. Epimera quarti paris fere quadrata, intus paulo angustiora, angulis obtusis. Palpi longiores, ad apicem internodii quarti pedum primi paris pertiuentes, hoc pari multo crassiores. Longitudo 1,8 millim.

Eroppen är myeket hög, nästan halfklotlik. Benen medelmâttigt långa, alla af ungefür samma tjoeklek; första paret något längre än kroppen, de trå följande paren obetydligt längre, skilnaden mellan tredje och fjerde deremot störst; alla äro försedda med mycket glesa hat', som vid lederna äro längst. Epimerer och palper såsom uppgifvits vid slägtkarakteren; de senare af kroppens halfva längd oeh försedda ned några fá korta hår å andra och tredje ledens öfre sida samt några fá, mycket fina, i fjerde ledens undre sida. Labium. tämligen bred, med tvenne korta spetsar i midten af främre kanten. Mandiblerna hafva en myeket lång, bakìt afsinalnande och föga nedåtböjd corpus, med stor concavering för musklernas fäste; klon stark och halfeirkelformigt böjd. Generationsfältet: Springan, som ä] tämligen lång, är frantill och baktill begränsad af tydliga tvärspringor; de oungifvande skifvorna äro halfmånformiga, tillsammans bildande en bredt hjertlik figm ${ }^{2}$ ); å deras yttre sida stá tre stora, ej ringformiga utan elliptiska eller oregelbundna stigmer, som ino nycket större än hos Piona och här upptaga nästan hela generationsskifvorna; den främsta är vanligen längst, framåt afsmalnande och stötande intill främre andan af generationsspringan. Alla tre äro omgifna af

1) Den i Schmeiz i Genever sjön förekommande H. Foreli (Campognatha Foreli, LeBEnT) är mycket tıög i sina rörelser och synes kuappast kunna höja sig från bottnen upp till ytan af ett några tum djupt vatten. Lefvande cx. af deuna art hafva gorlhetsfullt tillsändts mig af Prof. Forel i Morges.

2) Bruzeluus sïger, att dessa skifvor äro korta och tillsammans bilda cn rund figur. Hos intct af de många exemplar, jag laft tillfälle att unclersöka, har emellertid detta varit fallet, utan hafva alltid skifvorna visat den form, som ofvan uppgifvits. 
andra, mycket små, stigner. Hela generationsfältet mer bredt än lảngt. Midt emellan bakre indan af generationsspringan oeh kroppskanten ligger anus.

Färgen är hos denna art ofvan gulbrun med svartbruna eller srarta fläekar, rygostrecket mörkare. gulbrunt; undersidan är ljusare med trá mörkbruna fläckar bakom fjerde epimerparet, som onsluta en gulaktig flïck. Palper och ben hritgula, stundon dock mörkare.

Lïngd 1,8, bredd 1,6, palper 0,9 , fürsta benparet 1,85 , fjerde 2.1 millim.

Aggen stora, ljusgula, nästan hrita, lïggas i talrika kakor, merendels 50 a 60 j hvarje kaka. Larverna, som utkläckas efter fyra veekor, äro smalt ovala (Längd 0,30, bredd 0,16 millim.), genomskinliga, blâgrả, ned ljusbruna ryggfläckar sant en stor, hrit fläck a bakkroppen, hvilken är försedd med tvâl langt utskjutande, koniska knölar, försedda hvardera med ett borst af nästan samma längd. Ögonen mycket storà, svartbruna.

Ej sällsynt j sjöar och âar i Vestergötland, i Skâne allmän, enlig̣t Bruzclius, pả Gotland blott anträffad $\mathrm{i}$ en à vid Närs plestgârd.

\section{Hygrobates impressus n. sp.}

Corpus late ovatum, autice inter oculos impressiusculum, postice paulo latius, rotundatum, flarescens maculis fnscis; linea dorsmalis fusco-flava. Pedes, in primis par quartum, pro magnitudine corporis longiores quam in specie pracedenti, palpi autem breviores ad basin internodii quarti pedum primi paris pertiuentes. Oculi magni, rubli, Longitudo 1,4 millim. (Tab. IV, fig. 4.)

Froppen är bredt oval, i frümpe kanten nigot afsmalnande och med en obetydlig intryekning mellan ögonen, ej sa hög som hos föregảende art. Benen i förhảllande till kroppen vida längre. fjerde paret nagot smalal’e än de öfriga och betydligt längre än det tredje, ungefär lika lảngt som kºppen och palperna tillsammantagna. Palperna äro kortare ä halfva kroppsängden oeh nỉ till basen af första benparets fjerde internodie. Generationsfiallet: Springan ar kortare och de henne ongifrande skifroma smalare; vid hennes bakre gräns, som liksom främre saknar tvälspringor, stâ trenne korta hâr; stigmerna si̊som hos föregitende fart. Till fürgen äl den gulhrit med ljus- eller mörkbruna fläckar och mörkgult eller gulbrunt ryggstreck. Ben och palper wrígnla. Ögonen stora, rödaktiga. I Vestererötland i sjöar i Valle härad tillsammans med $H$. rotundatus, men vida sällsyntare. Mahändä är den blott andra larrstadiet af denne.

\section{Genus 6. MEGAPUS n. ‥}

Corpus lreve, molle, fere rotundatm, parva altitudine. Pedes a primo pari ad quartum crassindine decrescentes, pilis rarissimis brevibusque instructi, par primum scendo et tertio longins, quartum longissimum. Epimera parium primorum longissima, in medio curvata, infra labium approximata. Palpi breves, ad basiu internodii quarti pedum primi paris pertinentes et hoc pari duplo graciliores, pilis raris instructi, articulo secundo brevi et crasso, tertio nulto longiore et graciliore, quarto longissimo, inflato, quinto perparvo, murvato, for mugiformi. Area genitalis fere nt in genere Piona. Oculi magni, mediocriter distantes. 
Kroppen ir nästan rund, af ringa höjd, glatt, med mjuk kroppsbetäckning. Benen utmärka sig isynnerhet genom längden af första benparet, hvilket är längre än bade andra och tredje samt i tjocklek betydligt öfverträffande de öfriga paren, som blifva allt smalare samt sakna egentliga simhảr; första parets näst sista internodie är längst och tjockast, nästan kolfformig oeh mot spetsen räinnformigt urhalkad för upptagande af sista internodien, med hvilken den bildar ett slags griporgan, nästan såson hos Nepa. Vid slutet af den rännformiga urhálkningen stảr en nagot utåt och franât riktad grof och lang tagg, som vid stark förstoring äfven synes ränformigt urhalkad, och någrot lïngre utât på inre sidan en bred, nästan spjutlik dylik tagg; i spetsen af internorlien sitter på inre sidan ett langt, fint, hakformigt nedatböjdt har; sista internodien, som liksom hos de öfriga paren är kortare än de báda näst föregående internodiema, är smal sant något krökt och kan, som nämdt är, infühlas mellan de båda gröfre taggarne $\mathrm{i}$ den rännformiga fördjupningen. Första paret epiméper ïro ovanligt langa och smala, a midten nagot krökta samt löpa nästan tillsammans under labium, andra paret bredare men nagot kortare, öfrergå ned sina inre konturer omärkligt i kroppshöljet; mellanrummet mellan andra och tredje paren lika bredt som tredje paret, hrilka äro nästan rektangulära, smala, utît dock nagot bredare och tätt slutande sig intill de nästan tre-kantiga af fjerde paret; dessa äro som vanligt störst, nästan lubbelt större än tredje. De båda sistuämda parens inre ändar åtskiljas genom ett ovanligt bredt mellanrum. Labium, som genom ett obetydligt mellanrum är skildt från första paret epinerer, är långsträckt och nästan fem-sidig, bakảt afsunalnande, utan spår till utskjutande processer. Under den mot fräınre kanten belägna runda munöppningen synes ett särskildt smalt, nästan ovalt stycke. Palperna äro smala, nå till basen af fürsta benparets fjerde intemodie; andra leden kort och tjock, tredje nästan dulubelt längre men betydligt smalare, båda med glesa här på üfre sidan, fjerde längst nästan spolformig, med nigra glesa, fina hår a undre sidan samt ett gröfre; femte kort och krökt, slutar med en tvåtandad spets; vid dess bas stå å öfre sidan två korta fina hår. Generationsfältet, som ligger något närmare fjerde paret epimerer än bakre kroppskanten, delas af en kort springa, omgifven af tvemne halfmanformiga skifvor, bakom hrilkas yttre grüns trenne stigmer synas a hvarje sida. Midt emellan generationsfültet och bakre kroppskanten ligger anus; a hvardera sidan deron synas nära kroppskanten tvenne mindre stigmer, af hvilkal det yttre är störst oeh bakom fjerde epimerparer ett dylikt.

\section{Megapus spinipes n. sp. ${ }^{1}$ )}

Albo-flavescens in margine pellucidum, maculis flavo-fuscis; stria dorsualis lutea. Longitudo 0,75 millim. (Tab. I, fig. 4.)

Till fürgen äl den ofvan grá- eller hvitgul, nästan genomskinlig, med stora, gulbruna Hackar och mycket stort, ljusgnlt ryggstreck, som frantill utsinder tvenne armar a hvarje sida; fräıre delen af kroppen är nästan hvit, med en brun fläck, mellan

1) Synes i afseende pi̊ första beuparets form öfverensstämma med Atractides spinipes C. L. Kocr, men afviker derigenom, att stemaldelen ej är framstående, kroppen är rundad samt palperna vida kortare än hos detta slägte. 
oggonen. Undersidan ä hritaktio med brumaktiga fläckar bakom fjerde paret epinerer. Kring generationsfältet synas nästan radiert utgiende smala, gulhvita streck. Sjelfra öppningen ljusröd. längd 0,74, bredd 0,66, palper 0,30, första benparet 1, andra 0,80, tredje 0,90 , fjerde 1,2 millim.

Sällsynt $\mathrm{i}$ an vid Lyrestad och Fiftlered samt i Tingsjön i Vestergötland.

\section{Genus 7. MIDEA Brezelius.}

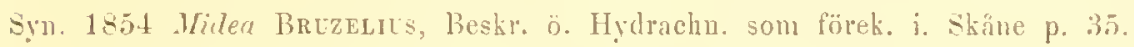

Corpus granulatum, durum, late oratum vel subjotunlum, in margine pilis raris instruetum. Porles breviores, duo paria anteriora pilis raris brevibus, duo posteriora pilis longissimis uatatoriis, internodiis guarto quintoque affixis, instructa. Elimera omma approximata, non iuter se concreta, scutum pectorale permagnum fommitia. Pulpi longiores, artirulo securdo et tertio crassis sed luevibus, eadem fere longitudinc, quarto longo, attemato, quinto parro, acutiusculo, secundo-quarto pilis maris instructis. renli satis approximati.

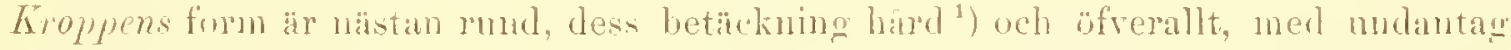
af genitalskifroma, mycket fint granulcrad. Benen äro af obetydlig längel; första pareet kortare än kroppens bredd, fjerde än dess längd, de bada sista frapen vid spetsen af fjerde och fente internouliema med oranligt linga simhits. Epimeremu bildat lins detta slagte jnga skilda grupper utan äro alla belägna tätt intill hrarandra, äro rätt stora och npptaga nâgot mer än hälften af den undere kroplssiclan. Första paret äro under labinm oftast sa förenade, att grämses dem mellan är ytterst svar att mpptäcka, fran labium deremot ino de allid skilda genom ett tydligt mellammm. Fjerde paret ino stora, nästan triangulära och af nngefär samma bildning som hos Limneria C. L. Koc.H. dock med den skiluad, att benen äro fustade vid len ofre yttre vinkeln, hos Limmexin vid den undre. De yttre vinklarne eller hörnen är, bär inyeket trubbiga och afrundade. Palpema tiimligen linga, andra och tredje lerlena korta och tjocka, af nästan samma längd, fjerde lang, längre än rle bada föregánde tillsammans, men betrdligt smalare, jämnt afrundad och ntan tänder, femte är kort och tillspetsald: i spetsen otyolligt delad. Ögmen merleluattigt stora. ej symerligen langt skildä).

Nagon skilnad könen emellan kan ej upptackas. Tag hat antriffat den i copnlation, men det oaktadt kunde mellan re bada individen ej den ringaste olikhet märkas.

\section{Midea orbiculata (MÜLLeR) BruzkLits.}

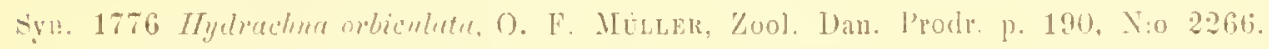

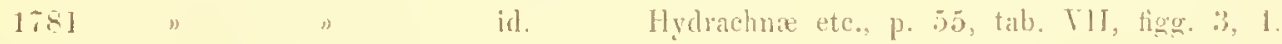

1793 Trombidium orbiculatum, J. C. Fabricius, Entom. syst. II. p. 105, X:o 3011.

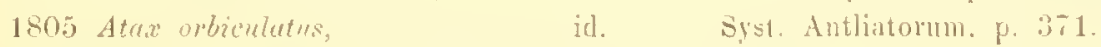

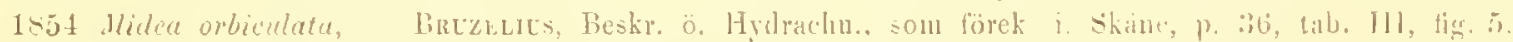

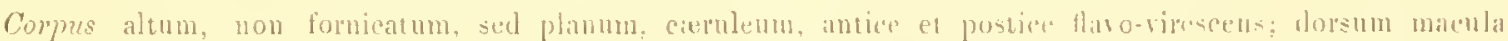
fusca, solea lerrese equine simili, ormatum, cujus pars anterior magna manla flava in duas divilitur: in

1) Alla föregatiende arter hafva mjuk kroppsbetäckning.

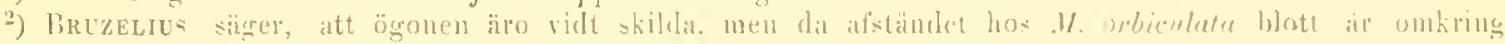

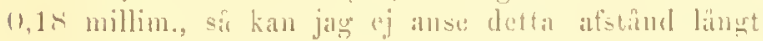


dorso duodecim stigmata, duas series lormantia, quorum sex exteriora pilis longis, sex interiora pilis brevibus, rix conspicuis, instructa sunt. Color magnopere variat. Pedes breviores, par primum latitudine corporis brerins, par quartum paulo longins, robusti, iuternodiis quarto quintoque pedum tertii quartique parium pilis natatoriis, internodiis duplo longioribus, instructis. Pulpi longiores, ad apicem articuli quarti pedum primi paris (ultra medium paris) pertinentes, collemque graciliores. Oculi prope marginem corporis siti, rubri, satis approxiuati. Longitudo 0,75 millim, (Tab. XI, fig. 1.)

Kroppen äl bredt oval, nästan rund, hög. men med platt rygg; den skarpa kant, som genom denna trära afplattuing uppkommer, synes under mikroskopet genom en syurilla sasom en intryckt linea (jfr. Bruzen heskrifning). I bakre kroppskinten synas tvả hål, som äro fästade pát undre sidan sant ả hvarje sida fyra mindre. Framför och bredvid hvardera ögat sta trenne mycket korta hâl. A ryggen synas $12^{1}$ ) stigmer i trenne rader länga kroppen, de tre yttre à hvarje sida med längre, de tre inre med korta, knappt synliga har. Benen aro korta och starka; den yttersta internodien ar kortare än den näst föregaende och a de tre första paren i spetsen nagot ridgad; fördjupningen för kłornas emottagande oval, liten; de duhbla kłorna, i synnerhet it fjerde benparet, smá, simbaren i spetsen af fjerde och femte internodierna a de trai sista paren än oranligt langa. omkring dubbelt längle än internodierna. Epimeremu. äro ganska langa; de tra frïusta paren nästan jämnbreda, andra paret nagot kortne ïn första och tredje, fjerde $j$ yttre andan dubbelt bredare än tredje, med de bảda börnen, isynnerhet det bakıe, myeket afrundade, dess inre hörn deremot ganska spetsigt. Labium kort, i frïmre indan bred, bakit hjärtikt afsmalnande. Mrndiblernas corpus liter. nagot mer an dubbelt lingre än klon, bakat bredare, utan nagon concavitet à afre sidan för mmsklernas füste; motsatta sidan nagot concar; klon är rätt stalk och krökt; visl dess bas sitter liksom hos Arrhenumes ett kort, nästan trianguliirt, himmotadt bihang, som dock lät affaller, da mandihlema uttagas. Palpernas tre första leder hafra hvalderal ett har ofvan, fjerde ett mycket kort och fint of ran samt ett lingere fint under it milten och ett kortale hatr nagot lingre fram, femte är försed med ett mycket kort weh lint a mulpe sidan. Generationstïlth. som hos denna art är mycket stort (1).21 millin. 1., 1),16 lor.). dełas af en lang springa, som börjar mellan

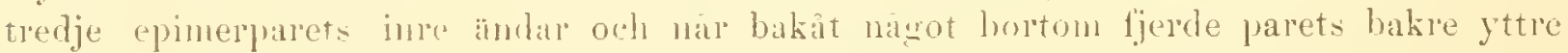
höru. benna springa ä omgifren af trenne glatta skifror, som tillsammans bilda en sammantryckt. nästan rhombisk tignll (nngefäl som hos Myurobates), hrilken ongifves af en rad smá och tiittstaende stigmer. Mellanrumuet mellan epinerernas inre andar. bakat begränsadt af generationsfältet, ä mycket litet. Mellan generationsfältet oel fjerde epinerpared sta trenne stigner, det framsta betydligt mindre. Bakon generationsspringan, nagot närmale bakknnten, liggere anus och ä önse sidor om denna ett stigna; utanlör dessa sta de trá langa, bakat riktade lânen, som synas i bakkanten.

Firrgen, son ej obetydligt valierar, air hos clenua art rantigen bláaktige, ej sallan grönaktig, ned främre och bakre kanten stötande i gult, a l'ygen star en nästan hästskoformig brum flack, som baktill är öplen, framtill afilelarl gemom en stor, vantigen oral, gul fläck, som stundom sträckel sig framit till ögonen. Dessia äro röda och be-

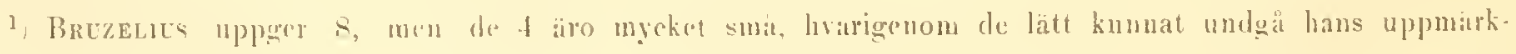
samhet. 
KONGL, SV. VET, AKADEMILNS HANDLINGAR. BANI), 17. N:O 3.

lägna nära kroppskanten. Under är kroppen ljusare, de yttre ändarne af cpinererua

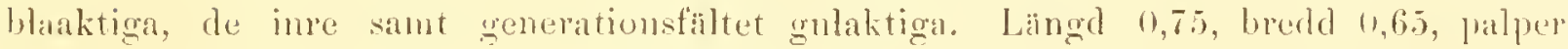
0,28, första bemparet 0,50 , fjerde 0,70 millim.

De ljusröda, runda, af det vanliga gelélika ammet omgifna raggen, har jag i maj manad fomnit $i$ de rimnformiga lladen af Sphugmum-arter, 8 a 6 ager tillsammans. Dot getelika amnet är af särdeles fast consistens. Dal larverna ntklacktes weh skiljovägrarne mellan aggen brusto, summo de föra länge omkring imman det lyckades dem att gru-

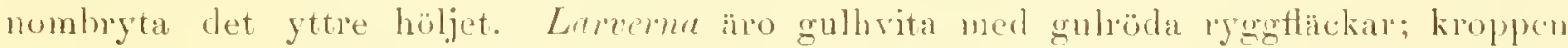
är mycket nedtryckt och försedd met skarpa kanter: i lakre kanten sta tra langa har al

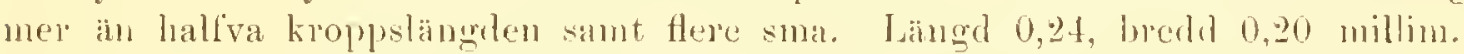

Dema art är mycket langam $\mathrm{i}$ sina rörelser och kryper oftast sakta omkring pa bottnen af det kärl, hvari den förvaras.

Under de senare aren har jay träfat den tämligen allmänt $\mathrm{i}$ vattensinnlingar kring Skara sâsom vid Björkelmnd, Brobacka, Lahall, Brumsbo storing atre, i flere sjöm i Vulle hälad, Gotand: Heirle träsk sant vid Kimner i Lummelunda, Blekinge: Fridlefotal. liomeby (lilljeborg), Skine: $\mathrm{i}$ en a pa sindhammanen (Bruzeruus).

\section{Geuns S. MIDEOPSIN n. gg.}

('orgus durum, glanulatum. fre potundatum, magnopere depressum, subtus partu anteriore valde conrexa. posteriore depressa; dorsum stigmatibus conspienis caret. Pedes perbreves; par primum corpore dimidin bresius.

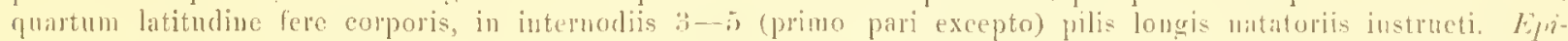

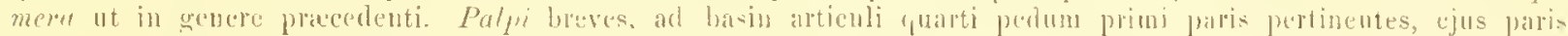

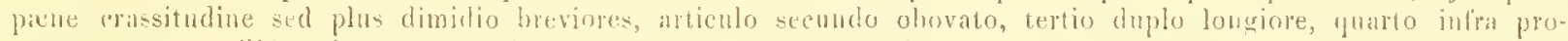
cessu cuncato, pilifero instructo, quinto parvo, ancuto. Conli in extremo margine corporis collocati, magni, distalltes.

\section{Mideopsis depressa n. sp}

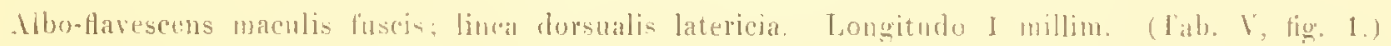

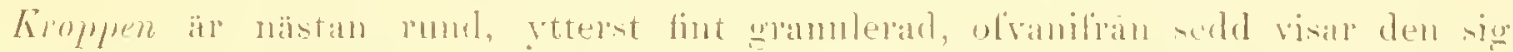

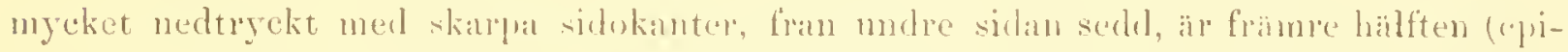
meraldeten) betydligt conves, bakre deten deremot allt mor sammantryckt; serlt flum

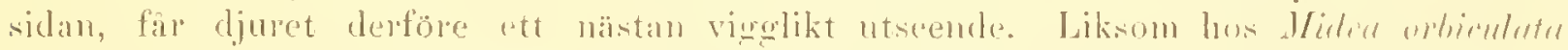

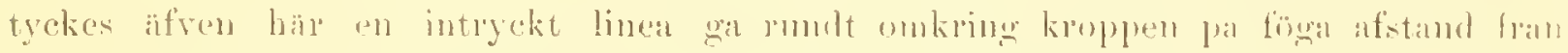

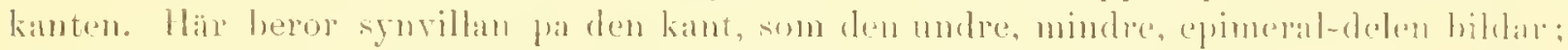
deman kant symes genom den ölverskjutande öfre sasom en intrykt linea. ligengen

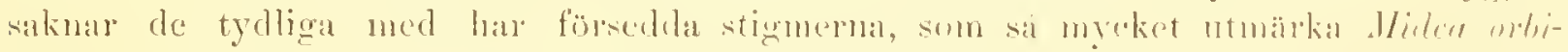

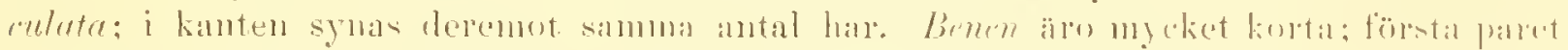

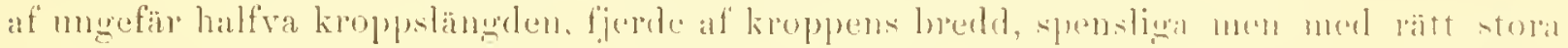

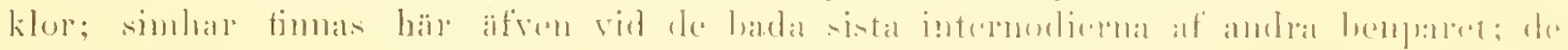

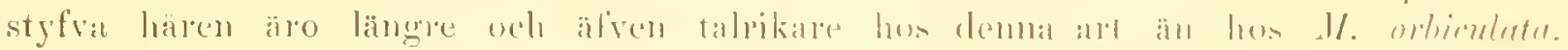

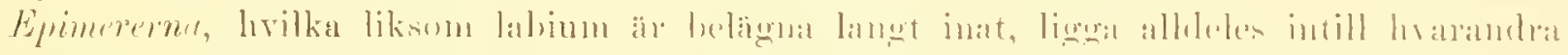

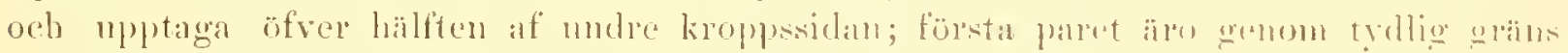

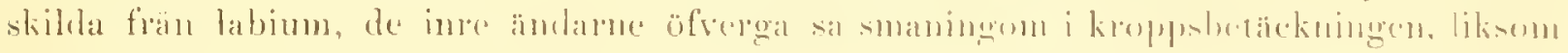


stundom afven andra parets, hvarigenom dessa båda epimerpar hlifva vida kortare äu hos Midea orbiculuto; tredje paret mycket langil, if naistan samma form som los nämda art; fjerde paret ater visar en afvikande, mer orgellounden form och aro dubbelt bredare än tredje (se fig.) Labium är hong, framtill olutydligt bredare, baktill jümnt afrundad och grenom et tydligt mellammm skild frân första paret epimerer. Palpernu äro korta, (sedda ofranifran, nä de med knappt halfra längden utanfür kroppskanten) af nästan samma tjocklek som första benparet och ndende till basen af dess fjerde internodie; första leden, som vanligt, mycket liten och rundad, a öfre sidan bärande ett kolt hâr, andra myeket tjock och kolfformig, trerlje vida kortare, men föga smalare, fjerde wästan lika lang som den andra och tredje leden tillsammans, mot spetsen obetydligt afsmalnande, kantig och a undre sidans midt försedd med en bred, mïtan viggglik, framat riktad process, som syues bildad af tva med hrarandra sammanvuxua tauder, sant med ett kort hà i hvardera ytterkanten: femte leden mycket liten, knappt längre än första, krökt och mycket spetsig, i spetsen tydlig̣t delad, a midten synas trå ytterst fina och korta har; å öfre spetsarne af andra, tredje och fjerde lederna twa kortare har, de a tredje leden stânde lingst och tjockast, de ả fjerde hörst obetydliga. Mandiblem, hvilka det, oaktadt allt bemörlande, jyekats mign att oskadade skilja från den harda labium, synas hatva en kort corpus och en ovanligt stor och böjd klo. Generationsfïltet: Springan börjar nngefär midt enellan de bäda inre hörnen af fjerde paret eprimerer, äl ganska kort och har a de omgifvande smala halfmanformiga skifvorna treme nastan rektangulära stigner, som synas rảgot fördjupade; omkring dessa skifvor gar en upphojd rand, som dock saknar de för Midea orbianlete ntmärkande sma stigmerna. Faltets bredd ân nagot mindre an dess langd. Mellan dess frame kant och fjerde paret cpimerer star ott stigma och bakom det

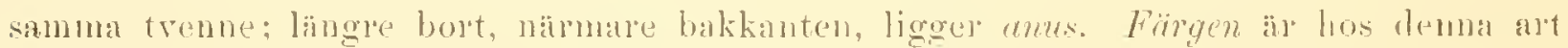
ofvan guthrit, med ljusare, gonomskinlig kant, rygeflackinme bruna eller srartbrum, rysgstrecket bredt, gult cller gulrödt. Ender är den gullyit med brumktiga epinerer; palper och ben hritgula, genomskinliga; a ömse sidor om generationsfattet stâr en brun fläck. Clymen stom, rörla, lângt skilda, belïgna alldeles i kroppskanten. Laingd 0,87 luedd 0,84 , palper 0,28, första benparet 0,45, andr:a 0,58 , tredje 0,60 , fjerde 0,85 millim.

Myeket liflig i sina rörelser, kryper stmmlom upl pat kanten af käulet, der den förvaras, och sitter der tämligen länge, imman den ater legifver sig ned i rattnet. Ej sa sallsynt i sö̈ar med klart vatten. Mälaren. Tenern, Asunden samt sjöar i Valle härad i Vestergiotand, Bohuslinn a Orust rid llulta.

\section{Genus 9. LEBERTIA n. g. ${ }^{1}$ )}

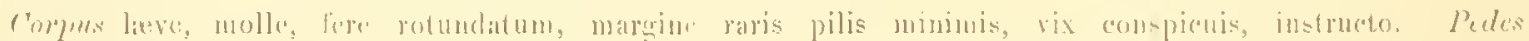

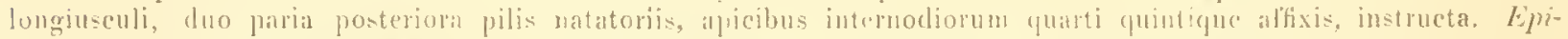
meru omnia utriusque lateris (primi pari- exeeptis) concreta. Palpi longi, fenues, articulis serundo ct tertio crassionbus, quato longissmo, dentibus carenti, quinto parvolo, acnlo. Oculi magni, propu marginem corporis siti, distantes.

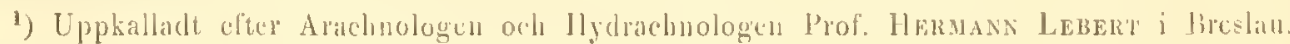


letta slägte, som i manga afscenden, isymerhet genom epimeremas fördeining, star nära föregrande, skiljer sig mest fran detsamma genom sin fullkonligt glatta och mjuka kroppsbetäckning. Eropreformen ä mästan pund, neh den nảgut nedtryekta rygen är försedd med flere stigner; i bakkantens sta mycket sma, knappt synliga har. benen äro

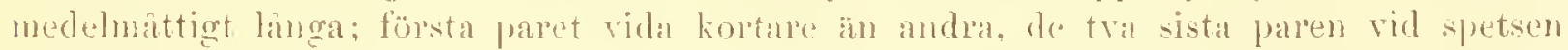
af fjerde och femte internodicrna ned simlar. Palperna äro langa med andra och tredje lederna tïmligen tjockn och korta; fjerde lïngst, saknande tänler sumt femte mycket liten och spetsig. G̈gonen stora, vidt skilda, leelïgna nära kroppskanten. Blott en art.

\section{Lebertia insignis n. sp.}

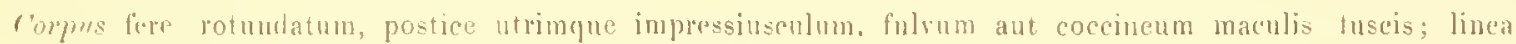
dorsualis rosea vel lutescens. Jorsum stigmatibus sedecin ornatum, fuarm octo in maryinibus ejus sital sunt, cetera duas series secundum medium dorsi fornant. Longitulo 1-1, m millim. (Tab, TllI, fig. 4.)

kroppen air bredt oval, nästan rund, med en unycket obetydlig intryckning i bakre kanten a ömse silor, glatt, men epimerer, labiun, palper och ben ytterst fiut

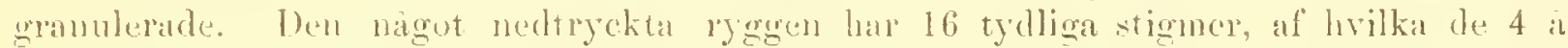

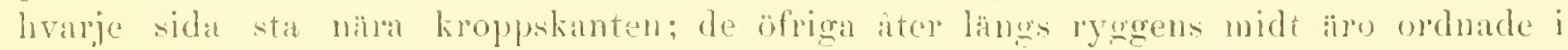
trenne rader; alla dessa stigmer äro försodela med knota har. Mlidt emellan de fyra

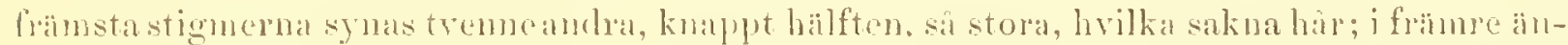

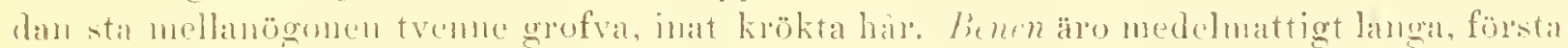
paret nagot kortare an kroppres brede och a obetydligt kortare an andril, skilnaten i längd mellan andra och trodje paren ej sa stor, mellan tredje och fjepde deremot nästan lika stor som mellan första och andra; fjerte paret är r.jubetgdligt längre an kpoppen. liarsta

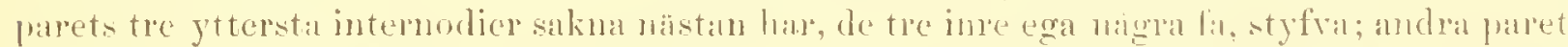
har en krans af langa och tjocka lar $\mathrm{j}$ spetsen af trealje och fjerde internodicrna, virl femte uagra glesa simhar, a sträickidan sitta pá de fyra fösta interuodierna nigra korta har. Tredje och fjerde paren äro vid spetsen af fjerde och femte internorliema

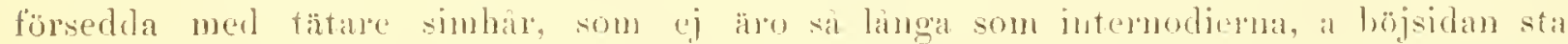

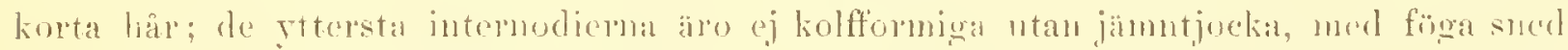
fördjupning för de svaga dubhelklorna. Epimererne äre utstande, i symerhet lörsta

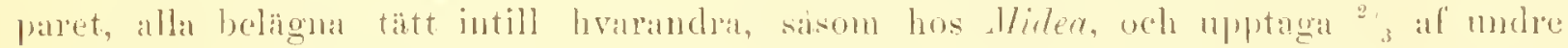
kroppsidan; första paret i frimme andan tillopetsade, i bakpe likalerder, under labium gränsande intill hvarandra, dock nued mer eller mindre tydlig gräns, tillsammans bil-

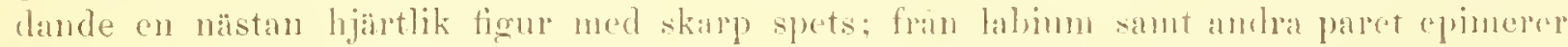

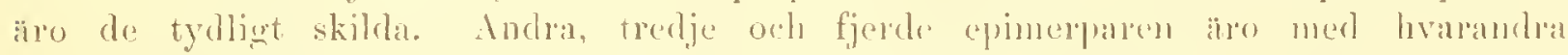

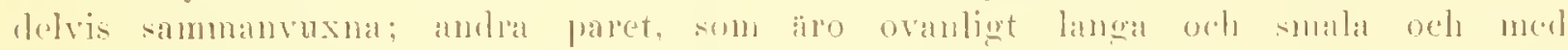

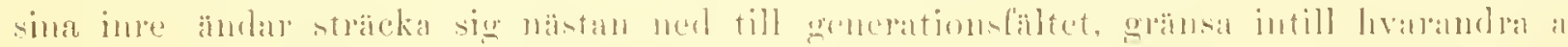

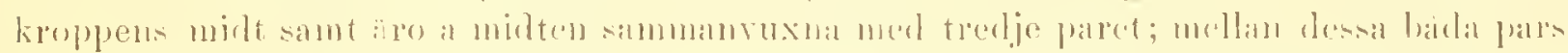

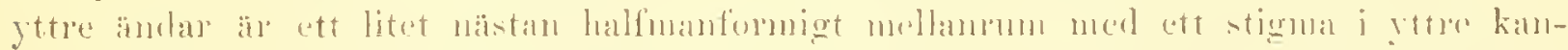

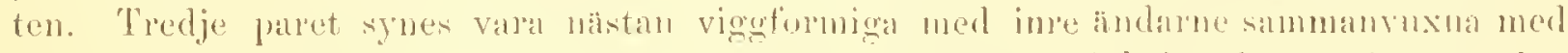

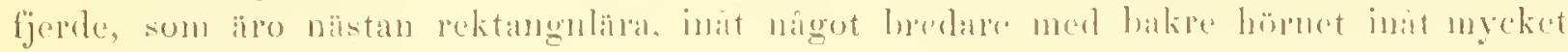


afrundadt; yttre ändan har främre hörnet spetsigt, bakre rundadt. Labium lang oeh smal, baktill afrundad, frantill obetydligt bredare och nerl en utbugtning a midten. Palperne äro lânga, nå nästan till spetsen af första benparcts fjerde internodie och äro betydligt smalare än detta par; andra leden tämligen lång och tjock, liksom den något kortare och smalare tredje kolfformig, fjerde längst, utat afsmalnande, fra nndre sidan nagot concav, femte mycket kort, füga lingre in första, nàgot krökt och mycket spetsig. Första leden har ett kort har ofvan, andra trenne har, sant ett nảgot bakat riktadt, långt och starkt å undre sidan, tredje leden tvâ mycket lảnģa a undre sidan, näistas lika langa som leden, och trenne å üfra, det ena nágot kortare; a fjerde ledens öfre sida stå i spetsen fem korta och fina "ppstiende hår, samt ả den undre tvenne. Mandiblema hafva ej symerligen lang corpus, men denna är bakat förlängd med en lâng och smal spets, bildande en mycket trubbig vinkel mot den egentliga corpus och vida längre än densamma, med en djup concavitet utefter hela dess längd för musklemas fäste. Klon är föga stark, nästan rak, med ett trubbigt, hinnartadt bihang vid basen, af klons halfva längd. Generntionsfältet, som pa trenne sidor omslutes af andra, tredje oeh fjerde epimerparens inre andar, visar en tämligen ling springa, begränsad franat af en lred och tydlig trärpringa, pa sidorna af trenne smala, bakat något bredare, uphöjula skifvor. hvilkas bakre ändar ga nagot nedom fjerde epimerparet och liksom hos Jfideopsis depresen visar trenne nästan rektanguläa fördjupningar a hvarje skifva.

Färgen är hos dennal ant unulöd med brunaktiga ryggflackar, mellan hvilka färgteckningen fram not ägonen ä ljust rosenoud; stigmema a ryegen nästan hrita.

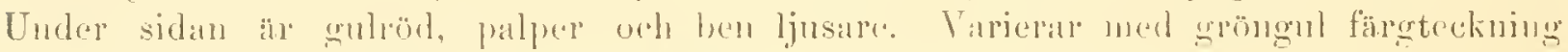
och nästan hvitt ryegestreck sant grallia palper orh ben. Lähed 1, 1. hreld 0,9, palper 0,1 ; första benparet 0,8 . andra 1,1 , tredje 1,3 , fjerde 1,4 millim.

I sina rörelser ár den tröğ, och släpar dä len kryper fran pa bottnen i det kärl, der den förvaras, liksom Hy!frobutes de båda sista benen efter sig. Oroad, betjünar den sig dock äfen af dem för att sa hastigt som möjligt komma undan. Tyckes liksom de bada föregáende arterna ej vara rofgirieg. bilott 5 exemplar har jag erhállit.

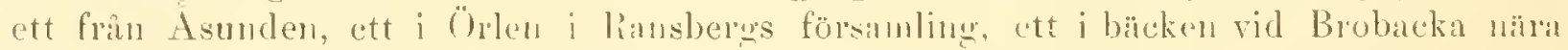
sikala, ett rid Ostersumd samt ett vid Grickjock.

\section{GenU: 10. PSEUDONARICA n. ‥}

Corpus lieve, seuto pectorali excepto, molle, depressiusculum, stria dorsuali carens, in margine pilis raris instructum. Pulpi longiusculi, tenues. C'eterum generi Marice simillimum.

Detta slägte äl $i$ sa manga afseenden ofverensstimmande med slägtet M/urtu, att jag länge varit tveksan, huruvida let horde uppställas sasom ett särskildt. Den mjuka kroppsbetäckningen, den nedtryckta kroppen, som ej är sammantryckt frin sidorna och alldeles saknar len intryekta linien langs rygen, hafva dock synts mig vara tillrickligt vigtiga àtskilnader für bildandet af att nytt slïgte. 


\section{Pseudomarica formosa n. sk.}

pyu. 18:5--41 Harice oblongu (', L. Koci, Dentschlands Crust. ete., h. 1:, fig. 9.

Corpus oblongo-ovatum, flaveseens, dorso fuseo, linea dorsuali abescenti. Pedes breviores, par primum latiturline corporis brevius, stenndum primo paulo longins, tertium et quatum eadem fere intur sf longitudinu, corpore paulo brevion; quartum apice seta una longa duabusque brevioribus instruetum, pili pedum ut in gurnere Merica. Palpi longiuscuil, paulo ultra miliun pedum primi paris pertinentes, hoc pari graciliores. Oculi rubri. approximati. Longitudo 1 millim. (Tab. V, fig. 2).

Kroppen är atlingt äggformig, nedtryckt, i främre andan nagot högre; här sta franför livarderal ögat trenne kolta borst och hakom ägonen ett stigma; i bakkanten sta trenne lïngre borst och a hvardera sidanfyra kortare. Benen äro tämligen kurta; första paret nagot kurtare an kroppens bredd, andra obetydligt langre, tredje och fjerle, som äro nisstan lika langa, aro nagot kortare an kroppen; hâren soń lus Marian, men andra paref har afven simhar i spetsen af fijerde och fente internodierna. Internodierna äro ej sa korta, tjueka och kulformiga som hos llarier, utan mer eylindriska; fjerde parets sista internodie har i spetsen ptt ganska langt och styft hat samt trenne myeket korta. De öfriga benen hafra särdeles sma klor, som synas vara enkla. Eprimerema, som äfren los detta slägte bilda en stor buksoblel, uppragande omkrime $2 / 3$ af undre kroppssidan, hafra langt framskjutande processer, af hrilka den fïrsta, som är lïngre än lahmm, i spetwn är rumbad och försedd med trenne korta och starkin samt nigot krökta tagyilr; dess hakre gräns är tydlig och visar sig sisom en spetsig kil. De öfriga parens processer äro kortare, men bredare och spetsigure och blott ett obetylligt stycke mot yttre andan skida frin hrarandra, a det andra paret star ett

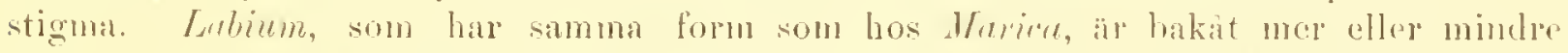
tydligr skild fran hukskighten. Palpermu äro mes langstriackta, hafra a andra och tredjo

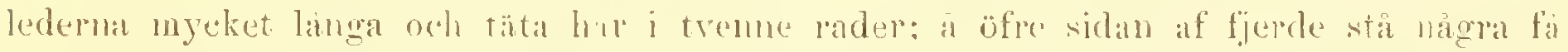

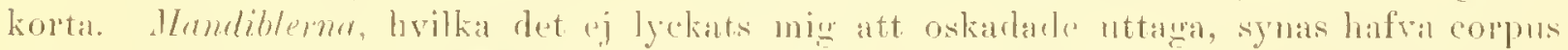

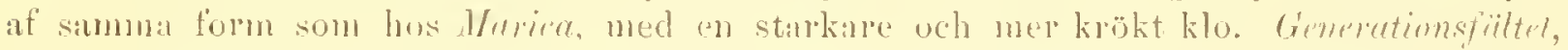
som är beläget i den halfcirkelformiga öplning, som bukskälden baktill hildall, delas af en tamligen lang springa. omgifven al tremne smala, halfmanformiga skifror, a brilka

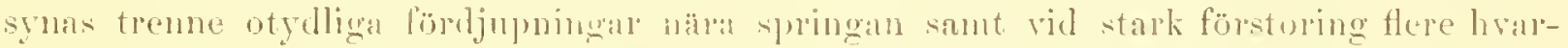

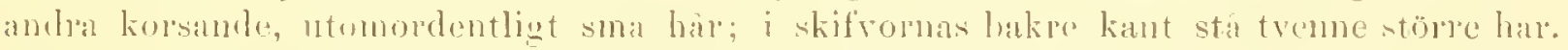

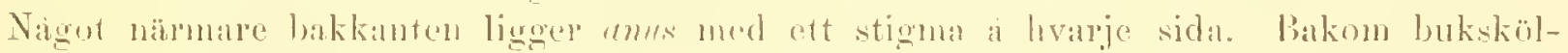

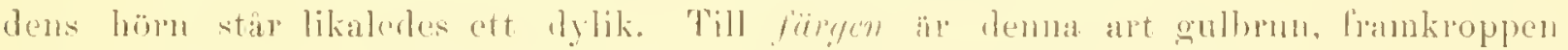

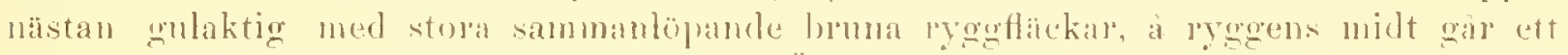

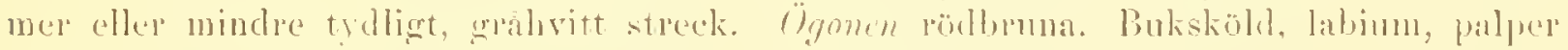
och ben grabla eller grealelina, bakkpopuen ljusuredelin, stumdom stötande i gult med

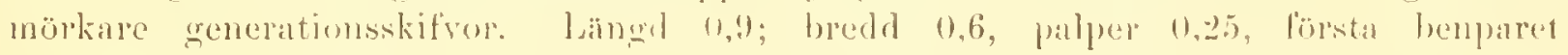
0,5, fjerde 0,8 millim.

Sälsynt i sjöar och dammar i Vestereötland: Vettern vid Rödesund; bjökelund, Brobacka och Brumslyo storinger vill Skara. 


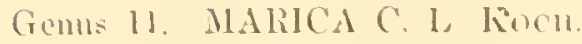

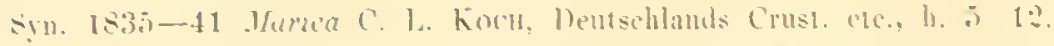

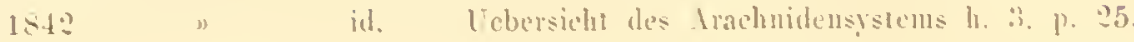

Corpus leve, durnm, fornicatum, oblongum, compressum. stria dorsuali instructum. Pedes. presertim par

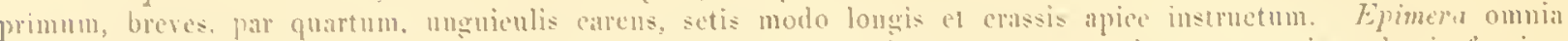
inter se concreta. semum magnum ventrale formantia inter quod ef partem superiorem corporis, velut in fornice, pedes affisi sunt. Palpi breves, tenucs, articulis tribus primis cadem fere longitudine ef crassitudine. quario Jongissino, quinto parrulo aculo. Couli satis magni, approsimati.

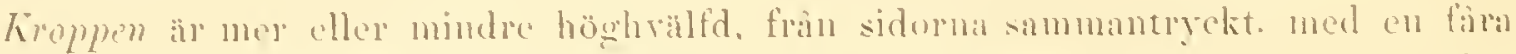

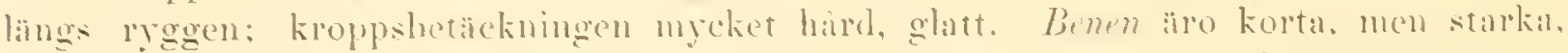

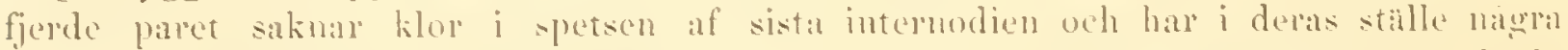

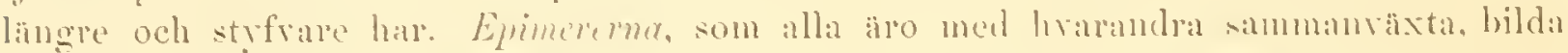

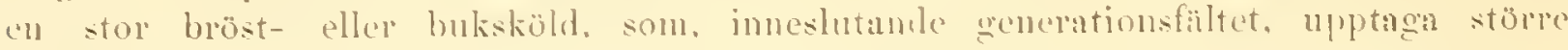

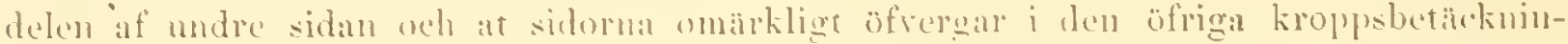

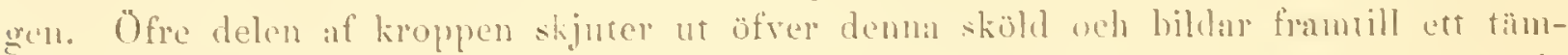
ligen stort hralf. I denna fördjupning äro henen fiastarke, de bakle högre upe in de

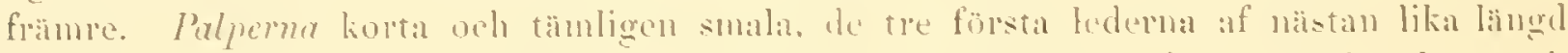
och tjocklek. den fjerde längst. eyludrisk, siknande taggar: fente mycket kurt och

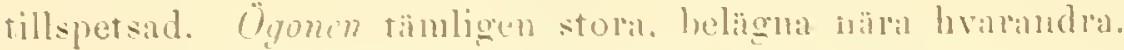

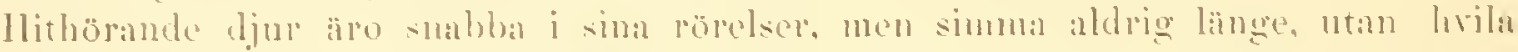

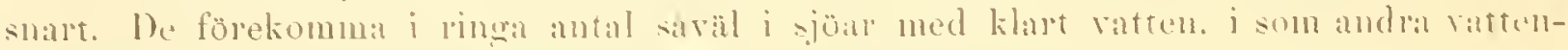
samblingar med mindre rent, bhott de äro rikil pa riixter.

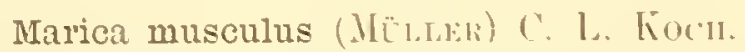

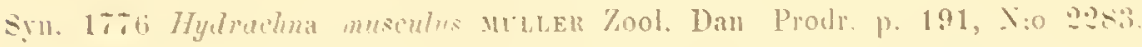

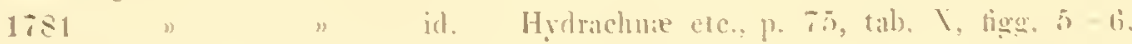

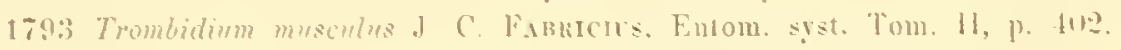

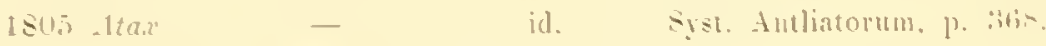

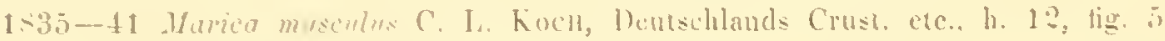

Conmes altissmum, adeo compressm ut nec dorso nec ventr, ayua deficiente, animal ineumbere possit:

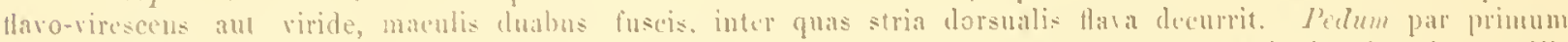

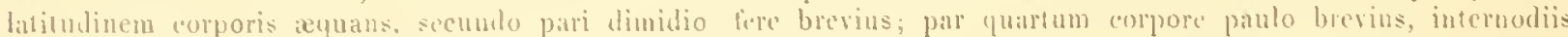
tento- uintoque pilis instmetis longioribus "l erassioribus, apicibus interuodiorum aftixis: duo paria posteriora natatoriis plis longis in apice anticuli quinfi instructa. Palpi breves. pedum pari primo graeiliores et ad redium hujus paris pertinentes. Gouli rubro-fusci. l,ouriulo o,s-1 millim. (lab. I, tign. 4.)

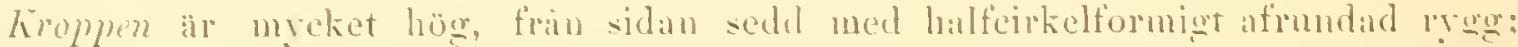
sidorna äro till den grad sammantrekta, att djuret ej utan stöd kim lägaga pa

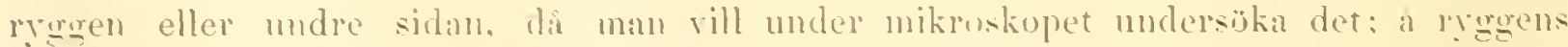

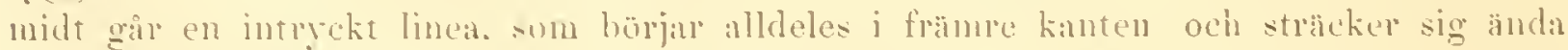
ned mot genitalfälet. Be nen äro korta: första paret likil langt som kroppens bredhl, andra nästan dubbelt längre än första palret. tredje föga längre än andra men betyd-

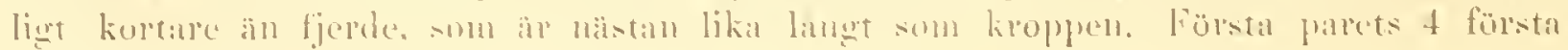


intermodiel mycket korta, tredje, fjerde och fente med korta, styfva har, nástall cirkelformigt omerifvande: spertsame, fjerde interuodiens har äro störst, fentes minst: andra

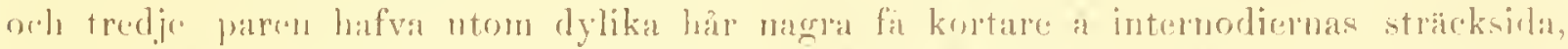
let sistnända paret virl femte intermodien wasra fa längre simhar, fjurdr paret, som iar förserlt med tät sittande har, har likaledes simbar vid fomte intermorliens sprets;

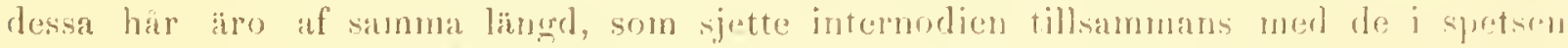

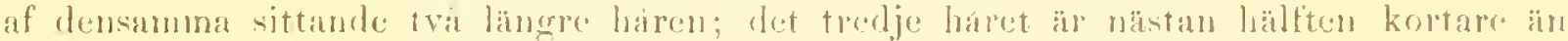
de bada andra. Alla intemodierma äro mer eller mindre kolfformiga ntobn sjette, som

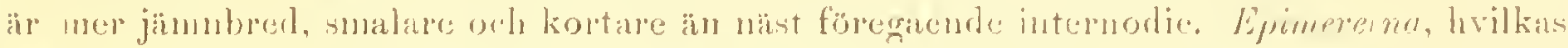
främre spetsar blott äro fria ooh framakjutande, ligga, da man ser djuret frán undre

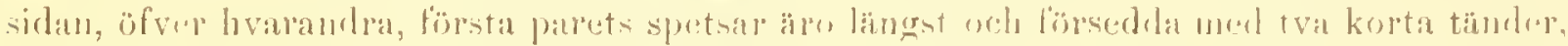

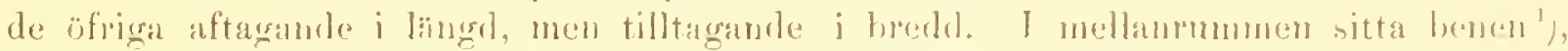

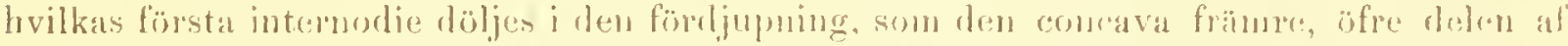

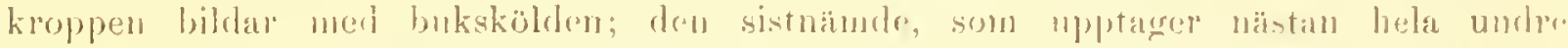

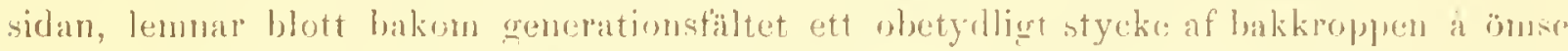

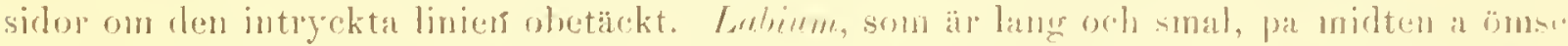

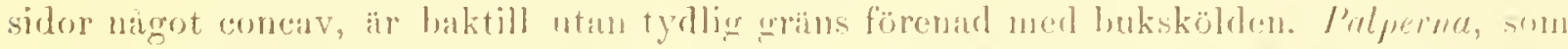

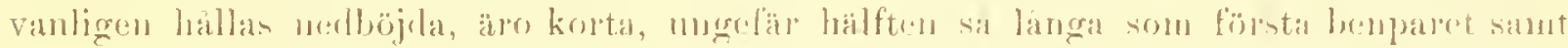

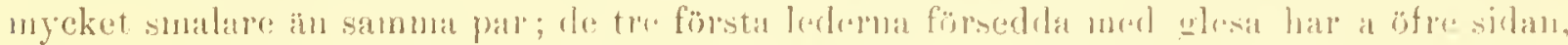

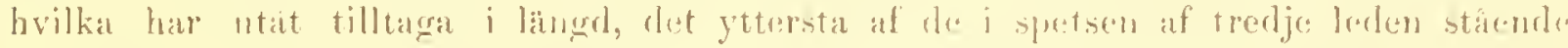

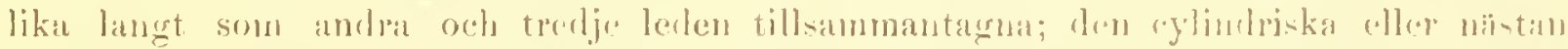

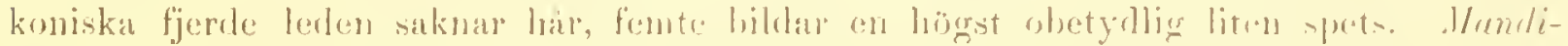

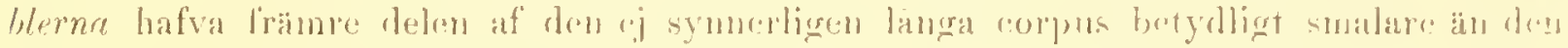

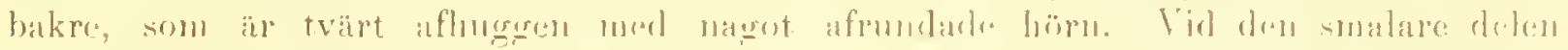

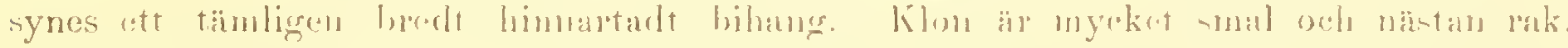

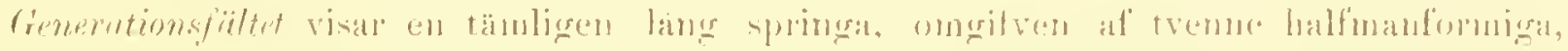

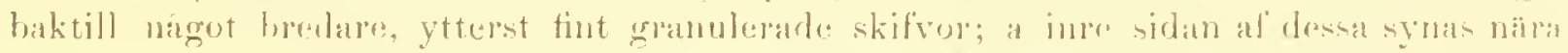

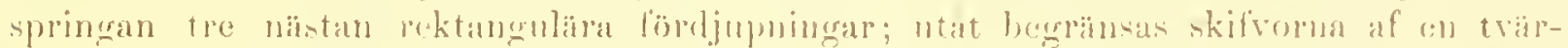

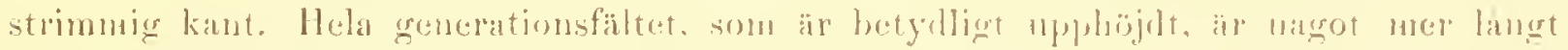

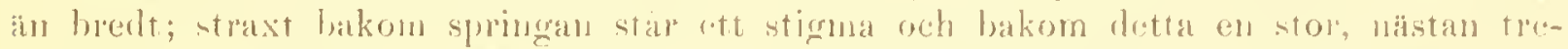

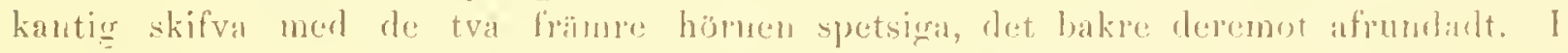

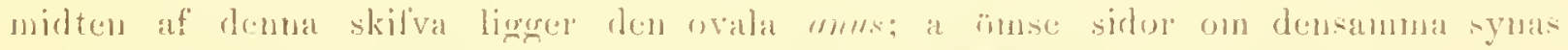

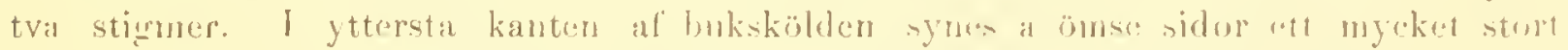
stigma och bakon det ett hakit riktadt har. Faryen, som ritt mycket varirar, är hos

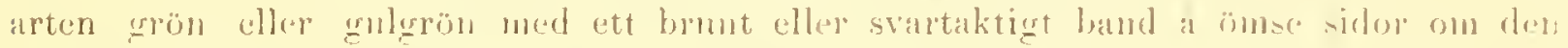
gulaktiga intryckta linicon; pa hvar sin sida om denna synas!" mörka punktformiga stigmer. C̈gonen, son ligga langt fram i kanten, äro riölat eller rörlbruna.

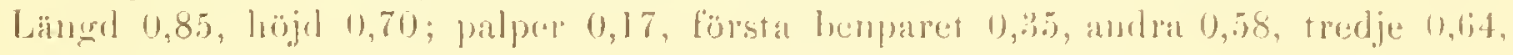
fjerde $(0,70$ millim,

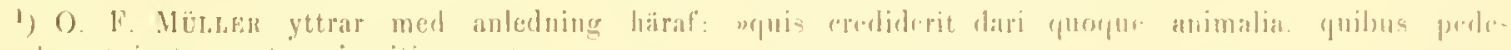
unter orulos rt imetrumentil oris -iti essente" 
Tämnligen sällsynt. Upland i Mälaren oeh Vitulfsbergssjön, Vestergötland i Åsunden, Hornhorgasjön samt flere sjöar i Valle härad äfvensom vid Björkelund och Tholsjöhult; Blekinge i Ronncbyån.

\section{Genus 12. AXONA KRAMER.}

Syn. 1875 Arona P. Kramer, Beitr. zur Naturgeschich. der Hydrachniden, p. 310.

Corpus durum, granulatun, depressum. Pedes breviores, pilis raris brevioribus iustructi, par quartum solum pilis natatoriis, internodiis quarto et quinto affixis preditum. Fpimera inter se concreta scutum magnum ventrale formantia. Palpi longiusculi, crassiores, articulo secundo dente instructo, quarto maximo, clavato, quinto minimo, curvato. Oculi permagni, distantes.

Detta slägte, som ända till år 1875 varit förenadt med C. L. Kocns Arikenurus, har myeket riktigt af ḰRAMER hlifvit skildt derifrân oeh uppstaldt såsom ett nytt. Dess palper, sammanvixta epinerer samt generationsfült äro högst olika samma delar hos sligtet Arrhenurus. Blott en art.

\section{Axona versicolor (MÜlLER, KRAMER.)}

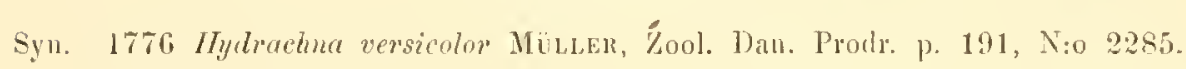

$1781-$ id. Hydraclune etc., p. 77, tab. V1, fig. 6.

1793 Trombilizm - J. C. Fabikicius. Ent. syst. Tom. II, p. 400, N:0 9

1805 Ata: - $\quad$ id. Syst. Antliatorum p, 367,

1835-41 Arrhenumus versicolor C. L. Koc1, Deutschlands Crust. etc., h. 13, figg. 16, 17.

1854 - $\quad$ - Bruzelıus, Beskr. ö. Hydrachı. som förck, i Skine, p. 33.

1875 Axona viridis KraMer, loco cit. p. 311, tab. $\mathrm{I} X$, fig. 19.

Femiua: Corpus obovatum, antice truncatum, postice impressione minima utrimque instructum, margine posteriore in medio exciso, articnlo quinto pectum quarti paris processu et appendicula carens; virescens, maculis fuscis; linea dorsualis brachiata, albescens. Longitudo 0,5 millim. (Tab. XI, tig. 2.)

Honu: Kroppen är mycket fint granulerad, nedtryckt, onvändt äggrund, i främle andan bred och tvär, i bakre afrundad med en obetydlig intryckning å ömse sidor samt i midten af bakkanten försedd med en inskärning; saknar lår i kroppskanten, med mudantag af de tvá vanliga framför ögonen. Binen äro tämligen korta; första paret nígot kortare äu kroppens bredd, andra oeh tredje obetydligt tilltagande i langd, fjerde nîgot kortare än kroppslängden, alla försedda med glesa hår; blott fjerle praret har några läingre simhar i spetsen af fjerle och fente internodierna; sjette internodien nigot kortare oćh smalare än den näst föregâtende, liksom de üfriga oj kolfformig; klorna äro smá, enkla. De med hvarandia sammanväta epimerema bilda en buksköld, som mpptager största delen af undre kroppssidan; dema sköld, som är lika hård som öfre sidan, är genom en mjukare kroppsbetickning förenad med denna. Da man betraktar djuret frin öfre sidan, synes den mindre buksköldens yttre kanter genom den öfre kroppsbetäkningen sisom en intryekt linea liksom hos Mided. Fürsta paret epinerer, som stüta tillsammans mnder

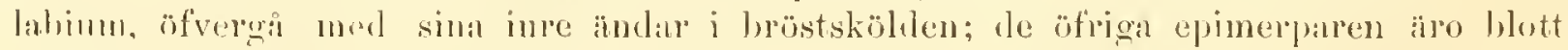

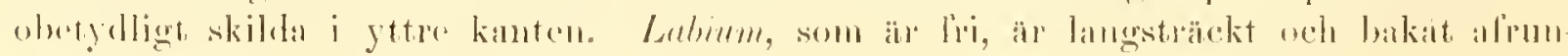


dad, framtill försedd med en trubbig process à midten. Mandiblema, som det ej lyekats mig att uttaga fullkomligt oskadade, öfverensstimma i det nürmaste med dem los Arrhemerus. Huruvida det limnartade bilnanget vid klons bas finnes, kan jag ej afuörat. Palperna, som äro lituga och tiimligen tjocka, nå öfrer mielten af fürsta benparet, till spetsen af dess fjerde internodie sant äro obetydligt tjockare ïn detta par. Första leden är myeket liten, andra deremot ganska tjock med en tagg i spetsen ¿ yttre sidan, tredje leden smalare och något längre, nästan jümntjock, bada med glesa lıă a öfre sidan, fjerde längst, öfver midten vidgat oth ả undre sidan concav i kanten uned korta, fina har; femte mycket kort oeh rörlig, kan nedläggas i förljupningen ¿ näst füregiende led. Generatiunsfïltet är beläget ytterst i bakkanten; slringan börjar straxt bakom bukskölden och sträcker sig ut till inskirningen; å ömse sidor on densamma stảr ett nästan rumdt fült, försedt ned tre stigner. Till färyen à den grönaktig med stora bruna ryggflickan och livitaktigt, ofta otydligt ryggstreck; ¿ labium synes en högröd fläck. Ögonen röda.

Längd 0,54 , bredd 0,40 , palper 0,25 , första benparet 0,38 , fjerde 0,52 millin.

Mas.: Corpus obovatum, antice truncato-rotudatum, postice acutiusculum, incisura carcns; articulus quintus pedun quati paris supra processu longo, curvato, iufra appendicula ctian longiore, sed graciliore instructus. Color flavescens aut ciululescens; iuter oculos maculat rubro-fusea, in dorso vitta transversa cierulea conspicitur. Longitudo 0,6 millim.

Hane: Kroppen ar längre och smalare an hos honan, framkanten hredare rundad, bakkanten spetsigare, men l’undad och saknande inskärning. Benen äro nảgot längre, och fjerde paret, som ranligen är smalast, î lı̈̈r tjockast; dess fjerde internodie, som ar kort och kolfformign, ntsänder frin sin üfe sida en ling process ntüfrer sjette internodien; denna process är ả midten nảgot krökt, nästan cylindrisk, och i spetsen fürsedd med några liugre hår; i intemodiens breda mudre sida synes ett lingt. smalt, nagot krökt, trubbigt bihang, lïngre än processen, oeh bredvid detta ett mgefür hälften sî låugt, spetsigt bihang. Femte internodien är likaledes tjoek men ling och năgot böjd, ¿a inre sidan försedd med talrika styf́a lıår och glesa simborst i spetsen; sjette har talriku finare hår a undre sidan och nästan rund fördjupning för de tämligen starka, enkla kloma. Bukskölden är mindre och upptager uístan ${ }^{2 / 3}$ af undre sidan; straxt bakom densamma sti generationskifvorna, som hafva oregelbunden form och liksom hos honan äro försedda med tre stigmer. Nidt emellan generationsfältet och bakre kanten ligger anus. Firgen är gullovit eller hlabit ned en rödbrun flack mellan ögonen, tvïrs öfver bakkroppen gîr ett blagrönt band. Mer liflig i sina rörelser är honan. Lälıgd 0,6 . breeld 0,4 millin.

Dema ant, af hvilken honorna äro vida allmännare än hanarne, fölekommer högst allnänt bâde $i$ rinnande och stillastiende vatten, isynnemet on bottuen ntgöres af dyjord eller lera. Lappland-Skine, Gotland, Öland. 


\section{Genu 13. ARRHENURUS DCGEs.}

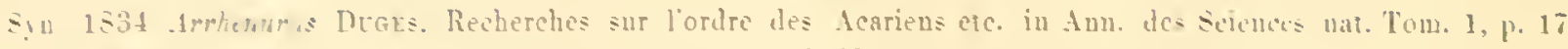

1.4: - C. L. Koch. Tehersicht des Arachnidemsylems h. ì, p. 1 s.

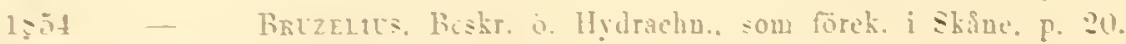

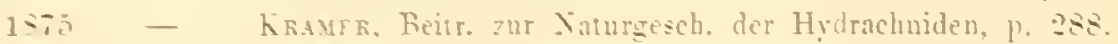

Corpus scabrum. durissimum. altum, sed rarius fornicatum, in dorso stria impressa, fignram oratam postice plerumque olsolian circuncludens: in margine posteriore sctas gerens. Pedes breviores, duo paria pusteriora (arius, par securdum) pilis uatatoriis deusis. iuteruodiis iertio-quintoque aftixis, instructa. Palpi ureves crassi. articulo querto inn rissimo, antice infra processum latum enitfenti. quocum articulus quiutus unsuiformis foreptem format. Covli non ita magni. distantes.

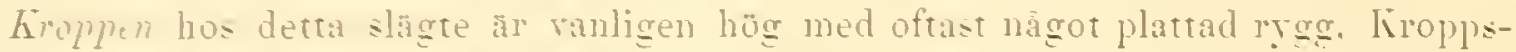
betackningen. som ar mycket loàd. risar en otalig mänğd smả gropar, hrarigenom den whallel et knottrigt eller skrotligt utsecnde. A rgogen synes en intryckt linea. som omslnter en stomre eller mindre oral tiğr. hrars bakre grans oftast är otydligg. Kroppsbetăckningen i denna liuea an mjuk, och den innesutna ovalen bildar derföe ett nästan fritt strcke. ett - slag = rygakold. Bakre kantels, som isynerhet hos hanarne är myekt olika bildad (se indelningen af arterna). ăr försedd med ti \& loar. Bemen äro tämligen korta, men starka: de bada bakre paren (stmndom äfren det andra), a tredje. fierde och femte internodiensa försedda med talrika simbar. Da det främsta paret epimerer under labium gränsa intill hrarandra, sa bilda pimerem hos detta slagte tre skilda grmpper. Paizenna äro korta och tjockin; första leden unçket liten. andra tjockast. mel tiock än lanğ. tredje anmu kortare och obetydligt smalare. Fjerde är längst. ungefär lika lang som andra och tredje tillsammans. i frămre andan nedtill med en bred, concar process. forsedd med ett har: med denna process bildar den korta. Kloformig̣a och mreket rörlig̣a femte leden ett slags tảng.

De hithörande talrika arterna fürekomma mest i klart ratten. mera sällan i damnar med drbotten. I sina rórelser äro de mreket smabba. Ofta kasta de. da de lirila, le bakre benen fram ofver rogenen. Traftis alluannare i copulation ăn andra Hydrachnider.

De 14 hithōrande arterua kunna pa följande sätt nppställas: 


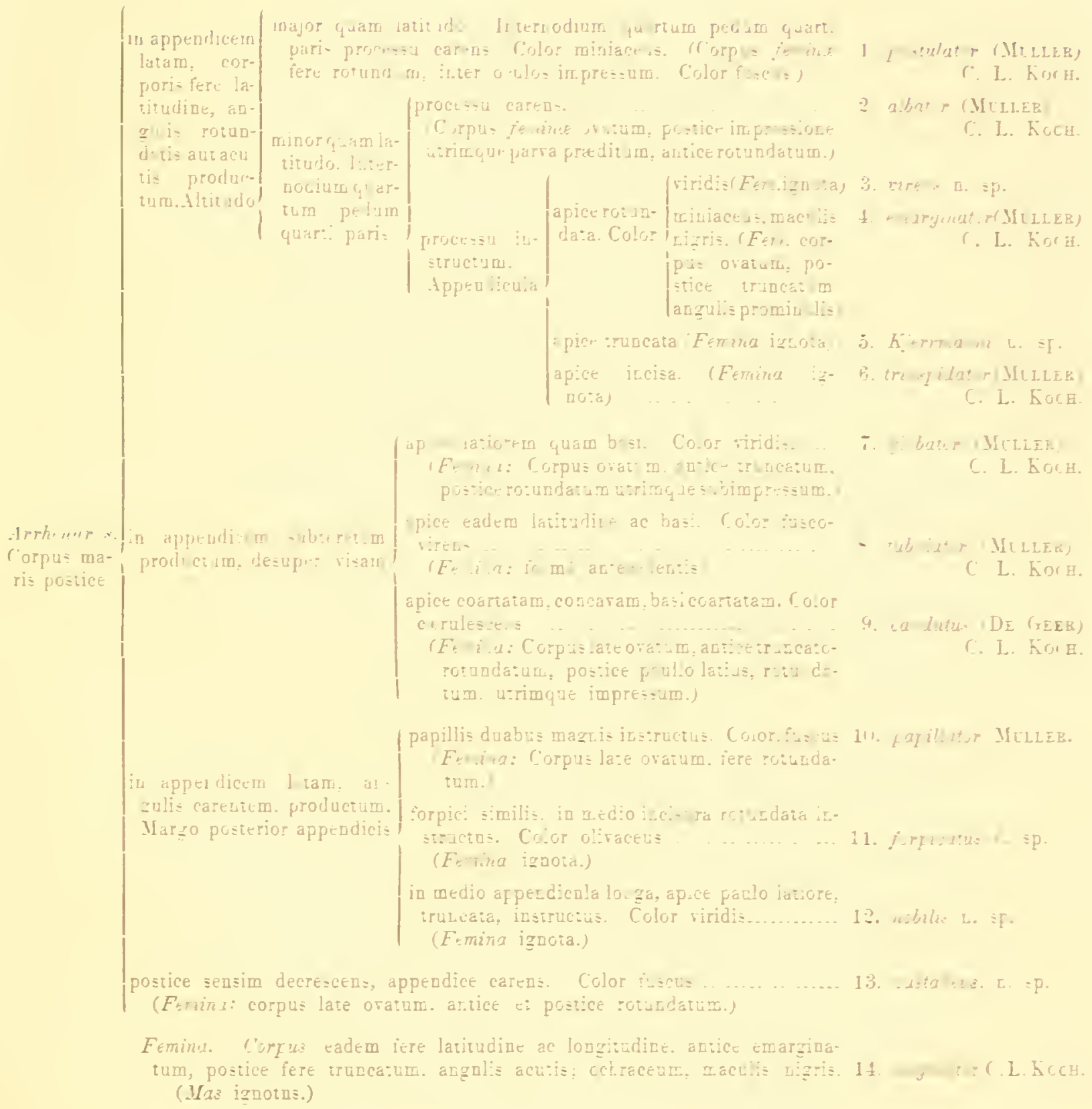




\section{Arrhenurus pustulator. (MüLLE1:) C. L. Kíon.}

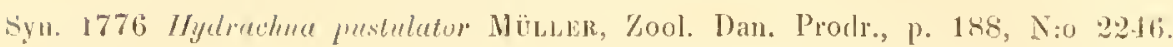

1781

1793 Trombidium

1805 d t $a x$

$18.31-45$ Arohenurus -

1854 id. Hydrachne etc., p. 32, tah. 111, fig. :3.

J. C. Fabricils, Ent. syst. Tom. 11, p. 103, x:0 21.

id. Syst. Antliatorum p. 360.

C. L. Kocir, Deutschlands Crust. etc, l. 2, fig. 21.

Bruzerits, Beskr. ö. Hyalrachn, som förek. i skine, p. 28, tab. 11, lig. 9.

Mas: Corpus altissimum, miniaceum, antice emarginatum, postice in appendicem, angulis rotumlatis productum, que a cetero corpure mints conspicue sejuncta est, quam apud species sequentes ct quat in mediu marginis posterioris bisinuati appendicula, apiec rotundata et incisa, instructa est; dorso gibbere magno plädito. Intcrnodium quartum pedum quarti paris processu carens. Longitudo 1,5 millim. ('Tab. VII, fig. 1.)

Hane: Kroppen är j följd af den stora knölen yả ryggen mycket hög, sia att dess löjd är större än dess bredd; framtill ar den afsmalnande med en liten intryckning mellan ögonen, något imnaför dessa stä korta, frumitriktade hảr; a hvardera sidan, straxt bakom fjerde epimerparct, synes en djupare intryckning, hvarigenom kroppens öfverging till det eljest fran densamma föga skilda bilanget förmedlas. Detta bihang slutar ined tvenne korta, bakat riktade, afrundade hörn. Midten af dess bakre kant är nagot franskjutalide och under fürsedd med ett mindre ntat och nagot nedàt riktadt, tapplikt bihang (appendicula), som, fuan molre sidan botraktadt, visar sig nästan cylindriskt med afrundad spets, i lıvilken synes en ciukelformig inskänning. Från öfre sidan sedt, visar sior nända bilang rännformight med sinal utât förenade spetsar bildande den cirkelformiga öppningen; midt i den rännformiga fördjupningen synes en liten spetsig, bakit riktad tagg; i hvardera sidan om bihanget stir ett mot detsamma krökt, starkt har, nästan af bihangets längd, och pa hvart och ett af de trubbiga hörnen af kroppers lakkant trenne harr, aftagande i langd uthot. Sedd fran sidan, visar sig frimre delen af kroppen, just der ägonen sta, försedd med tvenne mindue knölar. Ofvan dessa synes en tämligen betydlig intryckning, hraröfver den stola, framait afrumdade, men trära, bakat i höjd jümnt aftagande ryggknölen, hvilken upptager nästan hela ryggen, höjer sig. Pá denna knöl löper len intryckta linien, som bakit ofvergir till kroppens sidor mellan deras intryekning weh de afrundade lakkantshörnen. I bakre kanten, nägot framon det mindre, tapplika bihangets has, stî tveme knölar och omedelbart bakom dessa tvenne mindre, fürsedda med fina hår.

Benen äro tämliegen lảnga; fösta paret af kroppens längd, fjerde \$a längre, alla försedla med mycket tiita, kurta har a sträcksidan samt längre a höjsidan. Fjerde parets fjerde internodie är längst, och lika lang som de bijda füljande internodierna tillsammans, tjockast, ntait nagot kolfformig och pá ine sidan försedd med talrika fina simhàr, men saknande process; femte internodien, som än mycket kort, ar nàgot smalare och likaledes försedd med talrika simhàr, sjette nảgot längre äu fonte och betydligt smalare, ar jämnbred med liten, afrundad fördjupning i spetsen för de sma klorna. De två främre epimerparens yttre ündar äro tillspetsade och framstiende, de inre afrundade, andra paret skilda fran tredje genom ett lika bredt mollammu, som mellan de båda hakre

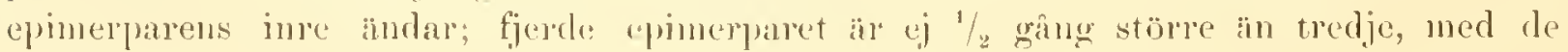


inve bakre hörnen ntdragna och spetsiga; bakom dem står ett stigna. Nidt emellan de nämda cpimerspetsarne och bakkanten ligerer anus, bakom hrilken kroppen ä något nedtryckt. Lubium, som är tydligt skild fran epimererna, bestar af tvid me.l bvarandra förenade, nästan halfmanformiga delar med de spetsade frimre andirne förenarle genom en mjukare himma. Mandiblerne hafva kort, nästan jänntjock eurpus med en kort. trubbvinklig förlängning baktill, ned obetydlig̣ fördjupning för musklema; den storia klon är mugefür hälften sa lang som corpus, föga böjd och med en liten fördjupning a yttre sidan; fràn dess bas uppskjuter mot spetsen ett langt, smalt bihang, nastan af klons langd. Pelperno hafra i spetsen af' den andra leden talrika längre hatr oeh pa den tjerde ledens öfe sida fyral kortale; den kloformiga fente leden är betydligt krökt. Färgen är hos hanen rödgul med mörkare anstryckning öfrel rygonen vid intryokningen a silorna; bihang, hen, epinerer och palper gulbrum. Ügonen äro mörkbruna. Längd 1,5 , hreeld 1 , palper 0,25 , föistal benparet 1,5 , fjerde 1,7 millin.

Feminu: Corpus altissimum, late-oratum, fere globosum, antice impressum, postice fere rotundatum, dorso requo, gibberibus carenti, rubro-fuscum. Longitudo 2 millim. (Tab VII, fig. 2.)

Honun, som äl störe än hanen, har kroplen nycket hög, bredt äggformig med en intryckning i främre kanten mellan ögonen, franför hrilka de ranliga hälen sta; bakkanten är bredt afrundad merl en högst obctydlig intryckning a ömse sidor"; hä sta tva små hår a hvarje sida och i bakkanten fyra längre. liyggen är jumn, sakmande knülar; den intryekta linien a ryggen är bakit försvinuande och inneshnter ett nästan cirkelrundt, stort rygastycke. Fösta benpart ar kortare an kroppens bredd: fjerde lika langt som kroppen; alla försculda med täta hàr oeh simhår sisom hos hanen; fjerde parots fente internodie an häl, som vanlient, längst. Emmeremu och habinm, som ano jtterst fint gramuleracle, äro belägna längro inat än hos hanen, och mellanmmmet mellan de tra bakre gruppernas inre ändar är här bredt, nastan duhbelt bredare än nellan-

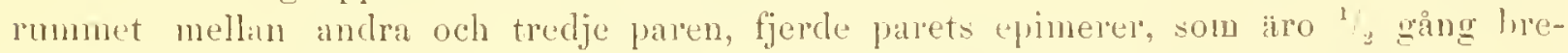
dare in tredje, hafra de inre, bakru hönen trubbiga och i den hakre kanten en obetydlig, trublig proress. Labium är kort och breed. Palperne nästan bildade sa som hos hanen, men med glesare har och femte leden rakane. Generationsfaltet ligger midt emellan fjerle epinerparet och bakpe kroppskanten; springan ar myeket kort, omgifren af trenne ghatta, halfenkelformiga skifvor. Fran liamre ändan af dessal utgar at hrardera sidan en ind tillspetsad, utat jämnbred och i ändan afrundad skifva, som ä mycket fint gramuleral. Till färgen valierar honan fran mökt röblom till gulröd, vanligen med treme mökalve Häckar, inom den intryckta rygolinien synes hos yngre individ pa ryggen en ljusare linea. Längd 2, bredd 1,3 , första henlaret 1, 1, fjerde 2 millim.

I min lilla redogörelse för Testergötlands Hydrachnicler 1870 beskref jag honan,

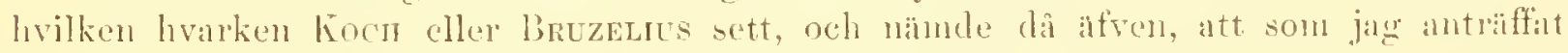

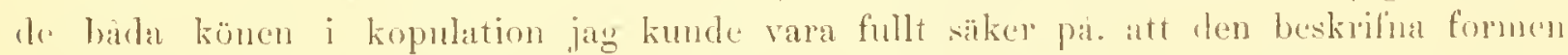

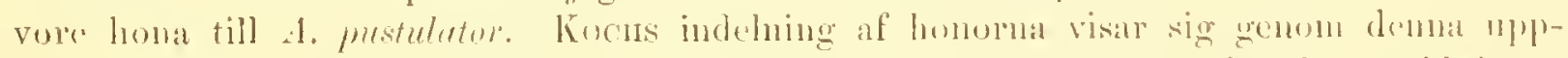

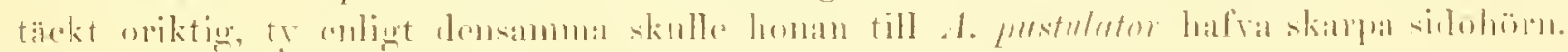


Myeket sällsynt. Upland vid Viłulfsbergr, Vestergötland vid Tholsjöhult i Undenäs församling och Skane vid Hasslemölla nära Veberöd (BuUzeluẹs). Virl Vitulfsberag voro honorna vida allmämare än hanarne, vid Tholsjühult ej sällsynta.

\section{Arrhenurus albator (Mülteli) C. L. Kíocıi.}

Syn. 1776 Hydrachna albator Mürter, Zool. Dan. Prodr. p. 189 N:o 2247.

1781 - $\quad$ id. Hydrachne ete., p. 33, tab. II, figg. 1, 2.

1793 Trombidium - J. C. Fabricrus, Eut. Syst. Tom. II, p. 403, N:0 20.

1805 Atax - id. Syst. Antiatorum p. 369.

1835-41 Armums - C. L. Косн, Deutsehlauls Crust. ete, h. 12, figg. 15. 16.

1854 - - Bruzelies Reskr. ö. Hydrachn. som förek. i Skåne p. 29, tah. III, lig. 2.

Mas. ') Compus rotundatum, antice emarginatum, postice in appendicem brcvem angulis prominentibus productum, in medio marginis posterioris appendicula apice acuto et utrimque dente magno instructa. Internodium quatum pedum quarti paris processu earens? ${ }^{2}$ ); pallide virescens, macula dorsnali alba. Longitudo circiter 1 millim.

Hane: Kroppen är något rundad med en intryckning i framkanten samt ej särdeles hög. Bakom fjerde epimerparet öf vergår den i en kort, något smalare förlängning ned ntdragna, uppåt och utåt riktade sidohörn, mellan hvilka den bakre kanten å midten gör en stark ntböjning. Under denna ä ett litet bihang fästadt, utat tilltagande $\mathrm{j}$ bredd och slutande med en fin spets samt på hvardera sidan om denna en bred, franåt och nedàt riktad, tand eller flik. Under detta bihang sitta tveme stora genomskinliga, i mirlten med hvarandra förenade, blảsformiga knölar. Pả hvardera sidan on detsamma sta, tvenne långa hur och pai de stora sidohörnon ett rlylikt. ${ }^{3}$ ) Den intryckta linien innesluter ett obetydligt ryggstycke, a hvar's bakre del tvenne knölar stå, KocH.) I ofrigt öfverensstämmer den ned A. trieuspidator. Färgen är blekgrön med en nästan luud, hvitaktig fläck pâ midten af ryggen. Pả fianme delen af kroppen stå tre svartaktiga fläckar samt längre bakăt tvâ längre. Längden omkring 1 millin.

Femina: Corpus ovatum, antice ef postice rotnndatum. ${ }^{4}$ )

Hona: Kroppen är äggrund, främre och bakre kauten afrundad. ${ }^{5}$ ) Färgen är lik hanens, men ryggfäckarne äro större. Lar ı andra stadict liknar myeket den beskrifue hanen, men har bakre kanten genom en djup inskärning delad i trenne breda, mudade flikar. Lüngd 0,7 , bredd 0,6 millin.

Sällsynt i Höje a nära lund (Bruzelues). Af larvformen anträffades 1875 några cxemplar i grafrarne vid Axevalla hus och i sjön vid Husgärtet i Vestergötamt.

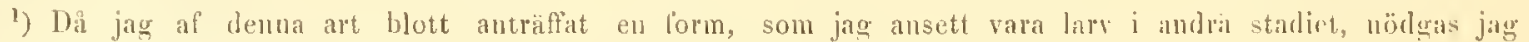
ut.eslutande följa BRuzeun beskrifning.

2) Kocn uppoer, att denna internodie är försedd med en lång proeess.

3) Sannolikt hafva uågra hår här undergätt författar(ns uppmiirksambet.

4) Eul. Koch: postiee truncatum angulis prominnlis.

5) [)'n sanare helt sikkert med nakgon intryekning ii ömse sidor. 


\section{Arrhenurus virens 11. sp.}

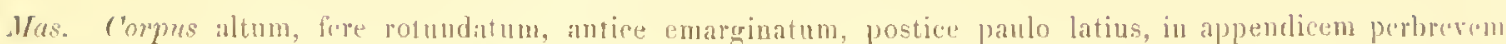
angulis acutis productum, in medio marginis posterioris appendicula satis longa, apice unulto latiore ibique rotumdala, instructum. Interublium quartum pedum quarti paris processu breviore preditum. Color probabiliter virescrus. Longituelo 0,7 millim.

Home: Kroppen ä.s hög, högst a midten, hvarefter den mot bihanget tamligen tvärt afphattas, frantill nagot afsmalnande med en intryckning mellan ögonen, bakat visar den straxt bakom fjerde cpimerparet un tvär intryckning, hvarefter den öfrergar till cot ganska kort, men bredt bihang, försedt med linga, vid basen breda men mot spetsen hetglligrt afsmahnande sidohöru, som äro utat och bakat riktade. Onkring högsta delen af ryergen gàr den intryckta linien, som ntlüper at sidurna franför bihangets siduhörn. I midten af bakre kanten stả tvenue mörkare, upphöjla junktel och straxt nedom dessil ett kort och loredt genonskinligt bihang, som ntat ai bredare och slutar med trenne utat riktade spetsar. Undes detta symes ett ammat, vid basen smalt, utât hetydlig̣t bredare och der afrundadt bihang, som fran undre sidan visar sig nästan püronformigt men fran den öfre nagot concavt. ¿ hrardera sidan on detta star utt styft j spetsen mot hihanget büjdt hảr; dessa bada har mötas nästan med sina spetsar utanför bihangets afrundade ändar; mellan lessa och silohölnen sta twenne langa har: läng w an hilanget, och vid basen af sidohörnen a me sidan trâ nagot mindre och i deras spets tva mycket korta och fiua har. Viel inknipningen ä sidorma samt frantör ögonen stá fina korta hâr. Benen likna dem hon A. tricuspdutor, men äro försedda med ghrsare och kortare har. Den vid fjerde intermodien a fjerde praret sittande processen in kortare och trubbigare, fürsedd med en knipla taitt sittande har. Epimerep, palper och mandibler si som hos A. tricuspridator, labium dock mes langsträckt. Bakom fijerde. epimerparet stal ett litet otydligt stigma a hvardera sidan. Till fïrgen ar den samolikt grön med palper och ben stötande i blatt.

Ett individ af ofvan beskifna art, som godhetsfullt blifrit mig tillsindt af licur Professor LuluJnbokg, hvilken tagit det vid Ronneby, hade en längre tid blifrit förraradt $i$ sprit, hrarigenom det naturligtris ar omojligt att noggrannt angifra färo-

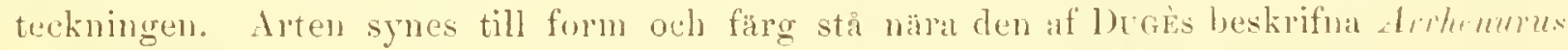
riridis, men skiljes tydligt, dels genom franvaron af de spetsiga knölarne straxt ofvanför det mindre hilanget, dek genom detas form Bakom fjerde epinerparet fïrekomma dessnton hos $A$. viridix ett störe och ett mindle stigna a hrarlera sidan.

\section{Arrhenurus emarginator (MCLLiR) ( . L. Koch.}

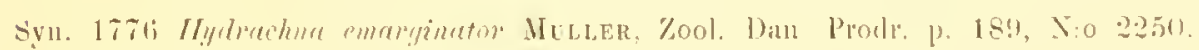

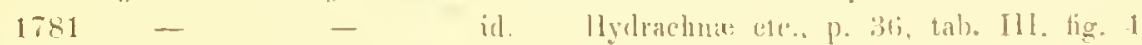

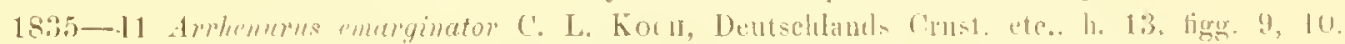

1854 Brutalle, Beskr. ö. Hytralon, som förck. i skille p. 2li. tab. Il, fige. $:-s$.

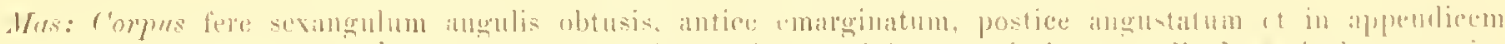

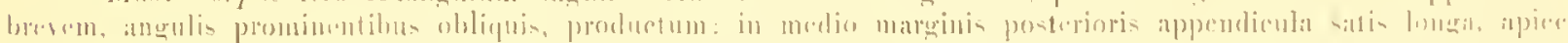


multo latiore, rotundata, utrimque acuta preditum. Internodium quartum pedum quarti paris proressu instructum. Color miniaceus, maculis nigris; appendicula, palpis pedibusque ochraccis. Longitudo 1 millim. [arl basin appendiculie.] ('Tab. VII, fig. 3.)

Hane: Kroppen är högr och bred, nästan sex-kantig, med mycket afrundade hörı, i fräimre kanten försedd med en intryekning inellan ögonen; bakom fjurde epimerparet afsmalnar den ganskil tvärt och öfvergir i ett kolt, men bredt bihang, som är försedt med breda, stora, utat och bakat riktade, nagot sneda sidoluörn. Ilidt emellan dessa synes i bakkanten ett bredt grenomskinligt bilang ned de spetsiga hörnen mer hakit in utat riktade. Under detta bihang sitter ett ammat, nistan tapplikt, något nediat. riktalt som, vid basen smalt, utat tilltager i tjocklek och shutar med bredt afrundade indar. $\left.{ }^{1}\right)$ Hảren sâsom hos föregånde art. Den iutryckta linien omsluter ett. stort ryggstycke och försvinner bakat vid intryekningen pil sidon'lla. Pa ryggen sta trenne trubbiga knölar, hvardera med ett bakat riktadt kort hår; längre bakat synes en dylik kuöl, försedd med tvả sidana hâ. Benens första par är llagot kortare än kroppens bredd, fjerde paret obetydligt längre än kroppen till basen af det mindre liihanget; de tva första paren försedda ned glesa lär, de tvá öfriga med tüa simbar å böjsidan; fjerde paret har fjerde internodien langst och försedt med en process, som är cylindrisk och nastan af samma längd som den korta och tjocka femte internodien, sant i spetsen bärande en kuippa krökta har. Epimerema: De tvâ första paren hafva $\mathrm{i}$ de frimsta ändarne skarla spetsar, lıvilka doek aj na utanför kroppen; mellanrummet mellan andra och tredje paren är af' ringa bredd, men doek betydligt bredare än mellanrummet mellan de båda bakre gruppernas inre spetsar; tredje praset, som äro något viggformiga, hafva det främre yttre höruet langt och spetsigt, det bakre kortare, trulbbigt: fjerde paret, som uro nästan dubbelt bredare, visa utat en lang, franat riktad process, som sträcker sig till tredje paret; i hakkanten en obetydlig inbugtning, i hvilken ett stigma synes; de inre, bakre hörnen iro hvarandra mycket närstaende. l’a gränsen till bihanget, som är vida lägre in den öfriga kroppen, star anus som i främre och bakre ändan är unycket tillspetsad. Lubium bred orh kort, baktill rundad. Fiargen. ar hos hanen rödgul med otydliga svarta flackar a ryggen; det tapplika bibanget, pralper', ben och epimerer gulaktiga.

Längd 1 , bredd 0,85, fürsta benparet 0,8, andra 0,9 tredje 1, fjerde 1 millin.

Femina: Comme ovatum, antice emarginatum, postice latius anerulis prominulis, medio margine rotundato, appendicula carenti. Color ut in mare. Longitudo 1,2 millim. (Tab. Y'Tl, fig. 1).

Hona: Kroppen ä. mycket hög, bredt äggformig med en intryckning i frankanten mellan ögonen; bakkantens midt murlad, å ömse sidor syues en intryckning med korta, men tydliga sidohörn, vid hvilka sitta tvenne har, det framre rakt, det bakre krökt. Vid livardera sidan af den rundade bakkanten sta tveme längue, raka har oeh il sidorna, midt för fjerde paret epimerer, ett myeket kort hâr; franför hrardera ögat sta treme lylika. liemen hafva myeket täta hâr och simhâr; fürsta paret är nagot kortare än kroppuns bredel, fjerde lika langt som kroppen; fjerde internodion är längst, sjette,

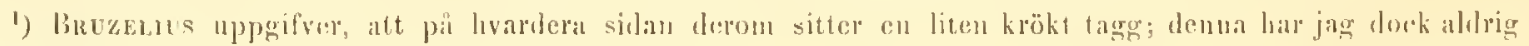
kitunat upptäicka. 
isymuerhet på fürsta och fjerde paret, vida smalare ïn femte. De frimme 'prmeremo hildade sasom hos hamen, men med längre framskjutande spetsar. Mellanrummen mellan epimergruperna tamligen breclar ${ }^{1}$ ); fjerde paret epinerer breda, nästan dubledt bredare in tredje paret. Generationsfïltet har nastan samma form som hos A. pustulutor, de lalfmanformiga glatta skifvoma äro bakat något smalale, och de vingformiga, mycket fint granulerade skifvorna, som utåt begrinsa dem, än kortare och utit tvärare. Fürgen hos honan är rödg̣ul med tydligare och störe svarta fläckal än hos hancn.

Läingd 1,2, bredd 1, första benparet 0,9, fjerde 1,2 millim.

De brumgula ägyen, som lägras 20 a 40 i hvarje kaka, utkläckas efter tvia à tre veckor. Larvema äro päronformiga, nyeket nedtryekta, liagula med gnlaktig teckning a ryggen. Ögonen mycket stora, mörkbruna; i bakkanten sitta trenne langa här och utanför dessa flere korta.

Längd 0,30, bredd 0,22 millim.

Denna art är allmän i sjüar och åar, sasom i Asmuden och vid Lindängen näral Ủriechamn, Bottensjön. Säfvean vid Alingsâs. äfen i minche häckar sason rid brobacka nära Skara, Tholsjöhult i Undenäs m. fl. st. I Skane ejöilsynt enligt linuzenes. Gotland vid Kinner, ; Gothemsân sant i en bäck uära Etelhems kyrka.

\section{Arrhenurus Kjerrmanni 11. sp.}

Las: Corpms eadem fere forma, qua 4. 'marginator, pro latitudine antem lonuius, autice altum, inter oculos emarginatum, postice in appendieen longiuseulam reliquo corpore multo angustionem prorluctam, cujus anguli prominentes acuti, retroversi sunt, in medio marginis posterioris appendicula apice latiore truncato-rotundata instructum Dorsum gibberibus duobus, altissimis, piliferis, prorsun directis, praeditum. Internodium quartum pedum quarti paris processum longum, apice piliferum emittens. Color flavo-fuscus, medio dorso, appendire appendiculaque flaveseentibus. Longitudo 1 millim. (Tab. VI, fig 3).

Hane: K'oppen är nastan sex-kantig, sisom hos A. emarginotor, men mera lảngsträikt och med mer afrundade vinkelhörn; frankanten mellan ögonen intryekt, bakkanten fölüngd till ett tamligen långt, men i förlällande till kloppens bredd smalt bihang, med utdragna, skappt tillspetsade, nästan rakt lakảt litdragna sidolıöru. Midt emellan dessa synes ett genomskinligt, himartadt, kort. men bredt lihang, som vid basen ar nagot bredare och har afrundade hön. Under detta star ett taplikt aller

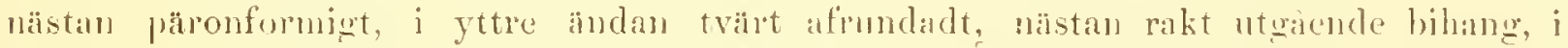
öfrigt, likt det, som förekommer hos A. emarginator. I rogggen, som framtill är ganskal hög, gâr längs efter densamma en obetydlig fördjupning, som afskiares af den bagformiga, intryekta linien, hvilken imesluter ett vida mindre styeke äl hos. 1. emmennator; bakit a önse sidor on dema fördjupning och indm ryegghinien sta näla bihangets bas trả höga, myckct spetsigga, flamat riktade knölar, i spetsen försedda med oft kort, fint hår; dessa knölar äro framtill mycket trära, nästan concavă, bakat deremut sakta sluttude. Vid basen af det himartade hilianget stá träme runda uphö̈ja punkter, hvar och en hïrande ett kort liar. Vid inknipningen straxt of vanför bi-

1) Hos yngre honor äro de jämförelsevis sualare. 
hangets början star ett hår å hvarje sida och framför ögonen tvenne dylika. Benen. äro längle $\mathrm{i}$ fürhallande till kroppen än hos A. emarginator; fürsta paret något lüngre an kroppens bredd, fjerde ej obetydligt längre än kroppen. Fjerde parets fjerde internodic försedd med en lang, obetydligt krökt process, omkring $2 / 3$ sil lang som femte interuodien och i den trubbiga spetsen försedd med en knipla krökta hår; de två främe benparen hafva glesa har. Epimererna bildade sasom hos $A$ emarginator, fjerde paret dock bredare $\mathrm{i}$ förhållaude till tredje. Labium, som i främre kanten är gauska bred, afsmalnar baktill, hvarigenom den blir uästan lijartlik. Palperna, af vanligg form, hatva a öfec lederna blott 1 ì 2 hár. Anus, som är oval, är belägen på gränsen till det nedtryckta bihanget. Vid basen af det tapplika windre bihanget star ett stigna. Till fïrgen alr den ofvan gnlbrun, nagot ljusare vid ögonen, å ryggens midt sant bihangen. Ügonen rödbruna, be]ägna nära kropjskanten. Undersidan nảgot nörkare med nästan gulaktiga epimerer och labium; ben och palper gulbruna.

Längd 1, bredd 0,78, första benparet 0,8, andrat 0,9, tredje 1, fjerde 1,2 millin.

Sälsynt, blott anträffad rid Björkelund nära Skara, der den först fanms af Apotekareu R. Kierrman.

\section{Arrhenurus tricuspidator (MüLLER) C. L. Kuch.}

Syı. 1776 IIydrachence tricespielator Mulder, Zool. Dan. Prodr. p. 189, N:o 2249.

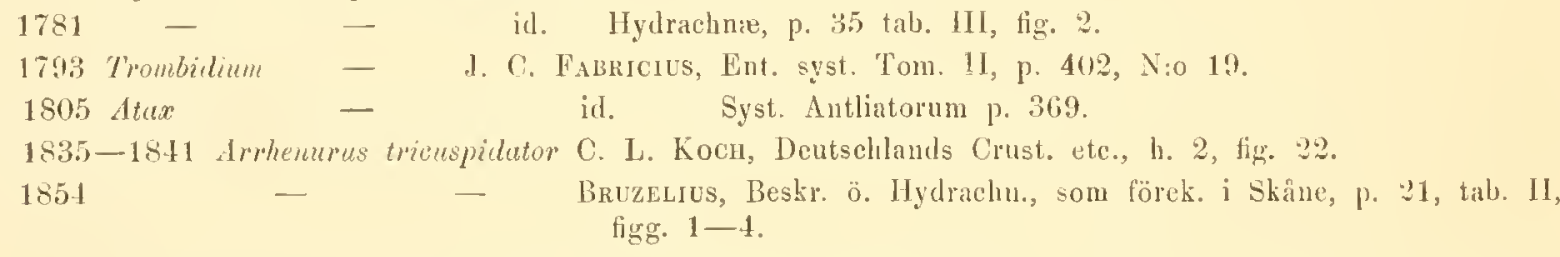

Has: Corpus eadem forma, uqua species priecedens, in appendicen longiusculam productum, cujus anguli obliqui et acntiusculi sunt, in medio marginis posterioris appendicula angustata, apice emargiuata instructam. Dorsum gibbcribus duobus parvis obtusiusculis prieditum. Internodium quatum pedum quarti paris processum breviorcu, apice pililerun, emittens, rolor miniacens maculis nigris, pedibus et palpis pallidioribus. Longitudo 1,3 millim. (ad basin appendicula). (Tab. TIII, fig. 2.)

Hane: Kroppen har nästan samma form som föregående art, är hög ả främre delen, mon saknal den längsgående intryckningen. Framom den bågformiga linien star a ömse sidor an obetydlig knöl, försedd med ett kort hår samt langre bakåt, nära bascu af lihanget, tvenne dylika; a hihanget synes en större trubbig knöl nned tvenne längre hâr, frin hvilken en spetsig förlingning tycks utgí rakt bakảt, med ett stigma i hvardera sirlan. Bihangets hörn äro mer ntât riktade och bredare än hos föregảende art, men smalare oeh kortare än hos A. emarginator. Bakkanten är mellan sidohörnen utskjutande, mularl och der försedd med ett mycket kort, men ganska bredt hinuartadt bihang af samma form som hos A. emarminator. Under detta sitter ett lảngt, och smalt, mot den mbngtade spetsen i bredd föga tilltagande, nedat riktadt bihang, hvilket, ofvanifrin sedt, är rännformigt ned nagot hopböjda kanter; fran mndre sidan serlt, synes detta bilang afrumblat. Vich basen af dess mudre sida står ett stigna. Håren i kroplens bakkant äro füstade pa samma sätt som hos A. emarginator. Benens första 
par kurtare an kropjens bredd, fierde lika lăngt som kroppen. Första paret försedt med glesal har. de öfriga paren, ispmuerhet fjerde, med ovanligt taita, kurtare och langre laảr; sistnämde pars fjerde internodie ntsändande en process, nagot mer än hälften sa lang som femte internodien och i spetsen försedd med en knippa mycket linga hàr, längre än sjelfva processen. Elimrigrnpuema äro skilda genom mycket smala mellandum; afstandet mellan andra och tredje paren utat dock bredare; tredje paret ovanligt breda och det fjerde dubbelt bredare an tredje; bakom det sistmanda paret stir ett stigma. Latium ïr mer långsträckt än hos A. énarginutor, men ej hjärllik, sasom los föregi̊nde art. Mantiblema hafva den vauliẹa formen. Pulperna äro besatta med tämligen talrika hà pâ ofle sidan af lederna. Till fïrym är den ljusöd, stundom stötande i gult med svarta ryggflickar; ben, palper och alpendicula ljusire.

meter.

Längal 1,:3, bredd 1, förstal benparet 0,85 , andra 0,95 , tredje 1, fjerde 1,25 milli-

Honan har jag ej anträfat, uch samnolikt är den ännu ej funnen ${ }^{1}$ ). Hanen förekommer silllsynf i sjöar och aar. Cpland i Fyrisan vid Utuma (Föret), Vitulfsber@er. Vestergötland i Venern vid Leckö, Asunden vid Ulricehamn sant i Säfvean vid Alingsăs. () land i Borgatriask. Skâne ej sällsynt enligt Bruzelils.

\section{Arrhenurus caudatus (1)E Geer) C. L. Koch.}

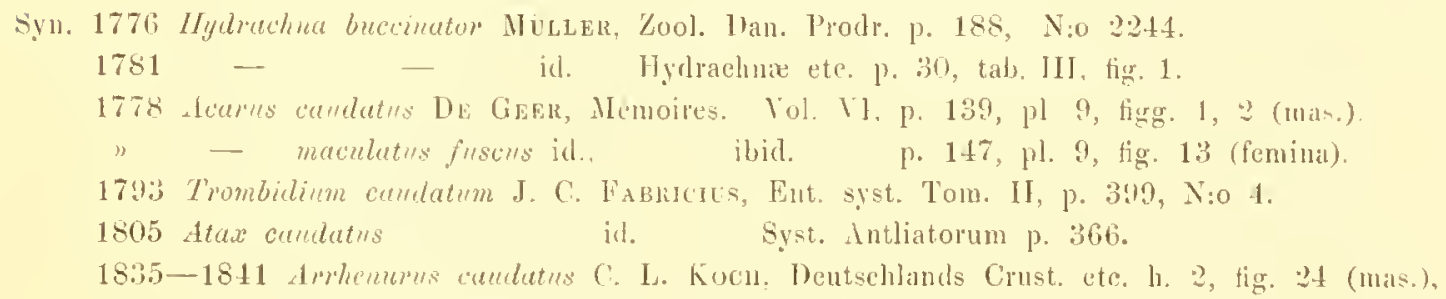

Mas: roppus obovatum, antiee rotundatum. impressione ntrinque instructum, postios in appendicem lonzam subteretem, basi eoartatam, medio erassissimam, apice supra concavan, trisinatam productum. Internodium quartum pedum quati paris processu perbrevi, sed erasso, apjec pilifero, instructum. ('olor citrulescens, antice llavescens; appendice basi corulescruti, reterum flavesenti, pedibus et palpis cano-curulescentibus. Longitudo 1,3 millim. ('Tab. 111, tig. 2)

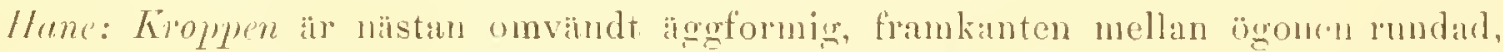
lakom dem försedd med en intryekning; sidolna raka, baktill mot bihanget smaningom afsmalnande; detta, som är nästall cylindriskt, ä mer än hälften sa langt som den ofriga kroppen, vid bascen smalist, hvarefter det lagot framom midten ridgar sige till sin största tjocklek och derefter not spetsen ater smäningom al'smalnatr. Fritu ötra sidan sedt, synes nagot, bakom len största förtjockningen en större mui knöl, lakom hvilken en i bürjan smal, men serlermera allt mer i bredel tilltagagande concavited visar sig, hvilken slutligen upptager luela öfre sidan af bilanget. Fran undre sidan sedt, synes ej denna, utan bihmeget tyekes vara eylindriskt mot spetsen och der sluta med afrundade sidohörn, mellin hrilka tvenne smấa afrnndade kü̈lar utskjutat; mellan dessa och bakkanten stí tremne hâr, ett längre och ett kortare, sant

1) I likhet med Bro\%eliss anser jag den al Kocu beskrilia honan vara hona till A. imargincetor. 
nagot framom concavitetens bôrjan tvenne hår â hvarje sida; à önse sidor om biluangets bas synes ett kolt hår. Ryggen är af ringa höjd, bakåt småningon sänkande sigr, IItan knölal'; den bagformiga linien, som ntlöper vid hihangets bas, inneshuter ett stort, ovalt ryggstycke. Benens första par är läugre än kroppens bredd, det fjerde uagot kortare in kroppen till yttersta spetsen af bihanget; detta pars fjerche internodic ă ej längre än den sjette och föga läugre än den fente, som är tämligen lång; den utskjutande processen ä myeket kort, knappt 1/3 sả lång som femte internodien.

Epimererna äro tämligen framstånde, dock na de ej utom kroppskanten. Fjerde paret aro dubbelt bredare än tredje. På den mot bihangets bas sluttande delen ligger anus, som är nästan rund och å ömse sidor omgifves af otydliga skifvor, nästan som hos en hona. Labium kort och bred, bakăt halfeirkelformigt afrundad, belägen ovanligt långt in. Palperna äro korta, niende till kroppskanten, fente leden mycket böjd, andra-fjerde med glesa hår å öfre sidan. Mandiblernas corpus kort, bakåt starkt vidgad, klon ofvan något concav. Fïrgen lıos denna art är grảblå eller svartblå, innm den bågformiga linien stå et par mörkare fläckar, frantill är den gulaktig, äfvenson på de två yttersta tredjedelarne af bihanget. Labium, palper, epimerer ocl ben grâblả.

Längd 1,3 till yttersta spetsen af bilunget, bredd 0,7 , bihanget 0,50 långt, 0,36 bredt, förstal beuparet 0,6 , andra 1 , tredje obetydligt längre, fjerde 1,2 millim.

Femina: Corpus parva altitudine, late ovatum, autice truncato-jofundatum, postice latius, rotundatum, utrimque impressum. (olor ut in mare. Longitudo 1,2 millim. (Tab. Xll, fig. 8.)

Hona: Kroppen ar bredt oval, i främre kanten myeket tvärt afrundad, i den breclare bakre likaledes afrundad med en intryckning ä ömse sidor, höjden obetydligr, isymuerhet frautill, ryggen utan knölar, den intryckta liniens bakre grins är här synligg, och det af denna linea inneshutna lyggstycket äl stort och langstrickt ovalt; i bakkanten stả trả langa hảr och tvenne kortare, vid intryckningen ett hår à hvarje sida samt läugre frum vid kroppens midt ett dylikt.

Benen äro tämligen korta och starka, första paret ej obetydligt kortale än kroppens bredd, fjerde ohetydligt kortare än dess längd. Epimerema äro smâ, ej franstaende, mellanrummet mellan andra och tredje paren obetydligt, mellan de bakre gruppernas inre andar ej bredare. Fjerde epinerparet ej dubbelt brealare än tredje. Straxt bakom dess inre, bakle, trubbiga hörn stâr ett stigma. Labium och palper bildade sâson hos hanen. Generationsfälet: De korta och bredt halfuanformiga, springan ongifvande glatta skifvorma ligga något närmare fjerke epinerparet in bakre kanten; de dem begriusande vingformiga, fint granulerade skifroma aro ovanligt korta, nistan rakt utit, riktade sant i yttre kanten afrundade. Närmare bakre kanten ligger anus och a ömse sidor derom star ett stigma. Till färgen är homan grả eller svartbla med fräınre delen rödgul; ögonen, som äro rödbruma, äro även omgifna af pödærult; pá ryggen sti nämare bakkanten, inom den intryckta linien, tremne svartaktiga fanckin.

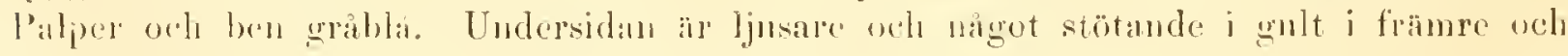


bakre kanten, epinererua äro gulaktiga, yttre ândarne grabla, de slata generationsskifvoma gulaktiga, de omgifvande granulerade skifvorma guablå.

Lïngd 1,2, bredd 1, första benparet 0,7, andra 0,85, tredje 0,9, fjerde 1,1 millim.

De stora, 0,2 millim. langa, rödaktiga ä!!ren, utklackas efter tre veckor. Larreme äro framtill afsmalnamele, baktill bredt afrundade med nedplattad ryger; frmm fïrgen hvit eller hrigul med an stor röel fläek a ryggen. Dema thack visar framtill tvenne atmulade lober, den mellersta leotydligt kortare, laktill ä den afrundad med an halfcirkelformign liten uringning i minlten. Ytterst i bakkunten synas trenne pa sma papiller sitande langa hehr, af halfva kroppslangden och ntanför dessa ett mycket kort

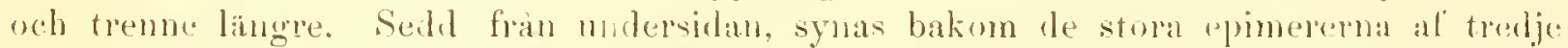

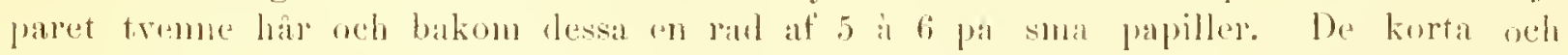
tjocka palpernal hafva is mellersta leden ett myeket langt hâr. De storn, mörk-

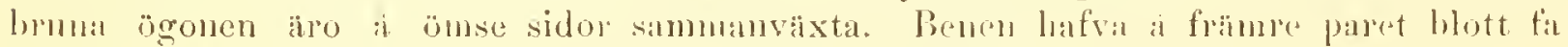
"rlesa hâr, a de bada bakre paren nagot täture och lingre.

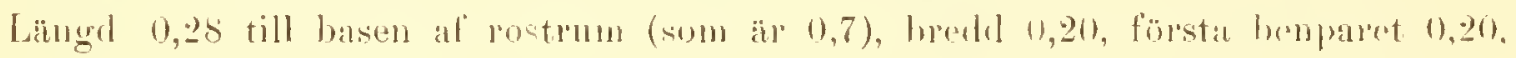
andra 0,24, tredje 0,28 millim.

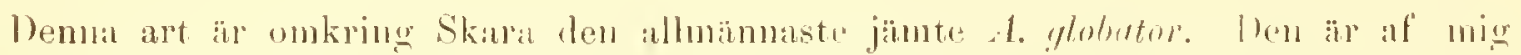

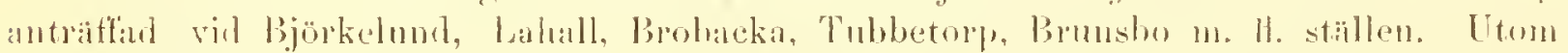

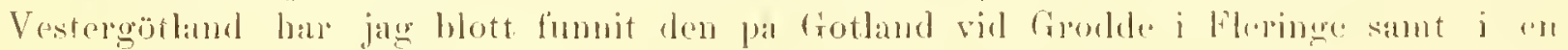
lam i parken vid lioma.

\section{S. Arrhenurus tubulator (MïLLER) ('. L. Kor'l.}

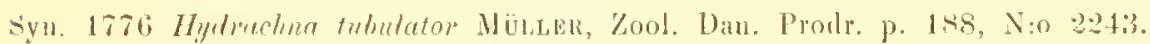

1781 - - id. Hydrachne cte. p. 29, tab. II, fig. li.

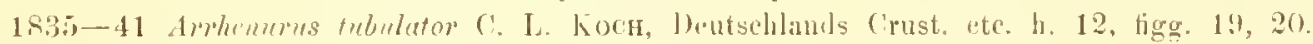

Ifas: Corpus eadem fere latitudine ae longitudine, antice paululum impressum, postice in appendicem corpus longitudine a puantem, lateribus parallelis, apier truncatum, productum. Interuodium guartum pedum quarti paris processum parvum emitteus. Fusco-virens, maculis nigro-fuscis, palpis pedibusyue viresentibus.

Hone: Kompen lika bred som limg, framtill något smalare med en obetydlig intryckning mellan ögonen, bakăt förlängd till ett jämnloredt bihang af samma längd som kroppen och med tväl ända; basen af bihanget in a öfre sidan försedd med en knöl; j bake ändan sta 4 hàr. Den intryckta linien inneshuter ett obetydligt ryggstycke; ¿t ryggen synas tveme störe knölar. De fränre epineremas spetsar äro myeket fram-

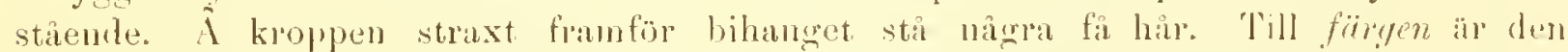

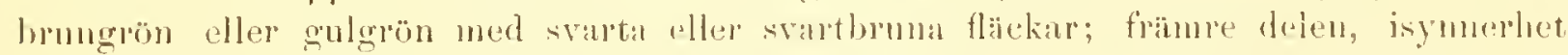
kring ögonen, crulaktig; hihanget vid basen hrmaktigt, i ytre andan grönt; lun och palper grölaktiga. 
Femina: Corpus ovatum, autice fere tuncatum, postice rotundatum impressione utrimque iustructum, angulis obtusis; fusco-virescens, maculis uigris. Longitudo $0,9 \mathrm{millim}$. ('Tab. XI, fig. 4).

Hont: Kroppen är tämligen lı̈g, äggformig, frantill starkt afsmalnande, mellan ügonen tvär, bakkanten i midten rundad, ä ömse sidor försedr med en tyllig intryckning, at sidorna begränsad af trubbiga höru; den intryckta rygglinien, som ifven bakit synes, innesluter en langstuickt, oval figur, som upptager störe delen af ryggen. A önse sidor om den rundade hakkanten stả tvi̊ länge hâr, vid de trubbiga hörnen tvenne kortare samt ett a hrarje sida. Benens första par är kortare än kroppens bredd, det fjerde lika langt som kroppen; alla hafva a tredje internodien utomordentligt linga, rätt utstaende har, mer än dubbelt sa langa som internodien, jïmte några kortare; fjerde och fente internodierna äro besatta med taita och mycket langa hår å de tre hakre paren. Epimerepnas spetsar ej sí framstiende som hos hanen, andra paret ovanligt breda i yttre ändan, genom ett obetydligt mellanimm skilka från tredje paret, som ej äro bredare än andra, men mycket langsträikta; fjerde paret äro föga bredare än tredje och ovanligt groft granulerade, mellanrummet mellan de bada bakre gruppernas inre andar obetydligt störe än mellan andra och tredje paren. Generutionsfïlet ligger nära fjerde epimerparet; de glatta skifvorna aro längsträckta, balfminformiga, de omgifvande fint grannlerade vingformiga skifvorna myeket lânga, naende nästan ut till kroppens sidor, främpe sidan nistan rak, hake nagot pundad, deras bredd af de glatta skifvormas längd. Nära bakre kanten ligger amus, omgifven af trå stigmer. Till füryen är honan olivgrön med stora, oftast distincta, svarta ryggflickar; ben och palper stötande i grult.

Hanen bar jag ej anträflat, honan deremot vid lirohacka nära Skara, i Semsjön i Gäseneds bärad, i Vassbotten i Vestergötland sant i lämtland i en bäck nära (Gstersund. Pii alla dessa ställen sällsynt.

\section{Arrhenurus globator (MüLLER) C. L. K’йH.}

Syı. 1776 Hydrachna globator Mülete, 7ool. Dan. Prodr. p. 188, N:0 2242.

$1781 \quad-\quad$ - id., IIydrachnit etc. 1. 2\%, tab. I, figg. 1-5.

1793 Trombidinu variator J. C. Fablacius, Ent. syst. Tom. II, p. 103, N:0 22.

1805 Atax - id. Syst. Antliatorum p. 369.

1835-41 Arrhenmus globator C. L. Koch, Jeutschlands Crust etr., l. 13, tigg. 22, 2:\%.

1854 - - - Bruzeluos Beskr. ö. Hydrachu., som förck. i Skåne, p. 31, tab. III, lim. :3.

Mas: Corpus subrotundum, antice paulum emarginatum, ferc truncatum, postice in appendicem corpors breviorem, apice quam basi latiorcm, subtruncatum productum. Internodium quartum pedum quarti paris processum emittens. Sordide virens, maculis fuscis, minus distinctis. Longitudo 0,8 millim. (Tab. I, fig. ?).

Hane: Kroppen är nistau rundad, framtill obetyrlige intryckt, naistan rak, baktill förlängd till ett bihang, som vid basen är smalt och lågt, ntåt bredare, à midten högst, derefter tamligen tvart aftagande i höjd mot bakre indan; denna är tvärt afhuggen med rundade hörn. Sedıl l'min yttersta kanten, synes denna liksom vara bildad af tväunc lager; frin hvardera höruet of det undre lagret ntgår rakt bakit ett lingert hinr, frin hvardera hörnet af det öfre tvenne kortare. A siclorna sta framför basen af förlangungen 6 it 8 kortare har. Ryggen, som framtill ar ganskr hög, altagel sa sma- 


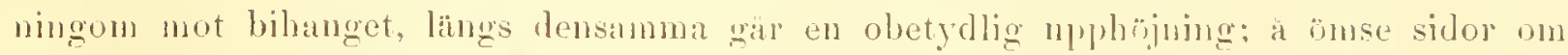
denna är den något concav och le yttre kanterna upphöjla. Egentliga knölar saknas; den bagformiga linien, som utlöper vid hasen af bihanget, innesluter ett ovalt stycke af obetydlig storlek. Bemen fürsta par ar nastan sa langt som kropyens bredd, det fjerde naistan sa langt som kroppon, bihanget inhegripet. Sistnändal pars fjerde internodie är forserld merl en kurt, nästan triangulär process, hesatt med glesa ha i spetsen; femt. intermolien ricl hasen mycket smal, a inre sidan visande con halfeirkelfolnig inbugtning; forde internodien aj dubbelt langre än fente, hada förseda med

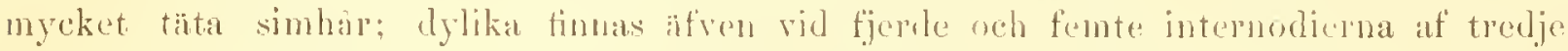
paret; de tra fräume palen hafva inga simlars. ntan hlutt glesare och styfrare har rid spetsen af internodierma. Epimereme frumse spetsar ajo mycket framskjutande, de

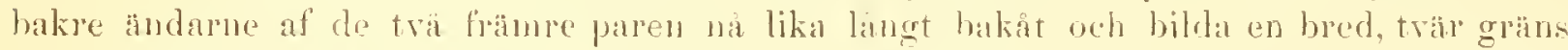
för ğxuppen. Melanrmunct mellan andra och tredje parens inre indar obetydligt, mellan de ytue vida störe. Fjerde paret obetydligt lmedare in tredje med nästan jämu bakkant och ej obetydligt mellanrum mellan de iure ändarne. Labium mycket bred och kort, baktill halfeirkelformigt mudad. Pà sluttningen mot bihangets bas ligger ams omgifven af trenne obetydliga, nagot upphöjla skifror. Till färgen an den ljusgrön elles gröngul med svartbruna, oftast ofydliga ryggfackar; palper orh ben gulgüna, epinerema gnlaktiga med de yttre spetsance gröna.

Iängd 0,8 till spetsen af bihanget, (som är 0,34), bredd 0,46, första henpritret 0,45, fjerde 0,75 millim.

Femina: Corpus late ovatum, antice truncatum, postice lotundatum, utrimplue subimplessum. Color ut in mare. Longitudo fere 1 millim. (Tab. X, fig. 3.)

Hona: Kroppen, som ej är symnerligen hög, är hredi äggformig, mellan ögonen tvär, bakkanten rundad med en obetydlig intryekning it ömse sidor: hiren sisom hos 4. tubulator. Den intryekta linien upptager storre delen af ryggen, är baktill otydlig och innesluter en ïggfornig figur. Benens fösta par ej obetydligt kontare an kroppens bredd, fjerde paret något längle an kroppen. Equmerema äro bildade sasom hos hanen, men hafva större mellanmm mellan grupperna. Labium mer längstrickt an hos hanen, Generationsfiultet ligger straxt bakon fjerde epimerparet; skifrorna aro ovanligt stora.

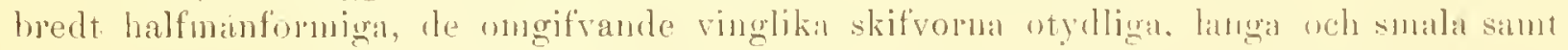
mycket bakit riktade. Nära bakre kanten ligger anus, med let vanliga stigmat a ömse

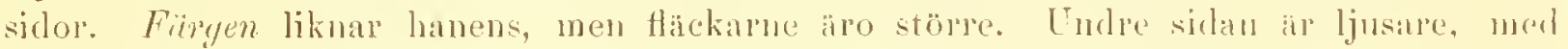
tremue stora, bruma Hackar bakom generationsfültet.

Länged 11,8 , bredd $0,6,6$, första benparet $(1,5$, fjerde $0,8-2$ millim.

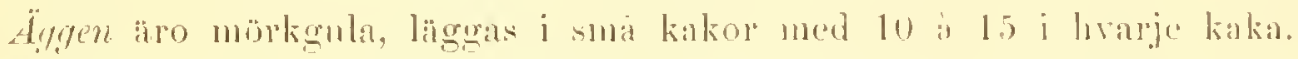

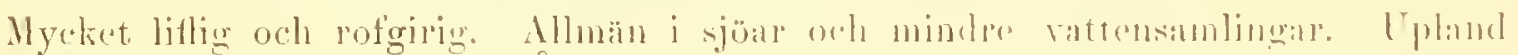

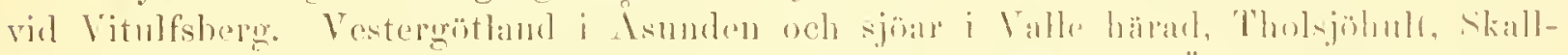

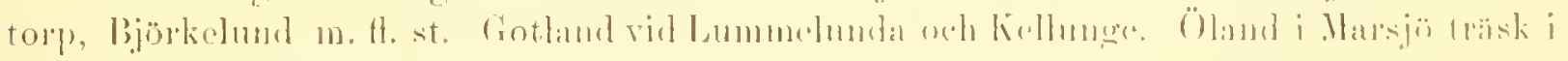
Fïral sh., lioleantriak. 


\section{Arrhenurus forpicatus n. sp.}

Has: rorpus fere octangulum, angulis obtusis, antice angustius, intra oculos paulum emarginatum, postice in appendicem latam, rotundatan, apice forpici similem, productum. Luternodium quartum pedum quarti paris processu carens. Color fusco-flavus, sape olivareus; appeudix basi aurantiaca, apice flava; palpi et pedes cano-flavi. Longitudo 1 millim. (Tab. VI, fig. ?.)

Hane: Kroppen är nästan att-kantig, med myeket afrundade hörn, framtill afsmalnande, ned en obetydlig intryekning mellan ögonen, baktill fönlïngd till ett bredt rundadt bihang, med en eirkelformig inbugtning i bakkanten, hvarigenom denma i högr grad liknar en hoftâng. Framre delen af kroppen ä ganska lı̈g, saknande knölar; den intryckta linien, hvars bakre ändar ej som vanligt utlüpa i intryckningen ofvan bihangets bas, utan i dess midt narma sig hvarandra, inmesluter ett mycket obetydligt, uvalt, mot bihanget afsmalnande stycke. Detta är tämligen högt och fortsätes bakåt a midten af det för öfrigt nedtryckta bihanget, men aftager alltmer i höjd och bredd och shtal med en liten spets nära den cirkelformiga inbugtningen; under denna star en rundad, obetydligrt franskjutande knöl. Vid basen af bihanget står à hrarje sida on den nämda upphöjningen ett kort laar och närmare yttre kanten tvenne längre å hvarje sida; a mudre sidan af de krökta spetsarne af bilanget synes ett nyeket langt och styft hả. Vid inknipningen niara bihangets bas saknas, ovanligt nog, hår, men nidt för fjerde epimerparet stir ett litet a hvardera sidan. Fürsta benparet något kortale än kroppens bredd, fjerde nogot längre än kroppen; de bada bakre paren med ovanligt talrika lång simhär a tredje, fjerde och femte internodiema fjerde parets fjerde led saknar process i spetsen. Mellanrummen mellan de olika epinergrupperna aro Jıeda, mellan fjerde parets ime andar ej smalare an mellan tredje parets. Den frionre gruppens bakre grans bredt afrundad. P’a sluthingen mot bihanget, $i$ en halfcirkelformig inbugtning af bakkanten, ligger unus, son äl mycket stor och alldeles rund. Lebimm är lika hred som lâng, hakat bredt afrmdad. P'alpernas andra led visar en fran alla öfriga arter afvikande form; den är nämligen kort oeh mycket tjoek samt har a inre silan en hö̈ knöl med en krans af tätt sittande, korta och tina hàr, öfrer hvilka ett större hâr står; ofvan leden, nära den tredje, synes ett längre hâr å ömse sidor; vid spetsen af den korta tredje leden sta tvenne nagot längre har. Färgen är hos denna art brungul eller olivgrön med fem mörkare fläckar a ryggen; bihanget är vid basen rödgult, mot spetsen gulaktigt; palper och ben grảgula.

Liangd 0,9 till bihangets spets (bihanget 0,25 lingt, 0,44 bredt), bredd 0,65 , första benparet 0,62 , andra 0,76 , tredje 0,4 , fjerde 1 inillim.

Mycket siallsynt. I Vestergütland har jag anträffat den vid Skalltorp, Husgärdet och Björkelund, hvarjänte jag genom Professur Lill..lebukg elhallit den fran Vitulfsberng i Lppland. Dess egendomligheter i flera afseenden gör migg büjd att anse den föl en larv i andra stadiet. 


\section{Arrhenurus papillator (MÏI,LER).}

Syn. 1776 IHydrachua papillator Milufr. Zool. Dan. Prodr. p. 189, N:0 2253.

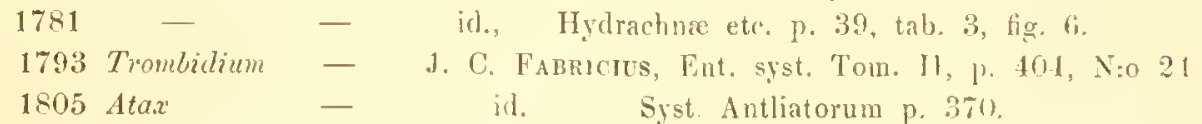

1Mas: Corpus subrotundum, antice panlum emarginatum, postice in appendicem productum brevissiman, sed latam, in medio marginis posterioris appendieula para, apice incisa, utrimyte papilla permagua, instructam. Intemorlium quartum pedum quarti paris proeessum satis longum emittens. Folor fuscus aut njoro-rubar. Longitudo circiter 1 millim. (Tab. IX, tig. 1).

Hane: Kroppen ïr af obetydlig hijd, något kantig, frantill füga afsunaluande, ned cn obetydligl intryckning mellan ägonen; haktill är den fölangel till etf utomordentligt kort men bredt bihang, utat begränsadt af en stor trublig kübl olleg.

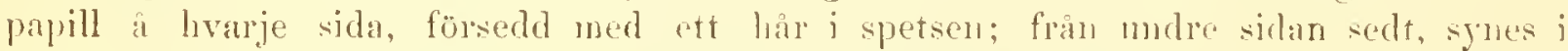
midten af deta bihang ett litet, dapuformigt (appendicula). som utat är hrealape med en ej obetydlig, nästan halfeirkelformig inskijping i midten; il hvardera sidan om detal mindre bihang star en mycket bred, obetydligt utskjutande knöl, namot intrrekt nedtill samt fürsedd med ett kort och tre linga har. (Demal knöl svnes vara hildarl af trenne, som sammanväxt). Från ofral sidan sỵes deta hihang knappt. hraremut a den något franskjutande miclen trenne mindre pajiller, livarderat fürsedd med langt har, risa sig. Ryggen är utan knölar, och den intryckta linien innesluter ett nästan cirkehundt styeke, upptagande största delen af densamma. Beme fürsa jar är obetydligt längre än kroppens hredd, fjerde föga längre an kroppen, bihangrot inberaknadt. De två hakre paren äro besatta med mycket täta simhår a tredje, fjerde och fomte internodierna. Fjerde parets fjerde intemodie ntsänder en tänligen lång, vid basen bred, men ntât afsmalnande process, försedd med talrika, böjda hả i spetsen; femte internodien är obetydligt kortare än sjette. 1)e främre epimerema franstảnde, men ej visande synnerligen langa spetsar; mollanummen mellan grmpperua äro smala, fjerde paret epimerer ganska breda, dubbelt bredure än tredje. Amus oval, linger som ranligt på sluttningen not bihanget sant är ongifven af trenne otydlig̣a, skiflikil upphöjnjugal. Till färgen är arten rödbrun, stmndom svarthrm med ett par hritaktiga flackar a främre delen. i hvilka de svartbruna ögonen ligga. Ben och palper nagot ljusare.

Längd 1,1, bredd 1, första benparet 1,05, fjerde 1,:- millim. (bilanget (1,1 langt, 0,6 bredt.)

Femina: Compes satis altum, late ovatum, ferc rotundatum, antice fere truncalum, postice rumcatorotundatum. Color ut in mare. maculis dorsualihus minus conspicuis. Longitudo 1.t millin. (Tal). IX, tig. Z)

Honan af desna ast är den största inom sägtet näst Homan af 4 . pustulutor.

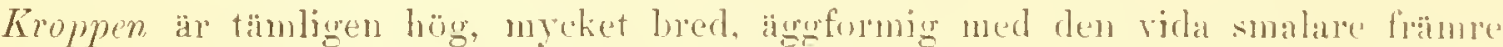
kanten trär cller trät afrundad; bakkanten ä äfen trint afrundad, ntan interekning

1) Dí MULLer p. 39 uppger, att han sett dema form i copulation med hanen all Armememe morulutor,

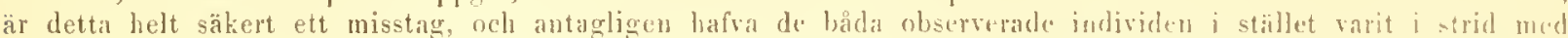

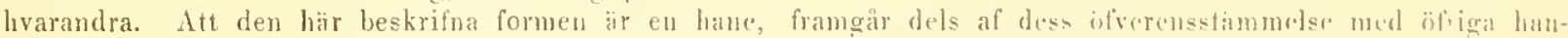
former, dels deraf, att den jämte honformen förekommer i samma lilla dam. dur för ofrigt, ulom .1. cuudutus,

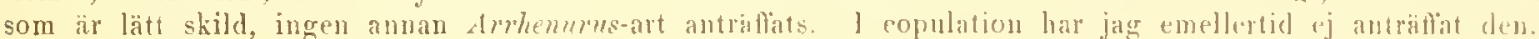


a sidona, den intryekta linien gaende nästan som hos hanen, men bildando en mer

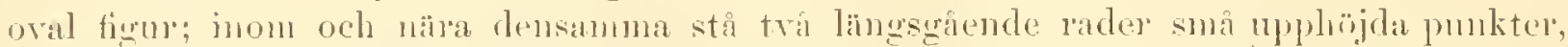
fem i harje rad. Epimerqupperma äro atskilda genom smala mellanrum, den främpe gruppens bakre grains brerlt lijärtik. Benen korta, första paret befyelligt kortare än kroppens bredd, fjerde nästau sa längt sum dersamma. Generationsfältet: l) glatta, springan ongiftande, skifroma äro mycket sula, halfmanformiga, utat begräusale af kurta, utat och bakat riktade, $i$ spetsen afrumdade vinglika skifror, hvilkas frinure. silor äro nagot concava, de bakre convexa. Amus ligger ej langt bakm dem; framför dem stal ett stigna och mellan deras yttre spetsal och kroppskanten treme, belïgna näl'a hvarandra; a ömse siclor om anus stril ett stigma, och bakom dessa tvenne näla hrallundla, bakom hvilka ett storle synes a hvardera sidan.

Liingl 1,8, bredd 0,6 , första benparet 1,1, fjerde 1,4 nillim.

lenna art ä ytterst sallsynt och has blott antriffats näla llellstenitore vid Skala.

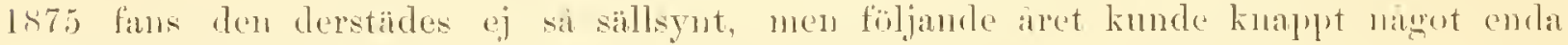
exemplar crhallas; 1877 syntes den ater nidget taluikare, isynnerhet homoma. Serlan

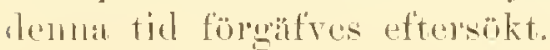

\section{Arrhenurus nobilis 11. - sp.}

Has: Corpus oratum. antire rotundatum, postice in appendicen longan et latan. npice truncatu rotundatim productum, in medio marginis posterioris hujus appendicis appendicula apice panlo latior et truncata conspicitur. Culor pallide viridis, maculis luseis; palpis et pedibus flavescentibus. Longitulo 1 millim. (Tab. $\mathrm{X}$, fig. 1).

Hane: Kroppen är äggformig, framtill runclarl, bakả förlängd till ett langt och bredt bihane, som utit ir tvint afrumladt och i midten forsedt med eft genomskinligt, langt och smalt mindre bihang, som mot spetsen ä nagot bredare sant trät afhugget. I hvardera sidan on detta ntegar ett annat bihang, som är halfinanformigt oeh tamligen bredt; dessa bada mötas med sina spetsar utanför det mellerstat bihanget: a ömse sidor derom sta tva linga hår, dubbelt längre än bihanget. Botraktas djuret frim öfre sidan, si synes a midten liksom hos $A$. tricuspidator och $A$. marginutor ofvan dessa bihang ett annat kort hilang, lika langt som hredt, genomskinligrt, j bakkanten försedt need tvenne inbugtuingar; a ömse sidor on detta star en kort knöl och ytterst ett lingt har. Den intryckta linien är bakat försvinumde och otydligure än hos ofriga arter inom slig get; det inmeslutna ryggstyeket är olretydligt. Livmergmppema âro skilda genom högst obetydliga mellanrum, fjerde paret inme ämdar mästan stätande tillsamunas. Dessa epimere äro nästan qradratiska, mej äu dublelt bredare än tredje paret. Labum kort och hred, baktill halfeirkelformigt rundad. Anns beliugen och hillad sasom hus füregaende art, men saknande de omgifrande

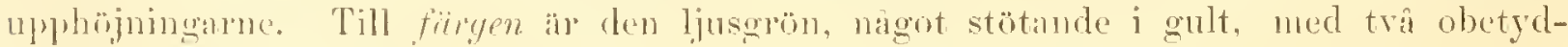
liga lowna rygentackar. Unrlersirlan, ben och palper gulgröna.

Blott ett enda cxemplar har jag erhallit i Oktolne $186 \mathrm{~S}$ i Mälaren vid Kungshamm pra 20) it 30 fots djup. 


\section{Arrhenurus castaneus 11. sp.}

Has: Corpus oblongro-ovatum, antice truncato-rotmulatum, postices serisim decrescens, roumdatum, appen-

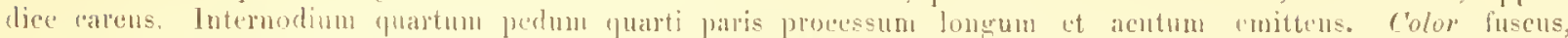
maculis nullis. Longitudo $(1, \$ 5$ millim. (Tab. IX, tig. :3.)

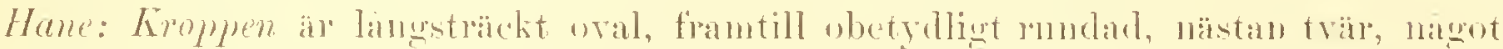

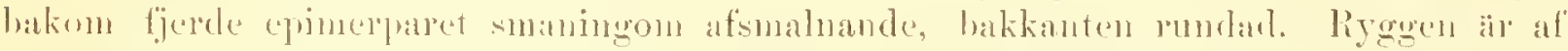
obetydlig höjd, den intryckta linion imeshter ett aflanget ovalt, i hakkanten nigent in-

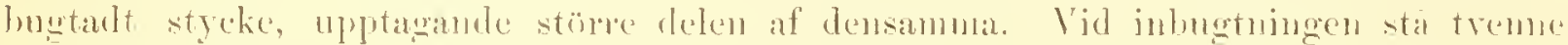

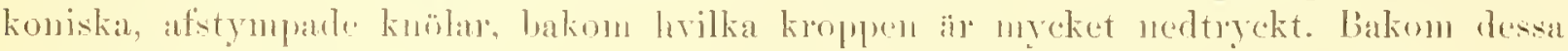

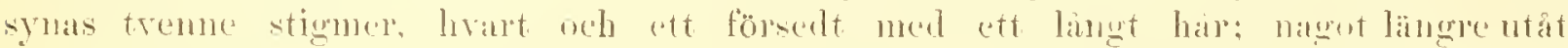
ett stigma a hrartera sidan, saknande har. I kanten sta trenne har a hrarje sja om

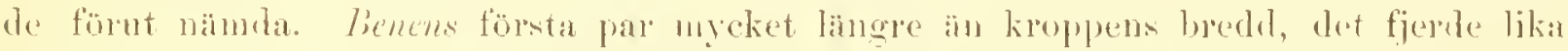
lanert som kpoplen; fjerte parets fjerde internorlie har samma form som bos A. per-

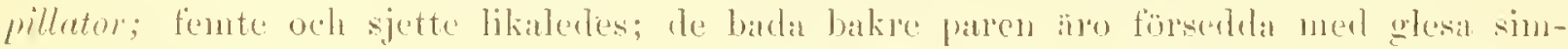
har. Mellannmuet mellan ambar och teedje epimer-paren tämligen smalt, mellan de

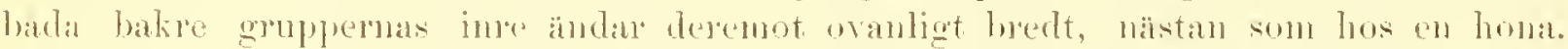

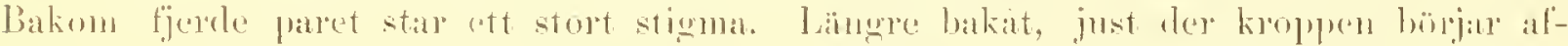
smahna, ligger anms, som in gamska stor, omgifren af tromme otylliga langa skifvor. Längst bort i bakre kanten syoes eft stigna, weh a hvadera siban ett mindre. Labium

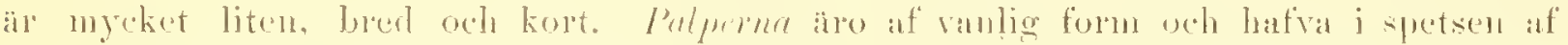

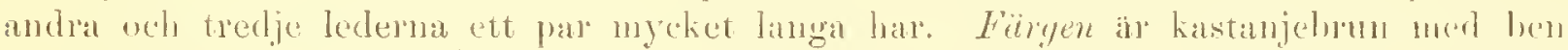

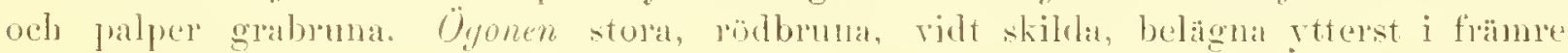
kinten.

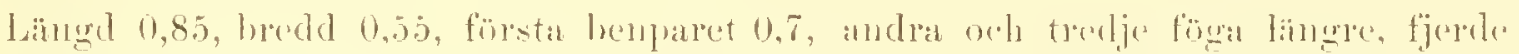
0,85 , paljer 0,20 millim.

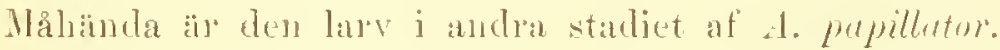

Femine: Corme late ovatum, antice at postice rotundatum, parvil altitudine. Color ut in mare. Lougitudo 0.95 millim. (Tab. IX, tig. 4.)

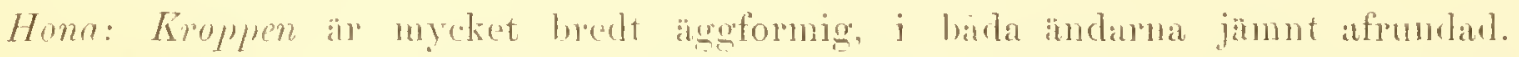

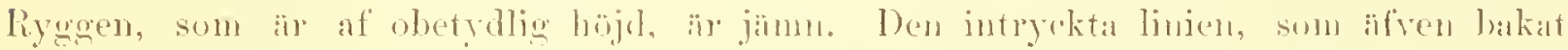

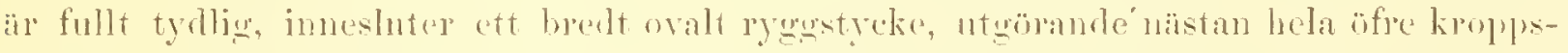
sidan; j bakkanten sta sex bar. bemen kortale än! hos hanell; första paref kortare än

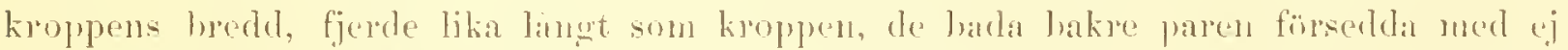

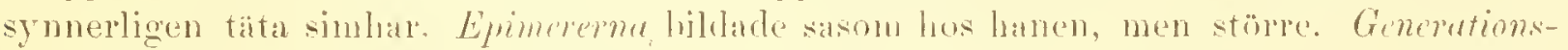

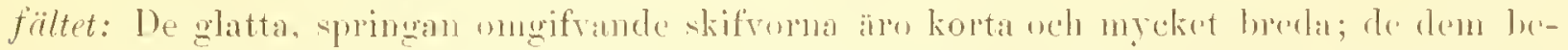

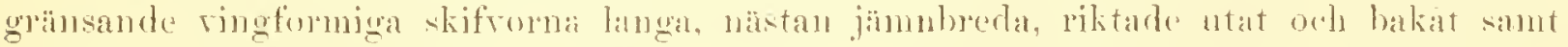
i spetsen afrundade. Fargen sadan som los hanen; stmudom symas it ryggen llagra otydliga, mörkare tläckir.

Liangd 0,95, bredd 0, \$0, första benparet 0,70, andrat 0,80, tredje 0,85, fjerde 0,95, palper 0,20 millim. 
Denua ant ä sällsyut och blott antriffad rid Björkelund och i bimusbo storäng niira Skina.

\section{Arrhenurus angulator C. L. KócH. ')}

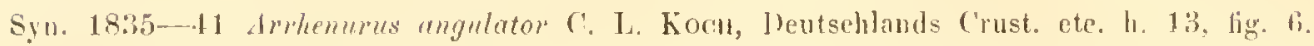

Femina: Corpus late ovatum, eadem fere latitudine ac longitndine, antice paulun cmarginatum, postion: fere truneatum, angulis acutis, in medio marginis posterioris rotundatum. Color ochraceus, maculis nigris. Longitudo 1,2 millim. (Tab. VT, tig. 1.)

Homa: Kroppen är nastau lika lored som lang, framtill naggot afsmalnande, mellan ögonen visande en bloctydligg intryckning. bakat mycket trär med spetsiga sidolö̈un, mellan lovilka kroppslsunten är bredt afrumdad. § ömse sidor on denna afrundning sta tra har, ett mycket langt och ett nagot kortare, vid hvardera sirlohörnet ett hà och midt für fïerde epimerparet ett dylikt; höjden ej stor. Den intryckta linion ä bakä fösrinmande ocli innesluter ett letydligt rygastycke af oval form. Bene? aro korta och tänligen tjocka; första paret ej obetydligt kortare in kroppens bredd, fjerde paret nigot kortare in densamma, alla paren ntom det första försedda med mycket talrika hår och simhar. Klorna mycket spensliga. Epimergrupperna aro genom suala mellanmm skilda fran luvarandra; den framse gruppens bakre gräns bredt hjärlik, de frimpe andarne med ganska stora, ehuru oj utom kroppen framskjutande spetsar; fjerde paret nätnu rektangulära med fögin märklan inbugtuing baktill och obetydligt hrerlate an tredje. Generationsfältet in belaget straxt hakom fjerde epimerparet; de glatta skifrorna üro bredt lalfuñnformiga; de deu ntât begränsande, fint grannlerare vingfomiga skifrorna korta, nycket bakat riktade samt j yttre indan rundade, ej afsmalnande. Anus, som ligger nürmare bakkanten in generationsfültet, är mycket liten, rundad och ä ömse sidor omgifven af de vanliga stigmerna. Färyen är los denua art grul med svarta flackar, ben och palpes gnlgrá eller gulgröna. Spetsarne af epimeserna äro mörka, nästan svartbruna, de släta generationsskifvorna ljusgula, de vingformiga gulbruma.

Iängd 1,2, bredd 1,1, fürsta benparet 0,80, andra 0,90, tredje 0,47 , fjerde 1 millim.

Siillsyut. Blott anträffad pâ Gotland vid Kimmer i Jummelunda, Heide trisk, Etelhem i biaken vid kyrkan samt i kellumge j en bäk nara prestgarden.

1) Euligt Kocus judelning af Arrhomms-arterna, hilken jag i almänhct föjt, skulle donua art höra till len första gruppen, men dii han ej fumbt hanen och jag redan vid beskrifning af honan till flrmemrus pustulator visat oriktigheten af hans tilluagagnende att fran ena köncts form sluta till det andras, har jag ansett

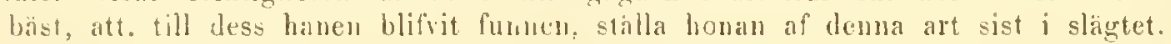




\section{Genus 14. ANURANIA n. g.}

Corpns lave, molle, satis alum, in dorso area ovata, stria limitata, carens. ibigur antem stigmatibus

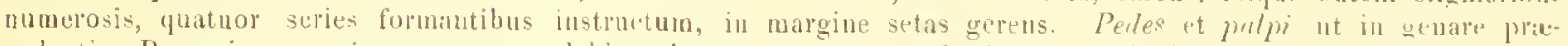
cectenti. Par primum epimeprum pone labium inter se comnatil. Oculi permagui, distantes.

I Inina föregảende redogörelser für Sreriges Hydrachnider: nNigra nya sronska arter och slïgten af Hydrahnidern, i Forhandlingrorne red de skmulinaviske Naturforskeres

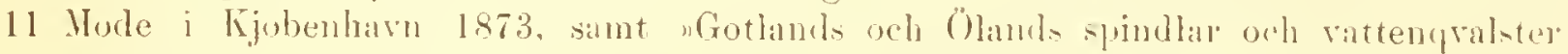

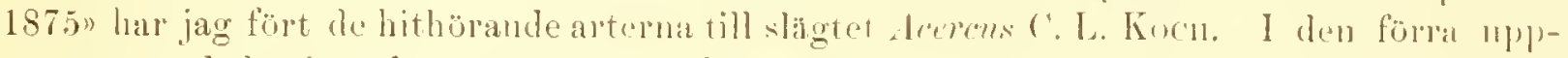
satsen uttalade jag den isigten, att detta kanske vore nindre riktigt, och jag är nu aldeles ofvertygad härom, enär jag fumit si manga och rigtiga skilnader mellan hithörande anter och Kocns Aetms-arter, att de omöjligen kuma höra till samma släite.

Frản Arrhenures, med hvilhet sägte detta fületer stor likhet, skiljer det sig lält genom den glatta och mjuka, nästan sidenlika kroppsbetäckningen, grenom frivaron af den intryckta rygglinien veh genom de sammanväixta fiansta epimererna.

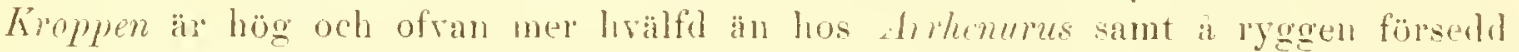
med talrika stigmer, ordnade i 4 rader; â undre kroppssidan synas äfren en mängrd dylika stigmer. Ben och palper hafva deremot samma form som hos dirhenurus. Grenerationsfältet afviker genom frảnvoron af de glatta, ljusa skifrorna, som alltid omgifra springan hos Arrkemurus. Här är generationsopplningen nästan rund och begränsas utat omedelbart af de vingtorniga, fint gramulerate skifroma, som äro korta, smala och nästan rakt utat riktade, frimpe sidan nägot concar, hakre convex. Till vistelseort och lefnadssät myeket liknande Arrhemures. Blott trenue arter hafva antraffats.

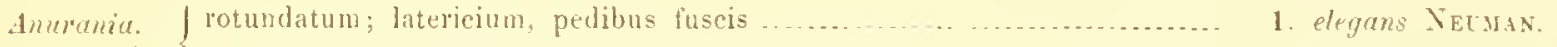

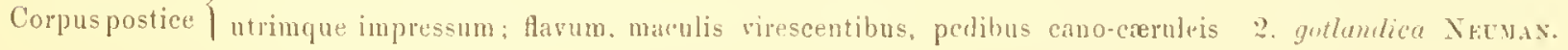

\section{Anurania elegans NeLMAN.}

Syn. 1873 tcereus elegans Netwax. Forh. ved Saturf-inodet i Kjoheuh. 1873, p. 408. fig. 3.)

C'urme late ovatum, fere rotundatum, urnicatum latericium, pedibus fuscis. Longirudo 1 milliur. (Taib. MIV.

Kroppen är nästan rund med hrälfet ryege, a hvals midt löpa trenne rader stigner,

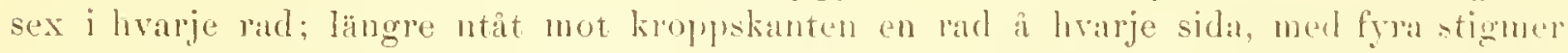
i hvarje, i bakkanten sti sex har, af hrilka fyra utga fin undue sidan uch tra fran den üfre, framom ögonen sta a hrarje sida tra hadr. A umbe silans bake del synas atta par stigmer, det ena i hrarje par dnbbelt stüres och ntsimdande ett kort har; mellan den frimre och de bada bakre epimererupperna stil afvern ett dylikt par.

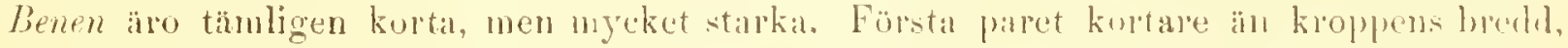

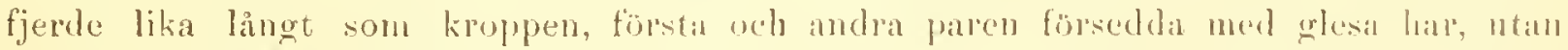

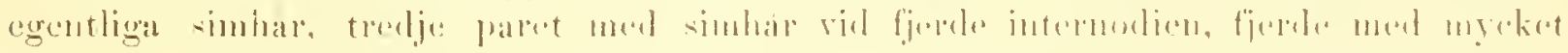


lánga och tata simhar vid tredje, fjerde och femte internodierna. Första paret epimerer äro ovanligt breda och langa, under labium med hvarandra fullkomligt sammanväxta. så att ingen grins kan upptackas; andra paret tydligt skilda frin första, betydligt kortape, viggformiga. De bada pareus bakre grans bildar en bredt hjärtik figur, hvars spets är något trubbig och nästan nedskjuter i jamnhöjll ned tredje paret. Mellanpummen mellan första mruppen och de båda ofriga obetydligt, mullan de bida bakre deremot a kroppens midt dubbelt större; tredje paret äro smala, fjerde nästan rektangulär, inat smalare med en obetydlig uthotning a midten af bakre sidan, naistan dubbelt störe än tredje paret. Ejimererna upptaga ej bälften af undre kroppssidan. Ej langt bakom dem ligger generationsfältet och straxt bakom detta den tanligen stora runda anms. Labium är fullkomligt firi och till formen hjürtlik; dess främre kant visar i midten en tydligt hegränsad oval figur, i midten delad af en springa. Ionna oval tyckes vara af mjukare, nästan hinuartad, consistens in den öfriga labium, som junte epinerer, ben och generationsskifvor aro tamligun hioda och mycket fint glanulerade. Mandiblerna hafva en näitin konisk corpus med en mycket stor och starkt böju, concav klo, mot hvars spets ett smalt bihang höjer sig frân klons bas liksom hos Amhenurus. Palperna, som likna dem hos Arhemus, bafva i framre ändan af andra leden en krans glesa, långa hår, på offe sidall af́ fjerde myckut sun och i dess concava främpe del, mot hrilken den femte hildal en tang, ett kort, styft hâr. Firgen är hos denna art nästan tegelröd med svarta ringlorniga stigmer a ryggen. Ögonen ovanligt stora, svarta, nästan trekantiga. Undersidan har samma färo, som den öfre; labium, epineres, ben och generationsfält svantalktiga.

Lungd 1 , hredd 0,9 första lonparet 0,7 , fjerde 1 millius.

Mycket sällsynt. Blott träffad vid Björkelund niira Skara, der ett enda cxemplar erhölls 1873.

\section{Anurania gotlandica Neuman.}

Syu. 1875 Aeprens gotlandiens Neumx, Gotands och Olands spindlar och vattenqvalster i Kongl. Vet.-Akar. Förh. N:0 2, p. 102.

Compe fere rotumetum, parva altiudine, postice utrimque improssiono vix conspicua instructum. flavum ant flavo-virescens, maculis olivaceis aut fuscis. Longitndo 0,9 millim. (Tab. XI, fig. 3.)

Kroppen äl nästan rund och af obetydlig hijjl med en högst obetydlig intryekning i bakkanten å ömse silor; i lyggens mislt synas, likasom hos föpexiende art, tva rader stigner med fen $i$ hrarje rad samt mot hvardera sidokanten en rad, innehallande tre. Af de sex haren $i$ bakkanten aro tva mycket fina och sran att upptaicka; stigmerma a unde sidan mngefur som hos föregiende art. Benen iro mycket korta, första paret kortare än kroppens bredd, fjerde si lingt som loredden; hlott sistnämda par försedt med simhin. Epimererna äro nästan bildarle soṇ bos A. degans, men den lörsta gluppens bikve grräms nedlöpel a midten med en skarp spets, och

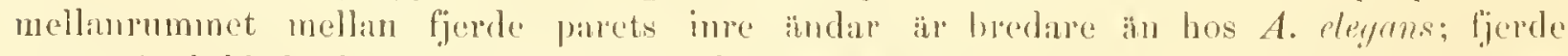

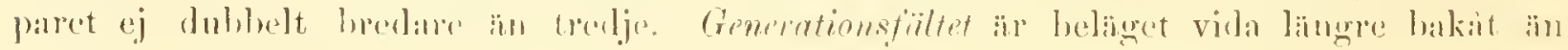


hos A. deguns; fjerde paret ci dubhelt bredare än trealje. Cienerationstialtet är beläget

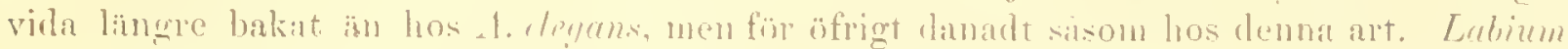

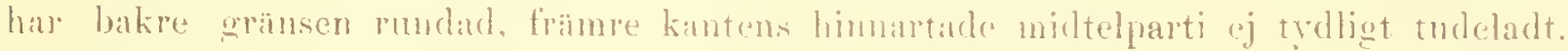
Mandiblemss klo rakare in hos d. elequns. Polpeme korta, nàende till spetsen at fürsta benparets tredje intermolie och af samma tjocklek sum detta benpar. Tjll fiirynn iir den valuligen gul aller sulerön (mera sillan gulpöd) ned grona eller brunaktiga Hickar. Palper, labium, epimerer och best sant generationskifrom grabla; bakom

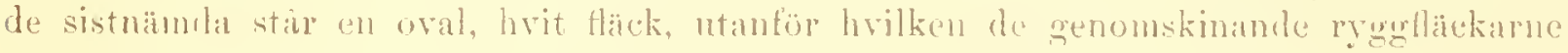
syilas.

Längd 0,9 , bould 10.8 , palper 0,2 , füsta benparet 0.6 , fjerde 0.8 millin.

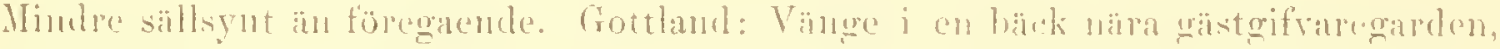

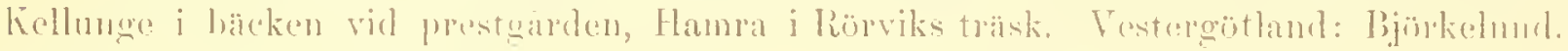
Bohuslïn: Orust vid Hulta.

\section{Genus 15. LIMNESIA C. L. Köo(n}

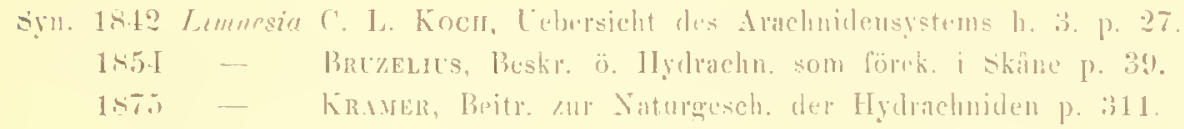

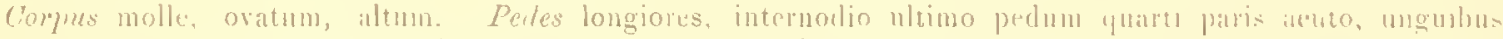

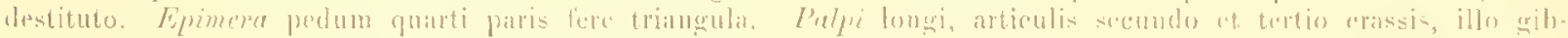

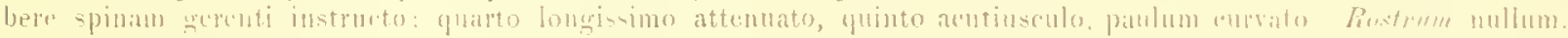
Dno paria ocelomm listantia, lini utrinsque lateris inter se ricini.

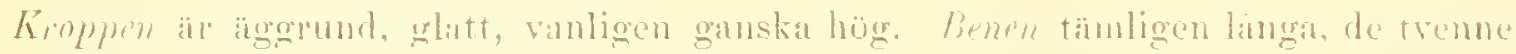

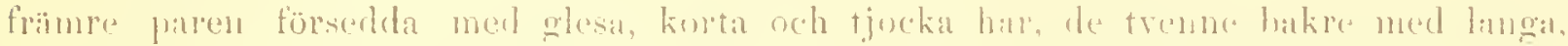

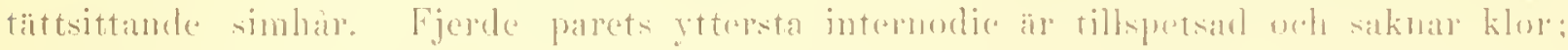

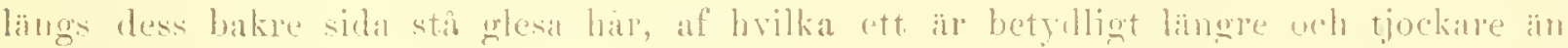
de ofriga: vid spetsen af tredje-fente intemodierna synas loreda, nastan spjutlika. i

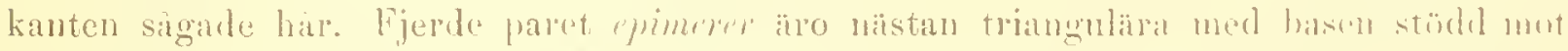
tredje paret och spetsen vind bakat uch utat; i denua spets sinter fjerde henparet intugalt.

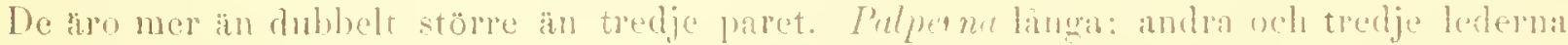

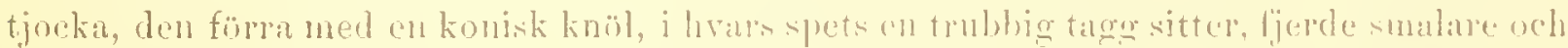

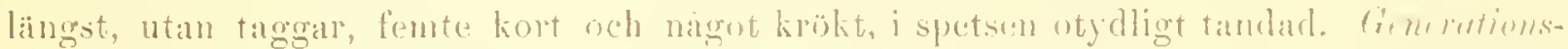

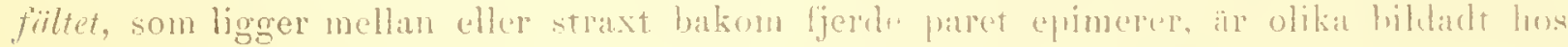

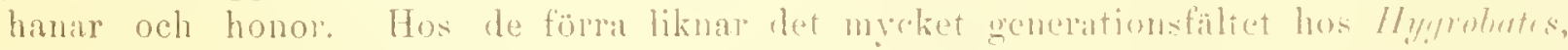
der de bada skifvorna, hrardera med sina tre stignes, hilda en mer ellor mindre lijartlik tigur med framat riktad spets. Ilos honorma derenot bildal desia skifior, som

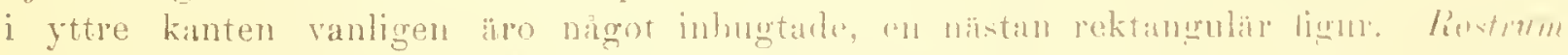

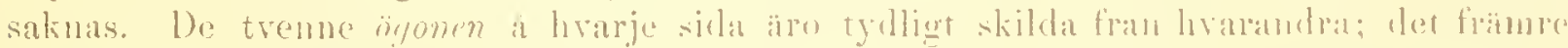

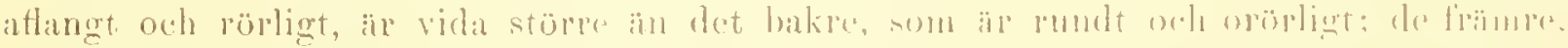

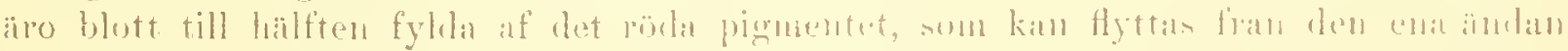

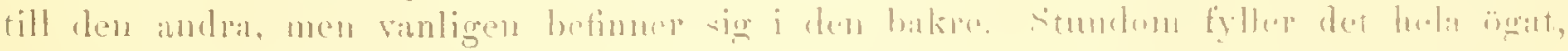

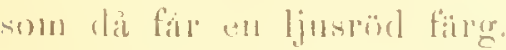

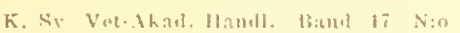


Hithörande ljur uppelâllil sig nïstan uteslutande i sjöar eller större valtendrag. som iro rika pa vattenvixter ( $L$. pardina och $L$. marmorata), sällan i. mindre dammar (L. maculatr). Ett mulantag hïrifrin gör dock L. histrimiar, som ganskia talrik finmes i de grunda kalkhaltiga trisken pa Öland, hrilka äro symerligen fattigar pal växter.

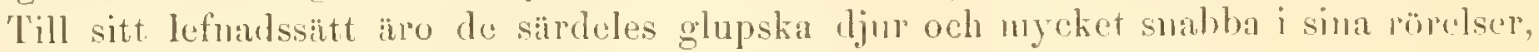
luvirföre deras rof ej lätt undgi̊r dem.

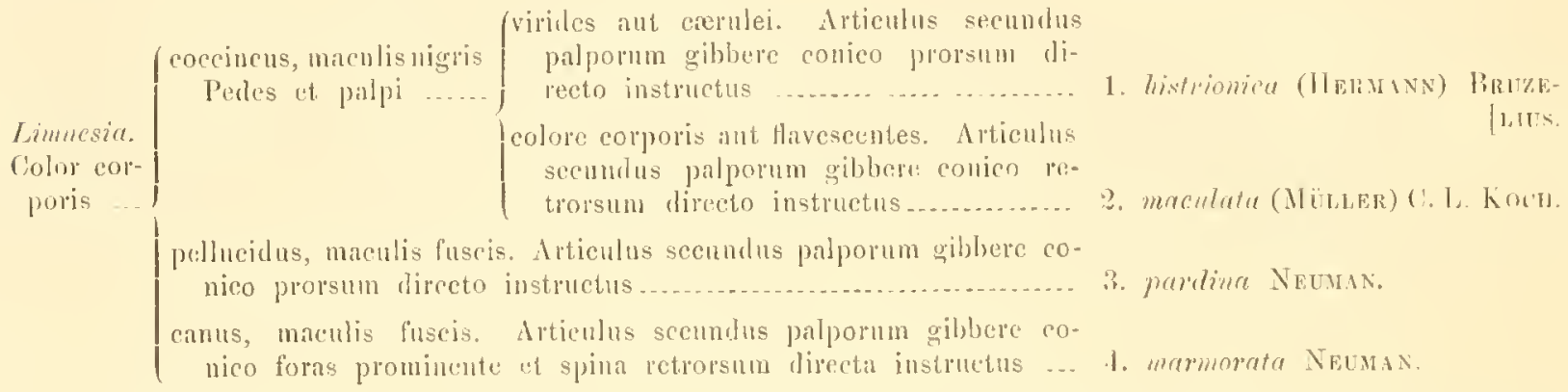

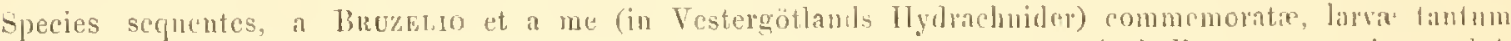

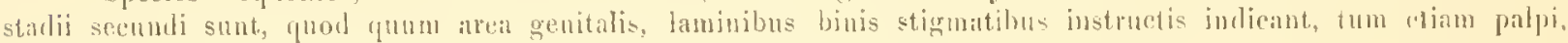
ynorum articulus secundus qibbere conico, spina gerenti, omnimo raret.

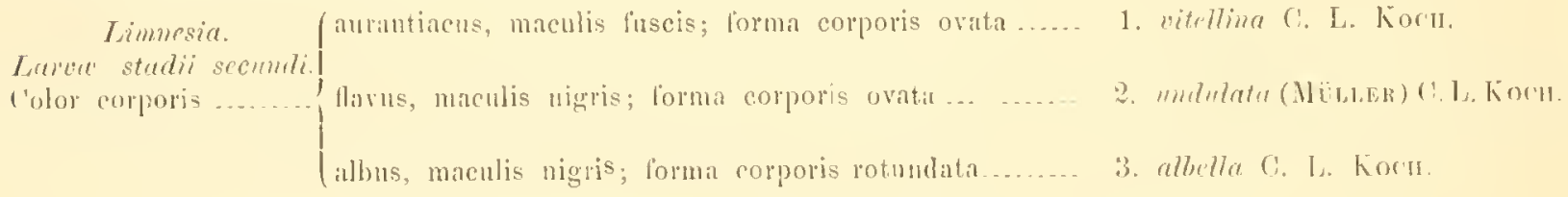

\section{Limnesia histrionica (Hermane) Bhizelus.}

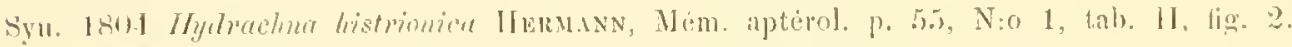

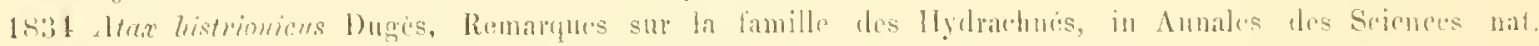

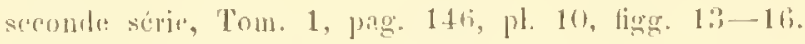

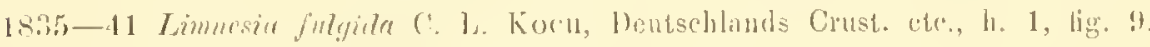

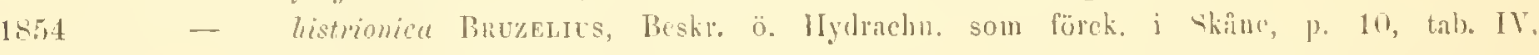
figg. $2-5$.

Coppus ovatum, altis-imum, corciucum, maculis nigris. Pedes longiusculi, carulci (olscure virirles Bury.), Juo paria interiora pilis perraris instrueta. Palpi erassissini et longissimi, peue ar hasin artieuli ultimi prelum primi paris pertinentes et hor pari duplo relassiores; articulus securdus, fribbere conico, propsum dirceto instruetus. Longitudo circiter 1,5 millim. (Tib. XJII, lig. 1.)

Kroppen är inyeket liög, bredt ïgrgformig. Benen af medelmåttig lïngl; första paret nagot kortare in kroppens bredd, fjerde ej obetydligt lingre in kroppers. Epimerernas första och andra par nastan raka och jimmbredil, betydligt kortare an hos föregiende art. Tredje paret ibo langa och utat obetydligt bredire, fjerde paret wit cj sà langt inat som trodje, leris yttre bakpe hörn tïnligen trubbiga. Labium, som air bredast nagot framför midten, ar delarl i tvenne hälfter af en längsganende springal frân framkanten till midten; här delar sig springan i tvenme, som wil till bakpe andan

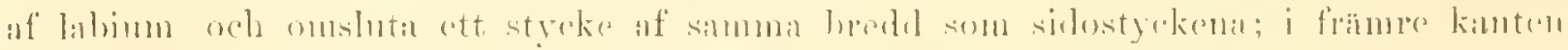

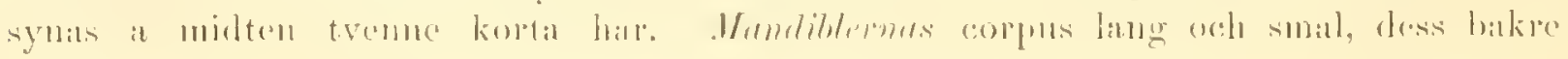




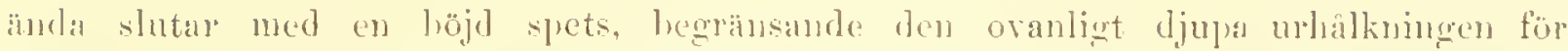

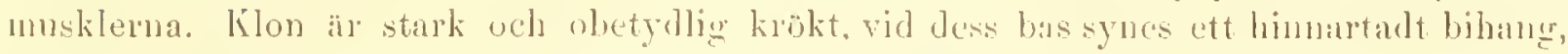
som ofta lätt skadas. da mandiblema uttanas. P'alperno äro ovanligh lảnga och tjorka ${ }^{1}$ ); de nâ nästan till basen af första benparets sista internodie, och deras andra led är dubbelt tjockare in samma benpar. 1) lumal led är försedd med en lang, framat riktad konisk knöl, pả luvilken sitter en kort, trulbijg tagg. A ofre sidan af andra och tredje leclerna synas flere korta och styfra har sand i främe ändan af tredje leden treme längre; undre sidan af fjende leden, son än nastan lika lang som andra och tredje till-

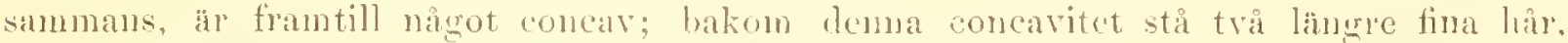
femte leden är liten och spetsig. Gemmationstaltet: Skifroma äro försedda med tvenue störe stjgmer i bakre ändan weh cett $\mathrm{i}$ den fribure; mellan dessa synas magra fat, mycket

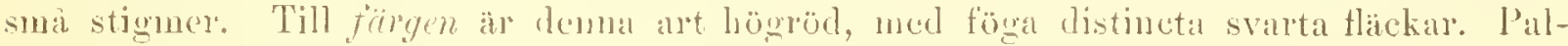
pere, hen, yttre ändarne af ejunererna sant labium, blàgröna.

Lingd 1,3, bredd 1,1, palper 0,95 , första benparet 1 , andra 1,2 , tredje 1,3 , fjerd. 1,7 millim.

En anman: Laingd 1,8, bredd 1,6, palper 1, första benjaret 1,25, andrar 1,45, tredje 1,5 , fijete 2 millim.

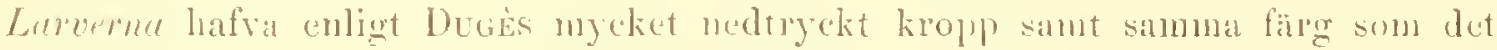
fullvixila djuret.

If mign blott antriffad i träsken a norra Oland, der den förekommer ganska allnän.") I Skane är den enligt Bruzelus ej sällsynt.

\section{Limnesia maculata (Müllem) Brizlidis.}

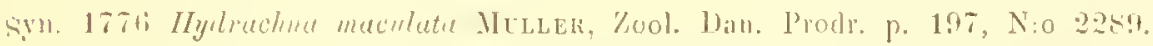

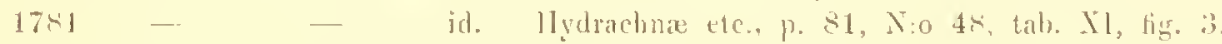

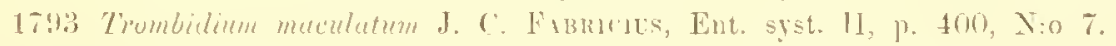

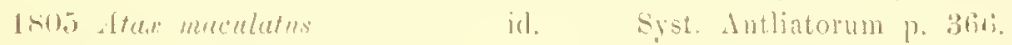

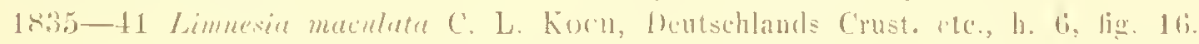

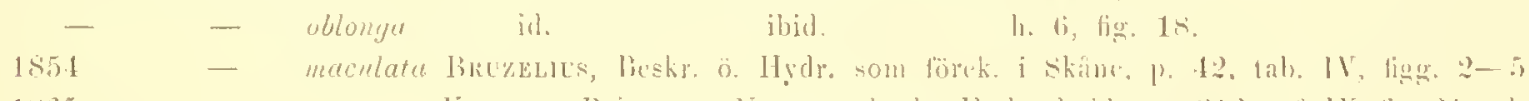

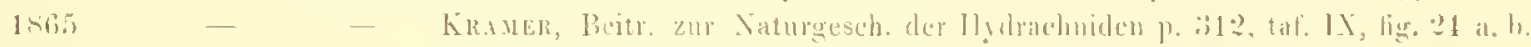

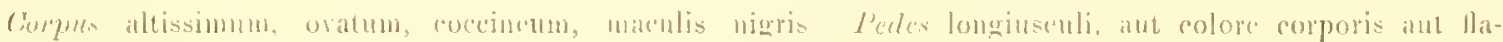

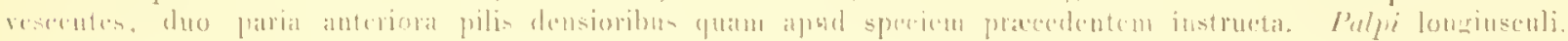

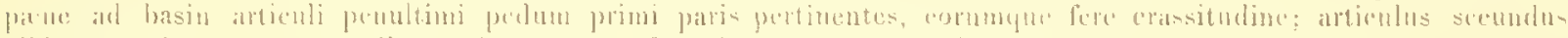

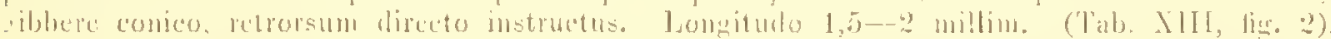

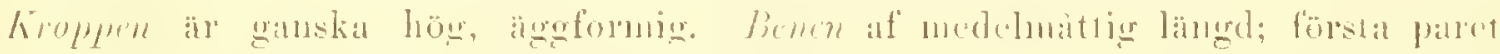

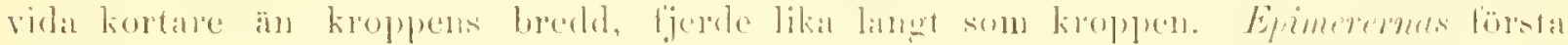

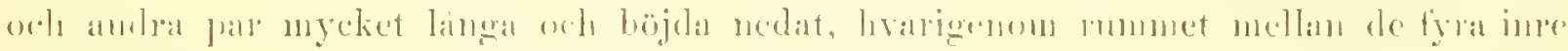

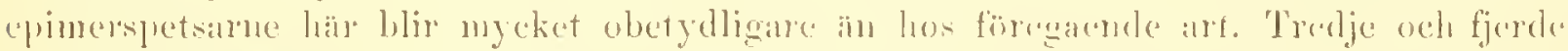

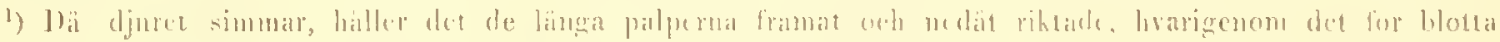

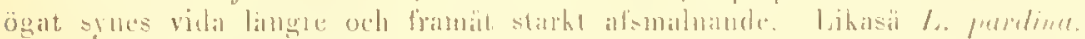

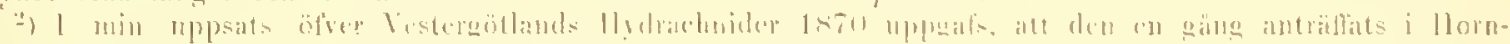

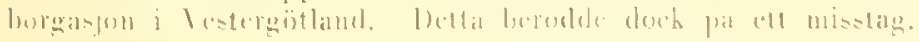


paren likna samma par hos L. histrinica. Mellan andra och tredje paren synes utat ett stiorre stigma. Labium liknar till formen föregaende arts; a midten symas treme tydliga stigmer. Mandiblormes corpus hal bakre ändan nästan rak och viggformig; klon är myekct mer krökt an hos föregarnde art. Palperme iro korta, na till spetsen af första parets fjerde intemodie och hafva samma tjocklols som detta benpar. Andra leden är försedd med en bakat riktad knöl, med en kort trublig taggeg. De glesa haren a ofre sidan af andra och tredje lederna äro proportionsvis vida längre an los föresacnde art. Generationsfïltet företer, jünfördt merl fürexacule arts, ringa olikhet; hos hanen, der det är 0,28 millim. langt och 0,30 bredt, äro stignema a skifrorma mycket stora orh af oregelbunken form; en mingd mycket smat stigmer symas mellan det frimsta, som ligger alldeles $\mathrm{i}$ spetsen af skifran, och det andra, som ligger a dess micht; hos homan ä fältet 0,28 millim. langt oeh 0,20 bredt; de mindre stignerna äro bär vida fürese. Anus, som ligger nürmare bakknten of kroppen an penelutionsfältet, has ett. litet stigma a livarje sida. Till fïrgen är atren högrö̉l med föga distincta svarta fläckar; palper, ben och mmodelar har jag oftast funnit hafva samma färg som kroplen, stundom stöta de åter mera i gulrört.

Länged 1,8, bredel 1,4, foursta benparet 1, ambra 1,3, tredje 1,4, fjerde 1,ŕ, palper 0,5 millim.

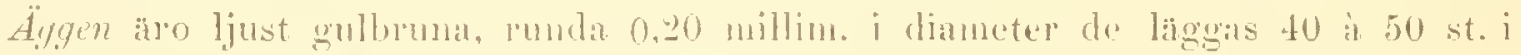
livarje kaka och utkläickas efter 4 in is veckor.

Lamerne hafia kroppen nedtryekt, oval, vid ögonen triart afsmahande till cu al'rundal förtingning, under lovilken ett stort lostrum sitter, baktill afsmalnar den

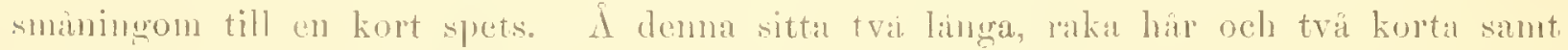
nagot langles utat ett ä hvarje sida. De tre cpimerparen a hvaredera sidan äro till störe delen sammanväxta med hvarandra och skiljas a kroppens midt endast genom eft myeket smalt mollanrmm. De bilda tillsammans en stor buksköld, som betacker hela molersidan ntom en obetydlig del af yttersta bakkanten, der generationsfälet äl. beläget. Detta delas af en kort springa, son är omgifven af tva nästan halfmanformign skifvor utan stigner. benen äro besatta med myclet glesal har; klorna aro enkla ơh löga krökta. Pulpemu, som symas vala treledade, sluta med en stark, böjd lilo oelı äro försedela med talrika llar, af livilka ett á andra leden sittande an mycket länght.

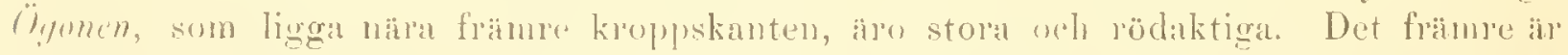
betylligt störe in det bakre. Vid hvardera palet synes ctt linght bakat bâgformight böjlt, hall. Till fiurgen är den blagul, stundon nistan gnlgrön med en gullvit trianEnlär flick à ryggen; framför demn fiack star en mindre, violett. Under ä den gulaktigr med de främre epinerjaren stötande j rödt; palper och ben äro gulhvital.

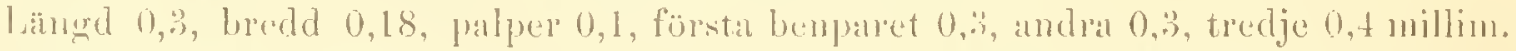
Canska allmän i sjöar och áar med klant vatten i Ljplambl. Vestergötland, Skante och blekinge. Gottland i Heide trïsk och Öland i Borga träsk.

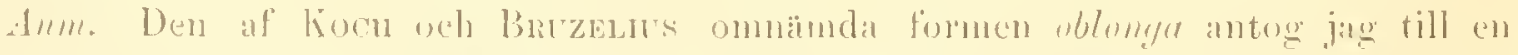

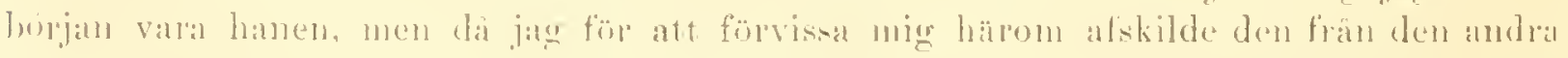

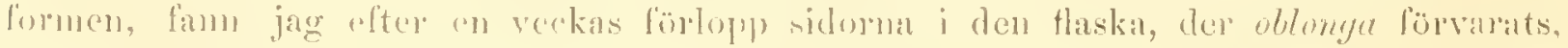

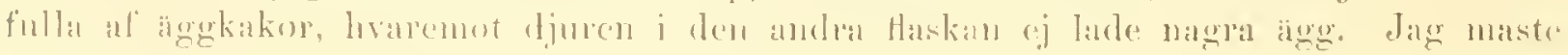




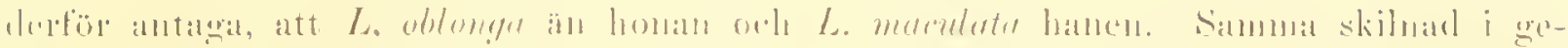

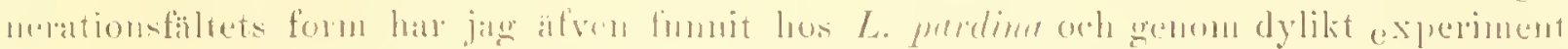

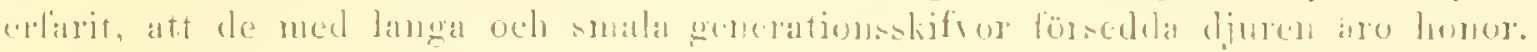

\section{Limnesia pardina Nisma.}

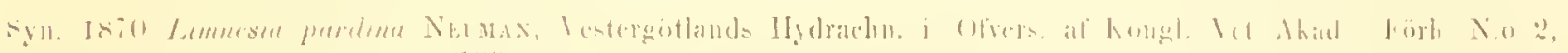
p. 103 .

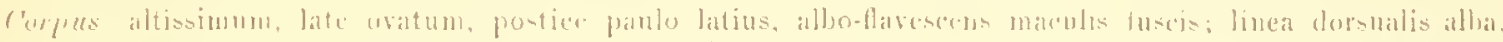

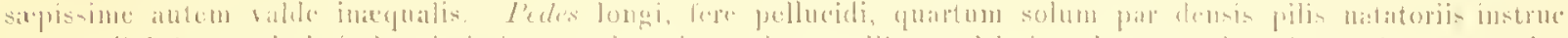

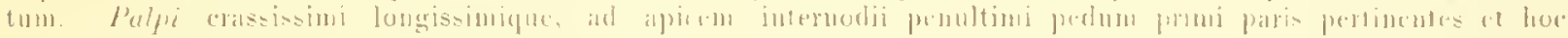

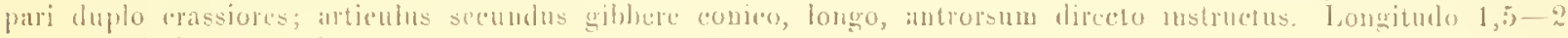
millim. (1ab. I, ligs. 3.)

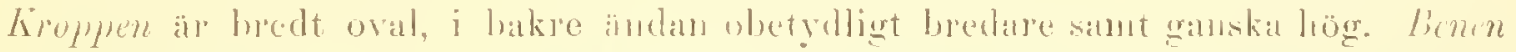
langa; första faret nästan af kroplens länged. de öfriga smaningem tilltagunde i längl.

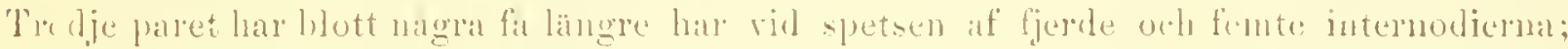

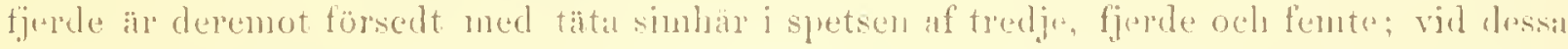
intermodies, i symerhet fierde, aro de fjälerlika stalka hapen symerligen vil utrecklade.

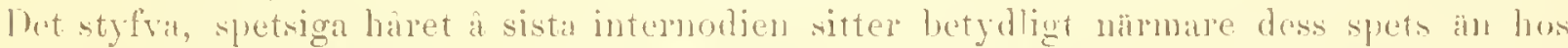

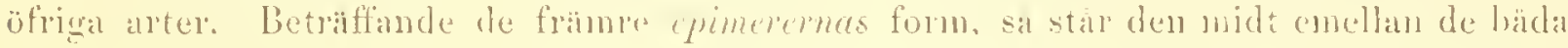

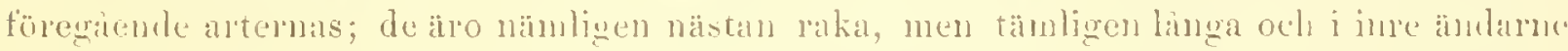
amska trubbiga. 'Tredje puret, som aro ganska langa, är inat ej afrundade, utam

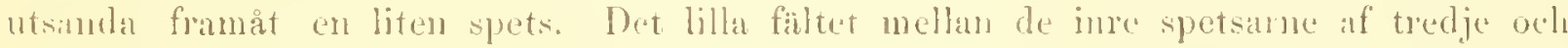
fljerde paren epinerer är mer oregebundet till formen än hos öfriga arter, der det irr

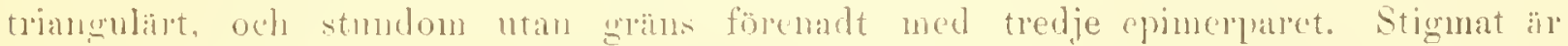
ären här oftast litet veh otydligt. Labium an mycket bred, ismmerhet a milten, framat orh hakit starkt afsmalnande. Mambliblernas corpus visar sammua form, som hos föregiande alt, wen klon ä mycker rakare, doek cj sil lak som hos L. histrionicu. Pal-

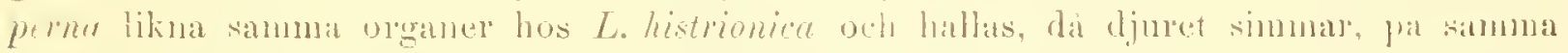

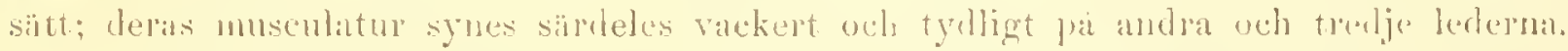

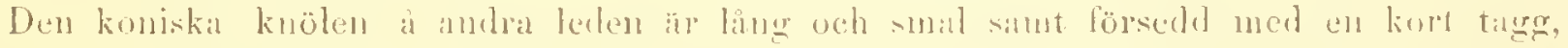

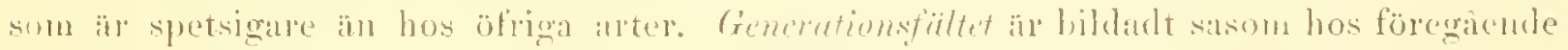

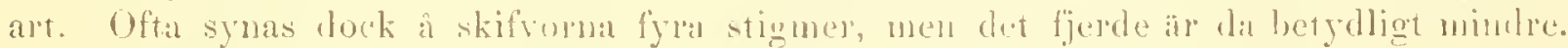

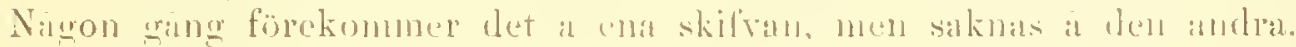

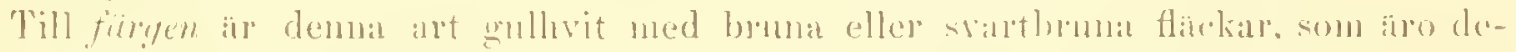

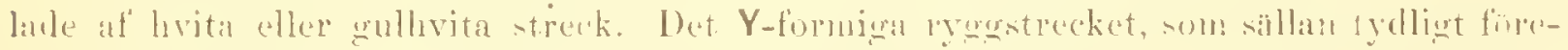

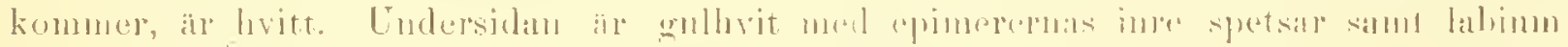

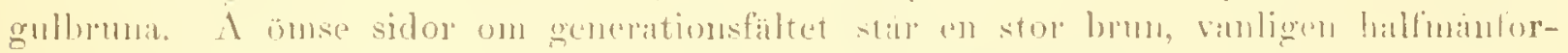

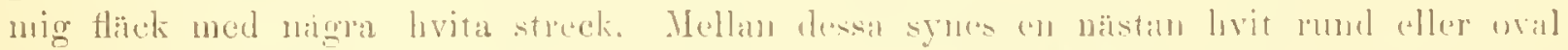

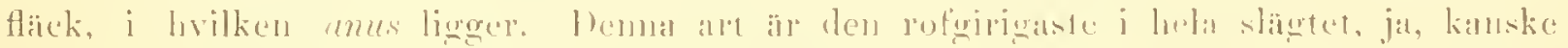

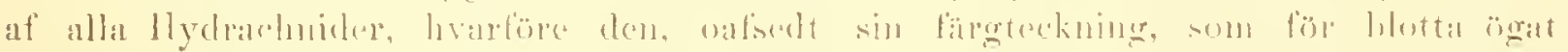

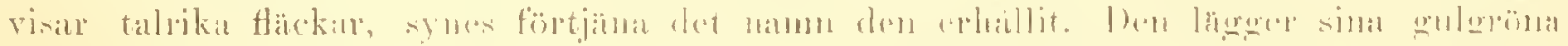

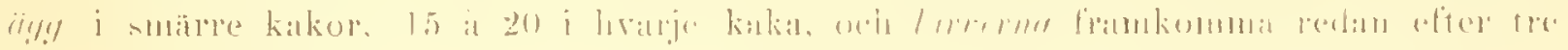


veckor. Dessa larver göra ett högst märkvindigh undantag fran alla aifrigu deruti, att

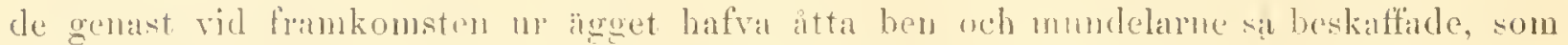
hos det fullt utbildade djuret. Första gângen jag bakttog aletta i họ̈ gran egendomliga fönlallande var 1874 vid ankomsten till Visby, dit jay fran Vestergötland medfürt ägg af nämola art. Under on tid af atta dagar hade jag ej obserrerat dessa ägeg, och kunde derföre ej afgöra, om icke larverua rodan moler dema tirl genomgatt sitt första stadiun, hvilket sảlunda skulke skett utan att tilloringa detsamma parasitiskt. Detta syutes mig emelleptid föga troligt, och jag hal sedan genom noggrannare observationer iakttagit, att de verkligen lemna äggen j ett stadimu, som motsvarar öfriga Hy-

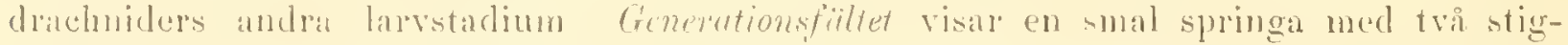
mes a lovaje sida. Till färgen aro dessa larver hvilalitiga, genomskinliga, a ryeggen försedda med en T-forming hrit figmr, omgifven af gult. Ben och palper mycket langar; de senale si langa som kroppen och tjockare än första benparet. De eljest hos larverna i kroppskanten ofta förekommande håren saknas allucles.

Längl 0,28, bredil 10,24, första benparet 1),34, andra 0,40, tredje 0,44, fjercle 0,74, palper 0,28 millin.

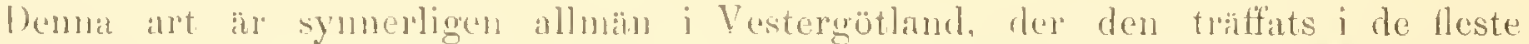

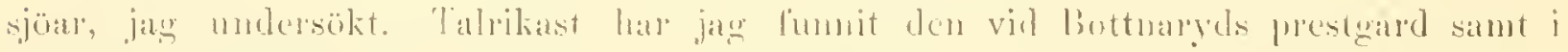

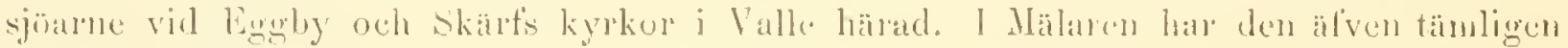
alluant antraffilts.

\section{Limnesia marmorata NiUMAN.}

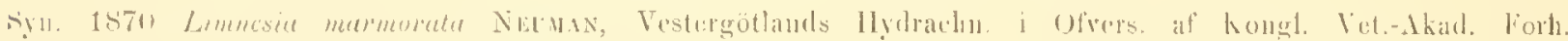
N:0 $\approx$, p. 109 .

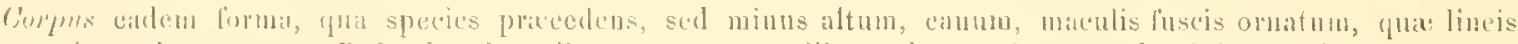

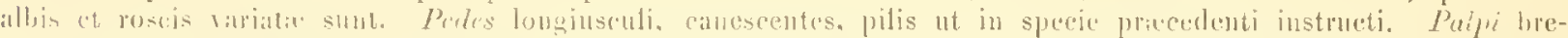

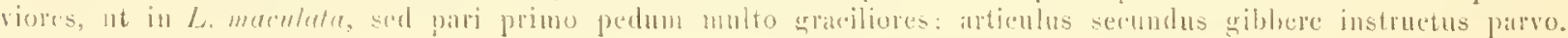

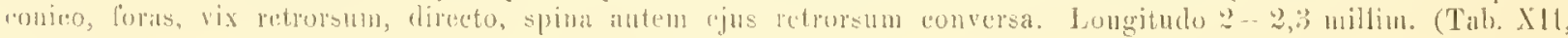
fig. 1.)

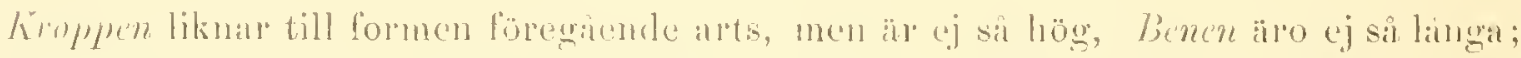

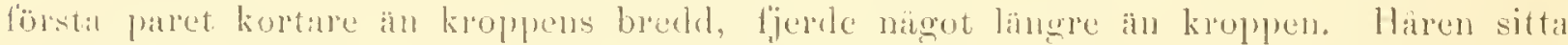

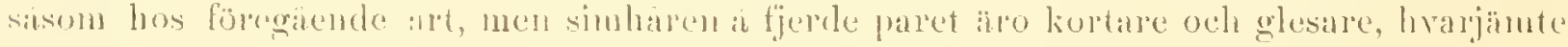

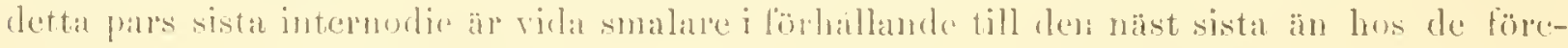

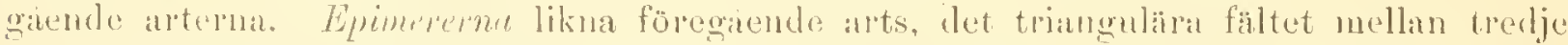

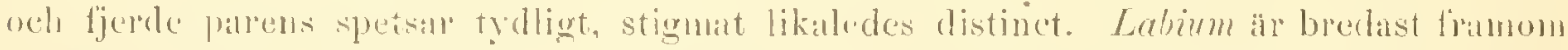

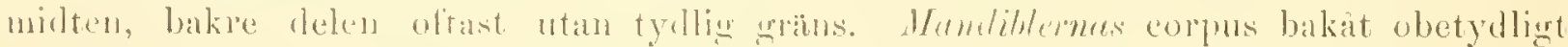

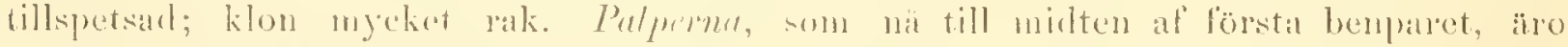
smatare än letsammat, deras andra led, som ä föga tjock, äl fölsedel med en liten obetydlign, lätt utstäende knöl merl en bakit riktad tagg, som blott synes vid starkare für..

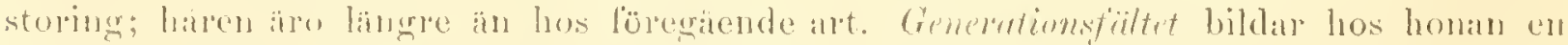

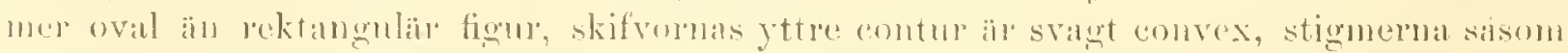

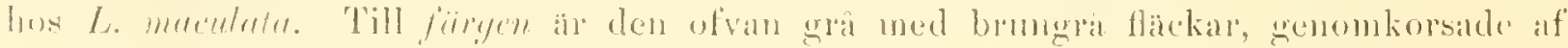




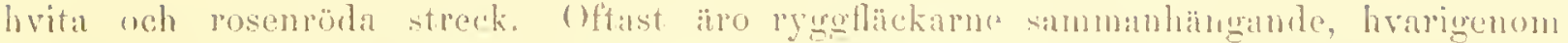

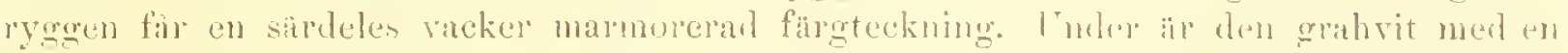

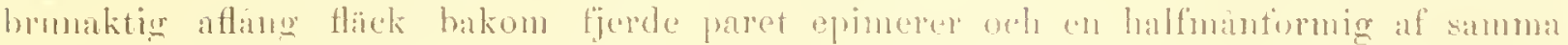

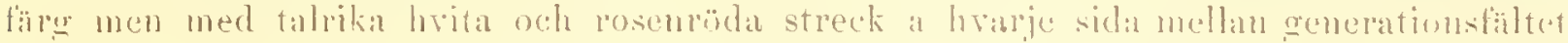
och antus.

Demma art, som jag blott anträfat i Mälaren vidk Kung wamm i September ochoktoler lsb6, fanns ler ej sal süllsynt. I sina rörelser är den i motsilts till nist füre-

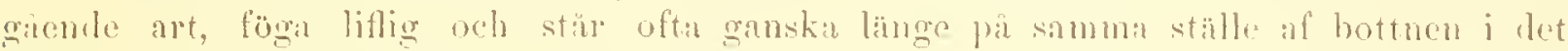

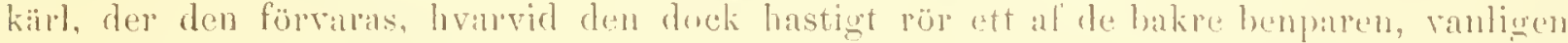

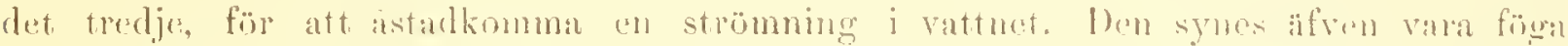

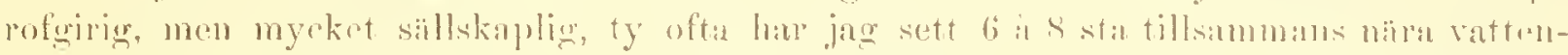

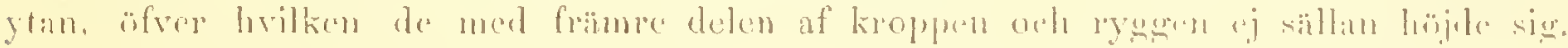

\section{Larra stalii secumdi:}

\section{Limnesia vitellina C. L. líocu.}

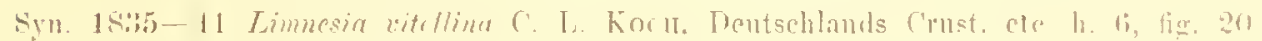

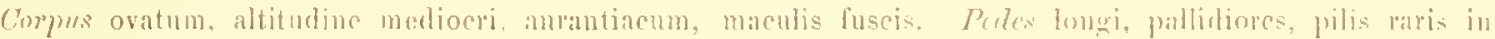

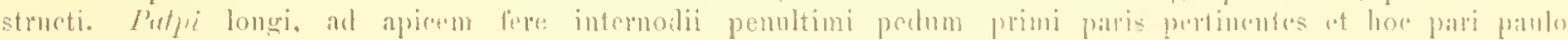
crasuines; articulns secundus gibbere conico sarens. Longitudo 0,5 millim.

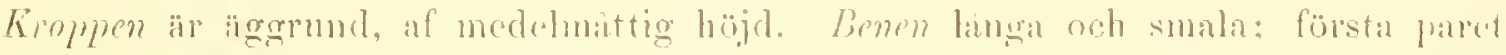

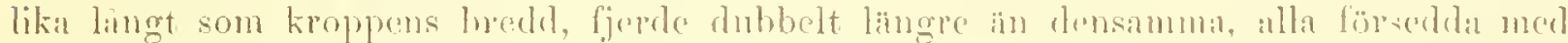

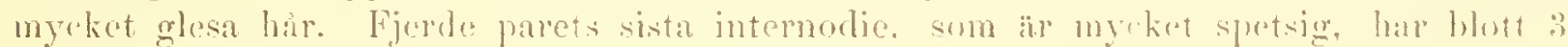

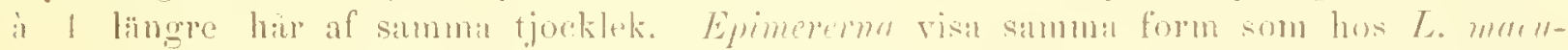
latu, och rummet mellan de fyra barens inre spetsar är högst obutrolligt. Jabimm ar bakit mycket afsmahnand och genom ett joing mallantum skildt frim första

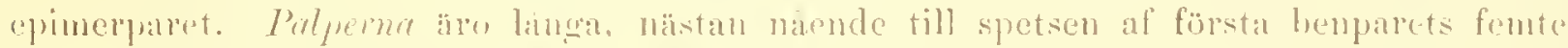

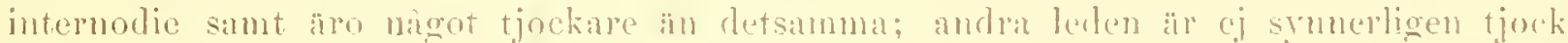
i förlaallande till tredje (jfr. L. mormuratu) samt sakmar alldeles knöl, balla dessal

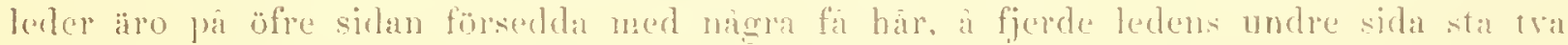

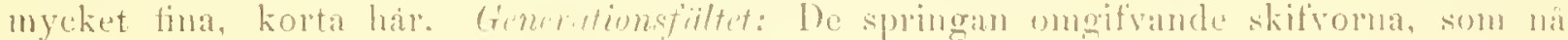
nästan upy till de inpe spetsarme af de bakre epomerparen, äro korta och breda, ej parallela ntan framàt lutale emot hrarandra samt försedda med tra stora stigner,

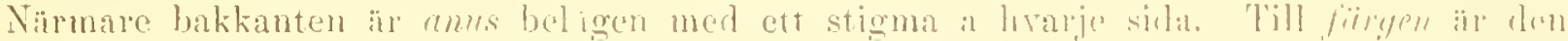

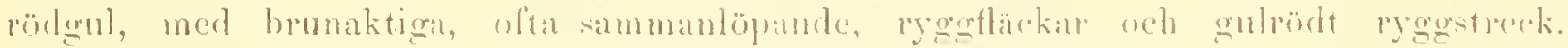
Palper och ben gullöla.

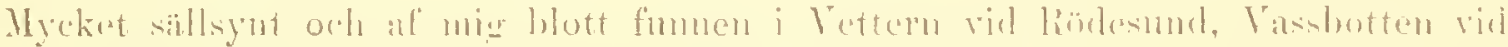

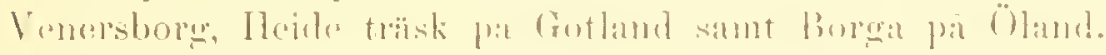




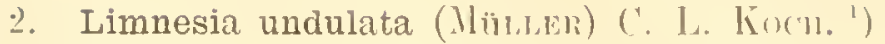

Syn. 1776 IIydraclena stmyatu MüLten, Zool. Dan. Prodr. p. 191, N:0 2288.

1781 - mululata il. Hydrachnse etc. p, 80, tah. X1, fig. 1

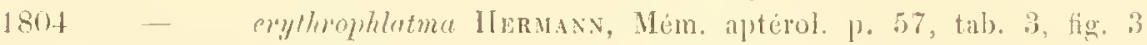

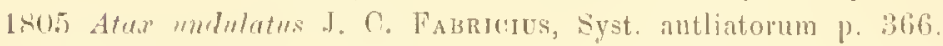

1835-11 Limnesiu undulata (. I. Kocu, Dentschlands Crust, etc. l. 6, fig. 1.1.

1851 - - Bruzelics, Reskr. ö. Hydpalın. som förek. i Skint p. 44.

1876 - Kraser, Beitr. zur Naturgesch. der Hpollachniden p. 312, taf. IX, fig. 20. 1,5 millim.

Corpus ovatum, flavum, marulis nigricautibus. Penles et palpi longi, flavescentes. Longiturlo cireiter

Kroppen är ägaformig, †änligen genomskinlix, med ganska langa ben och palper. Bakom det fjerde epimerparet ligger generatiousspringan, omgifven af tvenue skifvor, soul tillsammans billa en hjärtformig, med spetsen framat riktad fignr; it hvarje skifva sta tvenue stigmer. Till färg'n är den gul med svarta flackar, af hvilka tremle sta pá den framre delen af kroppen och tvemne langre, nitgot bugtiga, pâ den bakre; bakom symes en tvärfliick.

Är ej sällsynt i Skine och träffas tillhopa med $L$. histrimier och $L$. marulata.

Kraner uppuger samma art valua röd samt hafva benen aj mörkare än kropren. Fjerde benparets sista internodic har tva simbår, den näst sista wt vid spetsen oeh fyrat vid midten af densamma. De bâda bakre paren äro försedda merl golesab simhar. Eprimeremas inre spetsar äro langt skilda, hvarigenom meltanrummet blir ganska stort. Grementionsfïlter genom et betydligt inellansum skildt frin fjerde paret epimerer. IIvarje skifva, som hakảt är bredare, ar försedd med twâ stigmer.

Djurets lingd 0,73 , bredd 0,62 millim. Liflig i sina rörelser.

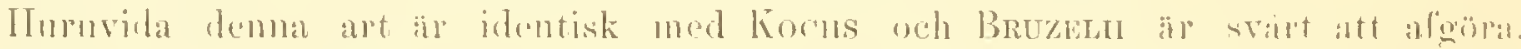
Itskilligt syues tala häremot.

\section{Limnesia albella C. I. Kocn.}

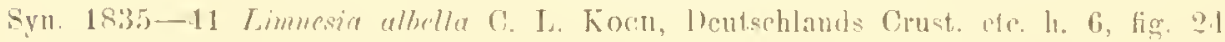

formes ferc rotundatum, parva altitudine, album, maenlis nigris. Pedes longions ct robustiores, pullu

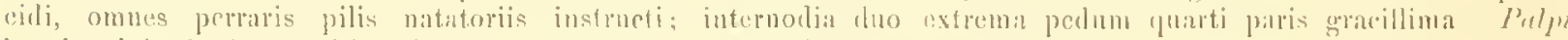

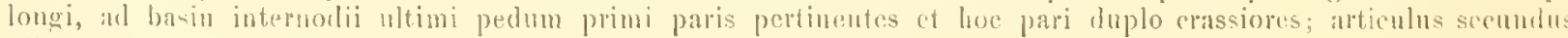
giblere careus. Longitulo 0,5 millim.

Kroppen air nastan pund, af linga höjd. Benen af medetrnettig längd och raitt starka; lörsta paret kortare än kroppens bredd, fjerde något langre an kinplen; alla

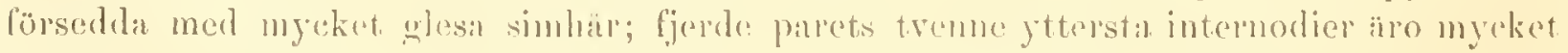
starkt afsmalnande, den sista har blott ett langre har nolla spetsen; den riast wista

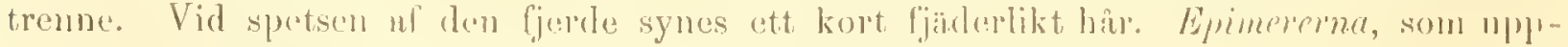

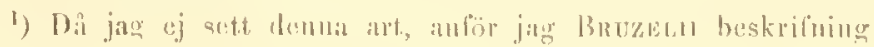


taga vida mindre an hälften af undre kpoppssidan, hafva de båda frimre paren raka, smala och nästan jämnbreda med de inre spetsarne nuder labium langt skilda. Mellanrummet mellan tredje parets inre spetsar ä mindre. Lalium är myeket kort och i bakre kanten bredt afrundad. Pulpeina aro mycket långea, naende till basen af första benparets sista internodie, samt dubbelt tjockare an detsamma; a andra och tredje lederuas öfra sida stå några korta hår. Generationsfältets skifvor äro mycket korta och breda, hvarigenom fältet blir dubbelt sa bredt som langt. De trå stigmerna äro mycket stora och upptaga nästan hela skifvan. Till färgen är den hvit, genomskinlig och försedd med stora, distincta, svarta fläekar. Ügonen rödal.

Längd 0,50 , bredd 0,46 , palper 0,30 , första benparet 0,40 , andra 0,50 , tredje 0,53 , fjercle 0,69 millin.

Af denua symnerligen rackra art har jag blott erhallit tre exemplar i Semsjön i Güseneds härad i Vestergötland.

\section{Genus 16. EYLAIS L.iTreille.}

Sỵm. 1796 Eylais Latrerlue, Précis des Caractères des Insectes p. 18.

1842 - C. L. Koch, Ucbersicht des Arachindensystems, L. 3. p. 33.

1854 - Bruzelius, Beskr. Ö. IIydrachn., som lörek. i Skáne, p. 51.

1876 - Kramer, Beitr. zur Naturgesch. der Hydrachniden p. 313.

Corpus lave, molle, ovatum, depressum. Pedes longiusculi, par primum pilis densis brevibns, secundum et tertium pilis densis et longis natatoriis. Juartum pilis densis et perbrevibus instruetum, pilis antem natatoriis plane carens. Palpi longiusculi, anticulis tribus primis crassis brevibusuue, quarto longissimo, tereti, in medio crassissimo, quinto parvo, obtuso, apice pilifero; articuli secundus - quartus pilis densis sed brevibus instructi. Duo paria oculorum approximata; bini utriusque lateris inter se proximi.

Kroppen är äggformig, nedtryckt; kroplsbetäckningen mjuk, sammetslik. Benen af medeluattig längad, fjerde paret saknar alldeles siuhar. Palperna äro för detta slägte säroleles utmärkande; de tre första lederna äro korta och tjocka, fjerole lüngrst och uästan spolformig, femte lifen och i spetsen försedd ned flera korta, styfva hár. l)e båda ägonparen äro belïgna nära hvalaudra. De af Kucu upputagna feun arterna auser jag, i likhet med Bruzelius, böıa föremas till en enda.

\section{Eylais extendens (MÜLLeR) LATReithF.}

Syn. 1776 Hydruchne extendens MüLler, Zool. l)an. Prodr. p. 190, N:0 2:272.
1781
id., Hydrachua, p. Bi, tab. $\AA$, fig. 1 .
179:3 Trombilium -

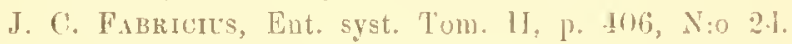
180:) Atar
id. Syst. Antliatorum p. : : : 2.
1796 Eylais -
Latreilte, Précis des Caractères des luscetes p. 18\%.
$18: 31$
Duges, Remarques sur la famille des llydrachues in Anmales des surences nat. Seconde serie, Tom. I, p. 156.
$18: 3.5-11$
C. I. Kocu, I)entschlands Crust. etc., h. 14, figrg. 21, 22
$1851 \quad-$
Bruzentes, Beskl. ö. Hydrachu., som förek. i skine p. 52, tab. 5, fierg. 6-10
$1876-$
P. Kuamer, Beitr. zur Xaturgeseh. der Hyilrachuiden, p. 313, taf. 1X. fier. 2.2.

Corpus rubrum. Longitudo 4-5 millim. (Tab. XIIt, lig. 1).

K. Sv. Yet. Ak, Hamell Band. 17. N:o s. 
Den mjuka kroppsbetäckningen visar vid starkare förstoring myeket täta, vågforformigt och nästan parallelt löpande, utomordentligt fina linier, mellan hvilka mycket små lingformiga figurer synas. Ejoinerernas betickning, som är hårdare, visar en nätformig teckning med langt utdragna maskor. § labinm, palper och ben äro dessa mer fyrkantiga eller rundade. Benen, som äro af medelmảttig längd, hafva första paret kortare än kroppsbredden, fjerde längre än kroppen; de tre första paren hafva korta och tjocka internodier, utom den yttersta, som liksom hos fjerde paret är smal och kortare än näst föregående intemodie; fjerde parets äro längre och nâgot smalare. Första parets äro försedda med mycket täta, korta hår å öfre sidan samt något längre, glesare å den undre; andra oeh isynnerhet tredje parets äro å undre sidan försedda med täta simhår vid tredje, fjerde oeh femte internodierna; fjorde parets sakna alldeles dessa ocl äro å sá väl öfre som undre sidan försedda med korta laảr. Den sista internodien ar lıögst obetydligt afsneddad och försedd med mycket starka och föga krökta klor. Epimererna äro små, fjerde paret minst, inat tillspetsade samt der obetydligt berörande andra paret; mellanrummet mellan andra och tredje paret jämnbredt, smalare an tredje parets bredd. Mellanrunmet mellan de fyra parens inre spetsar bakit vida bredare. Labium är framtill förlängd till ett slags kort och tjockt rostrum, a hrarss midt synes den något utstående, runda munöppningen, som är omgifven af en krans af fina korta hår. Uttagen och särskildt preparerad, visar labium bakom palpernas vidfüstningspunkt en lång, smal och nistan jämnbred process å hvarje sida, hvilken ungefïr midt ewot munöppningen bildar en nästan rät vinkel mot den öfriga delen af labium. Denna, som i bakre ändan är insknren, slutar med tvenne, parallelt med näinda processer löpande, korta spetsar. Mundiblernas corpus är ovanligt lång och smal, i bakre ändau obetydiligt tjockare sant något böjd. Klon, som ïr nästan så bred som främre ïndan af corpus, är kort, trubbig oeh krökt; till färgen är den nycket mörk, nïstan svartbrun och synes, ofta utsträckt ur munöppningen, som en mörk punkt. Palpema hafva de två första lederna mycket korta (deras diameter är större äu längden), tredje är utît mycket tjockare, kolffomnig, fjerde ungefür af samma längd som de tre fürsta tillsammantagna, spolformig, femte smal och trubbig, af tredje ledens längd. Den första leden suknar hår, andra har ett ì undre och tvenne ả öfre sidan, tredje ả främre delen af undre sidan försedd med talrika, tät sittande hår och a öfre ned fem, fjerde â öfre oel undre sidan med i rader sittande talrika har, femte har nagra fa hâr vid hasen, men i spetsen fem à sex taitt sittande, starka. Alla dessa hà äro korta. Generatimsfültet, sum ligger mellan andla paret epimerer är inycket litet, springan, som är kort, omgifves af tvenne chitinösa, glatta, smala skifvor. ¿ livarje sida sitter ett myeket litet stigna. Anus är stor och rund och ligger mellan fjerde paret epinerer. 1)e tvả ögompuren ligga nära hvarundra och det bakre ogat inycket nära det främre; de iiro belägna i en rektangulär chitinartad skifva, som nästan alldeles immeshter dem, och livarigenom de blifva alldeles orörliga; cornean är mycket liten. Nàgon skilnar mellan könen har jag ej kumat fimna. Till färgen är artun röd, stmndoun ljusare (yngre) stumdom inörkare (äldre). 
Rörande ägg och lareer fär jag meddela föjande:

1 medlet af juli inånal 1876 hade jag insarulat en stor mängd af dessa djur, som förarades $i$ ett vanligt dricksglas. I början af augusti märkte jag, att en af honorna börjat lägga ägg, och hennes exempel följdes genast af flera andra, sả att inom ett dygn störe delen af glasets botten sant en i detsamma hefintig Sphagmum-qvist voro betäckta af ägg. I glasets botten lago dessa i allmänhet i ett enda lager, men å Sphagmum-qvisten bildade de en tjock klump. Jag hade godt tillfulle att betrakta honornas beteende under ägglägrningen. Under det densamma fürsiggick, läto de ej lätt störa sig, om man vidrörle dem, och tyektes vara mycket noga ined, att äggen kommo i en beständ ordning. De framre benen böjdes, si att grenerationsöppningen kom alldeles intill glaset, hvarefter iggen med tillhjelp af desamma tycktes ordnas. Det hvitaktiga, klibbiga ämne, hraraf de omgifvas, hårdnar genast vid beröring med vattnet och blir så fast, att man med en stilett har svårt att genomborra det. Hvarje hona lägger 2 à 400 röda, runda ägg, 0,25 i diameter. Efter fem veckor utklïcktes hälften af de lagda ägren, hvarvid det egendomliga förhållandet visade sign, att larverna omedelbart lemnade valtnet samt med stor hastighet sprungo oukring pâ dess jta ${ }^{1}$ ) sumt glasets riagar. Blott med srărighet lyckades jag bemäktiga mig en del af dem. Deta ger mig anledning att tro, att de i likhet med larverna at Limnochares tilluringa sitt första stadium pí sidlana insekter, som lefva på vattenytan t. ex. Hydrometra. De àterstaende äggen utkläcktes först $i$ april månad följande àret. Larverna voro fullliomligt lika dem, som i angusti utkläclits, och betedde sig på samma sätt.

Larverna, 0,20 millim. länga oeh 0,12 millim. breda, iro af en oval form, hakảt Jock nágot afsmalnande med talrika hâr i kanten. De utıärka sig isynnerlnet genom benens spolformiga internodier, hvilka alla äro försedda ned tätt sittande hår, som a de sista internodiema äro längre än dessa. Sista internodien, som är utat mycket tillspetsad, slutar med en starkt böjd, svag, dubbel klo. Ögonen äro mycket stora, till färgen svartaktiga. Djurets färg ljusłöcl.

I motsats till Bevzelues ha jag funnit denna art föga çlupsk. Jag har aldrig sett den angripa andra Hydrachnider, men deremot faller len sjelf ofta offer för sina stamförvandter, äfven om dessa varit dubbelt mindre. 1 sina rörelser är den liflig, simmar fort, hrarunder den ej betjenar sig af fjerde benparet, som bålles rakt bakit sträckt.

Längd 4, bredd 3, första benparet 2,3 , fjerde 4,5, palper 1,9 millin.

Den förekommer allmänt i alla provinser from lappland till skane, Gotland och ()and.

1) Samma egendomliga föhallande har hucivs observerat hos larverual af Diplulontus sedpuleris, hvaremot han alteles oriktigt uplener, att larverna at Eylues gentet torka och dö, dit de komma ur vattuct. 


\section{Genus 17. DIPLODONTUS Duges.}

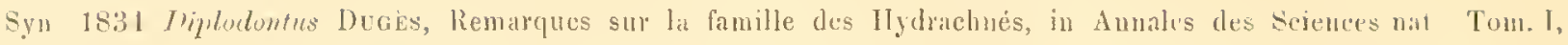
p. 144 .

1842 - C. L. Koch, Uebersicht des Arachnidensystems l. 3, p. 24.

1854 - Bruzelius, Beskr. ö. Hydrachn, som förek, i Skine, p. 44.

Corpus molle, depressum, ovitum (D). scupularis) aut rotundatum (D). filipes). J'edrs Iongiusculi, graciles ct, pari primo excepto, pilis natatoriis in intemodiis quarto et quinto instructi. J'alpi breviusculi, articulo tertio brevissimo, quarto longissimo, cum quinto extenso forpicem formanti. Rostrun breve. Oculorum duo paria inter se remota.

Kroppen är nedtryckt, obetydligt hvälfd, dess betäcknimg mjuk. Benen tämligen linga och mycket fina med simharr vid fjerde och femte internodierna af de tre bakre paren. Palperna af obetydlig linngd; tredje leden kortast, fjerde längst, sträckinde sig med en spets öfver femte, som är lângsträckt och rörlg̣, bildande med den förra ett slags tang. liostrum kort och smalt. De bada ögonparen lingt skilda, likaledes de bada ögonen i hvarje prar. Blutt en svensk art.

\section{Diplodontus filipes 1)LGÈs.}

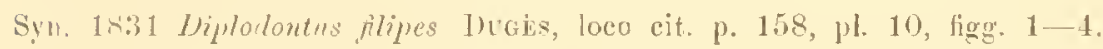

1854 - $\quad$ Bruzelius, loco cit. p. 45 , tab. IV, figg. $9-12$.

Corpus rotundatum, antice paulo latius, rubrum, maculis nigris confluentibus, perles et palpi tlasi. Longitudo 1,5 millim. (Tab. XII, fig. 3.)

Kroppen är nïstan rundad, i främre kanten nâgot bredare; å ryggen synes vid stank förstoring en inycket fin granulering, som å undre sidan är nästan omärklig. benen utmárka sig genom sin spenslighet; då djuret simmar onkring, kunna de med obevilpmadt öga knappast syuas. Första paret är kortare än kroppens bredd, fjerde, som är längst och tjockast, äl nagot längre än kroppen. Epimererna äro små; de treme första paren lảnga, smala och jümubreda, mötas nästan under labium; de bada bakersta paren äro genom ett bredt mellanrum skilda frân de främre; tredje paret jämubreda, ungefär lika hreda som andra; fjerde paret mer viggformiga, bilda tillsammans med tredje en nästan triangulär figur, hrars spets är riktad inåt; de båda parens inre spetsar langt skilda. Alla fyra paren äro försedda ned mycket fina hâr, hvilkal üro längst å fjerle paret. Detta är den enda liydrachnid, los hvilken jag funnit epinererna liksom henen försedda med hår. Bakom fjerde epimerparet stâr ett stigma. Lubium är lired, bakåt nagot afsmalnande och afrumdar, framtill förlangd till ett kort justrum. Ifandilderna hafva en sinal oeh lüngsträckt corpus med en förlängning baktill, som är längre än den egentliga corpus; vid basen af den föga krökta, starka klon symes liksom hos Arrkmures ett hinnartadt, tannligen bredt bihang af klons läned. Palpema, som na obetydlight utom kroppsaunten, till basen af första benparets fjerde led, äro smalare än detta par. Första leden är ovanligt lảng, längre än 
andra, som är dubbelt större än tredje. Fjerde äl längst och sträcker sig̨ med en lâng spets öfver femte, som äfven är spetsig sant rörlig, och med hrilken den bildar en lingstüäckt, spenslig tånğ. $\AA$ öfre sidan af första leden stâ trenue hàr, å andra ‘ undre sidan ett dylikt, rid basen af tredje trenne och vid basen af fjerde trenne längre hâr. Generationsfültet: Den korta springan, som är belägen midt enellan fjerde paret epimeres, är omgifven af treme ıpphöjda, balfuanformiga skifvor, hvilkas främre spetsar doek äro vida smalare än de bakre, hrarigenom de tillsammans bilda en nästan hjärtformig figur, med den trubluga spetsen franåt riktad. Y'ttre randen af dessa skifror är försedd med en rad större stigmer, innanför livilka betydligt mindre dylika bctäcka hela skifvorna. De inre och bakre kanterna af de sistuända äro fürsedda med kortal har, som korsa hvarandra. Den ovala anus à belägen miclt emellan generationsfältet och kroppens bakkant. De två ügomparen äro lingt skilda; det üfre eller bakre ögat ligger $i$ sjelfra kroppskinten, det mudre något nedauför densamma, livarföre det ej synes, da djuret betraktas fran ofre silan. Detta har sannolikt föranledt lioch att föra Diplodontus till den af honom uppstallda gruppen Hygrobutides. Till fïrgen äi den röd med omkring tio mörkare Hackar a ryegen, hrilka strálformigt utgả fran en gemensin micltelfäck. Epimerer, ben, labium palper och generationsfalt äro gula.

I sina rörelser är den föga liflig veh has aldrig synts angripa andra Hydrachnider, som varit förvarade i samma kär. Derenot blil den själf oftar ett byte för Tescea- och Limnesin-arter. Ej sïllsynt i V'estergötland t. ex. i an rid Lyrestad, i Bottensjön, Tholsjöhult, Mellby i Bjerke härad sant flera sjöar j Valle härad, Srenljunga. I Blekinge synnerligen talrik $i$ en liten sjö niảa Frillefstads preståard. I Skane säilsynt enligt Bruzeluus. Gotland: Heide träsk, Källumge i biicken vid prestgården samt Roma i en dam i parker.

\section{Genus 18. HYDRACHNA (MïlLei) C. L. Kocil.}

Sy̆. 1781 Mydrachnd Múber, Hỵdrachuse ete. p. $5 !$ et 63 (ad partem).

1542 - C. L. Косн, Uebersicht des Arachnidensistems, h. :3 p. 29.

1854 - Bruzelues, Beskl. ö. Hydrachn, som förek. i Skäne, p. Lh.

$1875-$ Kraver, Beitr. zur Naturgeseh. der Hydrachniden, p. 300).

1877 - id., Grundzïge zm systematik der Milben, p. 236

Corpus molle, rotuudatum aut late ovatum. Peeles breves, par primm pilis l'arioribus, retera paria pilis densis ae longis iustrueta. Labium in rostrum longissimum produrtum. Pralpi longiusculi, articulo primo arassissino, brevi; seeundo ejus loneritudine, tertio attenunto longissimo, quarto longitudine primi, cum quinto parvulo foreipem formanti. Oculi bini utruscue lateris proximi; duo paria medioeriter distantia.

Kroppen är rundad eller bredt oval, mästan klotrund; kroplesbetäckningen slät och mjuk. Benen korta, de tre hakre paren ned ovanligt täta och tänligen langa hàr. Labium ar förlängd till ctt rostrum, som når nästan till yttersta spetsen af palperna. Dessal, som frân sidorna äro tämliogen tilltryckta, hafra första leden nycket tjock, andra lü̈gst obetydligt längre, men smalare, tredje längst och ranskil smal, fjelde af den förstas längd med den a undre sidan füstade, tagglika. korta fomte leilen hildande cn tang. l)e bada ögonen i hvarje sida beligna nära hvaraudra: bida paren skilda genom medelmảttigt afstând. Trí arter. 


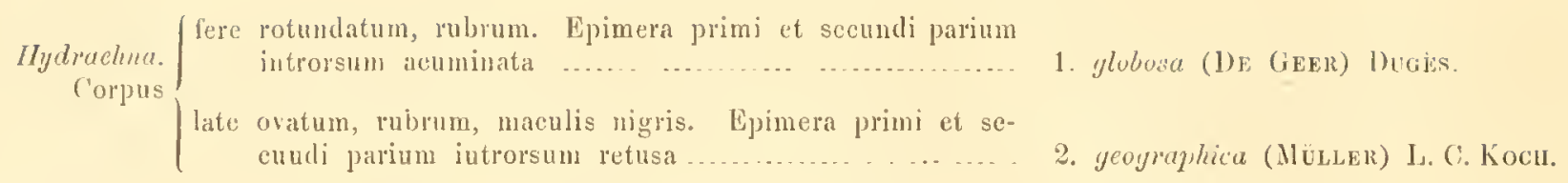

\section{Hydrachna globosa (DE GEer) Dugés.}

Sỵn. 1778 Acarus aquaticus globosus DE GeEr, Mémoires ete. Tom. VI], p. 146, pl. 9, figgr. 11, 12.

1793 Trombilinm ylobator J. C. Fabricius, Ent. syst. Tom. 1I, p. 40:3, N:o 23.

1815 Itax - id. Syst. Antliatorum p. 376.

1776 Ilýlrachna crucnta MüıLer, Zool. Dau. Prodr. p. 190, N:0 2273.

1781 - $\quad$ id., Hydrachne ete. p. 63, tab. 1X, fig. 1.

tí114 - globulus Hendans, Mém. aptérol. p. 56, pl. 11, fig. 15.

1831 - glubosa Duriès, Remarques sur la fanille des Iydrachnés in Annales rles Sciences nat. Tom. 1, ser. 2, p. 161 .

1835.11 - - C. L. Kocin, Deutschlands Crust. etc. h. 11, fig. 15.

1854 - - Bruzelius, Heskr. ö. llydrachu., som förek. i Skåne, p. 47, tib. V, fig. 1.

Conpes ferc globosum, rubrum. Pedes breves, par quartum vix longitudine corporis, duo paria posteriora densissimis pilis natatoriis instructa. Epimera duornm parium anteriorum introrsum acuminatia. fiostrum perlongun, longitudine f'cre palporum. Palpom anticuli secundus et tertius pilis raris brevibusçue instructi. Longitudo +5 millim.

Kroppen är mycket hög, nistan klotformig, med slät, starkt utspänd kroppsbetackning. Benen korta; fürsta paret kortare än kroppens lalfva längd, fjerde nágot kortare ïn kroppen. Första paret försedt med täta, korta hår å sträick- och böjsidan, andra med tiata simhår a fjerde och fente internodienna de bada sista paren hafva ï hela böjsidan utomordentligt täta, långa simhår. Epimererna äro smỉ. Första och andra paren nïstan viggformiga, andra något bredare och större, mellanrummet mellan andra och tredje paren af samma bredd som andra paret; tredje mycket korta, nästan rektanguläa, inåt nảgot af'smalnande och tvärt afiundade, griusa med lıela bakre kanten intill följande par, som äro betydligt längre, men föga lredare än tredje, i inre iindiun bredare och något concava, med en utskjutande trubbig process. Labium, som är tydligt skild frän första paret epinerer, är baktill rundad och framtill förlängd till ett langt rostrum, som vid basen är tjockt och tämligen utbredt, men sedan jämut afsualnar. Dettu rostrum, som nästan är af palpernas längd, äl nedảt böjdt. I det samma ligga mandiblema, hrilka icke såsom hos föregtende arter bestå af treme skilda delar, corpus och klo, utan utgöras af ett enda lingt utclraget, nästan sabelformigt styrake, il hvilket doek syues en antydning till grius mellan de bada mäuda delarne. Palperna ino från sidorna hoptryckta och symas kumm blott obetydligt skiljas från rostrum, intill hvilket de städse hallas. Första leden är något mer hög än limg med ett par glesa hảr ia öfre sidan, andras längd omkring 1/2 ging större in dess höjd, a

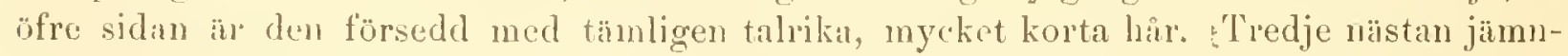
bred med tveme inyeket fina hår i spetsen ä öfre sidin; under dema led sitter den likaledes klolika femte leden, livars spets afven är nedât riktad, och som med föregående bildar ett slags tång med myeket korta käftar, af hvilka den undre är nagot större än den öfre. Generationsjältet, som äu beläget mellan de tva bakre epimerernas 
inre ändar, visar tvenne nästan halfmănformiga, i frimre andan nagot bredare, granulerade skifvor, som hos det utbildade djuret äro med hvarandra sammanvixta till ett bredt, nästan hjürtlikt fält. Frản en öppning straxt bakom spetsen af detta fält utgar. dả man tryeker pa djuret, ett kort, tubformigt, i kanten kreneleradt organ, som antagligen ä ett ägglaggningsrör, enär jag ej fumnit det hos alla individ. Närmare generationsfültet än bakkanten ligger unus. Oyonparen äro tänligen langt åtskilda och belignna på en något upphöjd, oval skifra; let främre i hvarje par betydligt större än det bakre och tydligen skildt frîn detsamma. Framför ögonen stàr ett kort lair, ntgående från midten af ett litet stigma. Till färgen ïr denna art röd, yngre individ äro ljusare, äldre deremot mörkare.

Lägger enligt 1)UGEs ${ }^{1}$ ) sina ägy i stjülkarne af vattenviater, i hvilka den med de spetsiga mandiblerna borrat hả. Aggen äo ovala, röda, ganska talrika samt ej ongifna af det vanliga gelélika skyddande imnet. Ur dessa ägg, som läggas i början aff sommaren ${ }^{2}$ ) framkomma efter omkring sex veckor lumerna, som hafva en oval kropl med ovanligt stort rostrum, som är nästan så stort som halfra kroppen. Benen äro af kroppens längd; fürgen ä röd. Dessa fasta sig pa vatteninsekter, t. ex. Nepa och Dytiscus, der man savail under vâren som sommaren och hösten anträftar dem. ${ }^{3}$ )

Denna art är ganska allmän och förekonnmer bade i rinnande och stillastaende vatten. I sina rörelser är den mycket snabb, men füga rofgirig. Upland, Testergötland, Östergötland, Blekinge, Skine, Gotland och Öland.

\section{Hydrachna geographica (MÜLLER) C. L. Koc11.}

Syı. 1776 Mydractina geagraphica MLLeer, Zool. Dan. Prodl: p 190, N:0 2270.

1781 - $\quad$ id. Hycluachne etc., p. 59, tab. VIlI, figg. 3, 4, 5.

$1885-41$ - - C. I. Koci, Deutschlands Crust. cte., h. 14, fig. 13.

1793 Trombidium geographicum J. C. Fabrucies, Ent. syst. Tom. II, p. 405, א:0 32.

1805 Atux geographicus irl. Syst. Antliatorum 1. 371.

Corpus late ovatum, altum, obscure rubrum, maculis magnis nigris. Pedes fere ut in specje pracedenti: par primum pilis densioribus instructum. Epimera parium duorum anteriorum introrsum retusa. Rostrum ct palpi ut in II. globosa. Longiturto $6-8$ millim. ('Tab. XII. (fig. ..)

Kroppen är bredt oval, mindre hög än hos föregiende art. Benens fürsta par försedt med mycket tätare hâr. De trenne frünre parens epimerer hafval de inre spetsarne trubbiga, för öfrigt äro de bildade sitsom hos H. globoser. Liostrum och pulper salsom hos denna. Generationsspringuns skifvor bilda tillsammans ett mer hjürtikt fült än hos föregaende art. Det dröjer länge, imman dessa skifvor raxia tillsammans, och till en början trodde jag, att detta var ntmärkande för arten, enä jag antriffat individ af 5 millimeters lïngd, som haft dem tydligt skilda. Pa Gotland erhäll jag cuellertid ett individ af 8 millin. längd, som hade skifvorna sammanvixta. Till fïrgen är den

1) Oaktadt jag ofta haft denua alt $\mathrm{i}$ mitt agrarium, har det aldrig lackats mig fí se den lägga ningra ägg. I fangenskapen har den vanliggen dött efter nigria dagars förlopp.

2) Den 30 juli har jag dock antriftiat en af igg alldeles uppfylld homa.

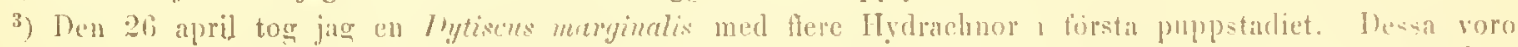

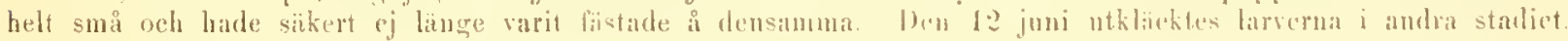


mörkröd ofvantill med stora svarta fluckar, som vanligen bilda ett bredt, framtill afbrutet oregelbundet band längs midten af ryggen. Palper, rostrum och ben rörla.

I sina rörelser är den ej så snabb som föregående.

Ganska sällsynt vid Björkelund och Brobacka nära Skara, Gotland vid Kinner.

Genus 19. HYDRODROMA C. L. Koch.

Syn. 1842 IIydrodroma C. L. Kосн, Uebersicht des Arachnidensystems, h. 3, p. 32.

Corpus lave, molle, ovatum, parva altitudine. Pedes, primo pari excepto, longiores, par primum pilis brevibus densissimis instructi, paria cetera quum tales pilos, tum densos et longos pilos natatorios, internodiis quarto quintoque affixos, gerentia. Labium in rostrum, palpis duplo brevius, productum. Palpi longiusculi; articuli tres primi eadem fere inter se longitudine, a primo ad tertium crassitudine crescentes, quartus longissimus, iis multo gracilior, cum quinto parvulo foreipem formans. Oculi bini utriusque lateris proximi; duo paria distantia.

Detta slägte, som står närmast Hydrachna, skiljer sig dock lätt derifrån genom sitt korta rostrum, som icke är hälften sả långt som palperma, sin obetydliga höjd sant palperuas och generationsfältens olika bildning. Blott en art är hos oss anträffad.

\section{Hydrodroma rubra (DE GeER, C. L. Koch ${ }^{1}$ ).}

Syn. 1778 Acarus aquaticus mubr De Geer, Némoires etc., Tom. VII, p. 141, pl. 9, figg. 3-11.

? 1835-41 Iydrachna punicea (. L. Koci, Deutschlands Crust. ete., b. 14, figg. 8, 9.

?1842 IIydryphantes punicens id. Uebersicht des Arachuidensystems p. 14.

1870 Iydrodroma umbrata Neum.ts, Vestergötlands Hydrachu. i Öfvers. Tet. Akad. Förh. N:0 2, p. 110.

Corpus rubrum supra, marginc anteriorem inter oculos scuto quodam capitali ornatum. Longit. 2 millim. (Tab. XlV, fig. 1.)

Kroppen är äggrund, af obetydlig höjd, kroppsluctickningen mjuk, synes vid obetydlig förstoring glatt, men visar sig vid starkare vara inyeket fint granulerad, likaledes rostrum, palper och ben; nära framkanten, midt emellan ögonen, synes en sköldlik chitinös skifva, som frantill är afrundad, ¿̊ sidorna inbugtad sant i bakre kanten utlöper i tvenne spetsiga hörm. Benens första par ej obetydligt kortare ìn kroppens bredd och försedt med symnerligen talrika, korta, styfva hår, som mot spetsarne af andra och tredje internodierna sta $\mathrm{i}$ kians; andra paret lika långht som kroppens bredd med glesare, längre hâr i spetsen af fjerde och fente internodiema; sista internodien obetydligt kortare än den naist föregâende, med en mycket liten, nüstan rundad urhålkning för mottagande af de smá enkla klorna. Fürsta paret epimerer grïusa intill rostrum; deras inre spetsar äro ej lângt skilda. Andra paret obetydligt bredare och kortare. Mellanrummet mellan detta och tredje paret af det semares bredd. Dessa epinerer aro lika breda som andra paret och nästan jümmbreda. Fjerde paret, som utăt äro lubhelt bredare än tredje, älo inât lika spetsiga som detta par, nüstan triangulara. liostrum, som ej är lülften sâ

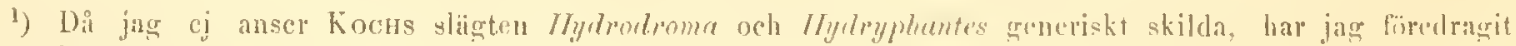
det föra slïgtnamnet. 
langt som palperna, ar utht hastigt afsmalnande och visar i spetsen en springa, genom hvilken mandiblerua stundom utskjnta sant trenne rakt utsticnde korta lıar a öfre sidan. Mandiblerna hafva en lingsträckt, jämnbred corpus, som baksit liastigt tilltager i tjocklek och derefter öfrergår i en lảng, füga krükt, spets med en stor fördjupuing för musklerna. Klon är ovanligt lang och stark, nästan rak, tydligt trekantig med inre sidan nûgot concav; till fürgen är den brunaktig. Vid dess bas synes ett himnartadt, uppat spetsigt afsmalnande bihang, som nar till klons midt. Palperna äro tämligen langa, nästan lıälften så lảnga som fürsta benparet, och naende till basen af dess fjerde internodie; de aro vida smalare än deta benpar med fürsta leden cylindrisk och nästan af sanma längd som de bida följande, fastän smalare; andra och tredje tilltagande i tjocklek not yttre ändarne; fjerde längst och betydligt smalare än tredje med en utskjutande klolik spets ä öfre sidan; femte kort och klolik, bildande med den nämde taggen ett slags tung, hvars bada käfar àro korta och nedat riktade liksom los Hydrachna. I spetsen af de tre första ledernal stâ nagra korta, „rlesa hår. tienerationsfältet: Springan, som börjar vid inre ändarna af fjerde paret epimerer, är lang och ongifves af tremne upphöja skifror, som mot främre ändan lyetydligt afsmalua och i sjäfia spetsen aro försedda med ett stort rmul stigua; utat aro de convexa ined en utskjutande pund knöl mot bakre kanten; nảgot hakom springans mirlt synes a ine sidan af lessa skifvor ett litet stigma. Anus, som är oval och tämligen stor, ligger närmare gunerationsfültet ïn bakre kropleskanten. Ögonparn langt skildat, belägua alldeles i kroppskanten, hrarje par staende pa en liten oral, upplöjd chitinskifvil, frïmre ögat dubbelt större an det bakre. Till färgen är den röd, sammetslik, med obetydligt ljusare ben och palper.

Längd 2, bredd 1,6, palper 0,5 , fürsta benparet 1,15, andra 1,55 , tredje 1,80 , fjerde 2,20 millim.

Mellan könen synes ingen annan yttre olikhet finnas, in aft honan har mellanrummen mellan epinerparens jure andar myeket bredare samt i fürhallande till kroplen mindre epimerer; generationsfïltet äl ej heller beläget sâ lingr hakat som hos hanen. I sina rörolser är denna art ganska snabb och betjänal sig vid simningen affen af fjerde benparet, som ocksia än försedt med tätil simhân. Di den kryper onkring, hvilket mera sällan hinder, släpar den vanligen detta par. Not vintern hyggrte de af migr förvarade af vaxiemningar ett slags bo, liknande ett cylindrislit rör, nästan som IVryganew-lavens, i hvilket de tillsammans (1; i gon) mest uplehöllo sig: sattus aquariet i

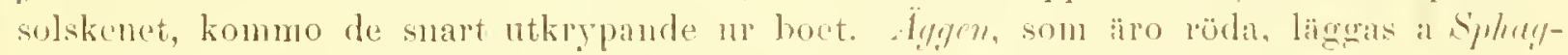
num-stjalkar och omgifvas af det vanliga geleatade inmot; efter omkring fyra veckol ntkläekas de röda lareerm.

Sedan jag ett helt àr haft denna art $i$ ett litet aquarimm. lade den andtligen bâ vâren följande aret ägg. Olyekligtvis blofvo de uyss kläickta lanverna förstörda, innan jag humnit beskrifvir dem.

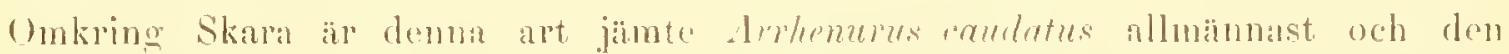
första, som risar sig, så suart isen smält i lammar neh dikril; mot slutet af sommancen

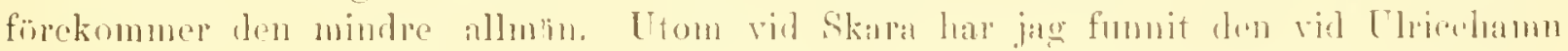


samt på Gotland vid Kinmer i Lummelmuda, Kapellshann och Gothem. Fn varietet med metallghinsande grön färge, variatio metullice, antraffades allunännare än hufvudformen flersticles på Gotland, t. ex. Kinner i Lmmmelunda, Kyrkeby i Etelhem, Heide i en "bryan nära triisket samt i (ija i vattensamlingar i stenbrotten.

\section{Genus 20. BRADYBATES Neumax.}

Sym. 187:3 Bralybutes Neuman, Nya svenska arter och slägten af Hydrachnider, Forll. ved Naturforsk. mudet i Kjobenlavin 1873, p. 109.

$18: 5$ - Neuman, Gotlands och Ölands spindlar och vattenqualster, i Öfers. af Kongl. Vet.Akad. Förhancl]. N:0 2, p. 104.

Cornus lave, molle, depressum, late ovatum, antice fere trincatum, angulis obtusis, ponc hos angulos conetatum, postice paulo latius, rotumdatun. Pedes pilis densis, perbrevibus instructi, longioribus pilis natatoriis ommino carentes. Rostrum et palin ut in genere praecenti. Oculi bini utriusque lateris proximi; duo paria mediocriter distantia.

Detta sligte, som bildar en tydlig öfrergaing till smmpqvalsterna, skiljes frin alla öfriga svenska Hydrachndslägten derigenom, att hithörande djur alldeles sikna simbâr. De krypil ocksa helt langsant omkring liksom Thyas och Limmorhares, frin hvilka de dock tydlignt äro skilda genom palpernas och rostri form, som i det nämaste öfverensstämmer ned Hydrodroma. Kroppen är mer nedtryekt än hos dema, med mjuk och glatt hetäckning, som även här visar sig fint granulerad vid stark förstoring. En alt.

\section{Bradybates truncatus NEUMAN.}

Syn, 1873 Bradybates trmeatus Neuman, loco cit. p. to9.

$1875 \quad-\quad$ id. $\quad$ - p. 104.

Femina: Corpus rubrum, epimera et peles miniacea, dorsum stigmatibus in quator series dispositis ornatum. Longitudo: millim. ('Tab. XIV, fig. 4.)

Hona: Kroppen nedtryekt, nästan jämnbred, i främre kanten tämligen tyär afhuggen med milten nagot framskjutande och afrundad sant trubbiga sidohörn, bakom dessa nagot inbugtad; bakkunten, som är nagot bredare, ä afrundad. Pai ryggen synas flere större stigmer, som äro orduade i fyra längsgaende rahler. Banen tänligen langa, första paret lika langt som kroppens bredd, andra och tredje smanningom tilltagande i längd, fjerde så langt, sum krolpen, alla med myeket tïta, korta oeh fina hår; internodiema, med undantag af de tre första, som äro obetydligt kolfformiga, jämnbreda, den sista obetydligt kortare an nast föregaiende internodie, med obetydlig fördjupning för upptagande af de smí enkla kloma. Epimerer, rostmom och palper som hos Hydrodroma, rostrum dock smalare och palpema nagot längre; de sistmämda ná till midten af' första lemparets fjerde intemodie. Mandiblemas corpus bildad sasom hos Hydrodroma, men klon ar vida mindre veh nagot mer krökt. Generationsfaltets springa omgifves af trä lingsträckta halfmanformiga, i bakre kanten bredare, myeket upuhöjal skifvor, $i$ hrilkas frimle ända syos ctt stigma och i den bakere, inat springan, ett

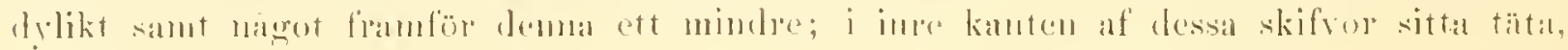


tina, hvarandra korsande hảr och i bakinndan, bakum de större stignurrua, tre störee, bakàt riktade, ¿ hrarje skifva. Tryeker man pi djuret, skilja sig dessa skifror och höja sig, hvarigenom öppningen liknar en till hälffen öppnad mussla. Sannma olikhet mellan könen som hos Hydrodroma. Midt enselan generationsfätet och bakkanton ligger anus. Mellan dema och nämda fält synas treme stigmer och et lylikt bakum hvar och en af fjerde paret phimerer. Gyomparen, som ej äro sa langt skilria som hos Hydrodroma, ligga nära främe kanten, a ömse sidor on den framskjutande midten; framom hvarje par star et kort hår och i spetsen af de afrundarde framkantshörnen ett dylikt. Till färgen är den röd, varierande frản mörkröd (ädre) till ljusröd eller rödgul. Ben, rostrum ochi palper äro ljusare rüdgula.

Mycket langsam i sina rörelser, kryper blott omkring pa bottuen eller växternas blad utan minsta förnaiga att simma.

Äggen äro rörgula ovala $(0,27$ millim. J.) och omgifvas af en obetydligr gelélik unassa. Deras utreckling has jag ej vidare följt.

Längd 2,1 bredd 1,6 , palper 0,7 , första lonparet 1,5 , fjerde 2,2 .

Myeket sällsynt i dammar kring Skara, t. ex. vid Björkelmud och Ilellstenitorp samt vid limmer pà Gottland 


\section{Explicatio tabularum.}

Tab. I.

Fig. 1. Atar crassipes (Mülder) Brozelus (Funina).

u. Animal pronum.

b. - - supinum.

c et $d$. Labium cum epimeris (duo posteriora ab anterioribus crrore lithographi disjuncta).

e. Palpi.

$f$. Mandibula ungue instructa.

g. Lamine genitales (separatim prieparate).

h. Apertura genitalis cum laminibus superioribus.

Fig. 2. Atax ypsilophorus Bonz (Femina).

a. Animal pronum.

b. - supinum.

c. Internodium ultimum pedum (fuati paris cum ungue (altera remota).

l. Inturnodium ultinum pedum primi paris cum unguibus.

e. Palpus.

j. Mandibula museulis adharentibus.

g. Lamina genitales.

Fig. 3. Limnegie pardina Neuman (Femina).

a. Inimal pronum.

b. - $\quad$ supinunı.

c. Labium a latere exlibitum enm pilpo musculaturam ostendente.

d. Mandibula musculis adbierentibus.

Fig. 4. Megapus spinipes n.

«. Animal pronum.

b. - - supinum.

c. Internodia extrema pedum primi paris e latere inferiore visa.

d. Palpus.

Tab. II.

Fig. 1. Piona mirre 11. spl:

a. Auimal pronum.

b. - supinum.

c. Pedum par quartum. 
Fig. 2. Nesced longicomis C. L. Kocir (Femina).

a. Animal proumen.

b. - - supinum.

c. Palpi.

c. Mandibula.

Fig. 3. Nesce brevipes n. sp. (Femina).

a. Animal pronum.

b. - $\quad$ supinum.

c. Palpus.

Figr. 4. Pioma glavescens Neumax (Femina).

a. Animal pronum.

6. - supinum.

c. Iuternodium pechm quarti paris ultimum eum unguibus.

c. Palpus.

e. Maudibula.

Tab. III.

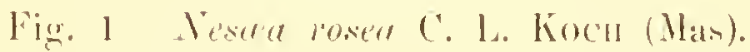

11. Animal pronum.

b. - supinum.

c. Internodium quantum pedum quarti paris.

d. Palpus

e. Area genitalis.

Fig. 2. Piome fuser Nebalas (Femina).

a. Animal prounn.

b. - - supinum.

c. Palpus.

r. Articulus palpi quintus cum apiec quati.

e. Maudibula.

Fig. 3. Neseen mirabilis n. sp. (Femina).

a. Animal pronum.

b. - supinum.

c. P’alpi.

d. Maudilula.

e. I'ili pedum quarti paris.

Fig. 4. Atrax remalis C. L. Koch.

a. Animal pronum.

b. - supinum.

Tab. IV.

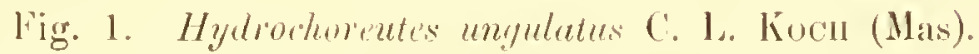

r. Animal pronum.

b. - supinum.

c. Pedun par quartum.

d. Area genitalis.

e. Pars posterior ejusdem apendiculam tripartitam fingens. 
Fig. 2. Hydrochoreutus eruciger C. L. Kocn (Fesnina).

a. Animal pronum.

b. - supinum.

c. - e Jatere visum.

l. Pajpus.

e. Area geuitalis.

f. Mandibula.

Fig. 3. Hydrochorentes filipes C. L. Kucn (Mas).

a. Animal prouum.

b. - supinum.

c. Area genitalis.

Fig. 4. Hygrobates impressus n. s1).

a. Animal pronum.

b. - supinum.

c. l'alpus.

l. Masudibula.

P. Area genitalis.

Tab. V.

Fig. 1. Hideopsis depressa 11. g.

a. Animal proum

b. - supinum (Obs. l'edes pro eorpore longiores).

i. Palpus.

d. Mandibula.

c. Area genitilis.

Fig. 2. Psendomarice formosa 11. ‥

a. Animal proum (pone oeulos duo stigmata).

b. - supinum.

c. Hpimera alterius lateris eum labio, palpo pedibusque.

l. I.abium e latere visum cum palpo.

c. Area genitalis.

Fig. 3. Nesua unquiculata n. sp.

a. P'alpus.

b. Mandibuliı.

c. Internodium ultimum pedun primi paris unguibus permagnis instructum

d. - $\quad-\quad \ldots$ quarti paris eum unguibus perparris.

Fig. 4. Nescea punctuta Neunan (Femina).

P'ars posterior lateris inferioris.

Fị. 5. Nesua pusilla Neuman.

4. l'al's posterior lateris inferioris (Femina).

l) - $\quad$ - $\quad$ - $\quad-\quad$ (Mis.)

Tab. VI.

Fịn. 1. Arrhemurus angulator C. L. Korn (Femina).

a. Animal promum.

b. - supiuแuा. 
Fig. 2. Arhemums forpicatus Ir. sp. (Mas).

a. Animal pronum.

b. - supinum.

c. Palpus.

1. Pedum par primum.

Fig. 3. Arrhemmes Kjermami n. sp. (.Ias).

a. Inimal pronum.

b. $\quad$ supimm.

$\therefore \quad$ - e latere visum.

1. Pedum par yuardum.

e. Palpus.

i. Mandibula.

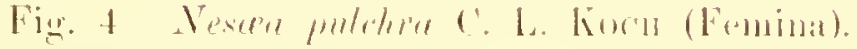

u. Animal promun.

b. - supinum.

c. l'alpus.

Tab. VII.

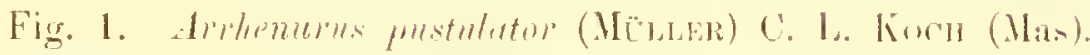

1. Inimal pronum.

b. - supinum.

c. - e latere visum.

d. Pars posterior lateris superioris appenliculam excavatam piloselus whibens

e. Pedum par quartum.

f. Jabium.

y. Palpus.

h. Handibula.

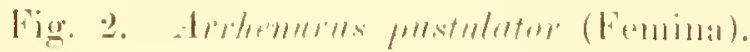

12. Animal promum.

b. - supsintin.

e. Pedum pall primum

c. Par quattum.

e. I'ilpuls.

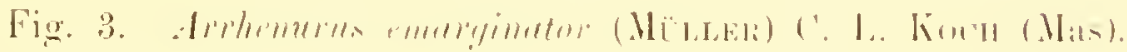

1. Animal pronum.

l. - - silpinum.

$\therefore$ - e latere visum

c. Pars posteriol copporis appendiculam at pilos ostemdus.

e. Pedum pal' quartum.

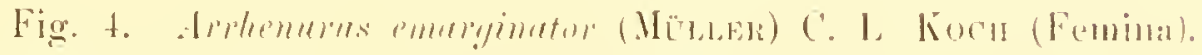
il. Animal prontum.

b. - supinum

r. P'edmum par primmm

1. $\mid$ in $p u n$. 
Tab. VIII.

Fig. I. Nesera derorata n. sp. (Feminia)

a. Animal pronum.

b. - supinum.

c. Palpus.

d. Maudibula.

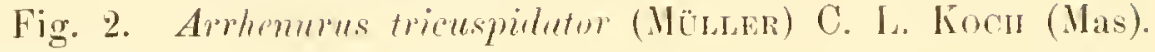

a. Animal pronum.

b. - supinum.

c. Apendicula e latere superiore visa.

Fig. 3. Piona albormis 1. sp.

a. Animal pronum.

b. - smpinum.

c. Palpus.

Fig. 4. Lebertio imsignis 11. ‥

a. Animal pronum.

b. - supinum.

c. Palpi.

a. Mandibula.

Tab. IX.

Fig. 1. Arrhimmus papillator (Mörese) (!. L. Kocn (Mas). a. Animal pronum.

b. - supinum.

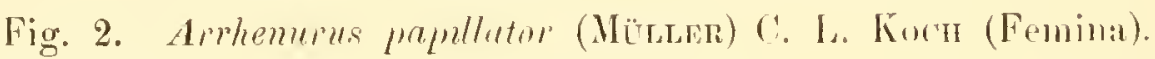
a. Animal pronum.

b. - supinum.

c. Palpus.

Fig. :D. Arhemmens astmens n. sp. (Mas).

a. Animal pronum.

b. - supinum.

c. Palpus.

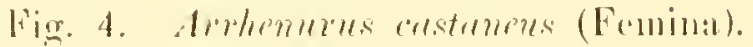

a. Animal pronum

b. - supintum.

Tab. X.

Fig. 1. Arrhemmens nolitis II. sp. (M:1s).

(t. Animal prounu.

b. - supinum.

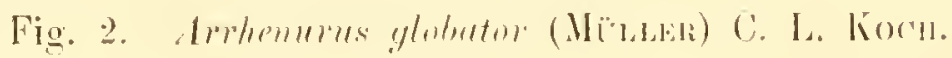
a. Animal promun.
b. - supinum.
c. - " latere vistum. 


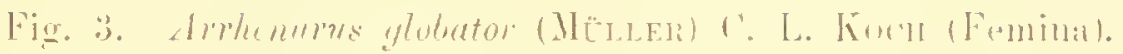
4. Animal proumm.

b. - sujinum.

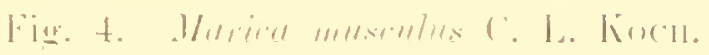

r. Animal pronum.

b. - - supinum.

$\therefore \quad$ - e latere risum.

d. Epimerorum par primum cum prele.

c. Pedum par quartum.

f. Pulpus labio altixus.

y. Naudibula.

4. Trea gentitalis: pone eam anns.

Tab. XI.

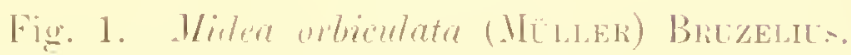

a. Animal pronum.

1. - supinum (1)b. Pedes pro iorpore longiores).

c. Yalpus.

d. Mandibula.

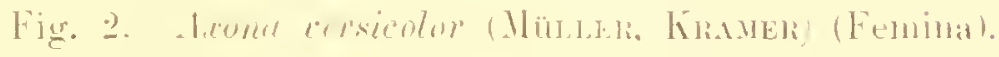

4. Inimitl pronum.

1). - supinum.

c. Palpus e latere visu.

l. Idem e latere inferiore visus.

Fig. 3. Inmonie getlemelica Nemax.

a. Animal promum.

b. - supinum.

c. Pilpus.

1. Nandibula.

Fig. t. Athrumus tubuterter C. L. Kon (Femint).

a. Lnimal promm.

l. - supinnm.

Tab. XII.

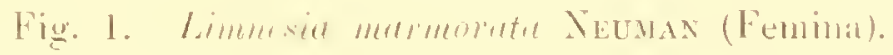

a. Animal pronum.

b. - supinum.

c. - e Jatere visum.

1. Palpr.

a. Ireat genitalis.

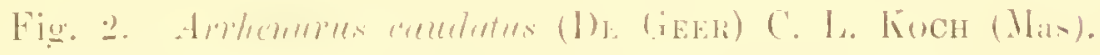
a. Animal pronum.

b. - sujiunm.

c. Palpi cum lalun

d. Mandibula.

c. Pedum par yuartum.

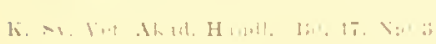




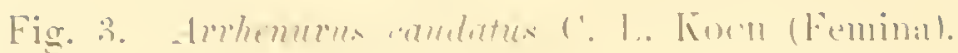

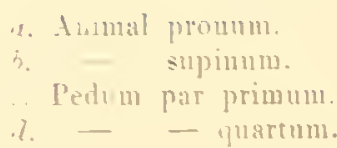

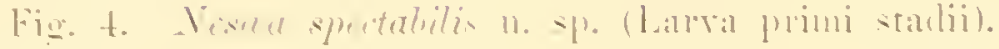

t. Inimal promum.

h. - - smpinum.

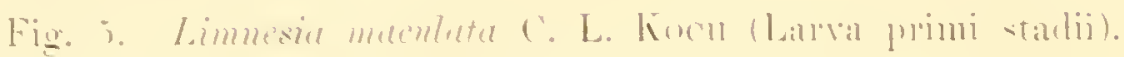
?. Lnima] promum.

3. - supinum

\section{Tab. XIII.}

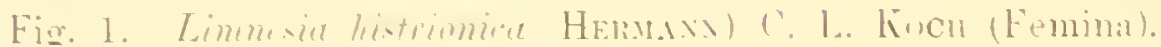

a. Animal pronum

h. - supjumm.

$\therefore$ - e Jatere visum

1. Labium enm palpo et pari primo peduu.

- Mandihula.

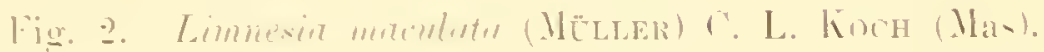

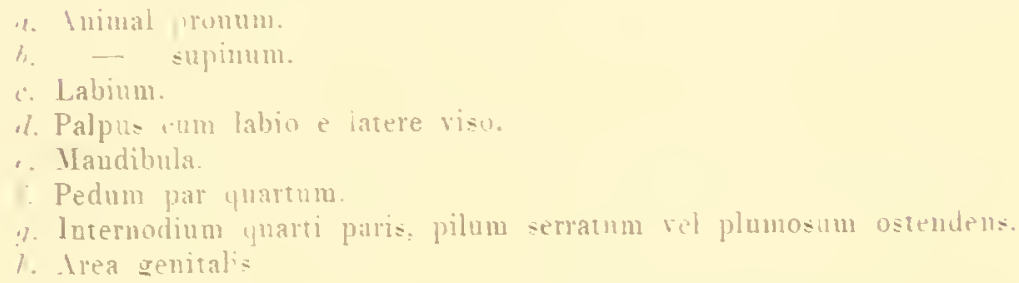

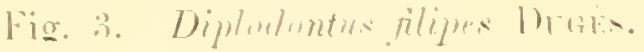

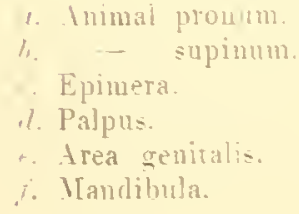

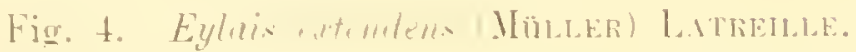

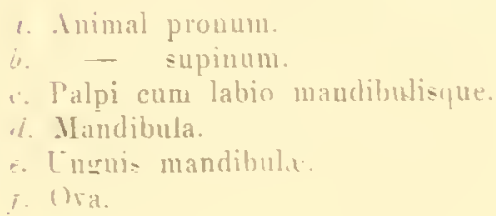


Tab. XIV.

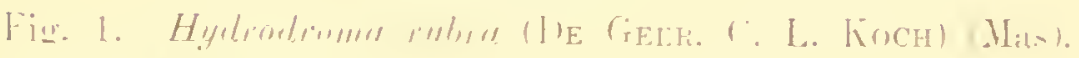

Pars anterior lateria superioris

b. Inimal supinum.

$\therefore$ Rostrum erem pripoi atrivi-

Ł. Iandibula.

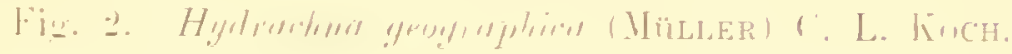

¿ tirimal promum.

b. - supinums.

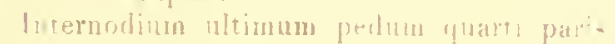

1. Kostrum eum palpis.

IIndibula.

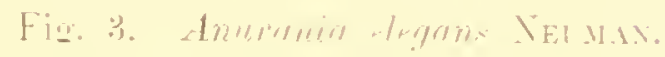

"thimal prontum.

b. - - ipinim.

Labium c im palps:=

l. Mandilunlit.

Intrundium ultumum pedum paria primi.

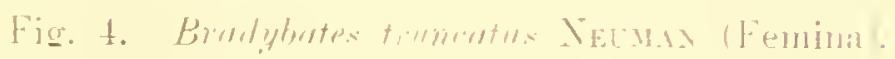

?. Animal pronum.

- supinum.

lipa genitali. 


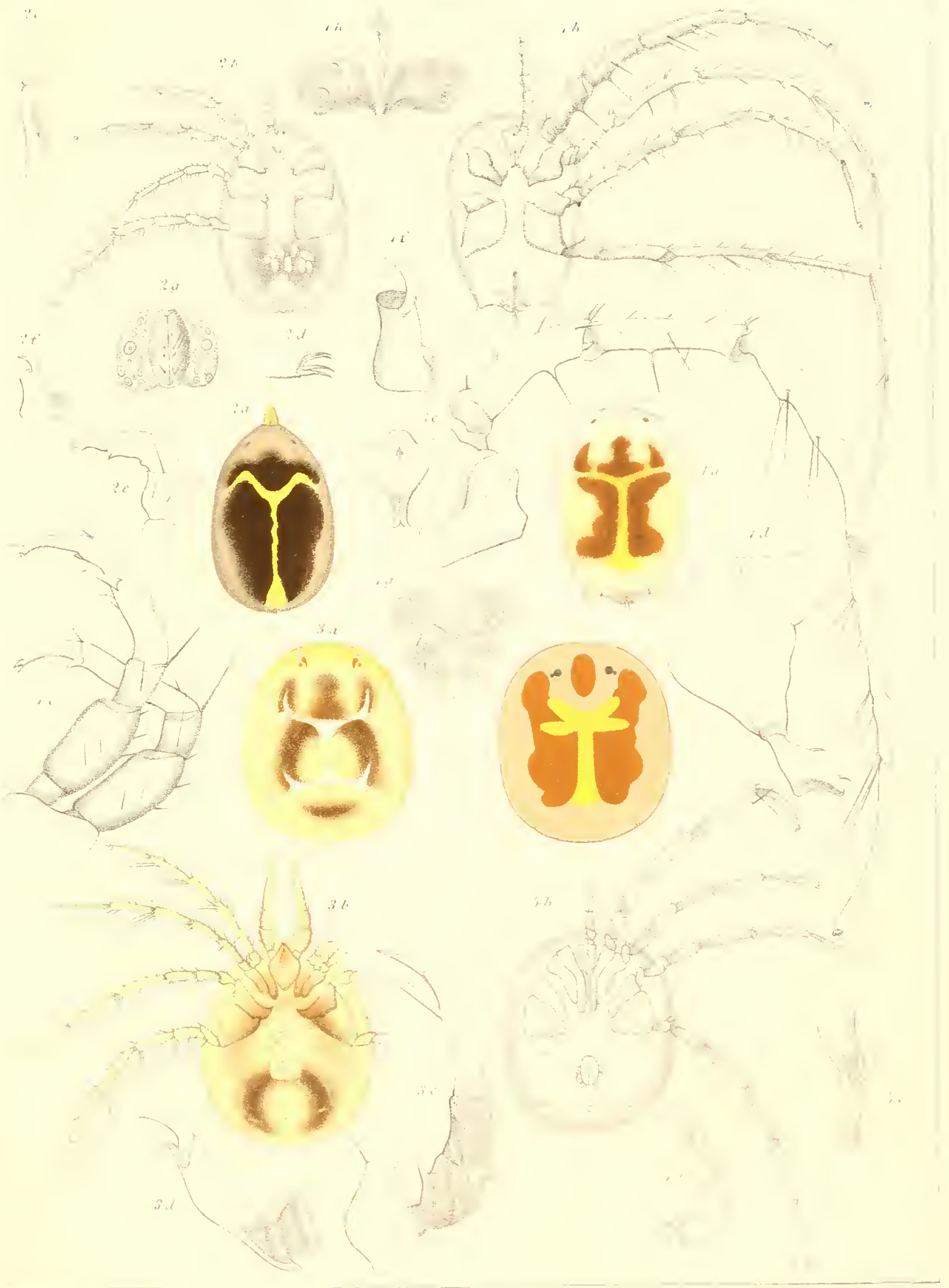






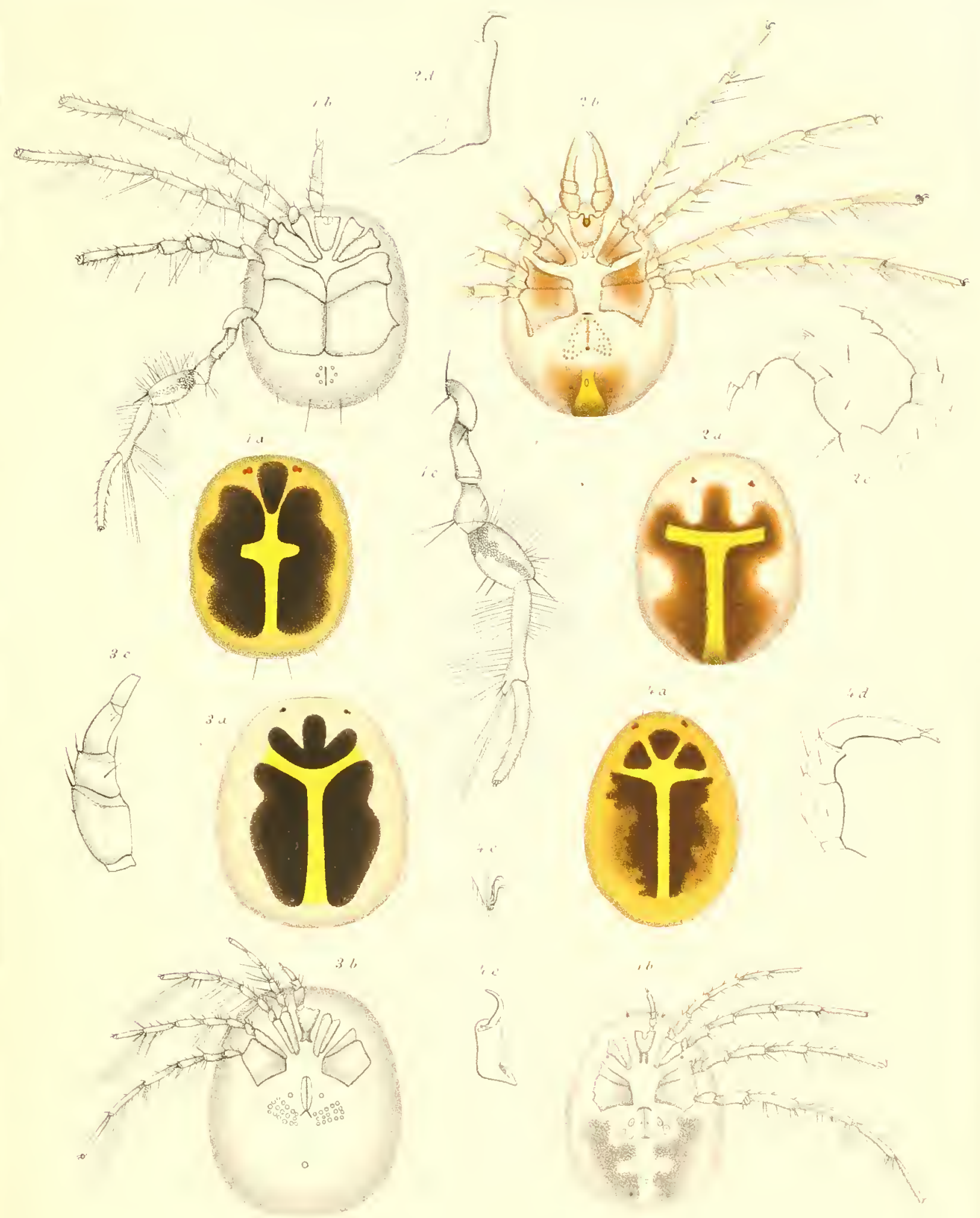





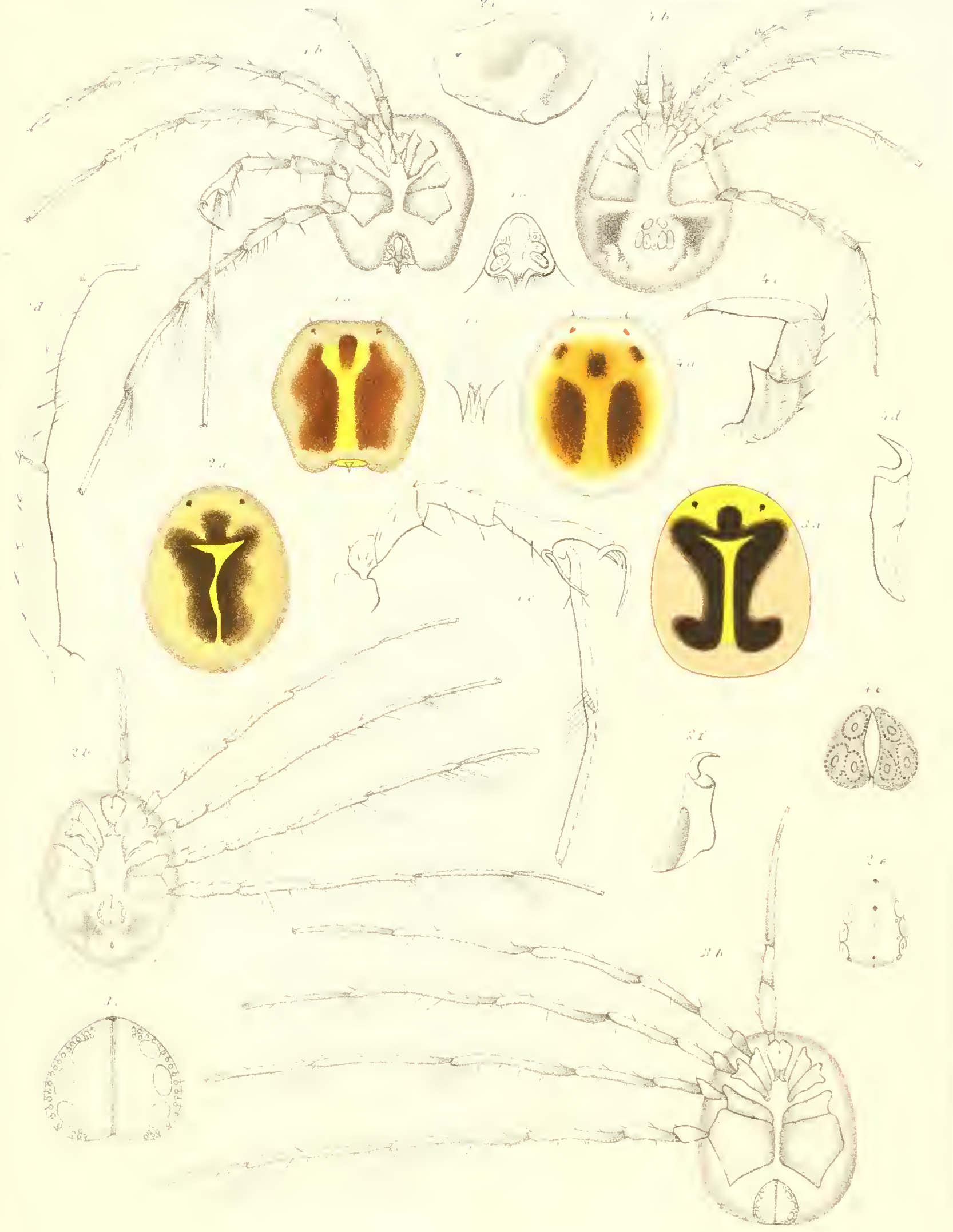





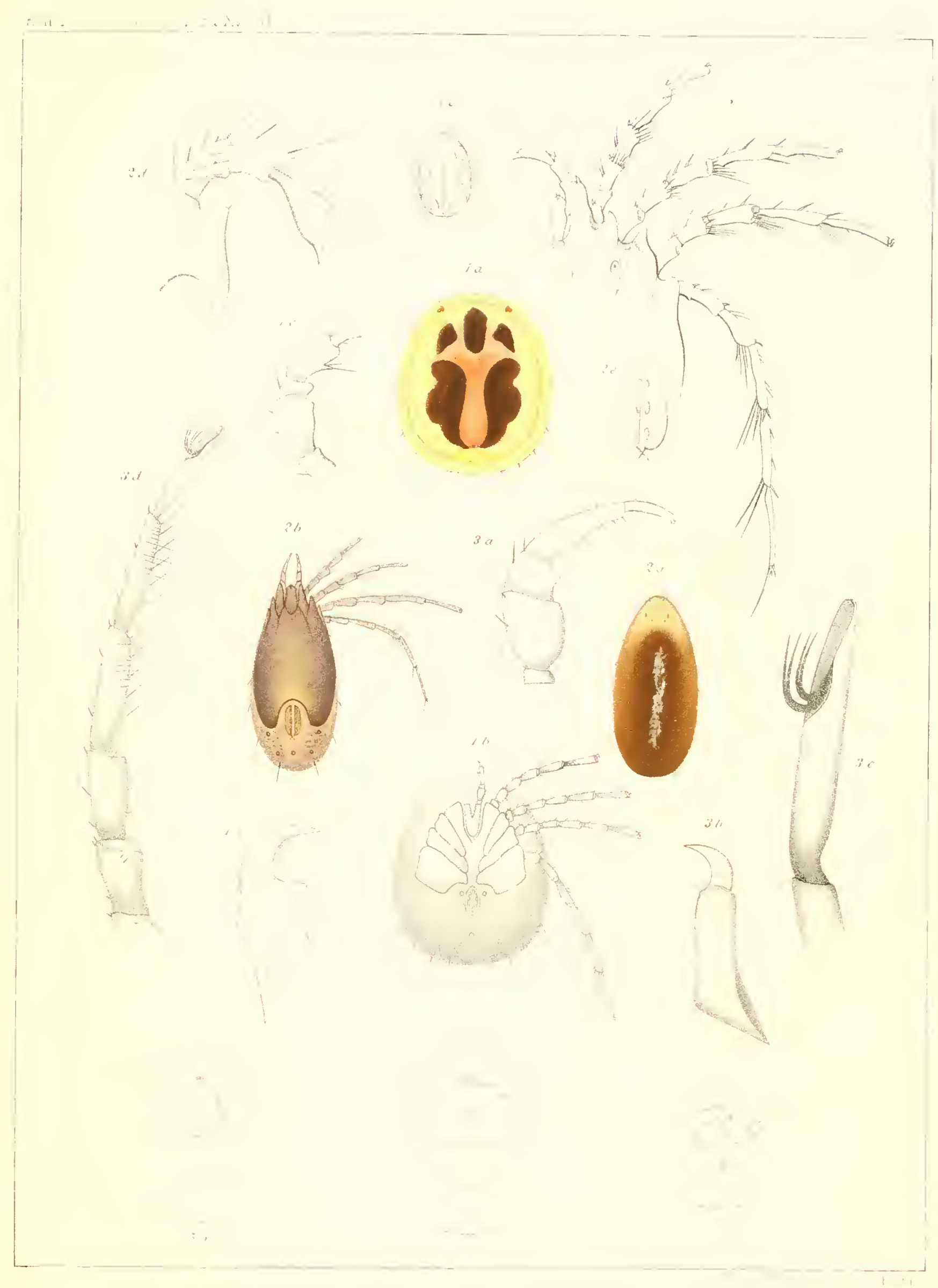





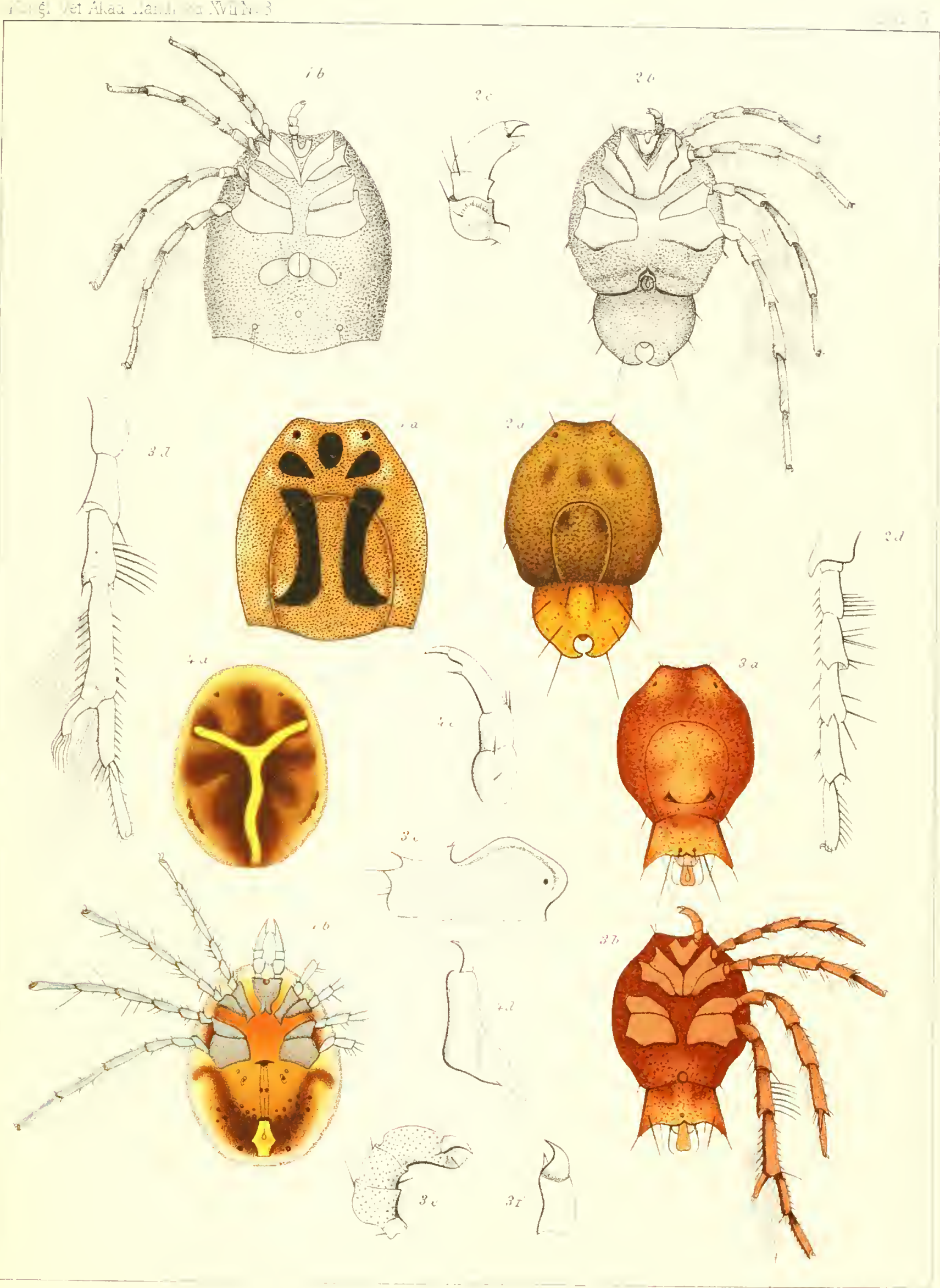


$\because$ 


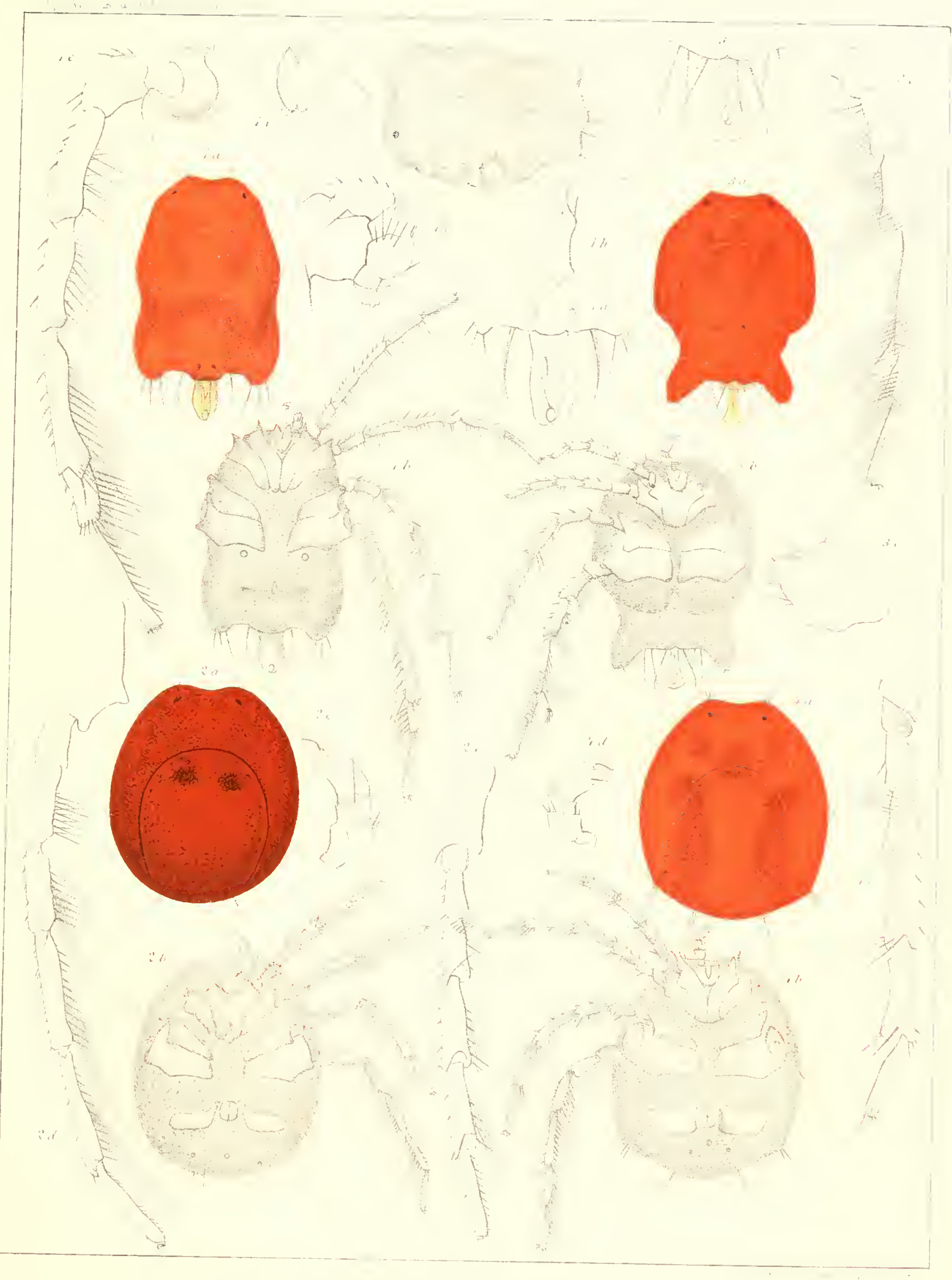




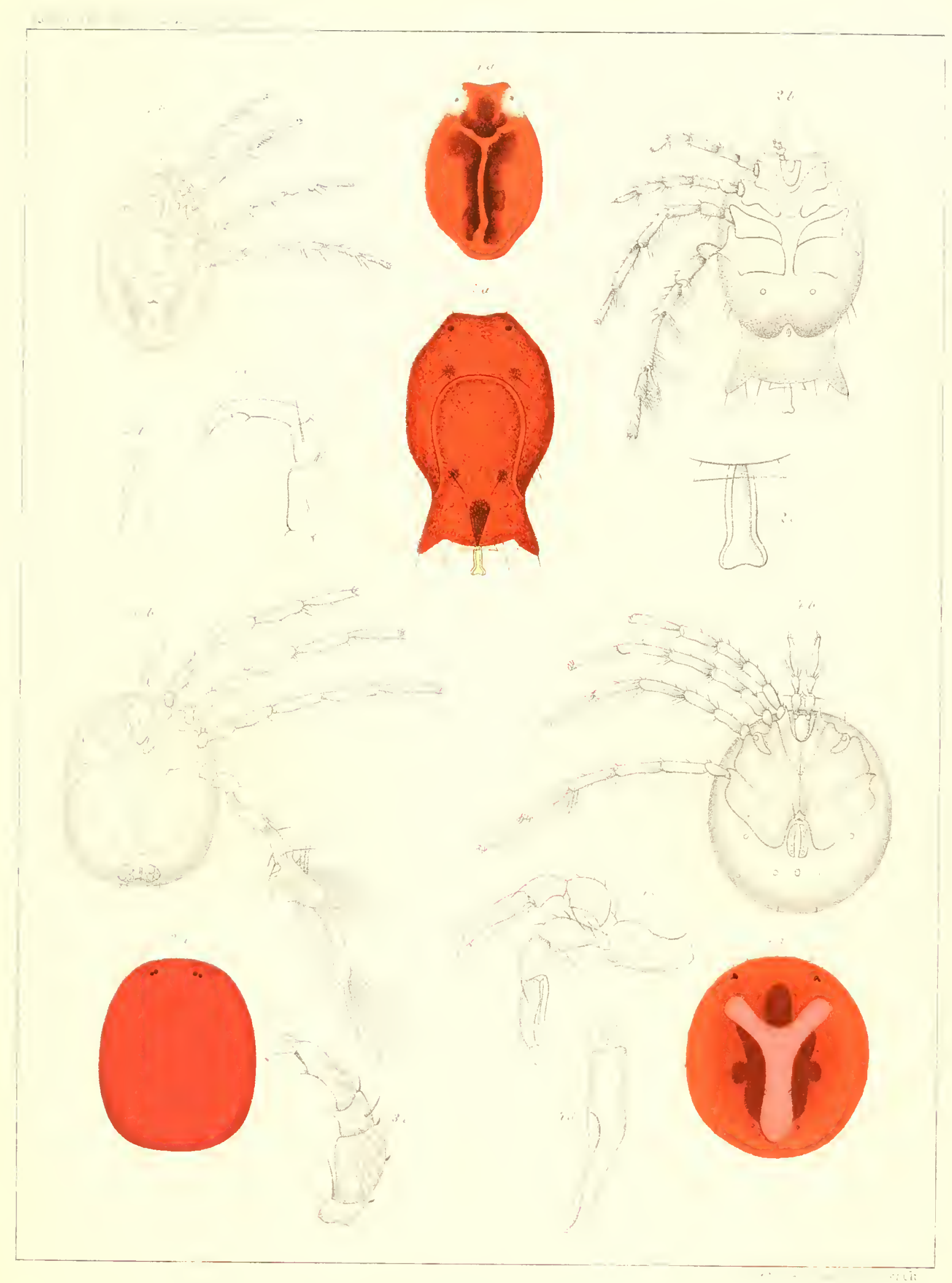

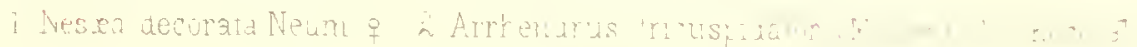




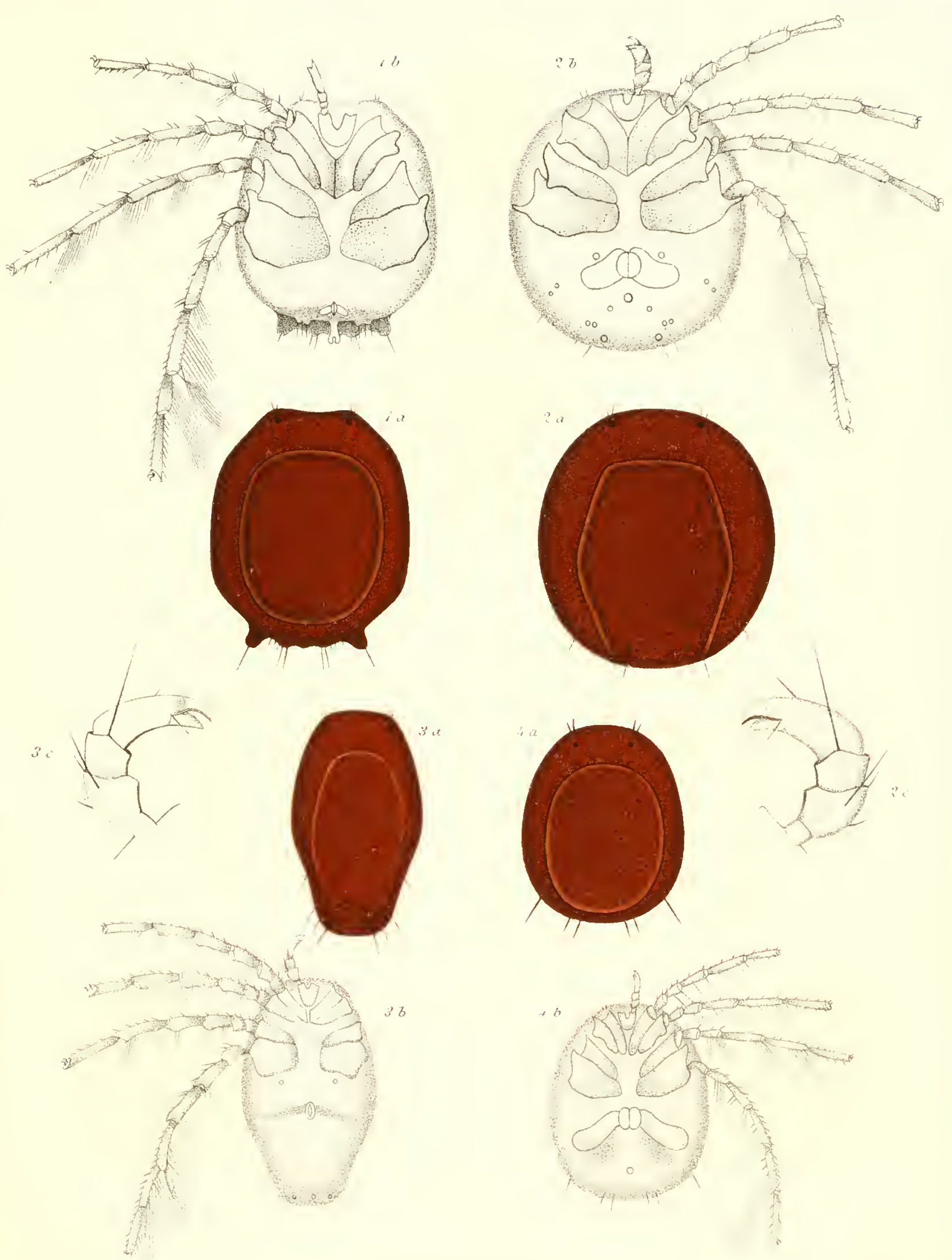


\section{-}




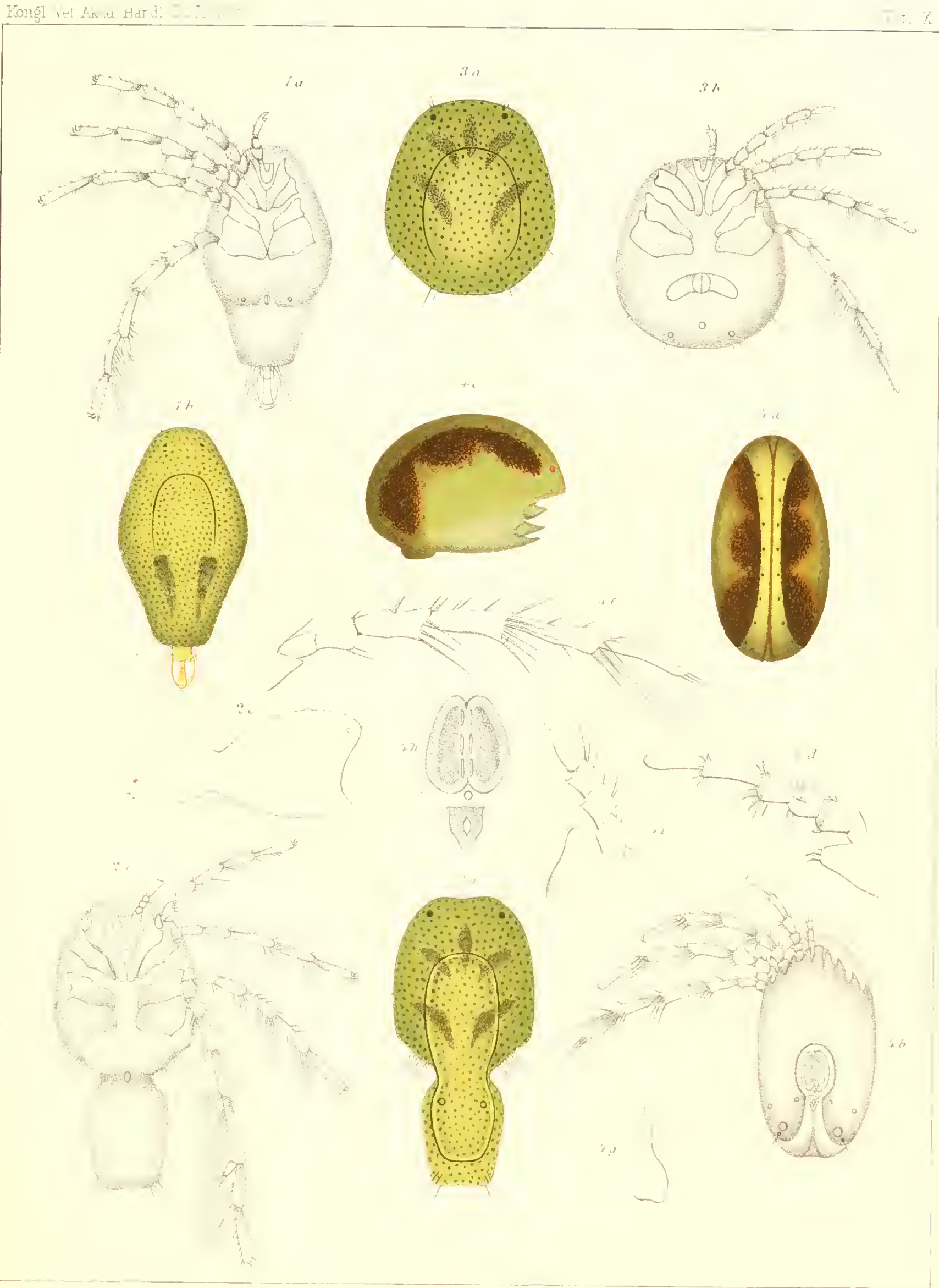




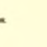




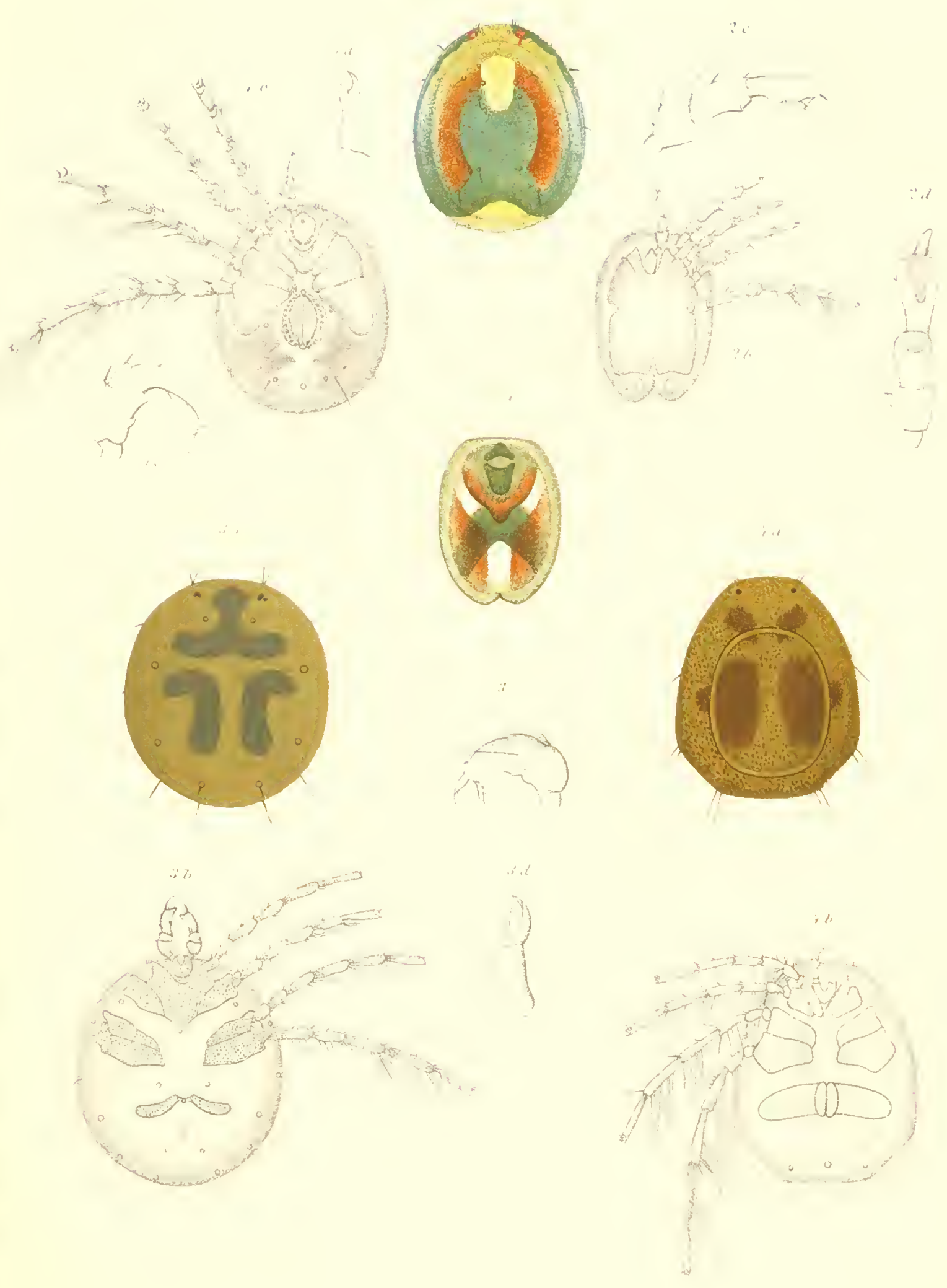





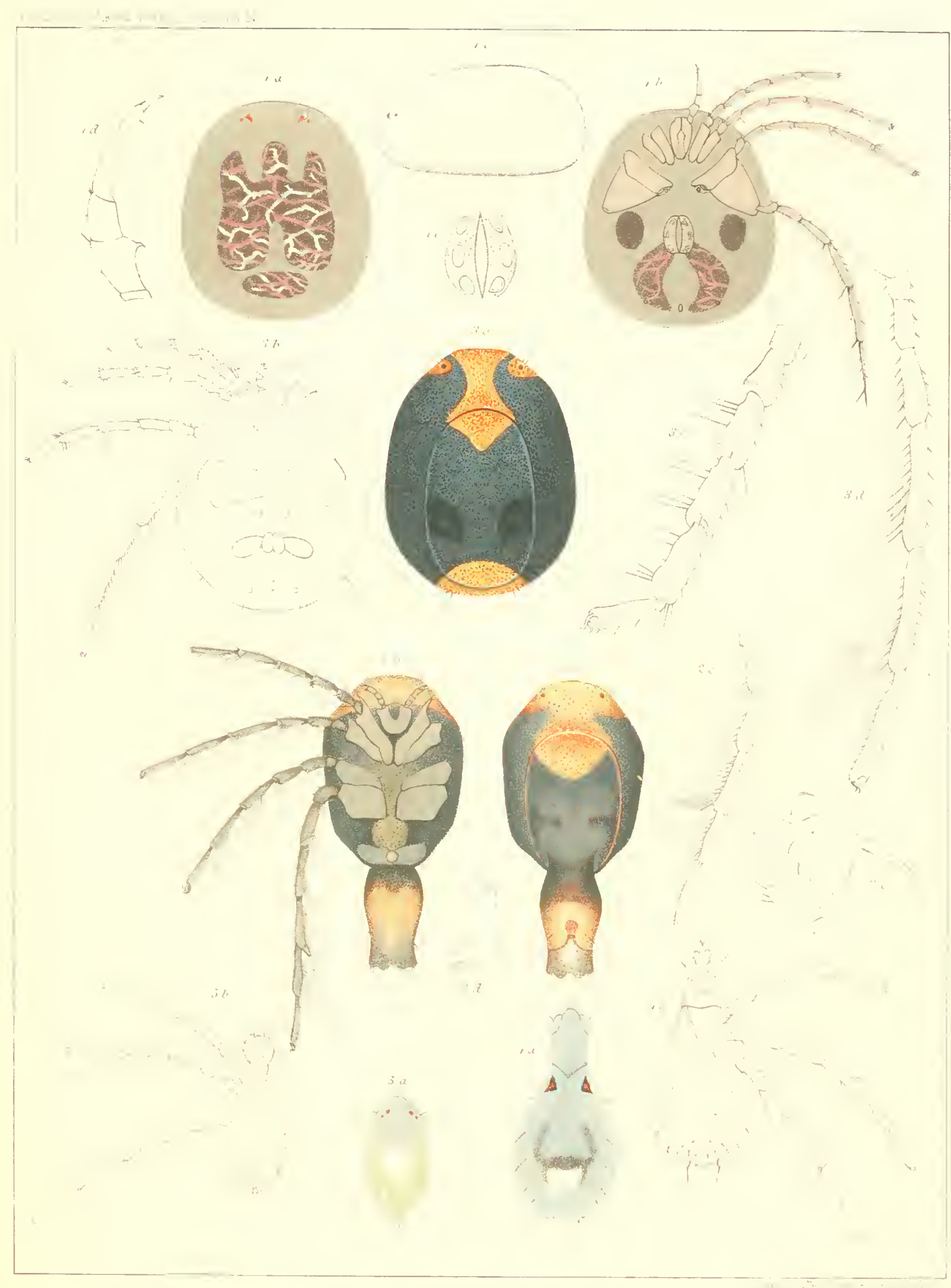





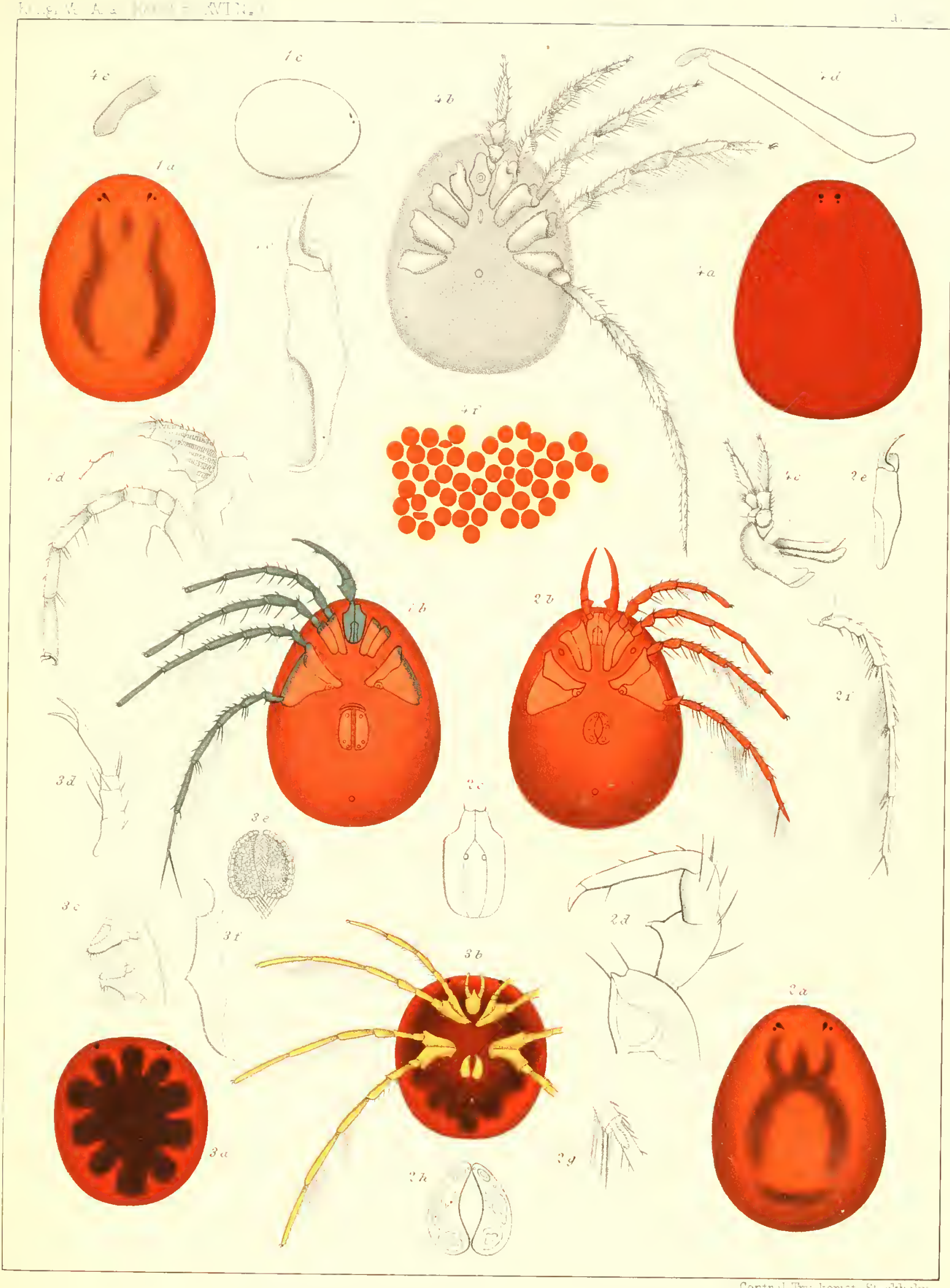


. 


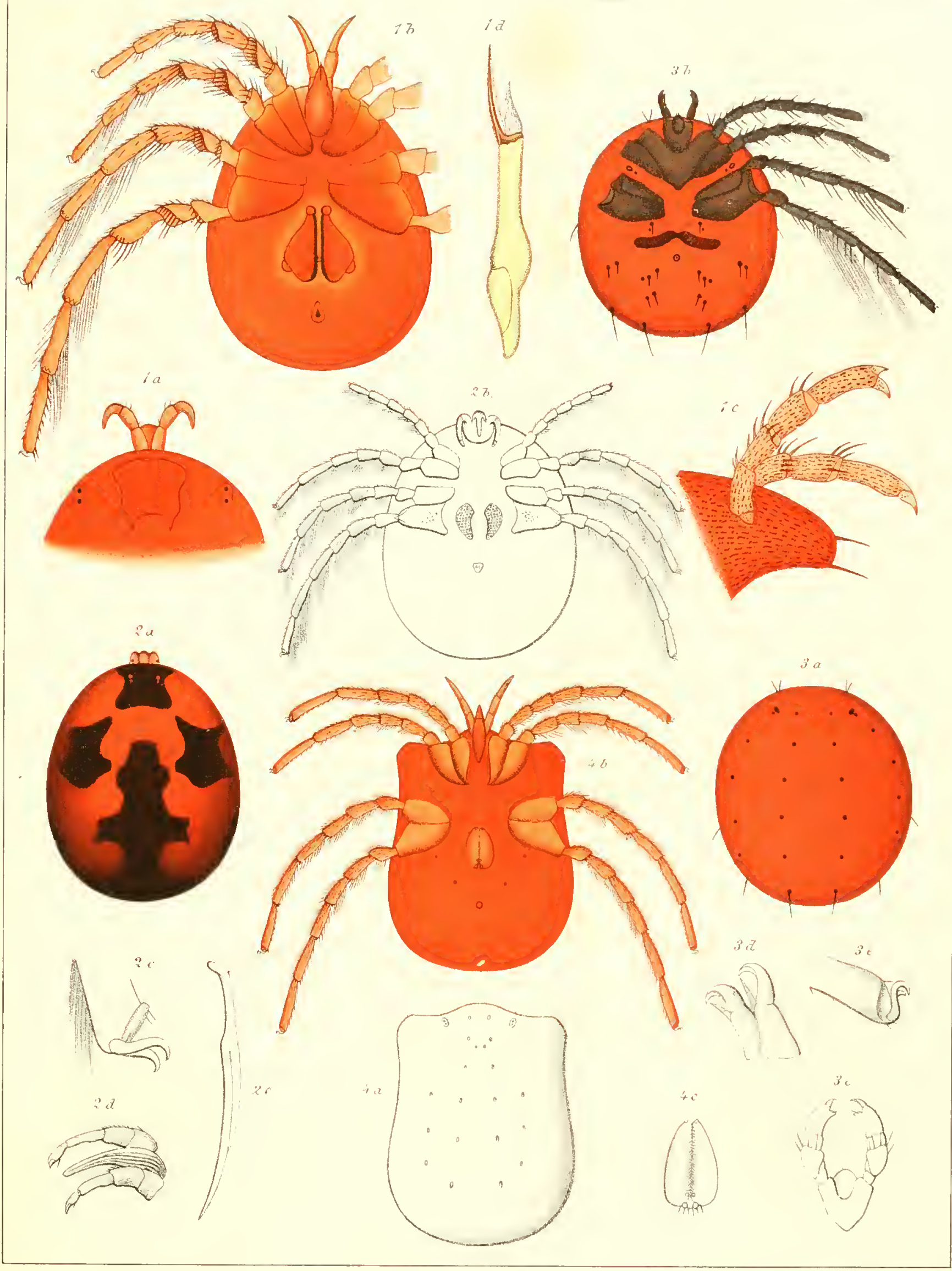




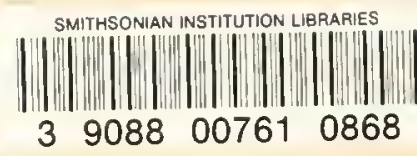

